\title{
DOLOR POSTOPERATORIO EN IMPLANTOLOGÍA ORAL
}

JOSÉ MARÍA YARTE AGUADO

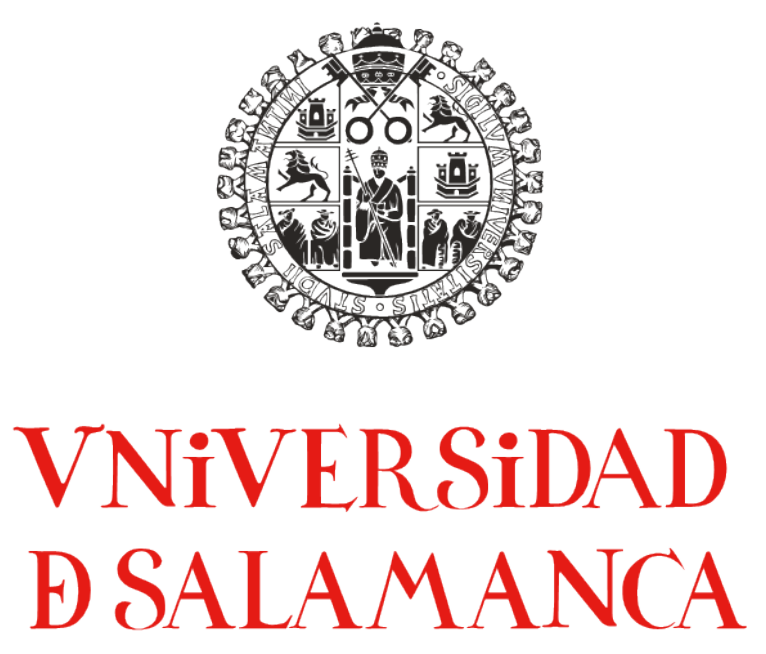

FACULTAD DE MEDICINA

DEPARTAMENTO DE CIRUGÍA

5 de Julio de 2013 



\section{DECLARACIÓN}

D. Antonio López Valverde y Centeno, D. Manuel Peix Sánchez y D. José Miguel Sánchez Llorente, doctores y profesores de la Universidad de Salamanca,

\section{CERTIFICAN:}

Que el trabajo titulado “DOLOR POSTOPERATORIO EN IMPLANTOLOGÍA ORAL" ha sido realizado por D. José María Yarte Aguado, bajo nuestra dirección, reuniendo a nuestro juicio los requisitos y méritos suficientes para que el autor del mismo pueda optar al Grado de Doctor por la Universidad de Salamanca.

Y para que así conste, firmamos la presente certificación en Salamanca a 15 de Mayo de 2013.

Fdo.: Prof. Dr. A. López-Valverde Fdo.: Prof. Dr. M. Peix Fdo.: Prof. Dr. J.M. Sánchez 



\section{Agradecimientos}

Al Dr. José Miguel Sánchez Llorente, gracias a él empecé esta aventura y gracias a él la he podido terminar.

Al Dr. Manuel Peix Sánchez, por aceptar la dirección de mi tesis sin conocerme y por dedicarme más tiempo del que seguramente merecía.

Al Dr. Antonio López-Valverde y Centeno, por mostrar tanto interés en mi trabajo y aportar toda su experiencia.

Al Dr. Clemente Muriel Villoria, que me aportó sabios consejos sobre el apasionante mundo del dolor.

Al Dr. Aurelio Criado Pascual, por su continua ayuda clínica y por motivarme en las primeras fases de mi carrera.

Al Dr. Luis Cuadrado, al Dr. Juan Garías y a la Dra. Adelaida Parra por su aportación en la recogida de datos.

A Ana Alonso Canillar y Sheila Gónzalez Cáceres, auxiliares sin las que este trabajo no se podría haber llevado a cabo.

A la Prof. $\mathrm{M}^{\mathrm{a}}$ Purificación Galindo Villardón, directora del Departamento de Estadística, por la realización de la parte estadística de la tesis. 

Dedicado a

...A mis padres, por darme unos principios y enseñarme lo verdaderamente importante en esta vida.

...A mi hermana, para que vea que por muchas piedras que haya en el camino, con esfuerzo y perseverancia, todo es posible.

...A Isa, porque desde que está a mi lado, todo tiene sentido.

...A Gonzi, Maxi y Edu, porque son parte de mí y el camino es mucho más fácil con ellos a mi lado.

...A todos los que me quieren y se preocupan por mí. 




\section{DOLOR POSTOPERATORIO EN IMPLANTOLOGÍA ORAL}

JOSÉ MARÍA YARTE AGUADO 


\section{RESUMEN}

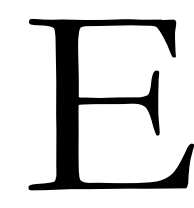

1 primer capítulo de la tesis doctoral, es una introducción donde se explica, brevemente, la historia de los implantes dentales, su uso en la actualidad y la evolución de la odontología, con respecto a la ansiedad que sufren los pacientes en la consulta odontológica, así como, su relación con el postoperatorio sufrido tras la colocación de implantes dentales.

Dicha introducción se divide en cuatro apartados. En el primero de ellos, se explica cómo se hace un diagnóstico correcto de un paciente que va a ser tratado con implantes dentales y los criterios básicos para una planificación correcta de la cirugía implantológica. Posteriormente, se explica cuál es el proceso que hay que seguir para llevar a cabo la intervención, preparación del campo quirúrgico, correcta elección de los implantes que se van a colocar, material necesario para llevar a cabo la cirugía, etc. Al final de este apartado, se explican todas las medidas postquirúrgicas que se deben seguir en el gabinete dental, después de la cirugía, así como las instrucciones y la medicación de las que se dispone, hoy en día, para tratar a estos pacientes. El segundo apartado, se centra en la relación del dolor y el postoperatorio sufrido por los pacientes a los que se les colocan implantes dentales. En primer lugar, se recogen los conceptos genéricos que existen en la actualidad sobre el dolor, se hace una clasificación de los diferentes tipos de dolor que se conocen y se intenta establecer la incidencia del mismo, en las cirugías implantológicas. En segundo lugar, se explica la fisiología y el grado de lesión tisular que se produce cuando se coloca un implante dental, explicando los mediadores del dolor que intervienen, así como sus vías de transmisión. En la parte final de este apartado, se establecen y analizan los factores personales, quirúrgicos y psicológicos relacionados con el dolor postquirúrgico y su relación con el postoperatorio implantológico. El tercer apartado, trata sobre la prevención del dolor en implantología dental. En este apartado, no sólo se analizaron los artículos referentes a la cirugía implantológica, sino que se estudiaron, también, todos los artículos encontrados referentes a técnicas quirúrgicas orales, parecidas a la implantológica, para obtener datos más globales del postoperatorio y poder, así, establecer comparaciones. El apartado, se divide en los pasos que hay que seguir para prevenir el dolor postquirúrgico, antes y después de la cirugía, tanto por el cirujano, como por el paciente, terminando con un análisis de los 
estudios sobre el tratamiento de los pacientes implantológicos y de todos los fármacos que están a nuestra disposición, para combatir el dolor y la inflamación, que son los síntomas más frecuentes tras este tipo de intervenciones.

En el segundo capítulo se establecen, de manera resumida, los objetivos de esta investigación y qué se espera conseguir con el estudio del postoperatorio de los pacientes tratados con implantes dentales, así como, los principales objetivos de este trabajo; el análisis del dolor y la inflamación que padecen los pacientes sometidos a cirugías implantológicas y el análisis de los factores que más interactúan con el postoperatorio implantológico, comprobando si la medicación que se establece como protocolo, consigue un correcto control de dicho postoperatorio y averiguando si se puede precedir de manera fiable el dolor que van a padecer estos pacientes.

El tercer capítulo explica la metodología seguida en esta investigación, así como todo el material utilizado. En el primer apartado de este capítulo se aborda el planteamiento del problema que queremos estudiar, el postoperatorio implantológico. A continuación, se establece el diseño técnico y funcional del experimento que se llevó a cabo durante 3 años. En éste, se describe el estudio que se realizó y sus principales características, así como las ventajas e inconvenientes de un experimento de este tipo. También se explican, los cuestionarios que se realizaron a los pacientes para la recogida de datos. En el segundo apartado, se explican todos los pasos seguidos por el ódontologo y su auxiliar, desde que comenzó la cirugía hasta que terminó el control del paciente, siete días después de la intervención. En el tercero, se explica la codificación de todas las variables que se han usado en los cuestionarios del estudio y que nos aportaron la información necesaria para establecer los resultados y conclusiones del mismo. En el cuarto, se definieron la población y la muestra del estudio. En el quinto, se explica el proceso que se llevó a cabo desde que al paciente se le practicó la cirugía implantológica, hasta que se le retiraron los puntos de sutura siete días después de la intervención. El sexto, trata sobre las técnicas de análisis de datos utilizadas para transformar los datos obtenidos mediante los cuestionarios, en resultados que pudieran ser analizados estadísticamente y de los cuales se pudieran extraer conclusiones. El último apartado de este capítulo es un diagrama resumen de todo el proceso investigador que se llevó a cabo durante el estudio. 
El cuarto capítulo, analiza los resultados obtenidos en el estudio. En un primer apartado se definiran las características de la muestra, reflejando los resultados obtenidos de cada una de las variables estudiadas, mientras que en el segundo apartado se recogen los mismos de manera escrita y mediante el uso de varias figuras y gráficas que muestran de manera más explícita dichos resultados.

En el capítulo quinto, se analizan y comparan los resultados obtenidos con la bibliografía existente. El primer apartado detalla y compara la metodología que se ha seguido en este trabajo con la empleada en otras investigaciones. En el segundo apartado se explican y comparan los resultados obtenidos en la investigación con respecto al dolor, la inflamación y el hematoma sufridos por los pacientes sometidos a la colocación de implantes dentales. En el tercero se analizan todos los factores, relativos al paciente, que pueden influir en el postoperatorio, mientras que en el cuarto se relacionan los factores quirúrgicos. A continuación, se explican los resultados que nos aporta el análisis en componentes principales, mientras que en último lugar se muestran las repercusiones clínicas que tienen los resultados obtenidos en la vida diaria de un odontólogo.

Finaliza la tesis doctoral con el capítulo sexto, en el que se extraen una serie de conclusiones sobre la cirugía de colocación de implantes dentales y el dolor postoperatorio. 


\section{Tabla de contenido}

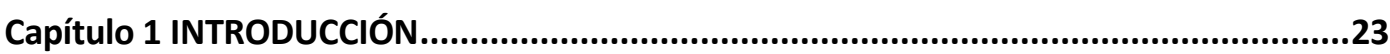

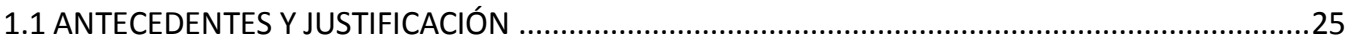

1.2 IMPLANTOLOGÍA: CARACTERÍSTICAS DEL TRATAMIENTO …….................................................30

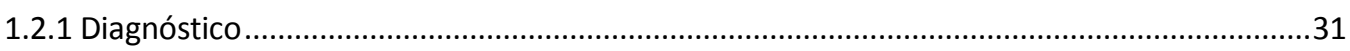

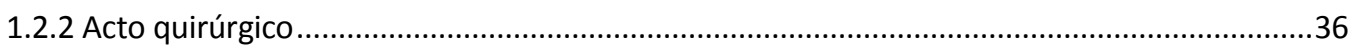

A) Preparación del campo quirúrgico …………………………..............................................36

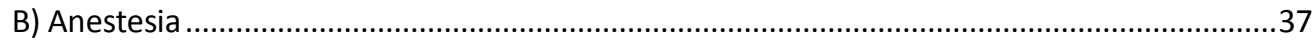

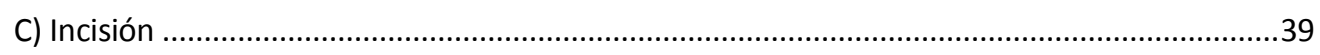

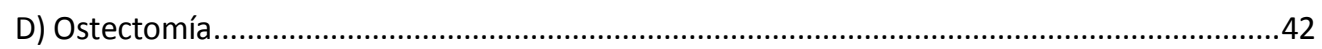

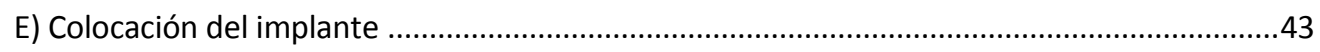

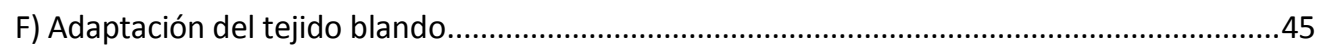

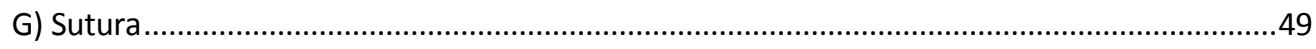

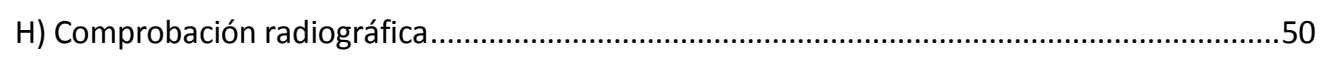

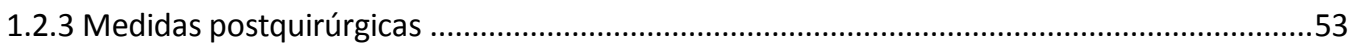

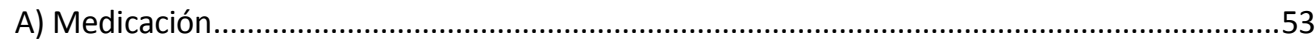

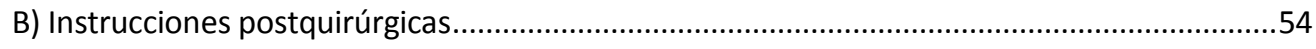

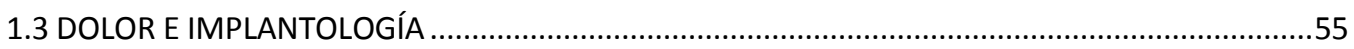

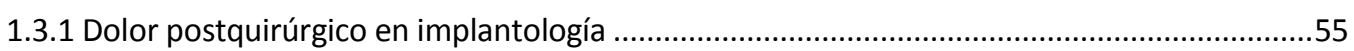

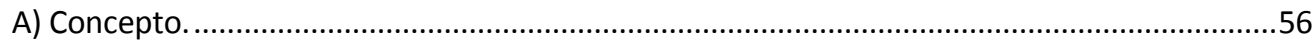

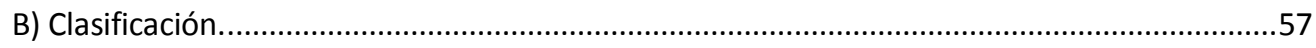

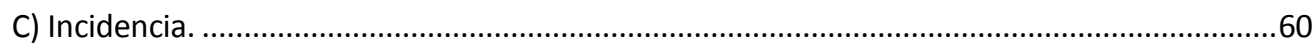

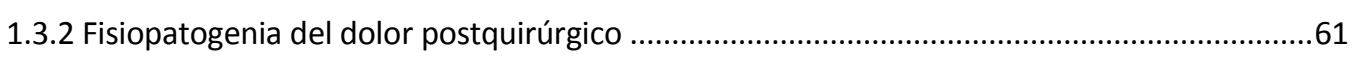

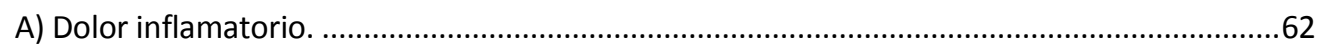

B) Mediadores del dolor e inflamación ...........................................................................63

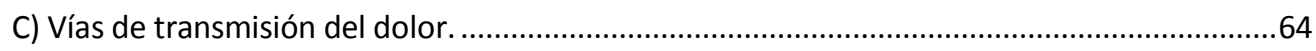

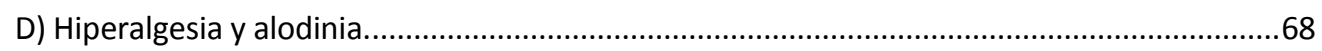

1.3.3 Factores relacionados con el dolor postquirúrgico..........................................................71

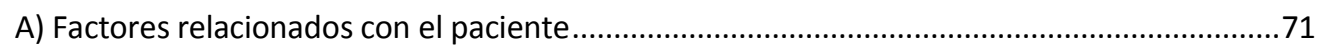

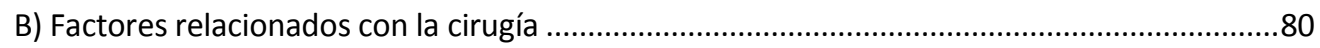

C) Factores psicológicos del paciente .................................................................................8

1.4 PREVENCIÓN Y TRATAMIENTO DEL DOLOR EN IMPLANTOLOGÍA .............................................86

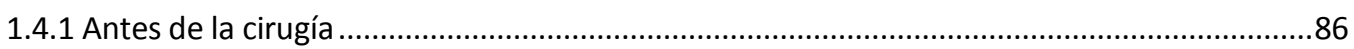




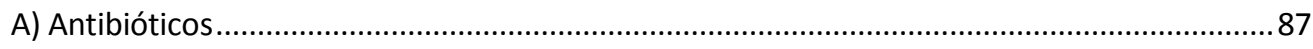

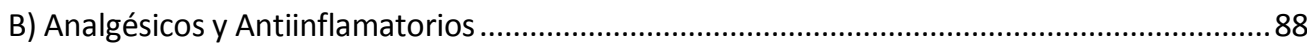

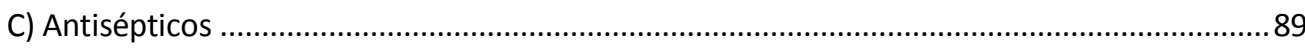

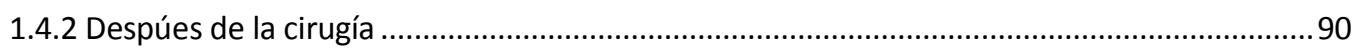

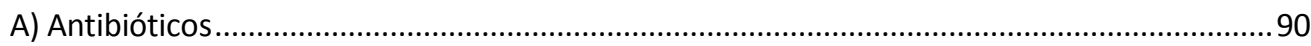

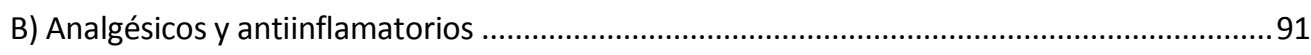

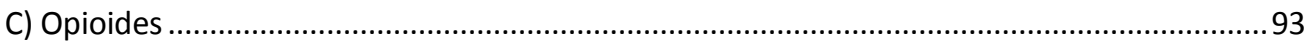

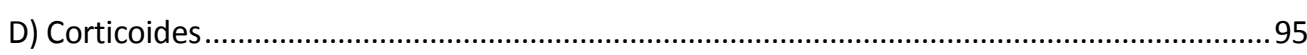

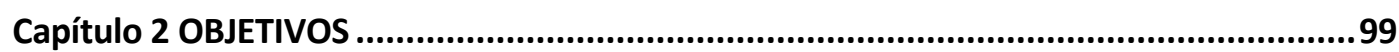

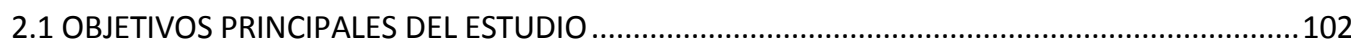

Capítulo 3 MATERIAL Y MÉTODOS ........................................................................ 103

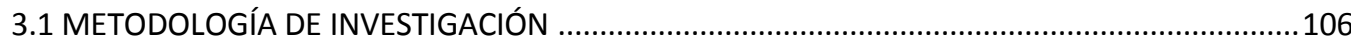

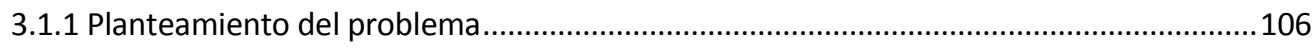

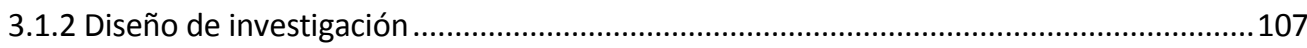

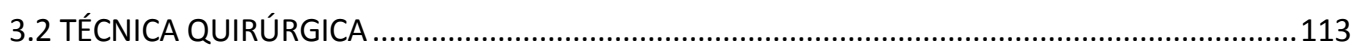

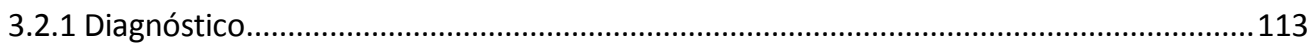

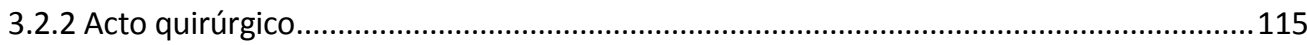

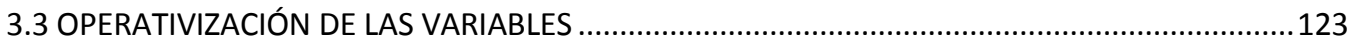

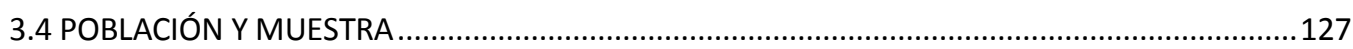

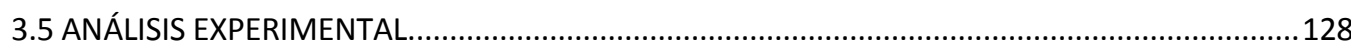

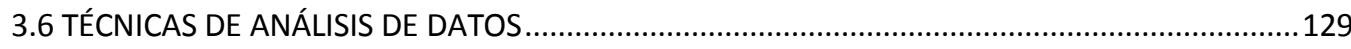

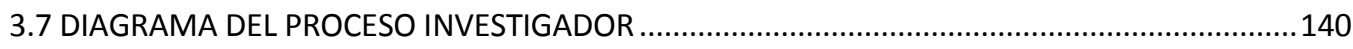

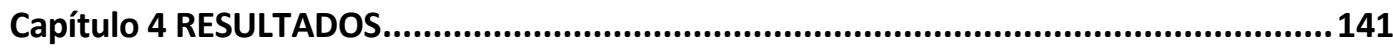

4.1 ADECUACIÓN DE LAS BASES DE DATOS PARA EL ANÁLISIS................................................... 144

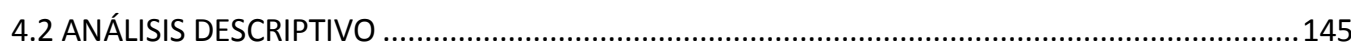

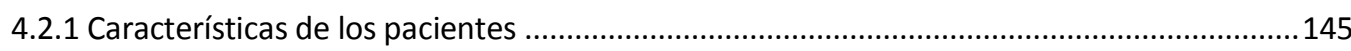

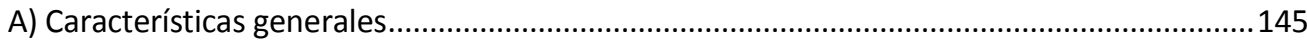

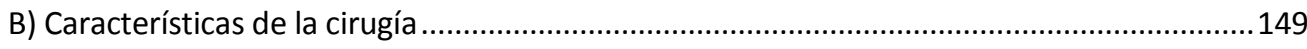

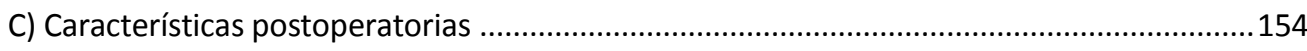

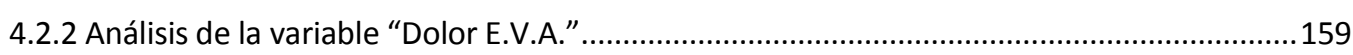

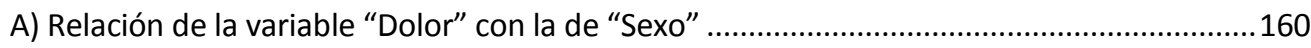

B) Relación de la variable "Dolor" con la de "Fumador" ......................................................... 161

C) Relación de la variable "Dolor" con la de "Higiene" ..........................................................162

D) Relación de la variable "Dolor" con la de "Enfermedades actuales" ................................... 163

E) Relación de la variable "Dolor" con la de "Alergias" ............................................................. 164 
F) Relación de la variable "Dolor" con la de "Medicamentos" ................................................165

G) Relación de la variable "Dolor" con la de "Número de implantes" ......................................165

H) Relación de la variable "Dolor" con la de "Situación del implante" ...................................167

I) Relación de la variable "Dolor" con la de "Anterior/Posterior" .............................................168

J) Relación de la variable "Dolor" con la de "Elevación de seno" ..............................................169

K) Relación de la variable "Dolor" con la de "Regeneración" ..................................................170

L) Relación de la variable "Dolor" con la de "Sedación” ..........................................................170

M) Relación de la variable "Dolor" con la de "Postextracción" .................................................171

N) Relación de la variable "Dolor" con la de "Colgajo" ..............................................................172

4.2.3 Contrastes no paramétricos para comparar dos muestras .............................................173

4.2.4 Análisis factorial para las variables del postoperatorio ....................................................177

4.2.5 Análisis trifactorial para las variables "Dolor", "Edad"y "Sexo" en busca de posibles

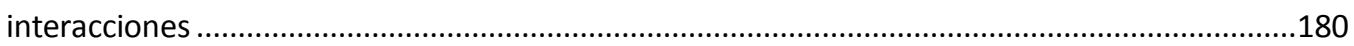

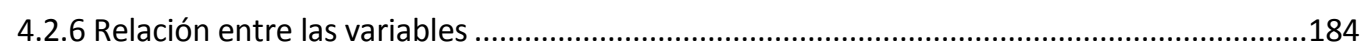

A) Relación entre las variables generales y la variable "Dolor" ..............................................184

B) Relación entre las variables generales y la variable "Inflamación" ......................................186

C) Relación entre las variables generales y la variable "Hematoma" ......................................188

Capítulo 5 DISCUSIÓN .............................................................................................191

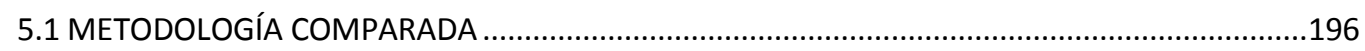

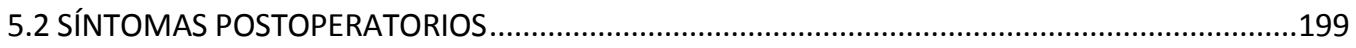

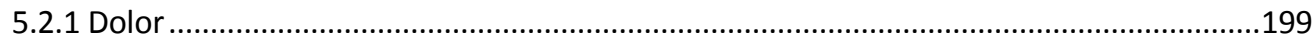

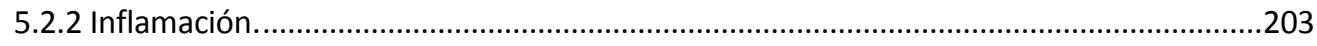

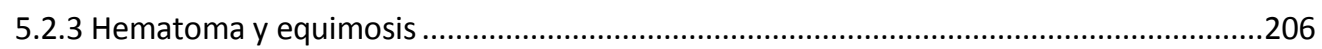

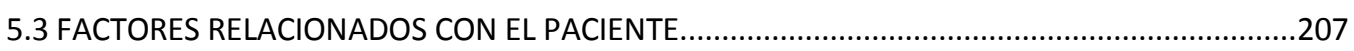

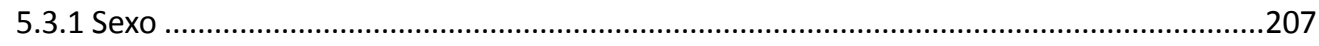

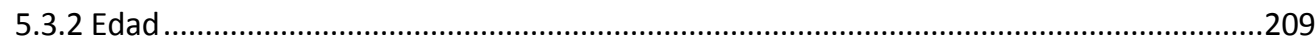

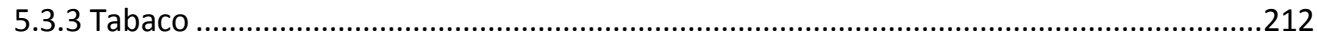

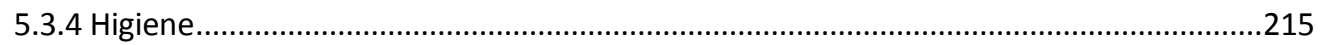

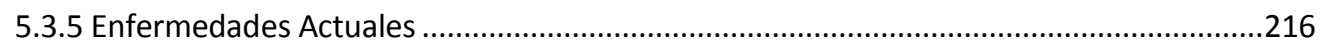

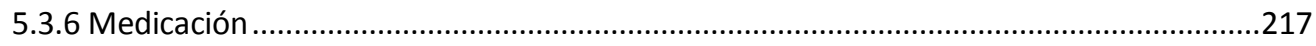

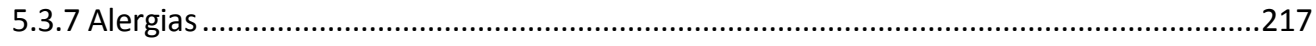

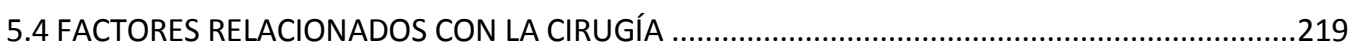

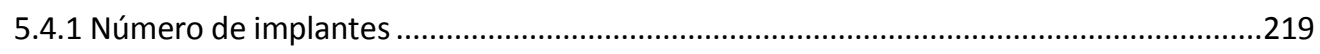

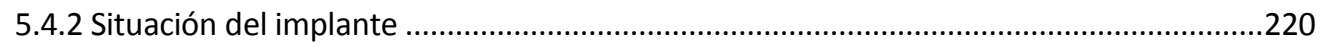

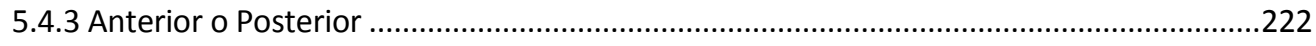

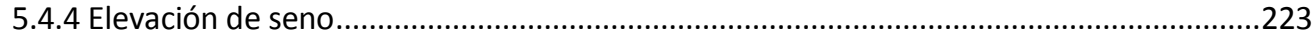




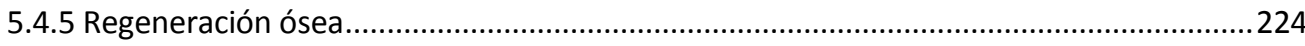

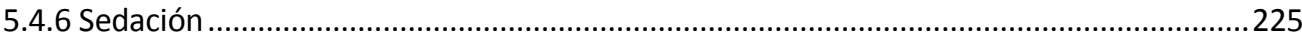

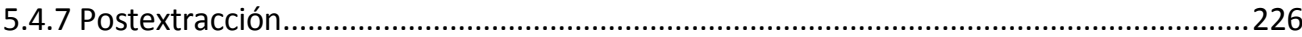

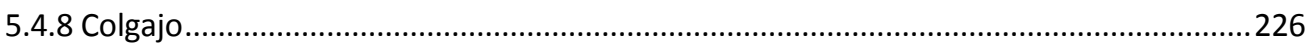

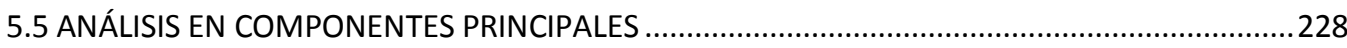

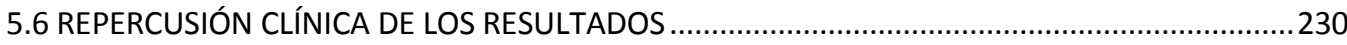

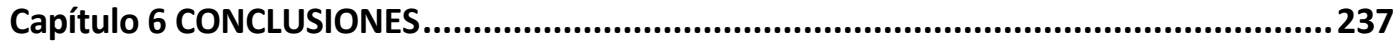

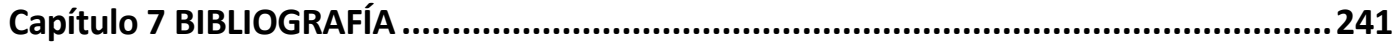

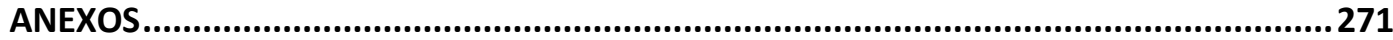

Anexo 1. Protocolo de prevención y tratamiento de las complicaciones irales debidas a la

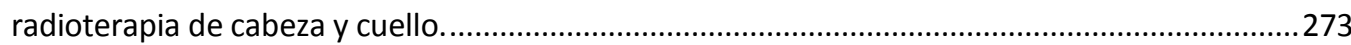

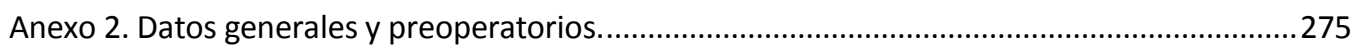

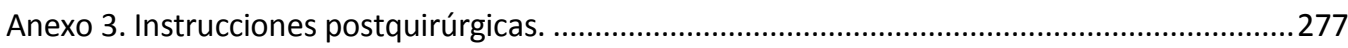

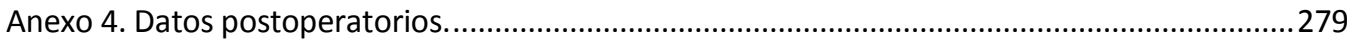

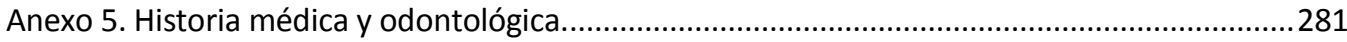

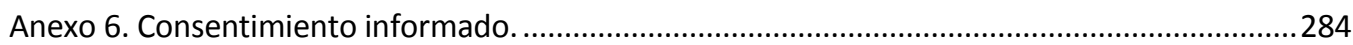

ÍNDICE TEMÁTICO............................................................................................. 286 


\section{Lista de figuras}

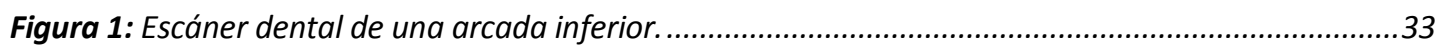

Figura 2: Elevación sinusal simultánea a la colocación del implante.........................................................34

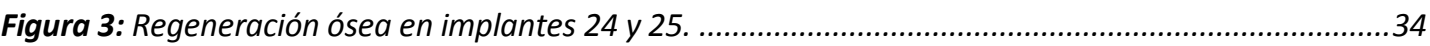

Figura 4: Férula quirúrgica para colocar cinco implantes en el maxilar superior...................................35

Figura 5: Colocación de dos implantes transmucosos a nivel del 23 y 24 .............................................40

Figura 6: Incisión paracrestal para colocar implantes en posición 16.....................................................41

Figura 7: Colgajo a espesor total con descargas mesiales y distales. .....................................................41

Figura 8: Fresas de ostectomía de menor a mayor diámetro............................................................42

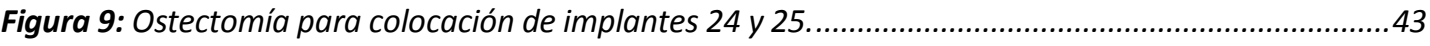

Figura 10: Paralelizadores situados en posiciones 31 y 41 ..................................................................4

Figura 11: Implante dental Zimmer..................................................................................................44

Figura 12: Colocación de un implante en posición 24.............................................................................45

Figura 13: PRIMERA FASE. Colocación de cuatro implantes y sutura del colgajo......................................46

Figura 14: SEGUNDA FASE. Colocación de cuatro tapones de cicatrización. ............................................46

Figura 15: Colocación de 2 implantes y tapones de cicatrización en una sola fase...................................47

Figura 16: Colocación sin colgajo de implantes en posiciones 23 y 24 ....................................................47

Figura 17: Colocación de un implante postextracción en posición 44 ......................................................48

Figura 18: Sutura de un colgajo con seda de 3 ceros..........................................................................49

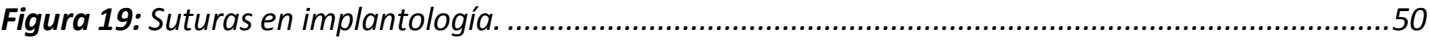

Figura 20: Implante colocado en posición 35.....................................................................................51

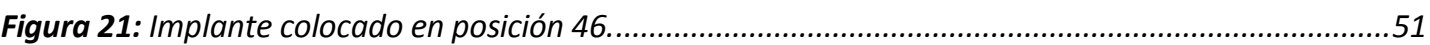

Figura 22: Implantes colocados en posición 14, 24, 25 y elevación sinusal directa en 16 y 17 ..................52

Figura 23: Implantes colocados en posición, 23, 24, 25, 46 y 26 con elevación sinusal indirecta..............52

Figura 24: Mediadores del dolor y la inflamación (Tomado de Peñarrocha, et al., 2001). ......................64

Figura 25: Vías de transmisión del dolor (Tomado de Okeson, 2006)......................................................66

Figura 26: Interacciones que alteran el sistema de reacción ante el dolor (Tomado de Rugh, 1987). .....84

Figura 27: Variables implicadas en el estudio..................................................................................109

Figura 28: Cortes de un escáner dental para colocar un implante en posición 42. ..............................114

Figura 29: Set quirúrgico para implantología oral (gorros, guantes, mascarilla y baberos estériles). ...115

Figura 30: Colutorio oral con clorhexidina para asepsia intraoral. ........................................................116

Figura 31: Anestésico utilizado para la colocación de implantes dentales. .........................................116

Figura 32: Incisión paracrestal con descargas mesiales y distales.....................................................117 
Figura 33: Incisión mínimamente invasiva con el bisturí circular.

Figura 34: Colocación de un implante dental mediante micromotor. ................................................. 119

Figura 35: Implantes colocados de manera manual en caninos e incisivos inferiores. .........................119

Figura 36: Colgajo suturado con seda de 3 ceros. ................................................................................... 120

Figura 37: Implantes colocados en posición 16, 24 y 25 con elevación sinusal indirecta........................ 120

Figura 38: Implantes colocacdos en posición 15, 16, 17, 24, 25 y 27 con elevación sinusal directa bilateral.

Figura 39: Diagrama del proceso investigador.............................................................................. 140

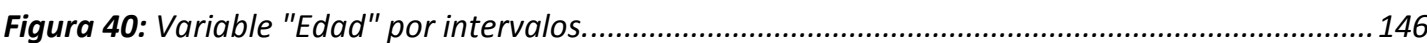

Figura 41: Distribución de la variables "Higiene". ........................................................................... 148

Figura 42: Distribución de la variable "Número de implantes"......................................................... 150

Figura 43: Distribución de la variable "Marca del implante" ............................................................ 151

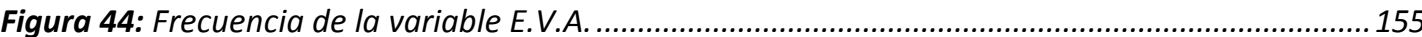

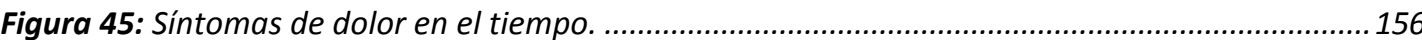

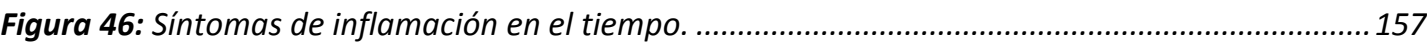

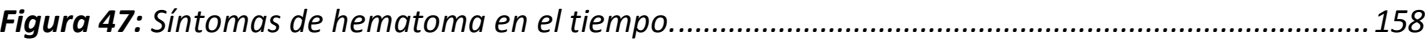

Figura 48: Distribución de la E.V.A. en la muestra en la que: "Dolor Tenue" = 0,1,2 y "Dolor Intenso" =

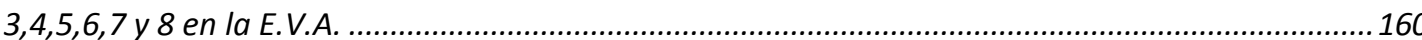

Figura 49: Distribución del dolor en relación a la variable "Sexo". ...................................................... 161

Figura 50: Distribución del dolor en relación a la variable "Fumador".............................................. 162

Figura 51: Distribución del dolor en relación a la variable "Higiene". ............................................... 163

Figura 52: Distribución del dolor en relación a la variable "Enfermedades actuales"........................ 164

Figura 53: Distribución del dolor en relación a la variable "Alergias". ................................................... 165

Figura 54: Distribución del dolor en relación a la variable "Medicamentos"....................................... 165

Figura 55: Distribución del dolor en relación a la variable "Número de implantes"........................... 166

Figura 56: Distribución del dolor en relación a la variable "Situación del implante"........................... 167

Figura 57: Distribución del dolor en relación a la variable "Anterior/Posterior". ............................... 168

Figura 58: Distribución del dolor en relación a la variable "Elevación de seno". ................................. 169

Figura 59: Distribución del dolor en relación a la variable "Regeneración"....................................... 170

Figura 60: Distribución del dolor en relación a la variable "Sedación".............................................. 171

Figura 61: Distribución del dolor en relación a la variable "Postextracción". ...................................... 172

Figura 62: Distribución del dolor en relación a la variable "Colgajo". .................................................... 173

Figura 63: Comportamiento del dolor según la edad.......................................................................... 183

Figura 64: Dispersión de la variable "Edad" frente a la variable "DolorE.V.A.". .................................... 183 


\section{Lista de tablas}

Tabla 1: Principales factores en el diagnóstico implantológico............................................................36

Tabla 2: Duración y potencia de los anestésicos locales. .......................................................................37

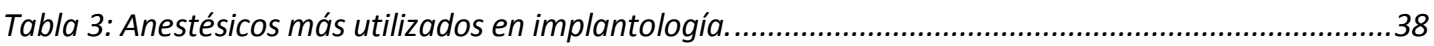

Tabla 4: Inervación y bloqueo anestésico necesario para la colocación de implantes dentales. ..............39

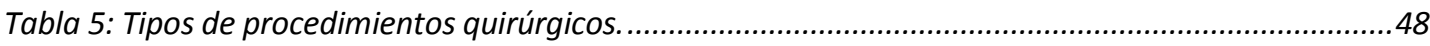

Tabla 6: Ventajas y limitaciones de los ensayos clínicos. ......................................................................108

Tabla 7: Secuencia de fresado para la clocación de implantes dentales...............................................118

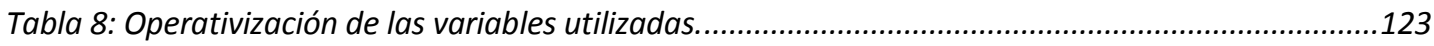

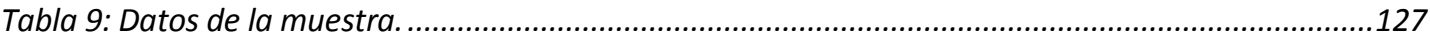

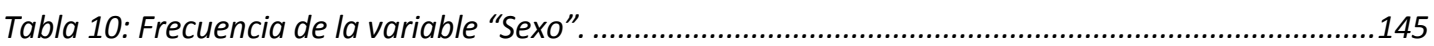

Tabla 11: Frecuencia de la variable "Edad" ........................................................................................146

Tabla 12: Frecuencia de la variable "Fumador". ....................................................................................147

Tabla 13: Frecuencia de la variable "Higiene". ...............................................................................147

Tabla 14: Frecuencia de la variable "Enfermedades Actuales". ........................................................148

Tabla 15: Frecuencia de la variable "Medicación" ....................................................................................148

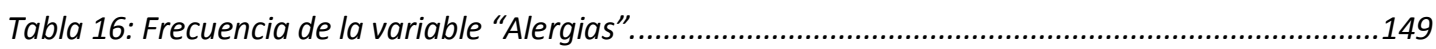

Tabla 17: Frecuencia de la variable "Número de implantes". ...............................................................149

Tabla 18: Frecuencia de la variable "Marca del implante".................................................................150

Tabla 19: Frecuencia de las variables "Maxilar o Mandibular" y "Anterior o Posterior". ........................151

Tabla 20: Frecuencia de anchuras y longitudes de implantes colocados. ..............................................152

Tabla 21: Frecuencia de la variable "Tipo de edentulismo".................................................................153

Tabla 22: Frecuencia de las variables "Regeneración", "Elevación de seno", "Colgajo", "Postextracción" y

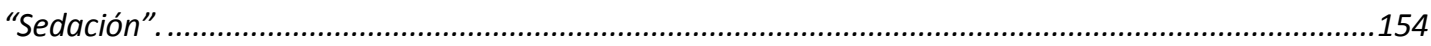

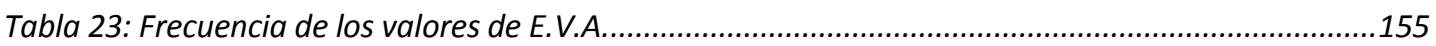

Tabla 24: Distribución y evolución temporal del dolor postoperatorio. ....................................................156

Tabla 25: Distribución y evolución temporal de la inflamación postoperatoria. .....................................157

Tabla 26: Distribución y evolución temporal del hematoma postoperatorio. .......................................158

Tabla 27: Prueba K-S de normalidad para la variable "DolorE.V.A. "...................................................174

Tabla 28: Prueba no paramétrica "U-Mann Whitney" para "DolorEVA" con variables nominales dicotómicas.

Tabla 29: Prueba no paramétrica "Kruskal-Wallis" para contrastar la relación de "DolorE.V.A." con las variables nominales politómicas. 175 
Tabla 30: Correlaciones no paramétricas de "DolorE.V.A. " y "Edad".

Tabla 31: Correlaciones no paramétricas de "DolorEVA" y "Número de implantes". ............................ 176

Tabla 32: Método de extracción: Análisis de componentes principales.................................................178

Tabla 33: Matriz de componentes rotados. .................................................................................... 179

Tabla 34: Prueba Chi-Cuadrado de independencia condicionada por edad, entre dolor y sexo.............. 181

Tabla 35: Prueba de Chi-Cuadrado de independencia condicionada por dolor, entre sexo y edad........ 181

Tabla 36: Prueba de Chi-Cuadrado de independencia condicionada por sexo, entre edad y dolor........ 182

Tabla 37: Tabla de contingencia para edad y dolor.

Tabla 38: Contrastes Chi-Cuadrado de independencia entre las variables generales y la variable "Dolor". 184

Tabla 39: Contrastes Chi-Cuadrado de independencia entre las variables generales y la variable "Inflamación". 186

Tabla 40: Contrastes Chi-cuadrado de independencia entre las variables generales y la variable "Hematoma". 188 


\section{Capítulo 1}

INTRODUCCIÓN 



\subsection{ANTECEDENTES Y JUSTIFICACIÓN}

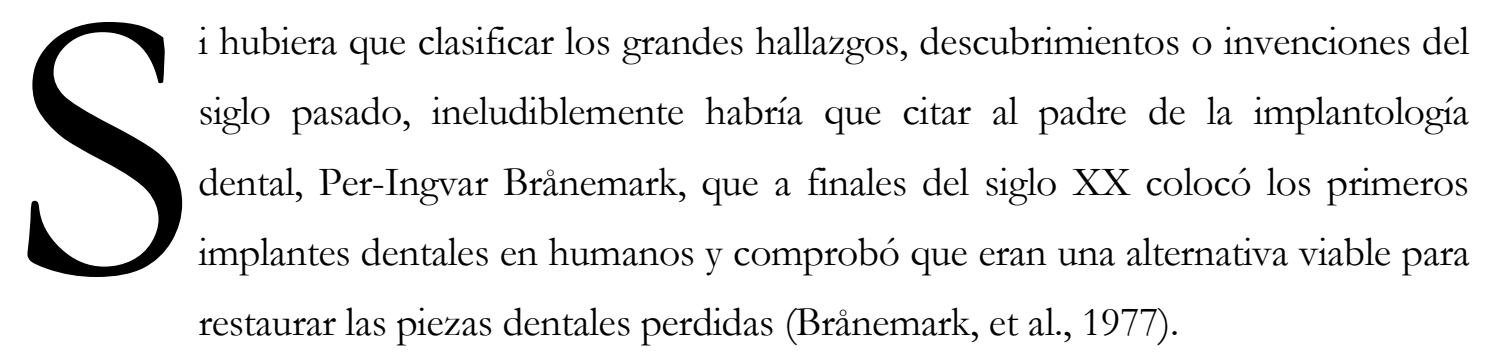

Los implantes dentales fueron desarrollados en 1952, en un laboratorio de la ciudad universitaria de Lund, Suecia, por el profesor Per-Ingvar Brånemark. Como en casi todos los grandes descubrimientos, el doctor Brånemark encontró por casualidad que unos restos de titanio que había introducido en la región ocular de unos conejos, no podían ser retirados de los mismos después del periodo de curación, ya que el titanio se había unido de manera irreversible al tejido óseo vivo, una observación que contradecía todas la teorías científicas de la época (Brånemark \& Breine, 1964).

En 1965 Brånemark publicó los primeros trabajos en los que demostraba que podía lograrse la oseointegración de implantes de titanio en los maxilares. A partir de este momento, la implantología empieza a tener un avance exponencial (Brånemark \& Breine, 1964, Breine, et al., 1961). Estas investigaciones, fueron la base para desarrollar el revolucionario sistema de implantes dentales aprobados por la Universidad de Göteborg, que contaba por entonces con gran cantidad de pacientes tratados con éxito.

El doctor Brånemark llegó a demostrar que, bajo condiciones cuidadosamente controladas, el titanio podía ser estructuralmente integrado en el hueso vivo, sin rechazo por parte del receptor, con un alto grado de predictibilidad y sin inflamación, a largo plazo, del tejido blando. Así, en 1977, Brånemark acunó el nombre de “oseointegración”, que definió como "la conexión directa, funcional y estructural entre el hueso vital y la superficie del implante" (Brånemark, et al., 1977).

En 1978 se celebró en Harvard, la primera conferencia sobre el Consenso de Implantes Dentales, en la que se mostraron todos los estudios realizados por los investigadores suecos en la Universidad de Göteborg, dirigidos por el doctor Brånemark y 
el doctor Albrektsson. Éstos expusieron y analizaron los criterios y estándares de los implantes dentales y su oseointegración (Brånemark \& Albrektsson, 1978).

En 1982 Brånemark presentó en Toronto, Canadá, un implante dental de titanio con forma de tornillo junto con su proceso de oseointegración, demostrando su éxito con pruebas clínicas de más de diez años (Brånemark, et al., 1977).

En Estados Unidos, desde 1983 hasta 2002, el número de implantes dentales colocados aumentó más de diez veces y entre 2000 y 2005, más de cinco veces (Misch, 2009).

Desde 1993 hasta la actualidad, los implantes dentales unitarios se han convertido en el tratamiento de elección para la sustitución de una pieza dental perdida, dejando a un lado, cada día con más frecuencia, la otra alternativa de tratamiento fijo: las prótesis con apoyo dentario. Esto se debe a que una prótesis fija con apoyo dental, tiene una tasa de éxito del 70\% a los 10-15 años de su colocación, mientras que los implantes dentales individuales pueden llegar a tener hasta un 97\% de éxito a los 10 años de haber sido colocados (Misch, 2009).

Hoy en día se colocan en Estados Unidos más de un millón de implantes dentales al año, mostrando una tasa de éxito superior al 95\% en la mandíbula y superior al 90\% en el maxilar superior (Misch, 2009).

Más del $90 \%$ de los odontólogos relacionados con la cirugía oral, emplean tratamientos implantológicos dentales en su consulta de manera rutinaria (Misch, 2009).

Esta revolución supuso una alternativa de tratamiento que no existía con anterioridad, ya que antes de la aparición de los implantes dentales las personas que perdían alguna o todas sus piezas dentarias sólo tenían dos opciones para restaurar dichas piezas; una prótesis fija con apoyo dentario o una prótesis removible con apoyo dentario y mucoso. Además este descubrimiento, ha promovido nuevas líneas de investigación que siguen evolucionando hoy en día, como la colocación de implantes dentales con carga inmediata, 


\section{Capitulo 1: Introducción}

implantes colocados postextracción, regeneraciones óseas en pacientes que no tienen suficiente tejido óseo para colocar implantes dentales, etc. (Misch, 2009).

Todo este progreso y las nuevas líneas de investigación, han conseguido que cada día más odontólogos coloquen implantes dentales en sus clínicas, mientras que las múltiples ventajas del tratamiento implantológico y el gran porcentaje de éxito del mismo, han provocado una demanda cada vez mayor por parte de los pacientes (Misch, 2009).

Más recientemente, se han publicado nuevos estudios que, en situaciones especiales, simplifican el procedimiento de colocación de implantes dentales. Surge entonces el concepto de "carga inmediata" que fue definido, como aquellas situaciones en las que se somete a los implantes dentales a una carga funcional en un período de tiempo inferior a 48 horas desde la colocación de los mismos (Degidi \& Piattelli, 2005). La notable capacidad de regeneración y remodelación mostrados por el tejido óseo, condujo a la hipótesis de que las altas tasas de éxito obtenidas, podrían darse también con una reducción del período de cicatrización, como expuso Brånemark en su nuevo trabajo "Brånemark Novum" (Brånemark, 2000).

Los protocolos implantológicos iniciales contraindicaban la carga inmediata, pues se consideraba necesario aplazar la carga de tres a seis meses después de la colocación de los implantes dentales. Se afirmaba que el trauma quirúrgico junto con la carga inmediata del implante, provocarían la formación de tejido fibro-conectivo en la interfase hueso-implante, lo que derivaría en la ausencia de oseointegración (Brånemark, et al., 1977, Laney, et al., 1986). Sin embargo, recientes descubrimientos clínicos, radiográficos e histológicos, evidencian que, en situaciones de implantes con carga inmediata, se puede crear tejido de mineralización en su interfase y ser estables en el tiempo, al menos cuando se dispone de buena densidad ósea (Degidi \& Piattelli, 2005).

Históricamente, la profesión odontológica ha sido siempre muy temida, ya que en la antigüedad los llamados cirujanos-barberos tenían que operar sin ningún tipo de anestesia y normalmente porvocando sangrías, para intentar curar a sus pacientes (Hoffmann-Axthelm, 1981). Esta aversión hacia los odontólogos se ha ido manteniendo en el tiempo, pues casi hasta finales del siglo XX, la odontología se basaba en extraer cualquier pieza dental que 
diera algún tipo de problema, y la mayoría de las veces, sin aplicar una técnica anestésica apropiada (Kent, 1997).

No obstante, la evolución de la odontología en los últimos 40 años ha transformado nuestra profesión, pues antes se practicaba una odontología agresiva, mientras que ahora es muy conservadora. Actualmente la odontología restauradora está muy desarrollada por lo que, salvo en casos graves como fracasos de piezas endodonciadas, fracturas dentales, etc., no se practican extracciones dentales (Misch, 2009). Toda esta evolución, ha supuesto también un gran avance de las técnicas anestésicas en los últimos años, ya que hoy en día se pueden bloquear todos los centros nerviosos de la cavidad oral, con técnicas de anestesia local sin mucha complejidad (Becker \& Reed, 2012).

Es cierto que los pacientes odontológicos asocian la cirugía de implantes dentales con la cirugía de extracción de los terceros molares o cordales, sin saber que normalmente, una cirugía implantológica es mucho menos agresiva que la extracción de un tercer molar inferior incluído. Aun así, está demostrado que por norma general, los pacientes que acuden a la consulta odontológica padecen ansiedad y, dentro de este grupo, los que más la padecen son los que se van a someter a cirugía implantológica (Brand, et al., 1995, Eli, et al., 1997, Lindsay \& Jackson, 1993, Kent, 1997, Soh \& Yu, 1992).

Esta ansiedad tiene una íntima relación con el dolor postquirúrgico que padecen los pacientes sometidos a la colocación de implantes dentales. El umbral del dolor se ve reducido por la ansiedad, lo que provoca que estos pacientes tengan un postoperatorio más complicado que los pacientes que no la padecen (Hashem, et al., 2006, LLorca, et al., 1989, Torabinejad, 1994).

Existen varios estudios que se centran en el postoperatorio de los pacientes sometidos a cirugía de implantes dentales y, aunque no existe un protocolo estandarizado de tratamiento de dichos pacientes, sí parece haber consenso en los factores que están íntimamente relacionados con el postoperatorio como son: el número de implantes que se van a colocar, el grado de higiene oral, la localización (maxilar superior o mandibular), etc. (Al-Khabbaz, et al., 2007, Eli, et al., 2003, González, et al., 2005, Guarinos, et al., 1998, Muller \& Ríos, 2001). 


\section{Capitulo 1: Introducción}

Hasta el momento, no se ha alcanzado un consenso en lo que respecta al tratamiento de los pacientes a los que se les han colocado implantes dentales. Hoy en día, la mayoría de los autores establecen una profilaxis antibiótica antes de la colocación de los implantes dentales o bien prescriben una cobertura antibiótica posterior a la cirugía, con una duración de entre cinco y siete días (Al-Khabbaz, et al., 2007, González, et al., 2005, Guarinos, et al., 1998, Romero, et al., 2006), sin embargo, estas afirmaciones han sido puestas en duda por varios autores (Espósito, et al., 2003, Mazzocchi, et al., 2007). 


\subsection{IMPLANTOLOGÍA: CARACTERÍSTICAS DEL TRATAMIENTO}

La implantología, es la disciplina de la odontología que se ocupa del estudio de los materiales aloplásticos que se colocan sobre el hueso maxilar o mandibular para posteriormente dar apoyo a una rehabilitación dental (Spiekermann, 1995).

El objetivo de la implantología no es sólo sustituir piezas perdidas, sino rehabilitar al paciente en función, comodidad, estética, habla y salud (Misch, 2009).

Los implantes dentales pueden ser de diferentes tamaños, superficies y materiales. Sobre ellos se diseñan las rehabilitaciones protésicas que van a permitir restituir las funciones masticatorias, fonéticas y estéticas del paciente. La elección del tipo de implante que se coloca en el paciente, se realiza en función del diagnóstico, pronóstico y plan de tratamiento interdisciplinario acordado entre el odontólogo generalista y un especialista en cirugía, periodoncia o prostodoncia (Misch, 2009).

Actualmente, la mayoría de los implantes intraóseos tienen forma de raíz dental y los materiales utilizados para su fabricación, son altamente biocompatibles como en el caso del titanio, lo que permite una unión al hueso biológicamente estable, denominada "Oseointegración" y descubierta por I.P. Brånemark en 1982 como se ha citado anteriormente en el apartado 1.1 ANTECEDENTES Y JUSTIFICACIÓN, de la página 25.

El procedimiento quirúrgico que se sigue para colocar un implante dental, no reviste excesiva complejidad para un profesional con formación y experiencia, sin embargo, existen muchos factores previos al acto quirúrgico que se deben estudiar y analizar con detenimiento, si queremos que la cirugía sea un éxito a corto y largo plazo (Misch, 2009, Raspall, 2006, Spiekermann, 1995). 


\subsubsection{Diagnóstico}

El éxito de una cirugía implantológica se basa principalamente en la elaboración de un diagnóstico correcto (Misch, 2009).

La evaluación médica del paciente tiene una importancia fundamental en implantología, quizás más que en otras disciplinas de la odontología (Redding \& Montgomery, 1990). Especialmente interesante es conocer la medicación que ha tomado el paciente en los seis meses precedentes a la futura intervención y sus alergias, así como llevar a cabo una revisión de todos los sistemas de su organismo (Misch, 2009).

En implantología adquieren una importancia especial los pacientes que padecen o han padecido alguna enfermedad sistémica como hipertensión arterial, infarto de miocardio, angina de pecho, diabetes mellitus, etc. De igual importancia son los fármacos que toma el paciente, pues también pueden influir en la cirugía. Así, fármacos inmunosupresores, anticoagulantes, bifosfonatos orales, etc., deben ser conocidos antes de la intervención para establecer un protocolo de administración o abstención correcto antes de la cirugía implantológica (Misch, 2009).

La irradiación de pacientes que padecen cáncer de cabeza y cuello, puede producir efectos adversos en los tejidos duros y blandos de la cavidad oral (Visch, et al., 2002). La osteorradionecrosis es el proceso de necrosis o desvitalización irreversible del hueso en la zona donde se ha producido la radiación, y es el efecto secundario que se da con más frecuencia cuando se colocan implantes dentales en pacientes irradiados previamente (Misch, 2009). La mayoría de los estudios muestran que, cuanto mayor es el tiempo transcurrido desde la radioterapia hasta la colocación de los implantes dentales, menor es el riesgo de osteorradionecrosis. Los autores no se ponen de acuerdo a la hora de establecer el período de tiempo ideal que se debe esperar, antes de colocar implantes dentales en pacientes sometidos a terapias de irradiación, pudiendo variar este tiempo entre 3 y 6 meses, 12 o incluso 24 meses (Misch, 2009).

En nuestro país se aplica un protocolo de prevención y tratamiento de las complicaciones orales debidas a radioterapia de cabeza y cuello. (Anexo 1. Protocolo de prevención y tratamiento de las complicaciones irales debidas a la radioterapia de cabeza y cuello). 


\section{VNIVERSIDAD}

BSALAMANCA

En último lugar, la historia clínica debe reflejar si el paciente es fumador y, en caso afirmativo, debe especificar el número de cigarrillos que fuma al día, así como el grado de higiene oral que presenta, pues ambos son aspectos que van a influir directamente en la colocación de los implantes dentales y en el postoperatorio, como se demuestra en el apartado A) Factores relacionados con el paciente, páginas 75 y 77.

Una vez revisada la historia clínica del paciente, se procede a realizar una exploración extraoral e intraoral tal y como se haría con cualquier paciente que acude por primera vez a una consulta dental (Misch, 2009). En primer lugar se lleva a cabo el tratamiento restaurador y periodontal del paciente en caso de que fuera necesario y, posteriormente, se procede al restablecimiento de las piezas perdidas.

Una vez comprobada la correcta situación médica y odontológica del paciente, se deben analizar los factores que van a afectar, tanto a los implantes como a la prótesis dental, que, posteriormente, llevará el paciente. Los más importantes son: la fuerza masticatoria, la parafunción, el espacio de la altura coronaria, la dinámica masticatoria, la posición en la arcada y la arcada antagonista (Misch, 2009).

Una vez analizados estos aspectos, se procede al estudio de la disponibilidad ósea del paciente en la zona que se va a tratar. Este parámetro es particularmente importante en implantología dental y hace referencia al volumen óseo del área edéntula donde se quieren colocar los implantes dentales (Misch, 2009). Anteriormente, este factor era determinante, pues no existían técnicas para generar tejido óseo en zonas que habían perdido masa ósea pero, en la actualidad se aplican múltiples técnicas para aumentar el tejido óseo y blando disponible del paciente. Por este motivo, se consideran primero las opciones protésicas definitivas, después los factores dependientes del paciente y por último la densidad ósea (Misch, 2009).

El volumen y la densidad ósea es un factor fundamental para el éxito clínico de los implantes dentales. Varios autores han demostrado a largo plazo que, cuanto menor es el volumen óseo y peor es la calidad ósea de la zona donde se van a colocar los implantes dentales, menor es el éxito de supervivencia de dichos implantes (Higuchi, et al., 1995, Misch, et al., 1999, Smedberg, et al., 1993, Weng, et al., 2003). 


\section{Capitulo 1: Introducción}

Para comprobar el volumen óseo disponible del paciente es necesario realizar un escáner dental del maxilar superior o de la mandíbula, dependiendo del lugar donde se vaya a efectuar el tratamiento.

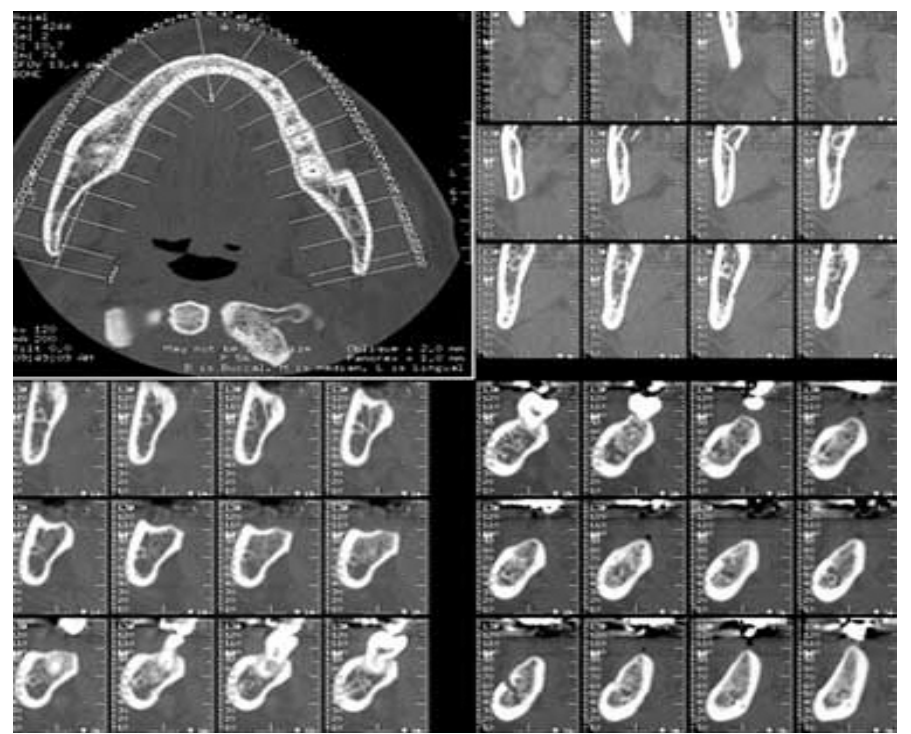

Figura 1: Escáner dental de una arcada inferior.

En el escáner podremos valorar si va a necesitar cirugía previa a la colocación de implantes dentales por falta de disponibilidad ósea como, por ejemplo, regeneración ósea guiada (R.O.G), elevación de seno, etc. En función de la perdida ósea que presente el paciente, esta cirugía de regeneración se realizará antes de la colocación de los implantes o simultáneamente en la misma. 


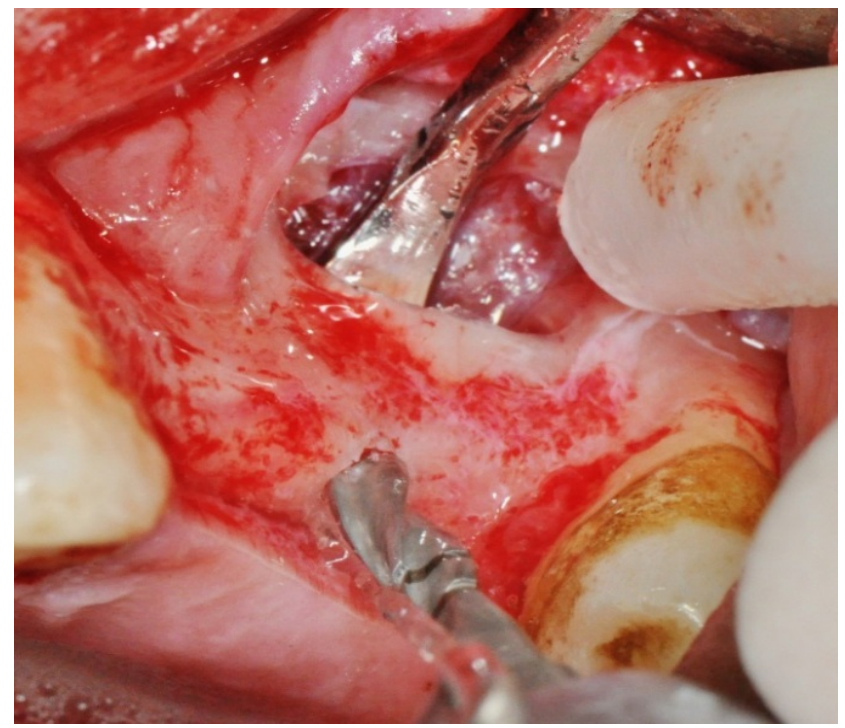

Figura 2: Elevación sinusal simultánea a la colocación del implante.

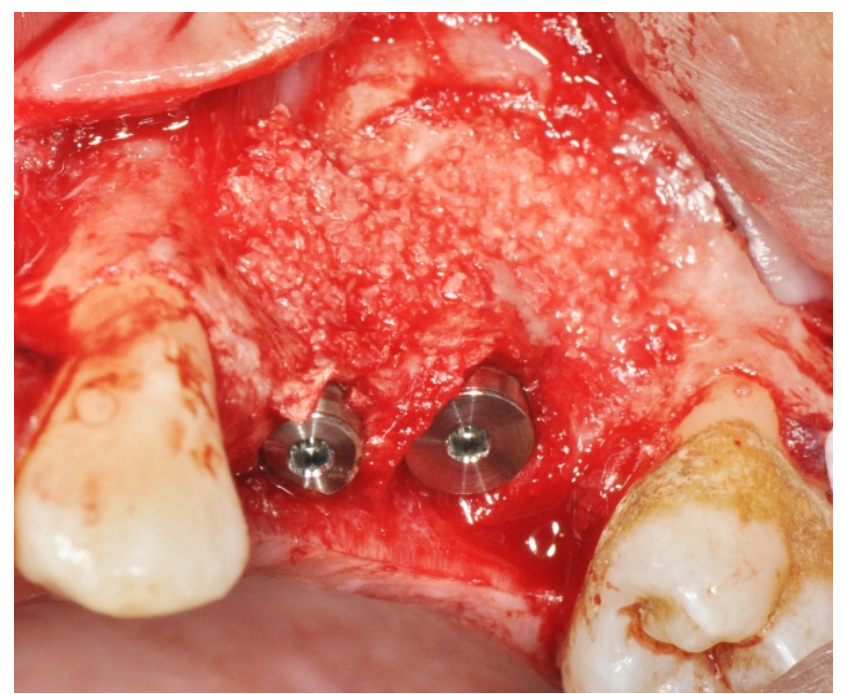

Figura 3: Regeneración ósea en implantes 24 y 25.

Tras la evaluación del escáner, se debe valorar el grupo en el que se encuentra el paciente, respecto al momento temporal para la colocación del implante dental. Existen cuatro posibilidades para colocar un implante dental en relación a la fecha de pérdida o extracción de la pieza dental (Machín Muñoz, 2002): 


\section{Capitulo 1: Introducción}

- Implante inmediato o postextracción: es el implante que se coloca inmediatamente después de realizar la extracción dental.

- Implante inmediato diferido: se espera únicamente a la cicatrización del tejido blando, que se produce entre uno y dos meses después de la extracción dental.

- Implante diferido: la colocación del implante se realiza tres meses después de la extracción dental, cuando ya han cicatrizado los tejidos blando y duro.

- Implante en hueso maduro: el implante dental es colocado cuando han pasado ocho meses o más después de perder la pieza dental.

Una vez comprobados todos estos aspectos, se elabora la férula quirúrgica que servirá de guía en la cirugía, a través de la cual se colocan los implantes dentales (Misch, 2009).

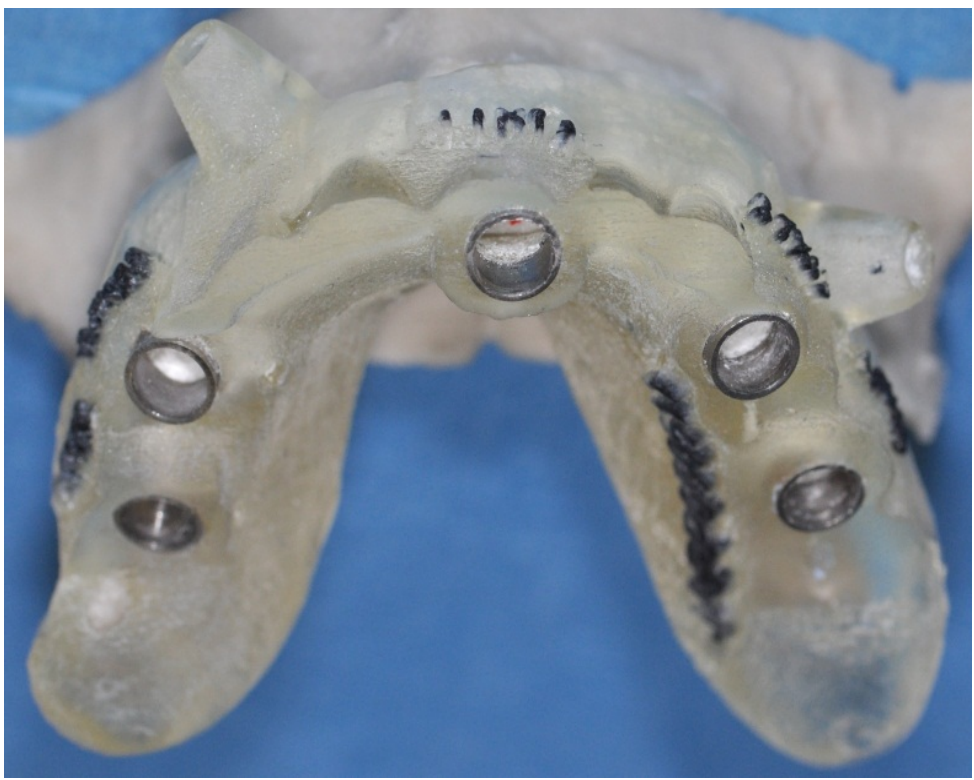

Figura 4: Férula quirúrgica para colocar cinco implantes en el maxilar superior. 
Tabla 1: Principales factores en el diagnóstico implantológico.

\begin{tabular}{|c|}
\hline DIAGNÓSTICO \\
\hline Historia médica y odontológica \\
\hline Factores protésicos \\
\hline Factores implantológicos \\
\hline Disponibilidad ósea \\
\hline ¿Regeneración previa o simultánea? \\
\hline Férula quirúrgica \\
\hline
\end{tabular}

\subsubsection{Acto quirúrgico}

\section{A) Preparación del campo quirúrgico}

Antes de la colocación de implantes dentales es deseable llevar a cabo una desinfección total del gabinete dental. La esterilidad total sólo se consigue en quirófanos muy preparados y es muy difícil de alcanzar en un gabinete dental. Sin embargo, sí se puede conseguir un ambiente aséptico, con la llamada técnica quirúrgica limpia que consiste en utilizar todo el material esterilizado y aséptico aún sin llegar a la esterilidad total, que es lo que suele encontrarse en los gabinetes dentales (Scharf \& Tarnow, 1993).

En cualquier caso, se ha demostrado que la técnica limpia o aséptica no difiere, en cuanto al éxito en la colocación de implantes dentales de la técnica estéril (Scharf \& Tarnow, 1993). 


\section{Capitulo 1: Introducción}

Todo el instrumental que se va a utilizar en la cirugía, es decir, motor para implantes, pieza de mano, bisturí, periostotomos, etc., debe estar estéril (Cícero \& Daudt, 2003, Misch, 2006, Misch, 2009, Raspall, 2006, Spiekermann, 1995).

Tanto el cirujano como el personal auxiliar que vaya a participar activamente en la cirugía, deben llevar guantes, gorro, bata y mascarilla estériles y desechables (Misch, 2009, Raspall, 2006, Spiekermann, 1995).

$\mathrm{Al}$ paciente se le debe practicar, antes de comenzar la intervención, asepsia extraoral mediante la colocación de un gorro y un babero estéril, así como, asepsia intraoral, mediante enjuagues de clorhexidina al $0,12 \%$, dos o tres veces antes de la intervención, tal y como se explica en el apartado C) Antisépticos, página 89 (Lang, et al., 2000, Quirynen, et al., 2002).

\section{B) Anestesia}

Los anestésicos más empleados en odontología son los de tipo amida, entre los que destacan: lidocaína, articaína, bupivacaína y mepivacaína. Sin embargo, varios de los anestésicos utilizados con más frecuencia en la consulta dental tienen menos potencia y duración de lo deseado en cirugía de colocación de implantes dentales. Por lo tanto, en implantología, se suelen utilizar anestésicos locales más potentes y duraderos aunque si la intervención no va a ser compleja o duradera, se puede emplear cualquier anestésico de los utilizados habitualmente en la consulta dental (Becker \& Reed, 2012, Haas, 2002, Misch, 2009).

Tabla 2: Duración y potencia de los anestésicos locales.

\section{DURACIÓN Y POTENCIA DE LOS ANESTÉSICOS LOCALES}

Acción corta y potencia baja: Procaína y Cloroprocaína.

Acción media y potencia intermedia: Lidocaína, Prilocaína y Mepivacaína.

Acción larga y potencia elevada: Tetracaína, Bupivacaína, Articaína, Etidocaína, Ropivacaína. 
Los anestésicos que más utilizan los cirujanos orales son la articaína y bupivacaína debido a su gran potencia y duración (Misch, 2009).

Tabla 3: Anestésicos más utilizados en implantología.

\begin{tabular}{|c|}
\hline ANESTÉSICOS MÁS USADOS EN IMPLANTOLOGÍA \\
\hline Articaína 4\% - Adrenalina 1:200.000 \\
\hline Bupivacaína $0.5 \%$ - Adrenalina 1:200.000 \\
\hline Mepivacaína 3\% - No adrenalina \\
\hline Lidocaína $\%$ - Adrenalina 1:100.000 \\
\hline
\end{tabular}

El primer paso del acto quirúrgico, es la anestesia de la zona a intervenir. Para la colocación de un implante en la zona mandibular posterior, se bloquean el nervio alveolar inferior o nervio dentario y el nervio lingual del lado que se va a intervenir, ambos mediante la técnica de anestesia troncular. Para colocar un implante en la zona mandibular anterior, se anestesia de manera infiltrativa, la zona vestibular de los incisivos inferiores para bloquear el nervio mentoniano. Si la zona que se va a intervenir es cercana al agujero mentoniano (entre primer y segundo premolar inferior), se debe anestesiar también, de forma infiltrativa dicha zona (Raspall, 2006).

Para intervenir en el maxilar superior se anestesian por el mismo método, el nervio maxilar o alguna de sus ramas y el nervio alveolar superior anterior, medio o posterior. Si la cirugía se va a practicar en la zona anterior, en ocasiones se requiere el bloqueo del nervio nasopalatino o esfenopalatino. Éste, se consigue anestesiando el agujero nasopalatino, situado entre los incisivos centrales superiores. Rara vez se necesitan bloquear los nervios 


\section{Capitulo 1: Introducción}

palatino mayor y menor, ya que éstos inervan el paladar duro y blando, respectivamente, pero a nivel posterior (Raspall, 2006).

Tabla 4: Inervación y bloqueo anestésico necesario para la colocación de implantes dentales.

\begin{tabular}{|c|r|c|}
\hline REGIÓN & NERVIO BLOQUEADO & TÉCNICA \\
\hline Mandibular Anterior & Mentoniano & Infiltrativa \\
\hline \multirow{2}{*}{ Mandibular Posterior } & $\begin{array}{r}\text { Dentario o Alveolar Inferior } \\
\text { Lingual }\end{array}$ & Troncular \\
\hline Maxilar Anterior & Alveolar Superior, Anterior y Medio & Infiltrativa \\
\hline Maxilar Posterior & Nasopalatino & Infiltrativa \\
\hline
\end{tabular}

\section{C) Incisión}

En cirugía oral, todas las incisiones se pueden realizar con la hoja de bisturí número 15, aunque hay zonas que son más sencillas de realizar con la hoja número 12. Las hojas de bisturí se usarán en una sola cirugía y se desecharán (Raspall, 2006).

Dependiendo de la disponibilidad ósea y del estado de los tejidos blandos del paciente, se pueden realizar distintos tipos de incisiones y colgajos.

- Implante transmucoso o cirugía mínimamente invasiva: en este tipo de cirugía no se abren colgajos para la colocación del implante dental, sino que simplemente, se elimina la porción de encía queratinizada necesaria para poder colocar el implante. El procedimiento se realiza con un bisturí circular de tres o cuatro milímetros (mm.) de diámetro. Esta clase de cirugía, sólo se puede realizar en pacientes que poseen buena disponibilidad ósea y un perfecto estado de los tejidos blandos, en la zona donde se van a colocar los implantes dentales (Becker, et al., 2005). 
Está demostrado que, mediante esta técnica, se consigue acortar el tiempo quirúrgico, se minimizan los cambios de la cresta ósea y se produce un postoperatorio más confortable (Becker, et al., 2005, Becker, et al., 2009, Lee, et al., 2011, Rousseau, 2010).

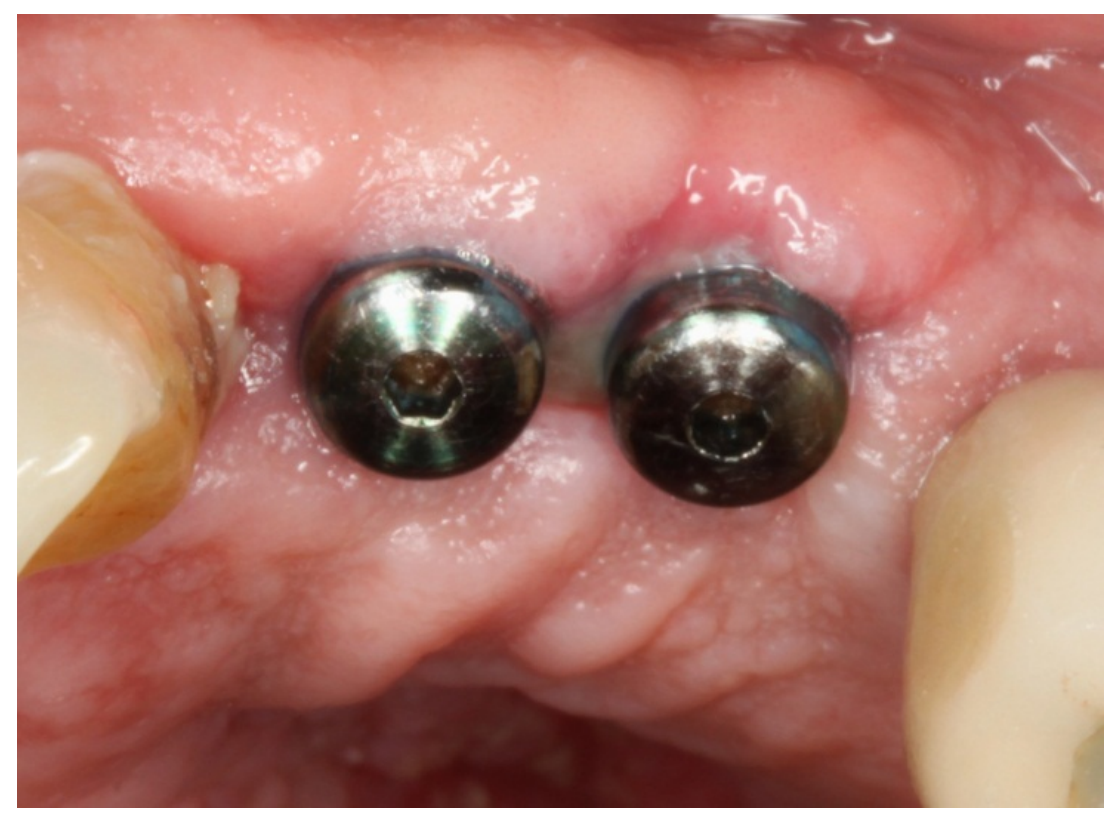

Figura 5: Colocación de dos implantes transmucosos a nivel del 23 y 24.

- Implante colocado mediante una incisión paracrestal: en los casos en los que hay una altura y anchura ideal del hueso remanente del paciente, pero el tejido blando no es el recomendado para realizar un implante transmucoso, el implante se coloca realizando una incisión paracrestal en la vertiente lingual o palatina de la región edéntula, para proporcionar mayor espesor de tejido queratinizado en la porción facial del colgajo. A continuación, se despega el colgajo hasta alcanzar la tabla ósea vestibular (Misch, 2009). 
Capitulo 1: Introducción

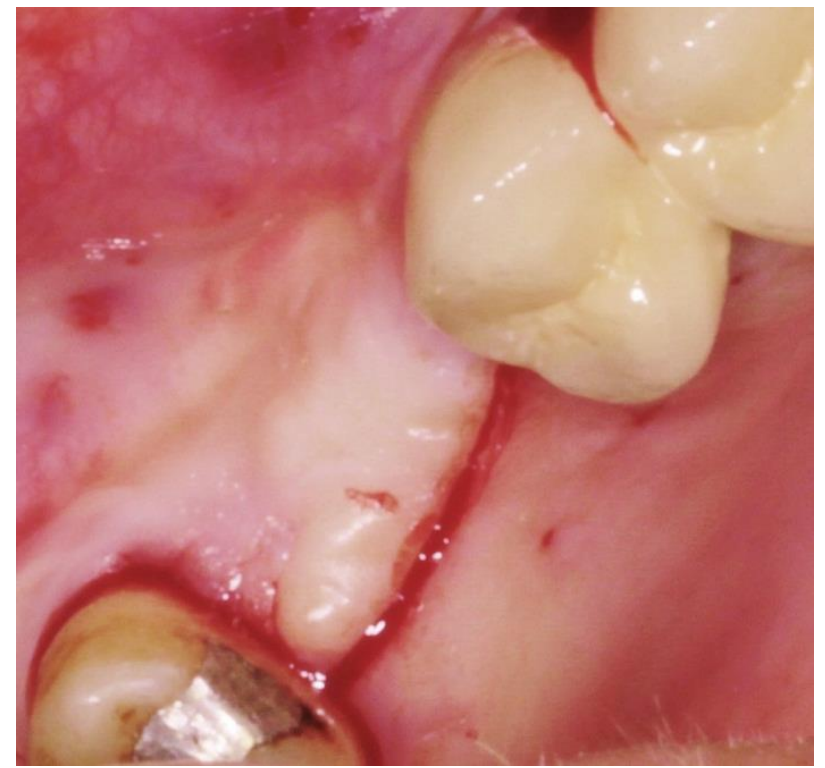

Figura 6: Incisión paracrestal para colocar implantes en posición 16.

- Implante colocado mediante un colgajo a espesor total: cuando la anchura ósea está comprometida o la cirugía va a ser compleja, como en el caso de colocación de varios implantes, regeneraciones óseas o elevaciones de seno, se realiza un colgajo a espesor total con descargas mesiales y distales a nivel vestibular (Branemark \& Albrektsson, 1978, Cícero \& Daudt, 2003, Misch, 2009, Raspall, 2006, Spiekermann, 1995).

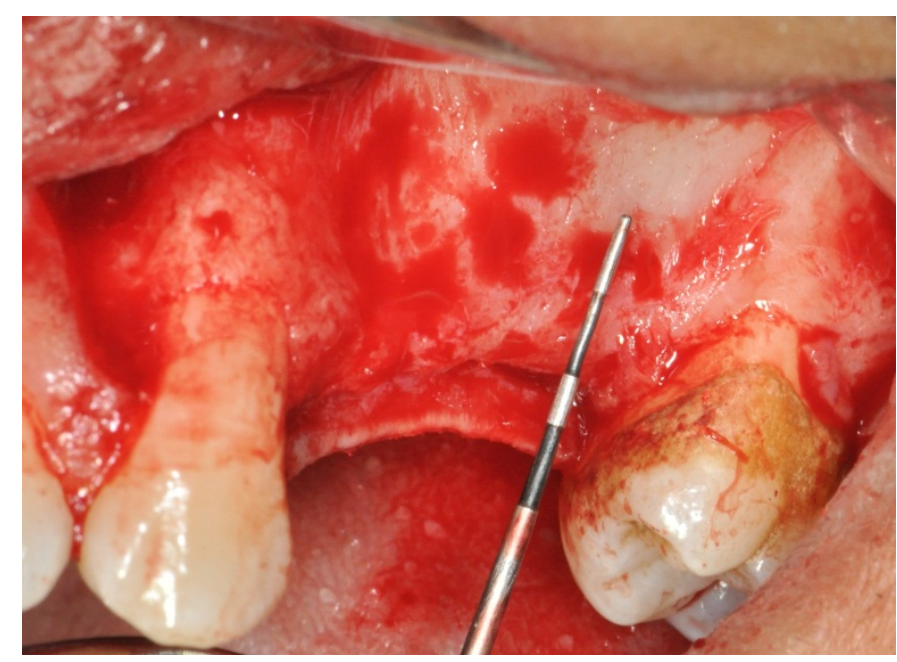

Figura 7: Colgajo a espesor total con descargas mesiales y distales. 


\section{D) Ostectomía}

Una vez realizada la incisión y separación del colgajo, se realiza la preparación del lecho del implante. En primer lugar, se adapta en la boca del paciente la férula o guía quirúrgica. Una vez ubicada en la posición correcta, comenzará el fresado óseo a una velocidad de 1200 revoluciones por minuto (r.p.m.) o superior y con abundante irrigación. El primer paso consiste en utilizar la fresa piloto o inicial a una profundidad de 3-5 mm., para comprobar la calidad del hueso y proporcionar una dirección adecuada a la secuencia de fresado, que se recomienda que sea perpendicular al plano oclusal (Cícero \& Daudt, 2003, Misch, 2009, Raspall, 2006, Spiekermann, 1995).

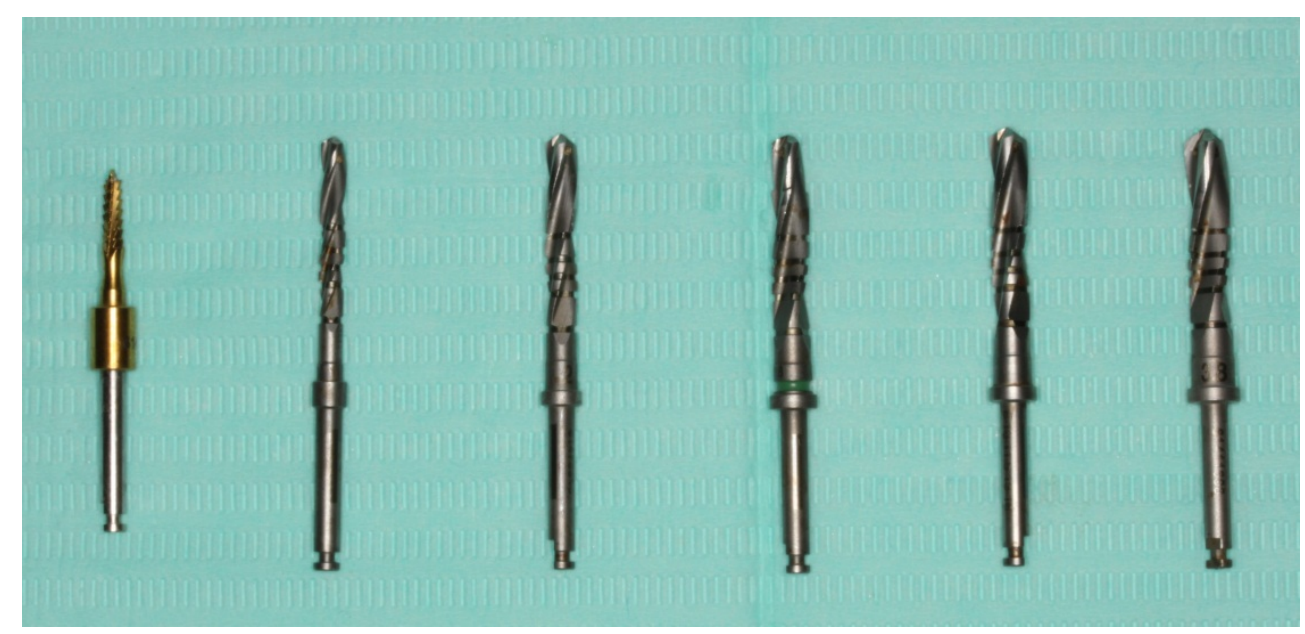

Figura 8: Fresas de ostectomía de menor a mayor diámetro.

Después de la fresa piloto, comienza la secuencia de fresado con la fresa más fina, de 2,3 $\mathrm{mm}$. de anchura normalmente y que se debe insertar siempre con la misma longitud del implante que se va a colocar. Una vez empleada esta fresa, se coloca un pin paralelizador para comprobar que la dirección del fresado es la correcta. A continuación, se debe seguir la secuencia de fresado óseo, aumentando el diámetro de las fresas hasta llegar a una anchura de entre 3 y $5 \mathrm{~mm}$. menor que el diámetro del implante que vamos a colocar. Así, para un implante de 3,7 $\mathrm{mm}$. la secuencia de fresado consistirá en: fresa piloto o inicial, fresa de 2,3 mm., de 2,8 mm., y por último de 3,4 mm., todas ellas a la longitud del implante que se va colocar (Cícero \& Daudt, 2003, Misch, 2009, Raspall, 2006, Spiekermann, 1995). 


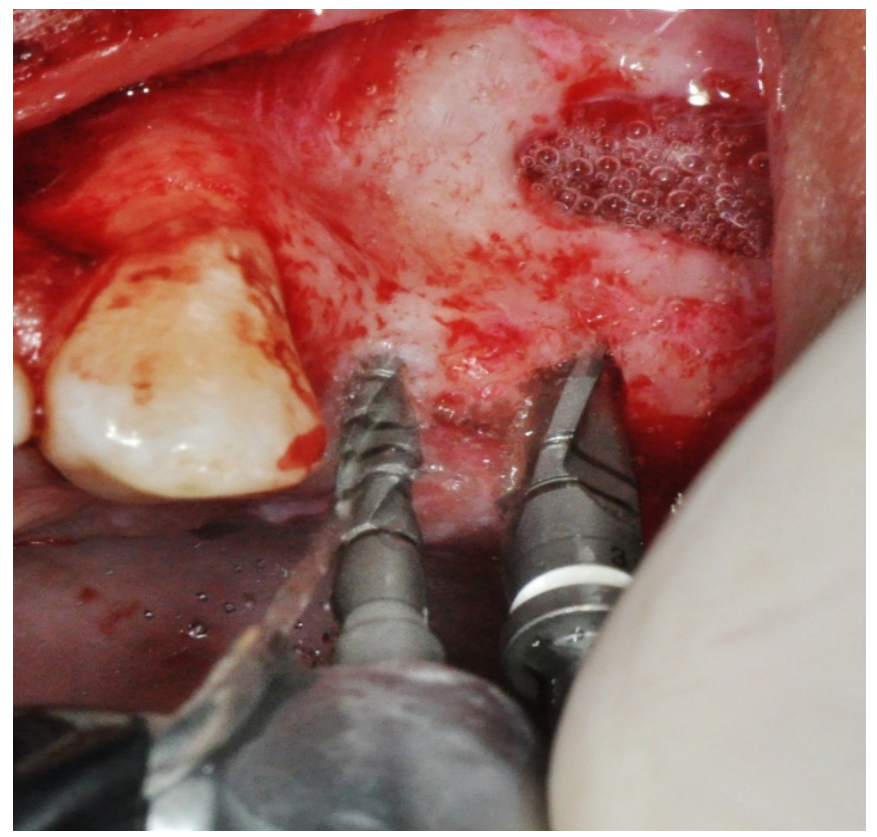

Figura 9: Ostectomía para colocación de implantes 24 y 25.

Uno de los principales objetivos de la preparación del lecho óseo, es evitar un calentamiento excesivo del hueso (Misch, 2009). El mejor método para combatir este problema, es aplicar abundante irrigación fría durante el fresado óseo (Brisman, 1996, Isler, et al., 2011, Misir, et al., 2009).

\section{E) Colocación del implante}

Cuando se finaliza el fresado del lecho óseo, se irriga con abundante suero salino, se aspira para eliminar posibles restos y se comprueba, finalmente, con un pin paralelizador que la angulación del fresado ha sido la correcta (Cícero \& Daudt, 2003, Misch, 2006, Misch, 2009, Raspall, 2006, Spiekermann, 1995). 


\section{VNiVERSIDAD \\ BSALAMANCA}

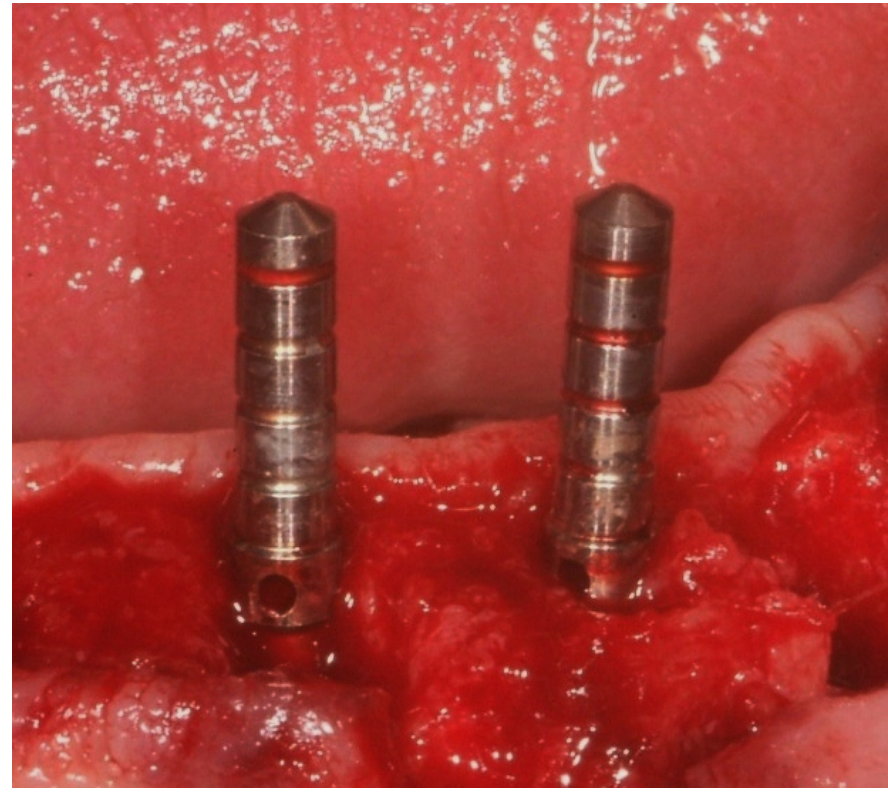

Figura 10: Paralelizadores situados en posiciones 31 y 41 .

Una vez comprobados estos aspectos, se cambia el programa del motor de implantes para que el implante dental penetre en el lecho óseo con una fuerza de entre $30 \mathrm{y}$ 50 Newton (N) (Cícero \& Daudt, 2003, Misch, 2009, Raspall, 2006, Spiekermann, 1995).

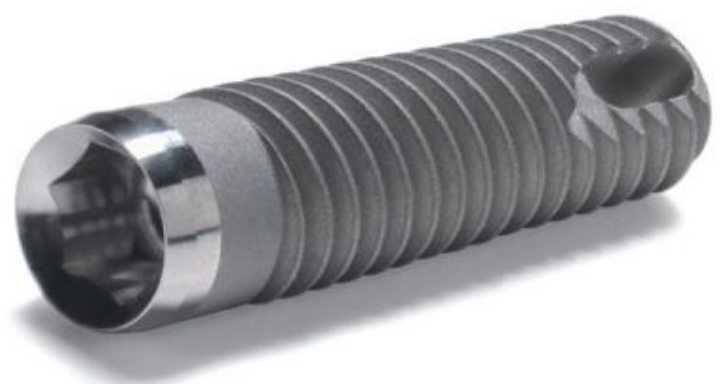

Figura 11: Implante dental Zimmer. 
Capitulo 1: Introducción

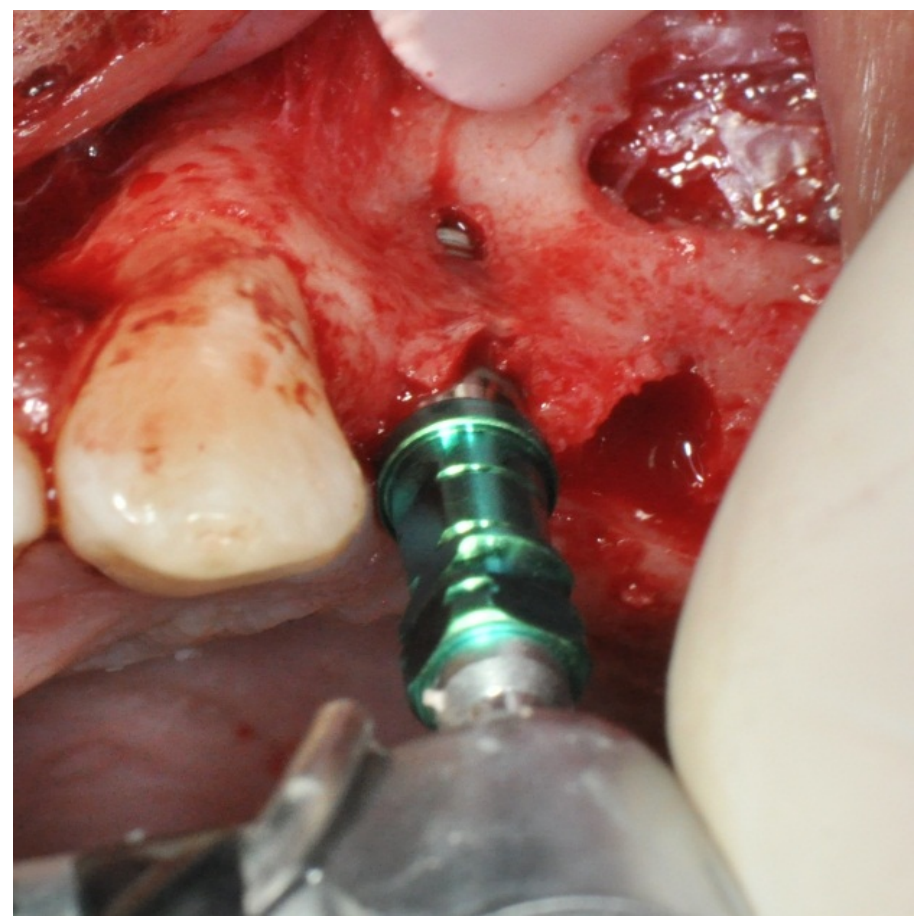

Figura 12: Colocación de un implante en posición 24.

\section{F) Adaptación del tejido blando}

Una vez colocado el implante, existen cuatro opciones de procedimiento quirúrgico:

$\left.1^{a}\right)$ Cirugía en dos fases: consiste en abrir un colgajo mediante una incisión paracrestal sin descargas, colocar el implante y cerrar con puntos simples. Se dejan pasar entre tres y cuatro meses desde el día de la intervención, si el implante fue colocado en la mandíbula y entre cuatro y seis meses si fue colocado en el maxilar superior, siguiendo el procedimiento tradicional descrito por Brånemark, como se explica en el apartado 1.1 ANTECEDENTES Y JUSTIFICACIÓN, página 25. Pasado este tiempo, se vuelve abrir un colgajo y se coloca un tapón de cicatrización sobre el implante para dejarlo descubierto (Brånemark, et al., 1977, Laney, et al., 1986). 


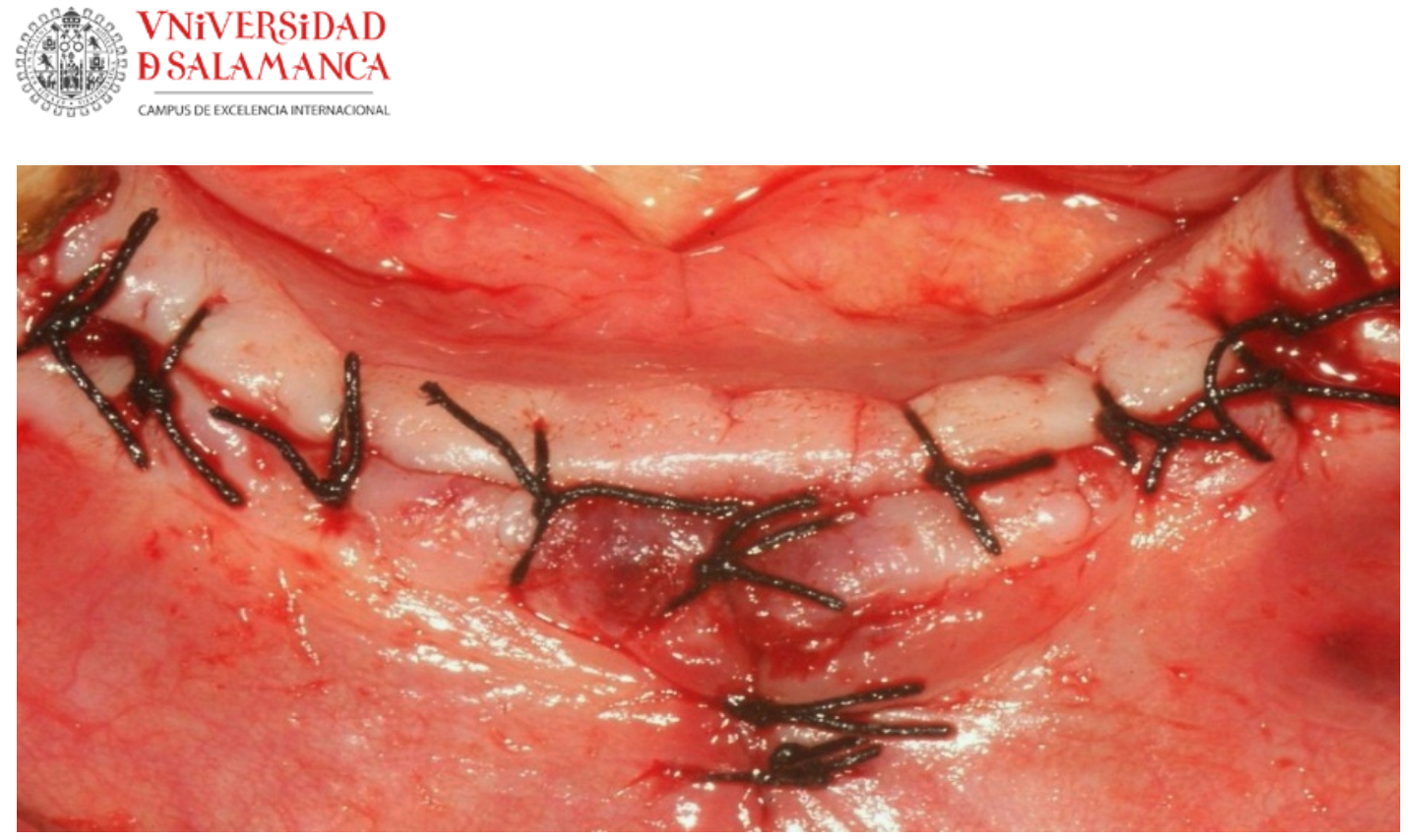

Figura 13: PRIMERA FASE. Colocación de cuatro implantes y sutura del colgajo.

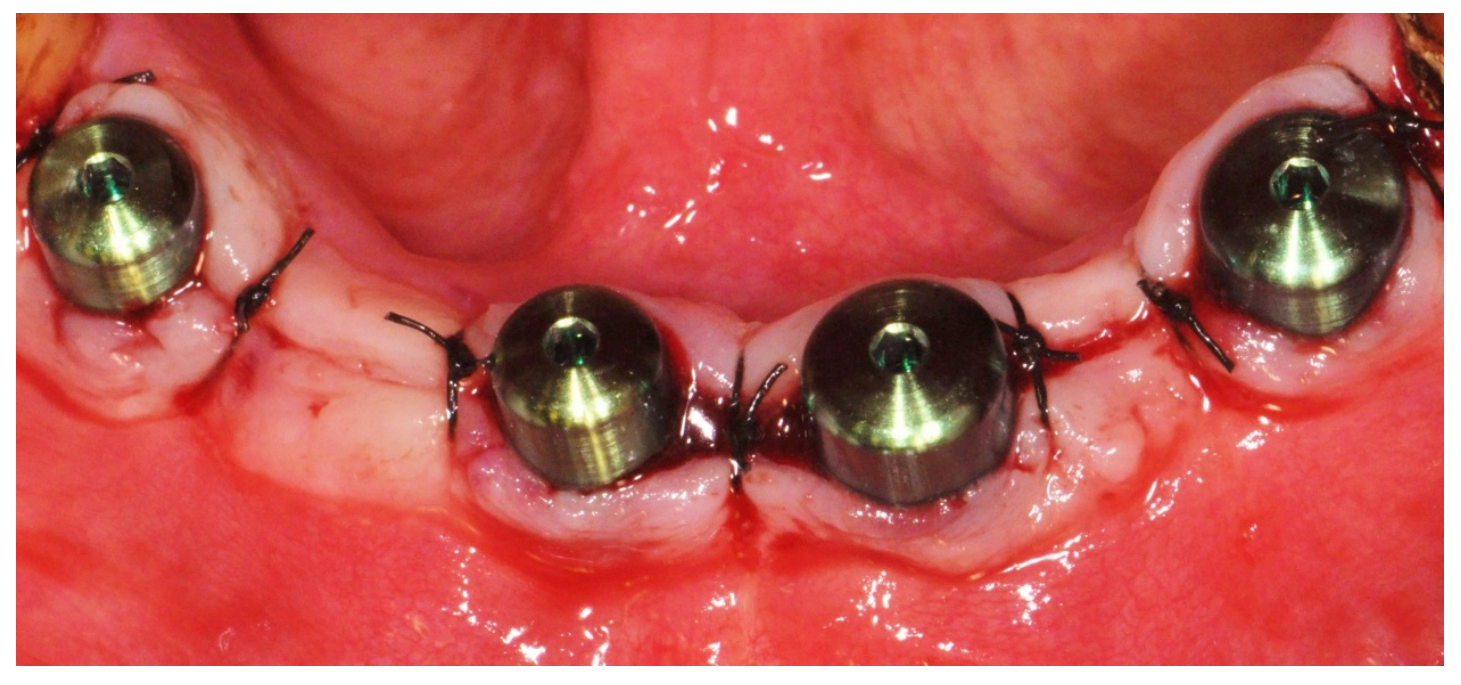

Figura 14: SEGUNDA FASE. Colocación de cuatro tapones de cicatrización.

$\left.2^{a}\right)$ Cirugía en una sola fase: consiste en abrir un colgajo mediante una incisión paracrestal sin descargas, y colocar el implante y el tapón de cicatrización en la misma cirugía, sin esperar los 4-6 meses de maduración del tejido blando, por lo que ya no habría que volver a abrir la zona en el futuro. 


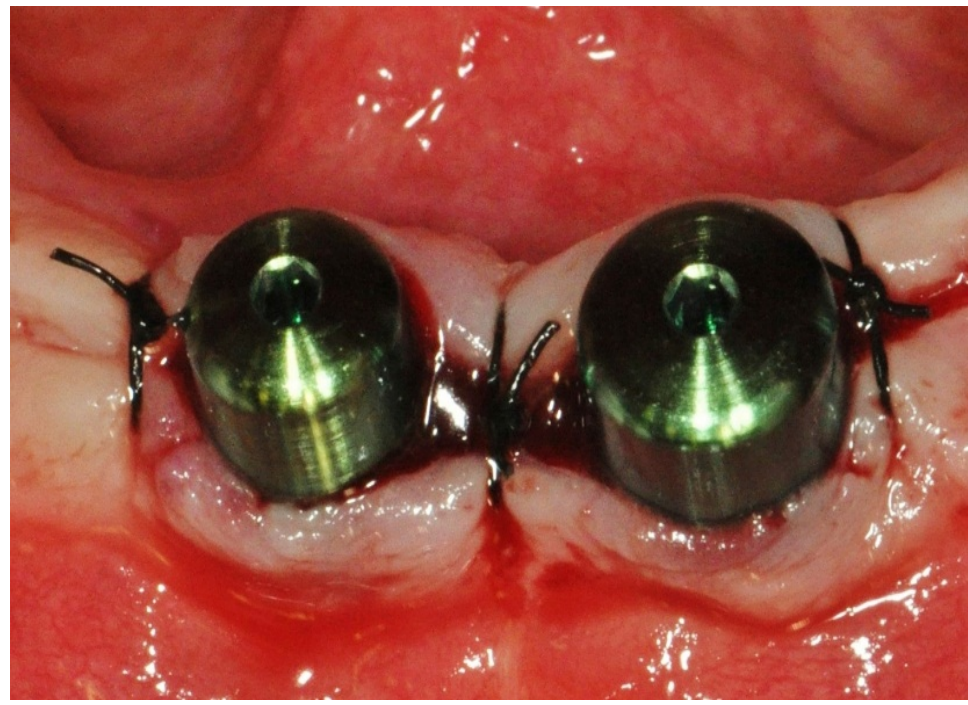

Figura 15: Colocación de 2 implantes y tapones de cicatrización en una sola fase.

$\left.3^{a}\right)$ Cirugía en fase directa: está indicada en pacientes con gran disponibilidad de tejido duro y blando, porque no requiere la realización de un colgajo, sino que el implante se posiciona directamente a través del tejido blando para posteriormente, colocar el tapón de cicatrización como se explica apartado C) Incisión, página 39.

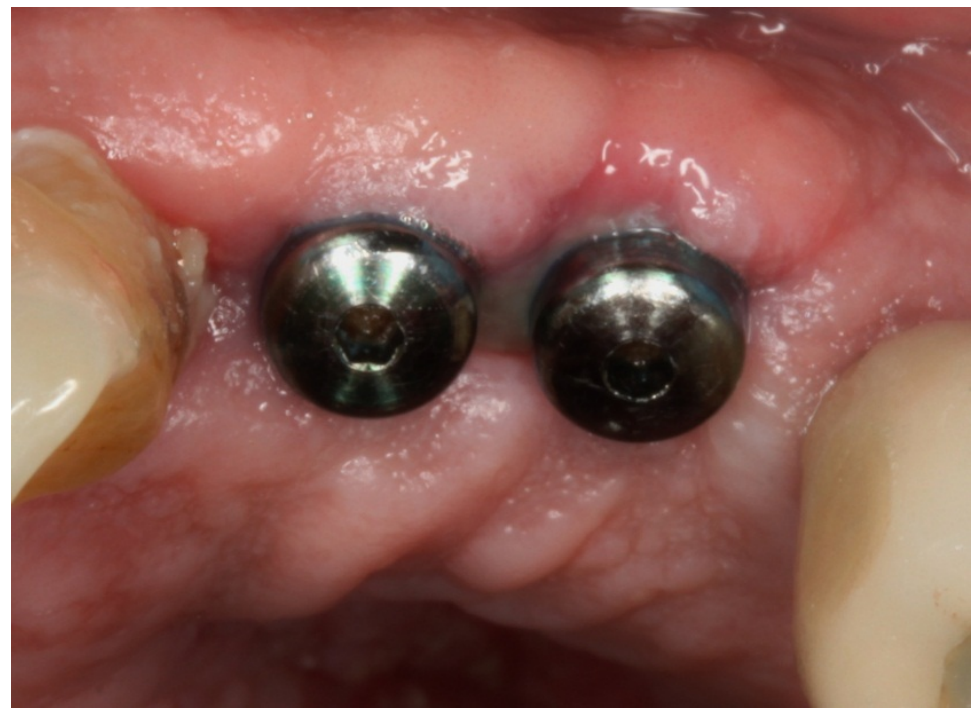

Figura 16: Colocación sin colgajo de implantes en posiciones 23 y 24. 
$4^{2}$ ) Cirugía postextracción: es el caso más complejo pues no se espera a la maduración de los tejidos duro y blando, después de la pérdida de la pieza dentaria, sino que se inserta el implante inmediatamente después de la extracción dental, colocando un tapón de cicatrización o una corona provisional inmediata, mientras cicatrizan los tejidos (Esposito, et al., 2010, Lang, et al., 2012, Machín Muñoz, 2002, Polizzi, et al., 2000).

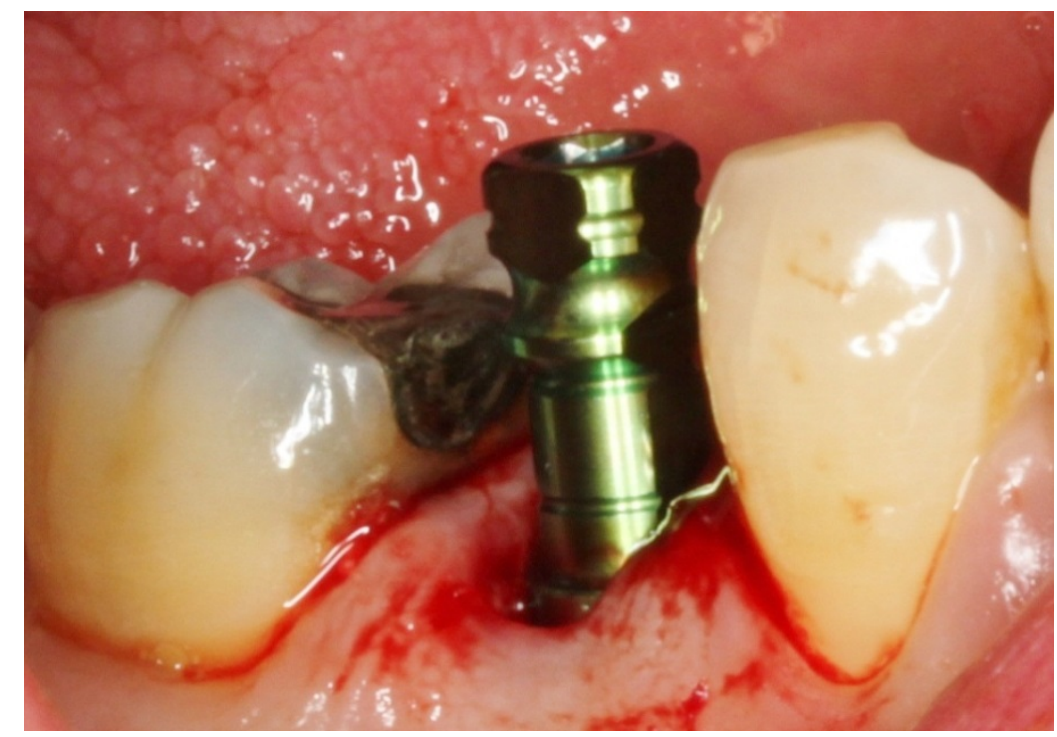

Figura 17: Colocación de un implante postextracción en posición 44.

Tabla 5: Tipos de procedimientos quirúrgicos.

\begin{tabular}{c|c|c|c|c|}
\cline { 2 - 5 } & Dos fases & Una fase & Directa & Postextr. \\
\hline Número de cirugías & 2 & 1 & 1 & 1 \\
\hline Control de la anatomía ósea & SI & SI & NO & NO \\
\hline Control de la ostectomía & SI & SI & NO & NO \\
\hline Tapón de cicatrización directo & NO & SI & SI & SI \\
\hline Tratamiento estético & NO & NO & NO & SI \\
\hline Exposición a bacterias & NO & SI & SI & SI \\
\cline { 2 - 5 }
\end{tabular}


Capitulo 1: Introducción

\section{G) Sutura}

Un buen dominio de las técnicas de incisión y sutura en cirugía oral e implantológica es una condición esencial para lograr resultados funcionales y estéticos satisfactorios (Karapetian, et al., 2012).

La sutura o sinéresis, consiste en la reposición de los tejidos blandos que están separados debido a una acción traumática o procedimiento quirúrgico (Felzani, 2007, Raspall, 2006).

El cierre adecuado de una herida por medio de sutura, posibilita la correcta cicatrización, reduciendo la probabilidad de complicaciones durante la fase de reparación de los tejidos. El cirujano bucal u odontólogo, debe poseer un conocimiento detallado de los distintos materiales e instrumentos, así como el dominio de las técnicas para efectuar la sinéresis de los tejidos (Gay, 1999, Raspall, 2006).

La sutura de una herida tiene como objetivos principales los siguientes: reposicionar el tejido blando llevándolo a su lugar inicial favoreciendo la cicatrización, mejorar la hemostasia de la herida y en ocasiones se puede utilizar durante la cirugía, para mantener los colgajos separados y facilitar la visión al cirujano (Felzani, 2007, Gay, 1999, Raspall, 2006).

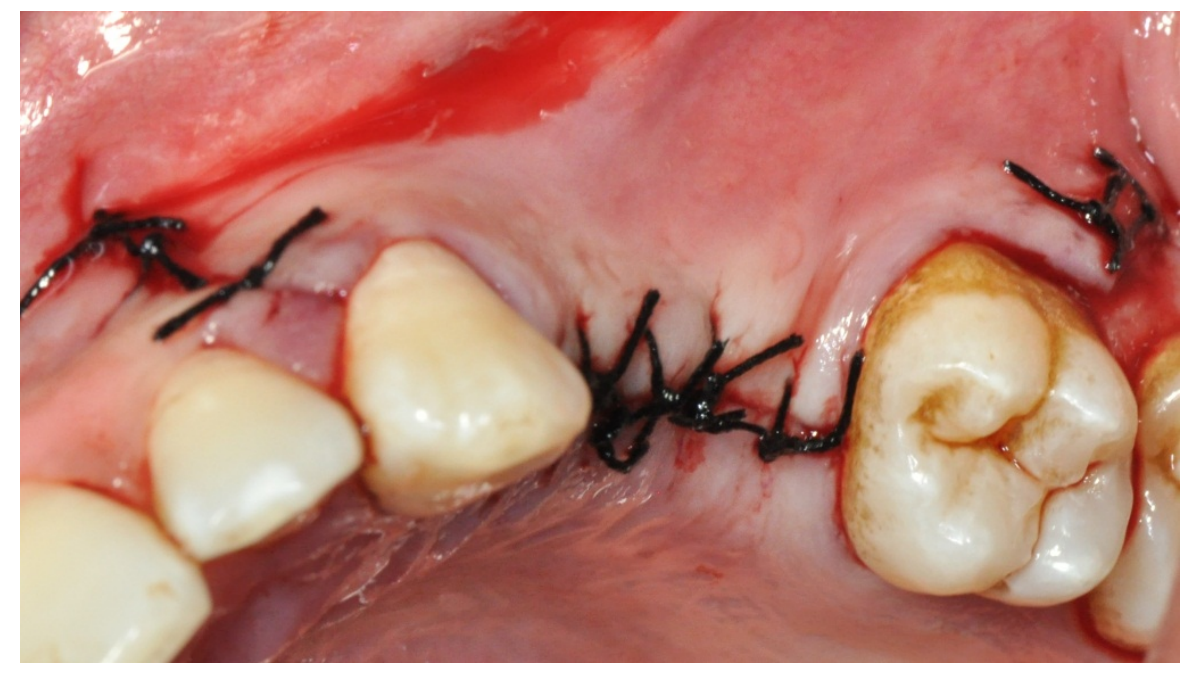

Figura 18: Sutura de un colgajo con seda de 3 ceros. 


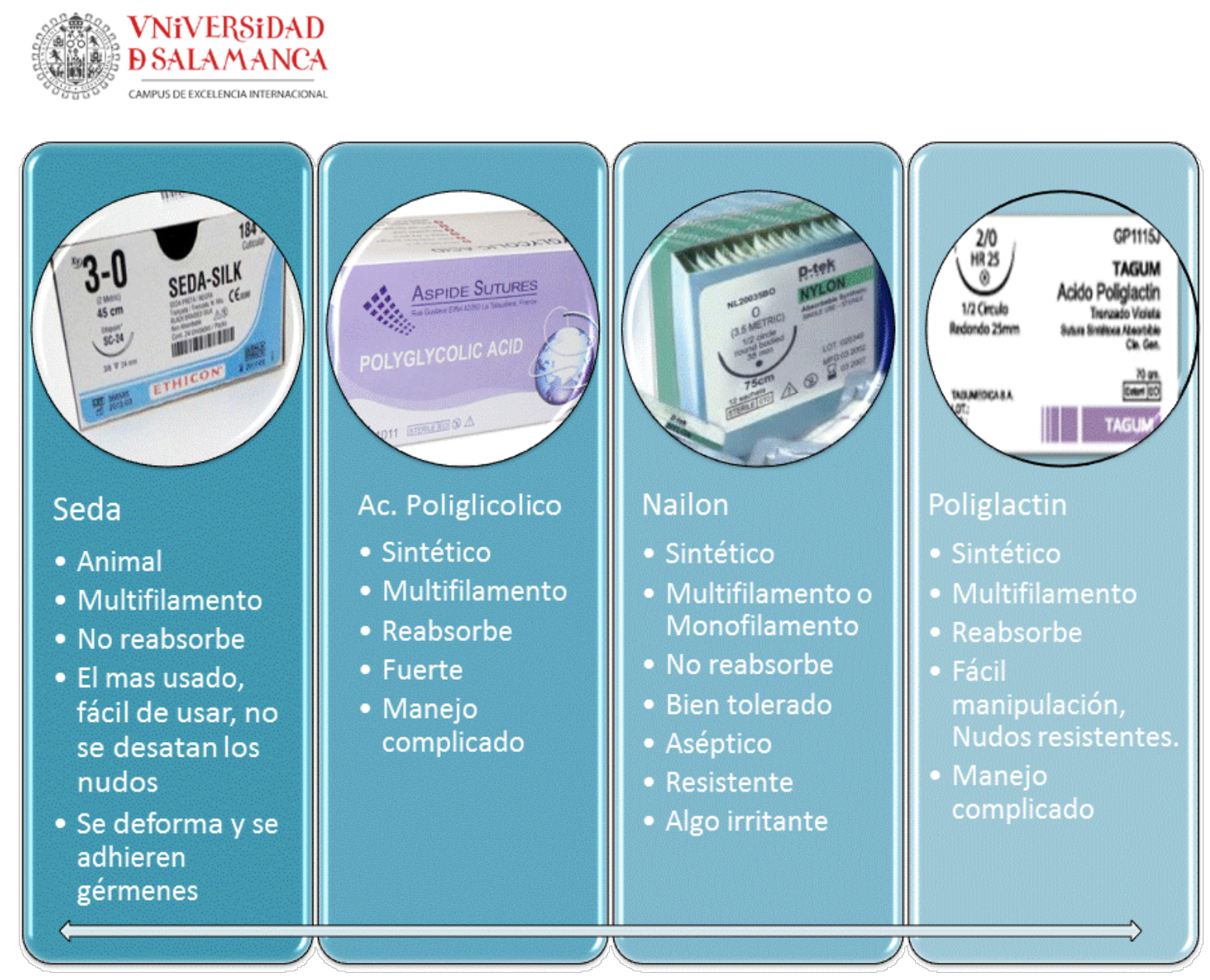

Figura 19: Suturas en implantología.

\section{H) Comprobación radiográfica}

Una vez terminada la cirugía implantológica, se debe realizar hacer una radiografía panorámica o periapical, para comprobar que el implante o los implantes están colocados en la posición que previamente se había calculado y que no invaden ninguna estructura anatómica importante. 
Capitulo 1: Introducción

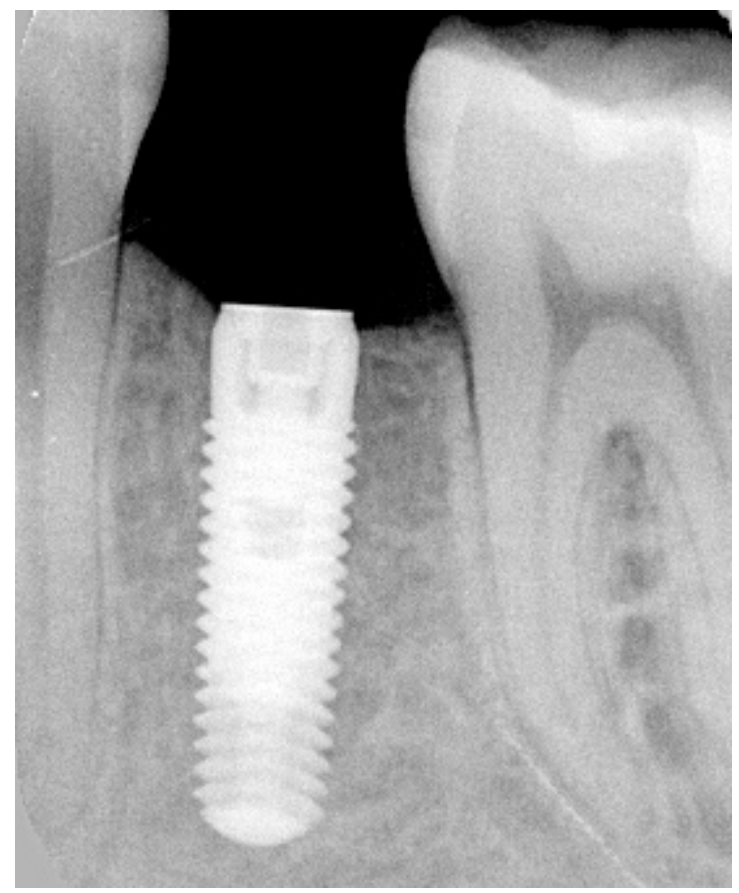

Figura 20: Implante colocado en posición 35.

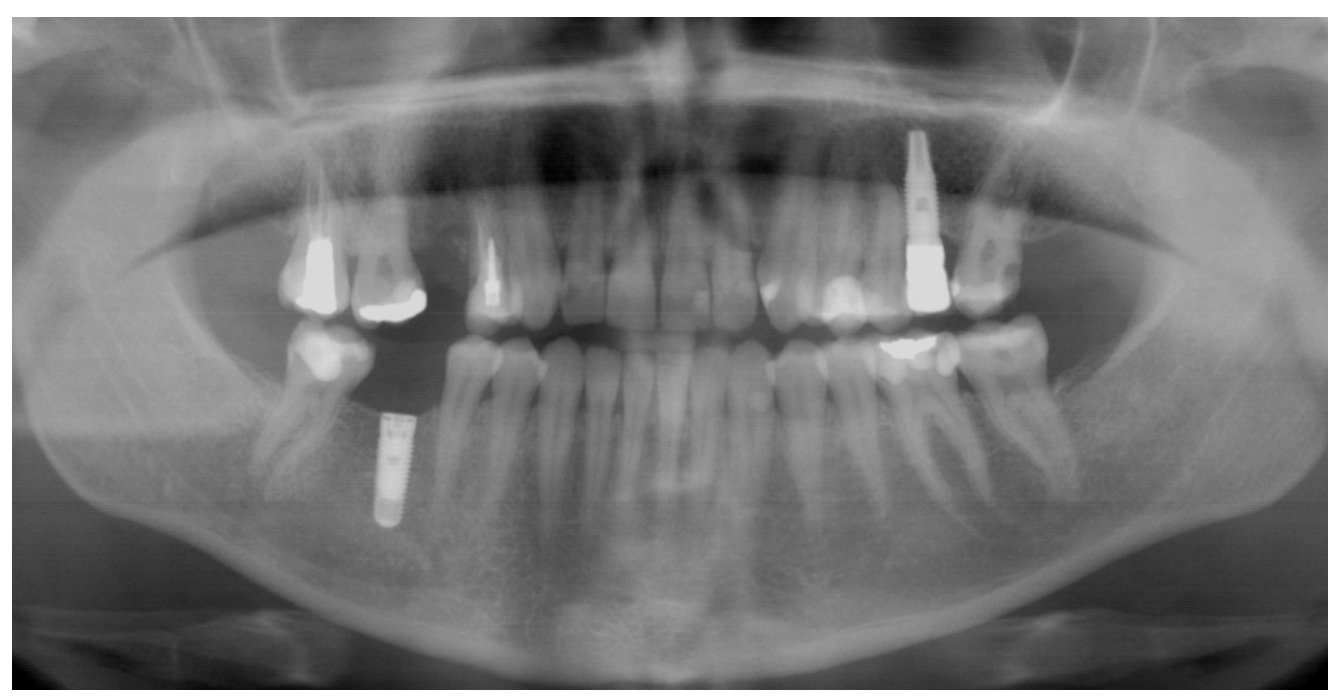

Figura 21: Implante colocado en posición 46.

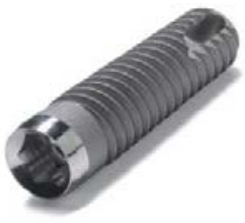




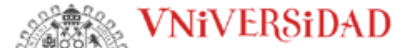

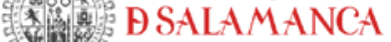

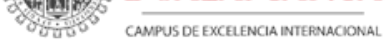

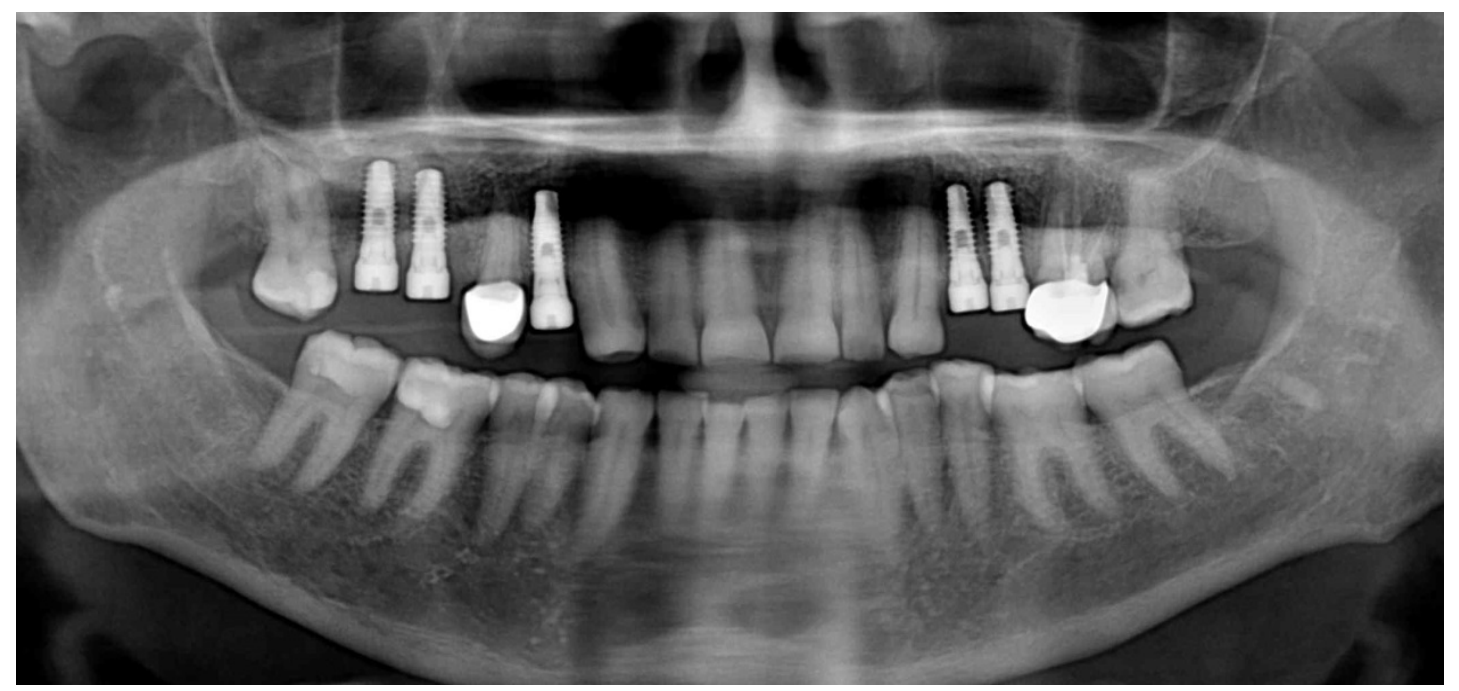

Figura 22: Implantes colocados en posición 14, 24, 25 y elevación sinusal directa en 16 y 17.

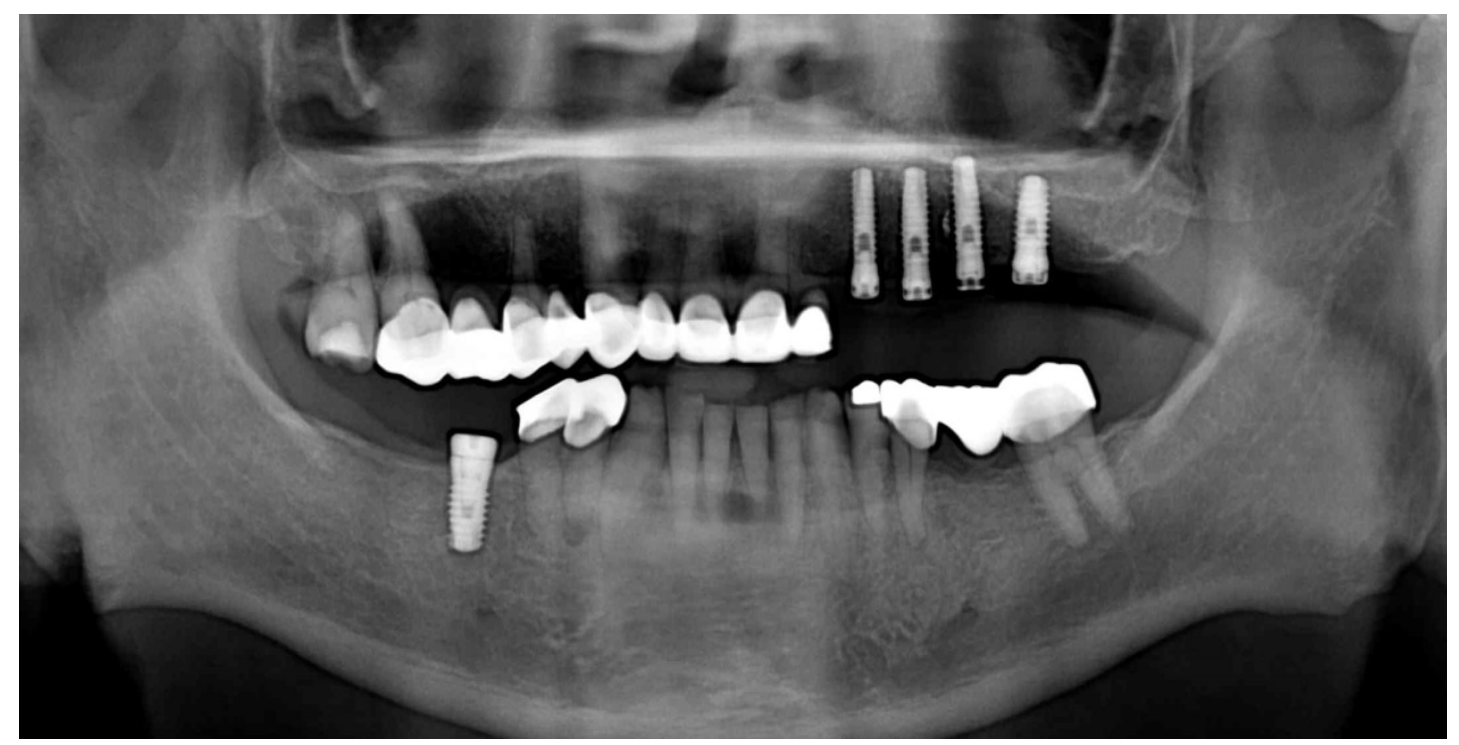

Figura 23: Implantes colocados en posición, 23, 24, 25, 46 y 26 con elevación sinusal indirecta. 


\section{Capitulo 1: Introducción}

\subsubsection{Medidas postquirúrgicas}

El postoperatorio implantológico abarca desde que se cierra la herida, con el último punto de sutura, hasta la desaparición total de los síntomas debidos a la intervención (Romero, et al., 2006).

Existen dos mecanismos fundamentales para lograr un postoperatorio confortable para el paciente; en primer lugar, una correcta cobertura farmacológica y en segundo una serie de recomendaciones que el paciente debe seguir escrupulosamente después de la cirugía (Romero, et al., 2006).

\section{A) Medicación}

El protocolo de tratamiento en pacientes sometidos a cirugía con colocación de implantes dentales varía según los autores pero, todos ellos, emplean antibióticos para prevenir una posible infección de la zona intervenida y una combinación de analgésicos y antiinflamatorios para combatir los síntomas postoperatorios (Al-Khabbaz, et al., 2007, González, et al., 2005, Guarinos, et al., 1998, Peñarrocha, et al., 2001, Romero, et al., 2006).

Guarinos et al., propusieron una pauta de tratamiento del dolor y la inflamación tras la cirugía oral. Así, estos autores hicieron una revisión de la literatura especializada concluyendo que la administración de fármacos analgésicos-antiinflamatorios debe comenzar en el momento de la cirugía, para que sus efectos se manifiesten antes de que se termine el efecto de la anestesia local, previniendo la síntesis de mediadores de la inflamación y el dolor. La pauta de administración consiste en el caso de cirugías más sencillas, por la utilización de AINES y, en caso de cirugía compleja, por la combinación de AINES y metamizol (Guarinos, et al., 1994).

La revisión realizada por Romero et al., en 2006 sobre el protocolo de tratamiento de los pacientes sometidos a cirugía oral, propone como tratamiento profiláctico la administración de antiinflamatorios no esteroideos (AINES), dos horas antes de la intervención, aunque también se pueden administrar justo después de la misma, produciendo el mismo efecto. En cuanto a la profilaxis antibiótica, no queda demostrado

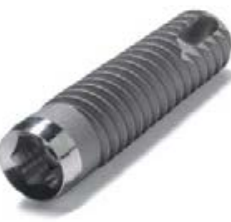




\section{VNiVERSiDAD}

isalamanca

que sea beneficiosa, por lo que ésta queda reducida a casos en los que se prevé cirugía de larga duración o para pacientes comprometidos. En estos casos, el antibiótico de elección será amoxicilina más ácido clavulánico de 2 gramos (g.), una hora antes de la intervención en pacientes no alérgicos a la penicilina y eritromicina en pacientes alérgicos (Romero, et al., 2006).

Después de la cirugía, sí existe un consenso de medicación de los pacientes sometidos a la colocación de implantes dentales. El protocolo de medicación postquirúrgica según estos autores consiste en (Al-Khabbaz, et al., 2007, González, et al., 2005, Guarinos, et al., 1998, Peñarrocha, et al., 2001, Romero, et al., 2006):

- Antibiótico: amoxicilina más ácido clavulánico de 500 miligramos (mg.), excepto a los alérgicos a la penicilina que serán tratados con eritromicina de $500 \mathrm{mg}$. Ambos se administraran por vía oral cada 8 horas durante 7 días.

- Analgésico y antiinflamatorio: ibuprofeno de 600 mg., que se administrará por vía oral cada 8 horas durante 7 días.

- Analgésico de rescate o emergencia: metamizol de 575 mg. en cápsulas de manera auxiliar. Éste se administrará, también por vía oral cada 8 horas, durante 5 días en combinación con el antiinflamatorio.

\section{B) Instrucciones postquirúrgicas}

A todos los pacientes se les deben dar, el mismo día de la cirugía, unas instrucciones que deben seguir durante los siete primeros días del postoperatorio. Entre las instrucciones postquirúrgicas más importantes se encuentran: la aplicación de hielo en la zona intervenida hasta 24-48 horas después de la cirugía, no ingerir líquidos ni sólidos hasta 4-6 horas después de la intervención, no tocar la zona hasta pasadas 24 horas, realizar enjuagues con clorhexidina en la zona intervenida a partir de las 24 horas, etc. (Romero, et al., 2006). (Anexo 3. Instrucciones postquirúrgicas). 


\subsection{DOLOR E IMPLANTOLOGÍA}

El dolor relacionado con la colocación de implantes dentales es de carácter neuropático y no difiere del que se puede observar después de otro tipo de cirugía oral, como consecuencia de la agresión de tejidos tanto, duros como blandos (Santamaría, et al., 1997). En general, tras la colocación de implantes dentales, en ausencia de complicaciones, el postoperatorio no es un proceso doloroso en sí, presentándose dolor entre leve y moderado en la mayoría de los casos (Christensen, 1991, Sada, et al., 1990, Santamaría, et al., 1997).

La sintomatología implantológica está relacionada con múltiples factores. Los que más se han estudiado han sido los relacionados con el paciente como; edad, sexo, higiene, tabaco, etc., y los relacionados con la cirugía como; número de implantes colocados, localización de los implantes, longitud de la incisión, etc. Todos estos factores están relacionados, estrechamente, con la sintomatología postquirúrgica que sufrirá el paciente después de la intervención.

El temor general que tienen los pacientes a los implantes dentales está ampliamente demostrado (Brand, et al., 1995, Eli, et al., 1997, Lindsay \& Jackson, 1993, Kent, 1997, Soh \& Yu, 1992), de ahí la importancia de conocer con la mayor exactitud posible, el postoperatorio que va a padecer cada paciente y tratarlo con prontitud y precisión, asegurando así un postoperatorio confortable y controlado.

\subsubsection{Dolor postquirúrgico en implantología}

La implantología es la especialidad odontológica que se encarga del anclaje de materiales aloplásticos en los maxilares, con el objetivo de crear elementos de soporte y sujeción para sustituir las piezas dentales perdidas (Spiekermann, 1995), como se definió en el apartado 1.2 IMPLANTOLOGĹA: CARACTERÍSTICAS DEL TRATAMIENTO, página 30.

La cirugía implantológica presenta dos síntomas característicos: dolor e inflamación y a veces, en menor número de ocasiones, puede ir acompañado de sangrado y hematoma.

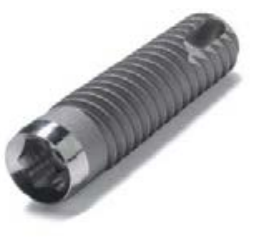


Estos síntomas son fácilmente controlables, si se han previsto y se actúa de manera adecuada (Misch, 2009, Romero, et al., 2006).

Todos los procedimientos quirúrgicos producen efectos secundarios como dolor e inflamación, dependiendo su magnitud del grado de lesión que se produzca sobre los tejidos (Misch, 2009, Peñarrocha, et al., 2001, Sanchís \& Peñarrocha, 1997).

Existe mucha variabilidad en los síntomas y en la duración de los mismos después de la intervención quirúrgica. Además parecen estar relacionados con el tipo de paciente, el número de implantes colocados, la duración de la cirugía, el daño tisular producido, etc. Conocer de antemano si el postoperatorio va a ser más o menos sintomático, nos permitirá alterar el tratamiento y efectuar un pronóstico aproximado (Romero, et al., 2006).

Varios estudios demuestran que la cirugía implantológica, por norma general, produce síntomas postoperatorios los primeros 7-10 días siguientes a la misma (García, et al., 2008, González, et al., 2005, Peñarrocha, et al., 2002).

El dolor es el síntoma postoperatorio que más sufren los pacientes odontológicos sometidos a cirugía de colocación de implantes dentales, seguido de la inflamación y, en mucha menor medida, por el edema (Al-Khabbaz, et al., 2007, González, et al., 2005, Fortin, et al., 2007, Hashem, et al., 2006).

\section{A) Concepto.}

El término dolor es definido, en la última edición del Diccionario de la Real Academia de la Lengua Española, como: “aquella sensación molesta y aflictiva de una parte del cuerpo por causa interior o exterior" y también, como “un sentimiento, pena o congoja que se padece en el ánimo” (Real Academia Española, 2001).

El diccioario médico define el dolor como una "sensación de molestia, angustia o agonía, más o menos localizada, resultado de la estimulación de terminaciones nerviosas especializadas" (Dorlands, 2011). 


\section{Capitulo 1: Introducción}

La Asociación Internacional para el Estudio del Dolor (IASP), señala que el dolor es « una experiencia sensorial y emocional desagradable, asociada con un daño tisular, real o potencial, o descrita en términos de dicho daño ». Dicha experiencia es siempre "subjetiva", de tal modo que debemos admitir y creer que la intensidad del dolor es la que el paciente exprese (IASP., 1979, IASP., 2000).

Esta definición del dolor ha sido completada por Stedman, que considera que este daño tisular esta mediado por fibras específicas del cerebro, donde su apreciación consciente puede ser modificada por diversos factores (Stedman, 2005).

Hoy en día la Asociación Internacional del Dolor, define el mismo como una “sensación consciente desagradable producida por una lesión real o potencial de los tejidos, que involucra cinco tipos de respuestas: sensoriales, motrices, emocionales, neurovegetativas y de memoria" (Treede, et al., 2008).

El dolor postquirúrgico es la consecuencia natural junto con la inflamación, el hematoma y el trismo, que se deriva de la cirugía oral. Se produce como respuesta a la lesión tisular y a los fenómenos reparativos que el organismo pone en marcha, y está estrechamente relacionado con los procesos inflamatorios desencadenados que ocasionan, además de dolor, rubor, aumento de temperatura y edema (Sanchís \& Peñarrocha, 1997).

Así, inflamación y dolor, son dos signos clínicos que se manifiestan de forma paralela y que obedecen a una misma fisiopatología (Sanchís \& Peñarrocha, 1997).

\section{B) Clasificación.}

El dolor, en términos generales, se clasifica según su tiempo de duración, en:

- Dolor agudo. Tiene un patrón bien definido en su comienzo, es de duración breve, normalmente semanas y siempre menos de 6 meses, rara vez presenta problemas y los síntomas desaparecen con el tratamiento y control del mismo (Gelb, 1994, Mahan \& Allining, 1991).

- Dolor crónico. Éste por el contrario no está bien definido, es más duradero, normalmente más de 6 meses y el paciente rara vez se cura (Santamaría, et al., 1997). 
Por lo tanto, después de una cirugía implantológica, salvo que se produzca alguna lesión anatómica importante, siempre nos estaremos refiriendo a dolor agudo.

En cuanto a la intensidad del dolor, la mayor parte de los estudios previos sobre el tema han utilizado una descripción verbal del mismo como: "ausencia, leve, moderado, severo" (Al-Khabbaz, et al., 2007, González, et al., 2005, Guarinos, et al., 1998).

Otros autores utilizaron una escala numérica o una analógica visual, donde el paciente valora el dolor padecido de 0 a 10, siendo 0 ausencia de dolor y 10 máximo dolor (Muriel, et al., 1989). La escala visual analógica (E.V.A.), es el método más sensible y el que más se utiliza en los estudios que miden la intensidad del dolor (Huskisson, 1983, Price, et al., 1983).

Bien sea por la referencia del paciente o mediante la utilización de alguna escala para medir la intensidad del dolor, se pueden determinar de forma general, tres niveles de intensidad del mismo (Melzack, 1975).

- Dolor de intensidad leve. Independientemente de su origen no compromete las actividades diarias de quien lo padece, se puede sobrellevar y el tratamiento es de demanda opcional; en la escala análoga del dolor hasta el valor 4.

- Dolor de intensidad moderada. Demanda tratamiento inmediato que si no se alivia puede interferir con las actividades diarias de quien lo padece y crear un estado de ansiedad moderada; en la escala análoga del dolor se encuentra entre los valores 4 y 7.

- Dolor severo. Interfiere claramente con las actividades del paciente, postra e inmoviliza al mismo y crea un estado de ansiedad extrema demandando tratamiento urgente; en la escala análoga del dolor el valor está por encima de 7.

Basada en los mecanismos moleculares y la vía de los circuitos neurológicos del dolor orofacial, su clasificación se puede hacer, también, según el factor etiológico y el lugar donde se activa la vía del dolor. Atendiendo a esta clasificación existen, dos tipos de dolor: 


\section{Capitulo 1: Introducción}

- Dolor nociceptivo. Resulta de la activación de los nociceptores en los tejidos como respuesta a los estímulos dañinos para el cuerpo. Frecuentemente, el tejido lesionado se encuentra acompañado de procesos inflamatorios (Treede, et al., 2008). Este tipo de dolor es el que se produce en cirugía de implantes dentales.

- Dolor neuropático. Ocasionado por una lesión que afecta, de manera directa, a las vías por las cuales transcurren las sensaciones dolorosas, como la lesión del nervio periférico, o por una lesión de cualquiera de las diferentes estructuras corticales o subcorticales (talámo, tallo cerebral) que recorren las sensaciones dolorosas dentro del sistema nervioso central. Ejemplos de dolores neuropáticos: neuralgia de trigémino, neuralgia posherpética, neuropatía diabética, dolor asociado al miembro fantasma, alteraciones tóxicas por medicamentos como los antirretrovirales, terapia oncogénica y complicaciones postquirúrgicas. El dolor neuropático es constante, ardiente y con una incidencia relativamente alta, hasta el 5\% de la población mundial (Workin, et al., 2003).

El dolor también tiene una dimensión afectiva y para tenerlo en cuenta en esta dimensión, Melzack desarrolló el McGill Pain Questionnaire que permite medir tanto la intensidad como la cualidad del dolor (Melzack, 1975).

La mayoría de los trabajos analizados estudiaron tanto el dolor como la inflamación (García, et al., 2007, García, et al., 2008, González, et al., 2005, Larrazábal, et al., 2010, Peñarrocha, et al., 2006), siendo menos los estudios que valoraban únicamente el dolor que padecieron los pacientes tras la cirugía (Al-Khabbaz, et al., 2007, Martorell, et al., 2004). Se encontraron también artículos que relacionaron ansiedad, aspectos emocionales y dolor (IASP., 1979, Guzeldemir, et al., 2008, Urban \& Wenzel, 2010).

Si no se advierte al paciente de lo que puede suceder, la percepción por parte del mismo puede verse alterada al aparecer el dolor de forma inesperada. También puede ocurrir, que el paciente, al saber que padecer dolor es normal, no lo manifieste a menos que se le pregunte. Este componente nos indica, lo importante que es para el paciente la experiencia en términos de sufrimiento y ansiedad. 
La explicación al paciente del tratamiento y de lo que puede ocurrir en el postoperatorio, será determinante en su percepción del dolor.

\section{C) Incidencia.}

La mayoría de los trabajos publicados hasta la fecha, se centran en dolor o en dolor e inflamación y, aunque la mayoría se basa sólo en esos dos síntomas, existe amplia variedad, relacionándose con distintas variables como tabaco, higiene, ansiedad, aspectos emocionales, etc. (Al-Khabbaz, et al., 2007, Eli, et al., 2003, García, et al., 2007, González, et al., 2005, Guarinos, et al., 1998, Peñarrocha, et al., 2001, Santamaría, et al., 1997).

Muller et al., encontraron que el 45\% de los pacientes que recibieron tratamiento implantológico, refirieron dolor en las primeras 24 horas del postoperatorio (Muller \& Ríos, 2001).

Guarinos et al., encontraron en su estudio que el pico de dolor se producía a las 12 horas de la intervención alcanzando 3,5 puntos en la escala visual analógica (E.V.A.) (Guarinos, et al., 1998). En otro estudio, Peñarrocha et al., encontraron que el mayor dolor se producía a las 6 horas de la intervención siendo éste de intensidad moderada (Peñarrocha, et al., 2000).

En la mayoría de los estudios hasta la fecha, se describe que el pico de dolor postoperatorio ocurrió pocas horas después de la intervención, encontrando que entre el 40-76\% de los pacientes refirieron de ausencia a dolor moderado (Chong \& Pitt Ford, 2005, González, et al., 2005, Iqbal, et al., 2007, Peñarrocha, et al., 2006, Seymour, et al., 1986).

En cuanto a la inflamación, varios autores están de acuerdo en que el pico máximo de inflamación se produjo, siempre, entre el primer y segundo día después de la intervención, encontrando que entre el $45-66 \%$ de los pacientes refirieron de ausencia a inflamación moderada (García, et al., 2007, Peñarrocha, et al., 2006, Tssesis, et al., 2005).

En algunos estudios, se encontró que la máxima inflamación se producía después de las primeras 24 horas de la intervención, siendo en ambos casos de intensidad entre media y 


\section{Capitulo 1: Introducción}

moderada (Guarinos, et al., 1998, Peñarrocha, et al., 2001). Para Tsessis et al., el 64\% de los pacientes estudiados no presentaron inflamación en las primeras 24 horas del postoperatorio (Tssesis, et al., 2005).

Sin embargo, también se han encontrado casos en los que la máxima inflamación se reportó a las 48 horas de la intervención, siendo ésta entre media y moderada (Peñarrocha, et al., 2006).

\subsubsection{Fisiopatogenia del dolor postquirúrgico}

La causa del dolor en cirugía implantológica, va a estar relacionada siempre, con el grado de lesión tisular que se produzca durante la intervención (Peñarrocha, et al., 2001, Sanchís \& Peñarrocha, 1997).

El grado de dolor, independientemente del tipo de agresión, es directamente proporcional a la intensidad de la lesión tisular, si bien engloba un conjunto de experiencias, tanto sensoriales como emocionales, que se deben tener muy presentes (Peñarrocha, et al., 2001, Sanchís \& Peñarrocha, 1997, Trowbridge, 1990).

La fisiopatogenia del dolor postoperatorio asienta sobre dos pilares fundamentales: la inflamación y el componente psicológico que modulará la expresión del dolor por parte del paciente (Peñarrocha, et al., 2001, Sanchís \& Peñarrocha, 1997).

Tener conocimiento del origen del dolor y de los factores que influyen en él, permitirá ejercer mayor control sobre el mismo y proporcionar así un postoperatorio más confortable para los pacientes (Romero, et al., 2006).

Cuando se coloca un implante dental, inevitablemente se está produciendo un daño tisular, porque se están lesionando en mayor o menor grado, mucosas y estructuras óseas (Peñarrocha, et al., 2001).

En una intervención quirúrgica en implantología, se produce siempre una agresión mecánica, debido al trauma que implica abrir un colgajo, la separación del tejido del 
periostio y el fresado óseo para la colocación de los implantes dentales (Peñarrocha, et al., 2001, Sanchís \& Peñarrocha, 1997).

Tres son los niveles de integración del dolor postquirúrgico: periférico, representado por una lesión tisular; medular, representado por la recogida de la sensibilidad nociceptiva y su transmisión y central que constituye la percepción a nivel del córtex cerebral de la sensación dolorosa (Peñarrocha, et al., 2001, Sanchís \& Peñarrocha, 1997).

\section{A) Dolor inflamatorio.}

La lesión tisular que se provoca durante la cirugía implantológica, desencadena una reacción inflamatoria que produce dolor (Peñarrocha, et al., 2001).

Los síntomas que aparecen después de la cirugía están relacionados con:

a) El tipo, extensión y localización de la lesión.

b) Reactividad de las estructuras lesionadas.

c) Grado de confinamiento del exudado inflamatorio.

d) La fase de la inflamación.

El dolor inflamatorio es producido por la acción de las prostaglandinas y la bradiquinina, sustancias que se liberan durante el proceso inflamatorio y que aumentan la vasodilatación local y la permeabilidad capilar, además de alterar la sensibilidad de los receptores del área afectada (Burgess, et al., 1973, Hedenberg-Magnusson, et al., 2001).

Esto conlleva una disminución del umbral del dolor, provocando que los nociceptores se muestren más sensibles y se produzca dolor primario espontáneo. 
Capitulo 1: Introducción

\section{B) Mediadores del dolor e inflamación}

Cuando a nivel periférico, se produce una lesión tisular, se activan una serie de mediadores de la inflamación que serán los desencadenantes de los síntomas, entre los cuales se encuentra el dolor (Peñarrocha, et al., 2001).

Las células dañadas durante la intervención activan:

A) Neurotransmisores: se encargan de transmitir impulsos a través del espacio sináptico. Entre ellos cabe destacar acetilcolina, noradrenalina y aspartato, de acción rápida y sustancia P y endorfinas, de acción lenta (Peñarrocha, et al., 2001).

B) Mediadores celulares: alteran la actividad eléctrica de las neuronas sensoriales. Entre ellos histamina, serotonina, prostaglandinas, ácido araquidónico, leucotrienos, interleuquinas, factor activador de plaquetas, etc. (Peñarrocha, et al., 2001).

C) Mediadores plasmáticos: a este nivel, se forman substancias como la bradicinina, que producen vasodilatación y aumento de la permeabilidad vascular (Peñarrocha, et al., 2001).

Las fibras receptoras del dolor, nociceptores, son directamente estimuladas o sensibilizadas por estos mediadores debido al incremento en la presión intersticial de los tejidos, al aumento de la permeabilidad y a la vasodilatación, provocando que las terminaciones nerviosas se compriman y aparezca dolor (Peñarrocha, et al., 2001). 


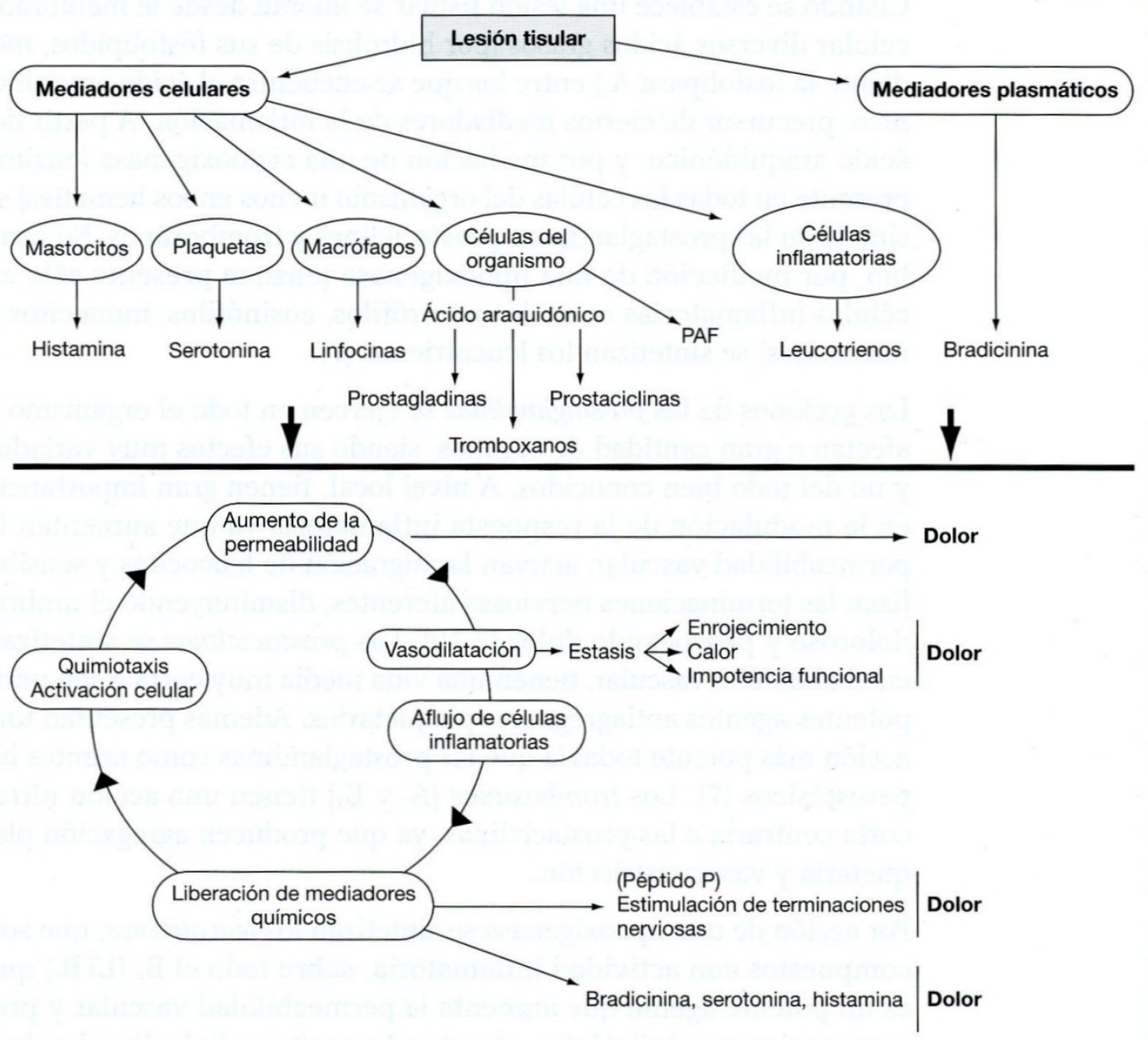

Figura 24: Mediadores del dolor y la inflamación (Tomado de Peñarrocha, et al., 2001).

\section{C) Vías de transmisión del dolor.}

Cuando se estimula un nociceptor periférico, tienen lugar una serie de procesos que llevan ese impulso al SNC y a los centros superiores para que sea interpretado y evaluado.

Una vez activado el nociceptor, el impulso es transmitido mediante una neurona aferente primaria. El cuerpo de la misma está situado en el ganglio trigeminal o de Gasser.

Esta neurona primaria, entra en el tronco cerebral y establece sinapsis, con una de segundo orden, en el subnúcleo caudal del tracto espinal del trigémino (Hargreaves, et al., 1995). 


\section{Capitulo 1: Introducción}

El subnúcleo caudal se considera la localización primaria de la información nociceptiva de la cara, aunque hay estudios que sugieren que el subnucleo oral puede jugar un papel importante en la nocicepción de las estructuras intraorales (Sessle, 1990).

Esta neurona de segundo orden, puede transmitir el impulso directamente hacia el cráneo por el mismo lado del cerebro, pero lo normal en la nocicepción es que cruce el tronco cerebral y ascienda por el tracto anterolateral del lado contrario.

Los impulsos nociceptivos transmitidos por las fibras primarias A-delta, más rápidas, establecen sinapsis en la lámina I del subnúcleo caudal y llevan los impulsos por el tracto neoespinotalámico directamente al tálamo. Estas fibras transmiten el dolor mecánico y térmico y, como van directas al tálamo, se dice que transmiten el dolor rápido (dolor agudo) (Okeson, 2006).

Sin embargo, los impulsos transmitidos por las fibras $C$ establecen sinapsis en las láminas II, III y V. Estas neuronas llevan los impulsos por el tracto paleoespinotalámico, que no va directamente al tálamo sino que se proyecta a la formación reticular del tronco cerebral. Estas son las que transmiten el dolor lento (dolor profundo y sordo) (Okeson, 2006). 


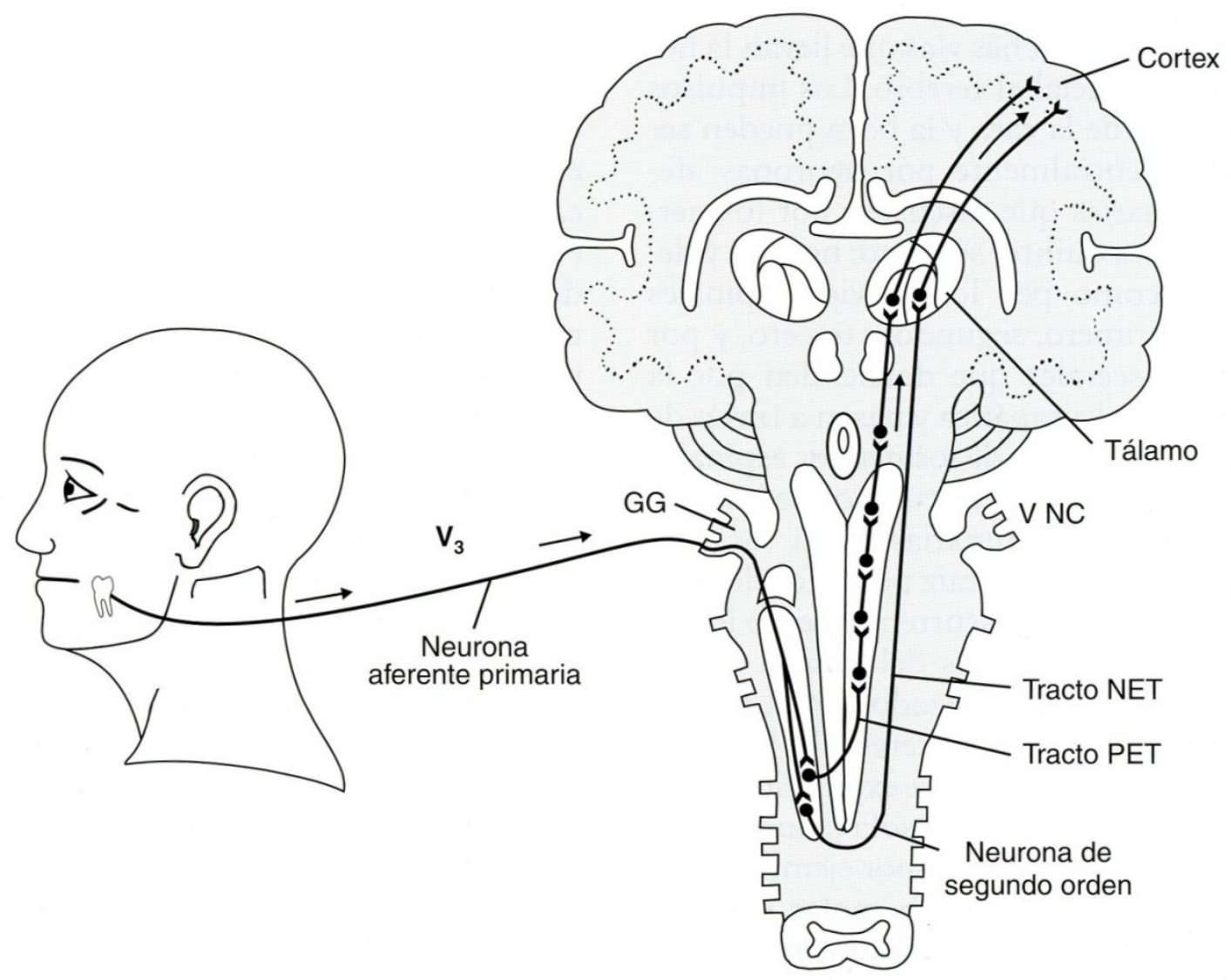

Figura 25: Vías de transmisión del dolor (Tomado de Okeson, 2006).

El núcleo caudal es un lugar importante, pero no exclusivo, para procesar la información nociceptiva de la región orofacial. Este núcleo tiene una organización anatómica similar a la del cuerno dorsal de la médula. De la misma forma el núcleo caudal, juega un importante papel procesando las señales nociceptivas recibidas de las fibras $\mathrm{C}$ y Adelta y las modifica por la modulación que recibe de regiones cerebrales superiores. Esta modulación superior puede provocar que las señales nociceptivas se incrementen (hiperalgesia), disminuyan (analgesia) o se malinterpreten (dolor referido) (Okeson, 2006).

Desde un punto de vista funcional, el cuerno posterior de la médula tendría cinco componentes principales relacionados con la interpretación de las señales nociceptivas (Hargreaves, et al., 1995, Okeson, 2006): 


\section{Capitulo 1: Introducción}

I. Terminaciones centrales de fibras aferentes. Son las terminaciones de las fibras $\mathrm{C}$ y A-delta que transmiten información liberando aminoácidos excitatorios, como glutamato o neuropéptidos (sustancia P, CGRP).

II. Circuito local de neuronas. Regula la transmisión de señales nociceptivas desde las fibras aferentes a las neuronas de proyección.

III. Neuronas de proyección. Cuyos cuerpos celulares están en el cuerno dorsal de la médula y conducen, a través de sus axones, la información del dolor orofacial a las regiones más rostrales del cerebro. Se han descrito tres tipos principales de neuronas de proyección:

A) Neuronas de proyección, específicamente nociceptivas, que reciben información de las fibras aferentes nociceptivas.

B) Neuronas de proyección mecanorreceptoras de bajo umbral, que reciben información de fibras no nociceptivas (ej. fibras A-beta).

C) Neuronas de proyección de espectro amplio y dinámico (W.D.R.: Wide Dynamic Range), que reciben información tanto de fibras nociceptivas como de no nociceptivas.

Tanto las neuronas de proyección, específicamente nociceptivas como las W.D.R. tendrían un importante papel al codificar el dolor orofacial, la hiperalgesia y la alodinia.

La vía de salida más importante de todas las neuronas de proyección es el tracto espinotalámico. Éste cruza hacia el lado contralateral de la médula y asciende hasta el tálamo. Desde el tálamo una neurona adicional envía información a la corteza cerebral a través del tracto tálamo cortical.

La percepción del dolor ocurre principalmente en la corteza cerebral.

IV. Glia. Aparte de soporte de las células también está implicada en la modificación de las señales nociceptivas. La glia responde a los estímulos nociceptivos liberando citoquinas como la interleuquina 1-beta o T.N.F. (Tumor Necrosis Factor). 
V. Neuronas descendentes. Son terminaciones nerviosas de neuronas descendentes, modulan, inhibiendo o facilitando, la transmisión de la información nociceptiva.

Un importante componente de este sistema analgésico endógeno, son los péptidos opioides endógenos (EOPs), con propiedades similares a los péptidos exógenos. La familia de los opioides endógenos incluye las encefalinas, dinorfinas, y péptidos relacionados con las beta-endorfinas (Hargreaves, et al., 1995).

También, el sistema canabiode endógeno inhibiría las terminaciones centrales de las fibras C.

Vemos por lo anteriormente expuesto, que el dolor no es únicamente el resultado de un estímulo nocivo sobre el diente o los tejidos circundantes (Hargreaves, et al., 1995).

\section{D) Hiperalgesia y alodinia.}

En respuesta a la inflamación periférica, el sistema del dolor puede modificar, sustancialmente, las características de la percepción ante un mismo estímulo doloroso (Hargreaves, et al., 1995).

La hiperalgesia, se define como un incremento en la percepción ante un estímulo doloroso mientras que la alodinia, es la reducción del umbral del dolor, de forma que estímulos que previamente no eran dolorosos, se perciban ahora como tales. Por ejemplo: la percusión de la encía con un instrumento romo, que no es dolorosa en condiciones normales, se torna molesta cuando hay inflamación (Hargreaves, et al., 1995).

Alodinia e hiperalgesia, pueden presentarse durante la inflamación de tejidos externos como la piel o en nuestro caso en los tejidos periodontales, así como pueden producirse, también, en tejidos profundos (Hargreaves, et al., 1995).

La hiperalgesia, es debida tanto a mecanismos centrales como periféricos.

A nivel periférico, varios mecanismos contribuyen a la hiperalgesia: composición y concentración de mediadores inflamatorios, cambios en las fibras aferentes (activación y 


\section{Capitulo 1: Introducción}

sensibilización, sprouting, proteínas), presión y temperatura de los tejidos, interacciones en fibras simpáticas aferentes, plasticidad de las fibras A-beta (Hargreaves, et al., 1995).

En cuanto a los mediadores, su concentración es importante porque debe ser suficientemente alta para permitir su unión y activación con los receptores P.

Además de la activación y sensibilización, las fibras aferentes periféricas responden a mediadores como Nerve Growth Factor, que incrementa la síntesis de proteínas, de sustancia P, CGRP y la proliferación de fibras terminales en el tejido inflamado (Hargreaves, et al., 1995).

Esta proliferación de fibras terminales en tejidos inflamados, contribuye a incrementar la sensibilidad dolorosa en casos de grandes cirugías como la colocación de varios implantes dentales, elevaciones de seno, regeneraciones óseas, etc. (Peñarrocha, et al., 2001, Santamaría, et al., 1997).

Ciertas fibras aferentes, responden también a los mediadores inflamatorios sintetizando otras proteínas tales como tetrodotoxin (T'TX)-canales sodio resistentes. Estos canales iónicos, son sintetizados por la mayoría de los nociceptores y activados por mediadores inflamatorios (Eglen, et al., 1999).

Otros procesos. pueden contribuir a los mecanismos periféricos de hiperalgesia y alodinia. Las fibras A-beta, normalmente funcionan como mecanoreceptores de bajo umbral y no vehiculan señales nociceptivas. Sin embargo, bajo ciertas condiciones de inflamación, estas fibras comienzan a secretar sustancia P y desarrollan unas nuevas terminaciones centrales en la médula espinal dorsal, inervando regiones que contienen neuronas nociceptivas (Neumann, et al., 1996).

El mecanismo anterior hace posible que, en determinadas condiciones, haya un componente de alodinia por transmisión nociceptiva de fibras A-beta (Neumann, et al., 1996).

Otros estudios, han implicado fibras simpáticas en la activación de fibras aferentes nociceptivas C, ante ciertas formas de lesión tisular (Perl, 1999). 


\section{VNiVERSIDAD}

BSALAMANCA

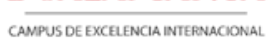

Tomados en conjunto, varios mecanismos periféricos contribuyen al desarrollo de alodinia e hiperalgesia. Sin embargo, no todos son igualmente activos en las distintas situaciones de dolor agudo o crónico (Hargreaves, et al., 1995).

Los mecanismos centrales de alodinia e hiperalgesia, implican un incremento en la excitabilidad de las neuronas centrales y, se cree, que es el mayor mecanismo de hiperalgesia (Sundqvist, et al., 1985).

La sensibilización central resulta de una descarga de impulsos de nociceptores C. Ello, produce una liberación central de glutamato y sustancia P, así como otros neurotransmisores, produciendo la activación de los receptores centrales para el primero (Receptores NMDA y AMPA) (Hargreaves, et al., 1995).

Bajo estas condiciones, la estimulación de las fibras A-beta, normalmente de bajo umbral, producen una respuesta aumentada, y ello contribuye, al mecanismo central de la alodinia (Hargreaves, et al., 1995).

Varios mecanismos más han sido propuestos como activadores de la sensibilización central: incremento en la liberación de neurotransmisores por las fibras aferentes primarias, cambios en receptores postsinápticos en el sistema de segundos mensajeros, en protooncogenes, en los opioides y canabiodes endógenos, sensibilización central, reducción en la inhibición presináptica y postsináptica, windup, neuronas oscuras y la activación de la glía (Hargreaves, et al., 1995).

El concepto de sensibilización central es importante, porque implica receptividad o sensibilidad dinámica del sistema nervioso central, ante la llegada de estímulos periféricos. Dicho de otra forma, el mismo estímulo no siempre produce la misma respuesta.

En cirugía implantológica, es raro que se presente hiperalgesia preoperatoria (clínicamente medida como dolor preoperatorio o alodinia) pero, cuando ésto ocurre, supone un factor de riesgo para la aparición de mayor dolor postoperatorio. 


\section{Capitulo 1: Introducción}

La presencia de este factor de riesgo, debe alertar al clínico, que adaptará la estrategia de tratamiento, para contrarrestar un previsible nivel más alto de dolor, después de la cirugía implantológica.

El conocimiento de los mecanismos de la hiperalgesia y alodinia, es crítico para un correcto manejo del diagnóstico y tratamiento del dolor.

\subsubsection{Factores relacionados con el dolor postquirúrgico}

\section{A) Factores relacionados con el paciente}

\section{Sexo}

En lo que se refiere al sexo, existe bastante variabilidad en la bibliografía revisada, al igual que con la edad, pues algunos estudios no establecen diferencias significativas entre hombres y mujeres mientras que otros, establecen una clara diferencia entre las mujeres y el aumento del dolor postoperatorio.

Peñarrocha et al., estudiaron 226 implantes colocados en 80 pacientes y no obtuvieron diferencias significativas en cuanto al sexo y el dolor percibido por los pacientes sometidos a dicha cirugía (Peñarrocha, et al., 2000). González et al., y Guarinos et al., estudiaron, respectivamente, 131 implantes colocados en 41 pacientes y 161 implantes colocados en 70 pacientes y en ninguno de los dos casos, se establecieron diferencias significativas entre sexo y dolor postoperatorio en implantología oral (González, et al., 2005, Guarinos, et al., 1998).

Sin embargo, existen varios estudios sobre el postoperatorio implantológico, que mostraron un mayor dolor en mujeres que en hombres tras la colocación de implantes dentales. Eli et al., encontraron en su estudio del año 2000 que las mujeres sufrían mayor ansiedad y mayor dolor que los hombres después de someterse a una pequeña cirugía (Eli, et al., 2000). Por el contrario, estos mismos autores, en su trabajo del año 2003, no encontraron diferencias significativas en el dolor padecido por hombres y mujeres después de colocarles implantes dentales. La explicación que dieron fue, que en el último estudio, se

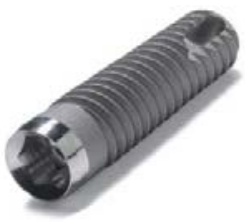


practicaron intervenciones de mayor envergadura y, por tanto, los niveles de ansiedad y dolor padecidos por hombres y mujeres se igualaban (Eli, et al., 2003).

Urban et al., observaron también, mayor dolor en mujeres que en hombres, siendo éste más ostensible, el segundo día después de la cirugía (Urban \& Wenzel, 2010). En el estudio más reciente sobre el postoperatorio implantológico Al-khabbad et al., encontraron diferencias significativas entre hombres y mujeres tras la colocación de implantes dentales, siendo las mujeres las que más dolor padecían (Al-Khabbaz, et al., 2007).

Si analizamos los estudios sobre cirugía de extracción de terceros molares inferiores incluidos, encontramos resultados igual de ambiguos que en el caso de cirugías implantológicas.

Se encontraron muchos trabajos en los que las mujeres padecían más dolor que los hombres durante el postoperatorio y que precisaron más medicación (Berge \& Bøe, 1994, Fisher, et al., 1988, Kalkman, et al., 2003, Olmedo, et al., 2002, Sanchez, et al., 1995, Seymour, et al., 1985).

De todos los artículos revisados, sólo Capuzzi et al., observaron que los hombres padecieron mayor dolor que las mujeres en la extracción de terceros molares inferiores incluidos (Capuzzi, et al., 1994).

Por otro lado, bastantes autores no encontraron resultados estadísticamente significativos entre el dolor padecido por hombres y mujeres después de este tipo de cirugía (Capuzzi, et al., 1994, Collins, et al., 1997, Hansson, et al., 1989, Infante, et al., 1995, Lombardía, et al., 1989, Sáez, et al., 1999, Taenzer, et al., 1986).

En el resto de intervenciones a las que se puede someter un paciente odontológico, encontramos resultados muy diversos. En el artículo publicado por Al-khateeb et al., sobre el dolor padecido en pacientes después de una extracción dental, se observó que las mujeres padecían más dolor que los hombres, durante los 7 días posteriores a la extracción (AlKhateeb \& Alnahar, 2008). 


\section{Capitulo 1: Introducción}

Las intervenciones periapicales son otra clase de cirugía en odontología, aunque cada día su uso es menor, debido a la evolución de los implantes dentales. Así Peñarrocha et al., obtuvieron en su estudio sobre 60 pacientes sometidos a este tipo de cirugía, que el dolor y la inflamación fueron similares para hombres y mujeres (Peñarrocha, et al., 2006). Al igual que con la edad, la mayoría de estudios sobre este tipo de intervenciones no obtuvieron diferencias entre el postoperatorio sufrido por hombres y mujeres (Brown, et al., 1990, García, et al., 2007, Iqbal, et al., 2007, Lin, et al., 2006, Meechan \& Blair, 1993, Peñarrocha, et al., 2006, Seymour, et al., 1986, Tsesis, et al., 2003).

En cuanto al postoperatorio sufrido después de cirugía periodontal, Canakçi et al., encontraron en su revisión, que tanto hombres como mujeres padecieron el mismo dolor tras la cirugía (Canakçi \& Canakçi, 2007). En otro trabajo de Eli et al., sobre la memoria del dolor tras un tratamiento periodontal tampoco se encontraron diferencias de género (Eli, et al., 2000).

Hay que destacar que, en general, en la mayoría de estudios experimentales sobre el postoperatorio quirúrgico, las mujeres mostraron mayor duración e intensidad de dolor que los hombres (Morin, et al., 2000, Unruh, 1996, Wiesenfeld-Hallin, 2005).

\section{Edad}

En la mayoría de los estudios revisados, no existe diferencia significativa entre la edad del paciente y el dolor y la inflamación postquirúrgica sufridos tras la colocación de implantes dentales (Al-Khabbaz, et al., 2007, González, et al., 2005, Guarinos, et al., 1998, Muller \& Ríos, 2001, Peñarrocha, et al., 2000).

Respecto al postoperatorio implantológico únicamente en el estudio llevado a cabo por Urban et al., se encontraron diferencias significativas en cuanto al dolor padecido por los pacientes en relación a su edad. En él, se dividió a los pacientes en dos grupos, uno con mayores de 50 años y otro de igual o menor edad, encontrando que los pacientes de mayor edad sufrieron menos dolor que los pacientes más jóvenes (Urban \& Wenzel, 2010). Kalkman et al., en su artículo del año 2003, ya habían observado que los pacientes más jóvenes, son los que más dolor refieren durante el postoperatorio de la mayoría de intervenciones quirúrgicas orales (Kalkman, et al., 2003).

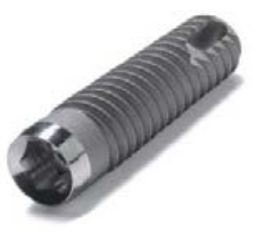




\section{VNiVERSiDAD}

osalamanca

En otras cirugías como la extracción de los terceros molares inferiores incluidos, se observan resultados diferentes. Varios autores coinciden en que la edad no está relacionada con el dolor y la inflamación que padecen los pacientes, después de extraerles un tercer molar inferior incluido (Fisher, et al., 1988, Gillies, et al., 1987, Kalkman, et al., 2003, López, et al., 2006, Martínez, et al., 1995, Peñarrocha, et al., 2001, Sáez, et al., 1999, Seymour, et al., 1985).

Por otro lado hay autores, que refieren que los pacientes de mayor edad sufren mayor dolor que los más jóvenes. Este incremento de dolor en los pacientes mayores, se asocia a la mayor densidad ósea que poseen y a que el ligamento periodontal que tienen es más estrecho, por lo que, normalmente, las intervenciones son más largas y cruentas (Bello, et al., 2011, Bruce, et al., 1980, Capuzzi, et al., 1994, De Boer, et al., 1995, Fisher, et al., 1988, Infante, et al., 1995, Olmedo, et al., 2002).

En un artículo de Bello et al., se encontró, que los pacientes de mayor edad padecieron un peor postoperatorio general (inflamación, trismus, malestar en la zona, etc.) que los más jóvenes, sin embargo, durante las primeras 24 horas después de la intervención, los mayores sufrieron menos dolor que los de menor edad (Bello, et al., 2011).

En cuanto a los estudios sobre cirugía periapical en relación con la edad y el postoperatorio quirúrgico, se encuentran también resultados muy dispares. Si bien es cierto que, en la mayoría de los artículos revisados, no se encontraron diferencias significativas, entre la edad de los pacientes y el dolor sufrido tras la intervención (Brown, et al., 1990, Chong \& Pitt Ford, 2005, García, et al., 2007, Lin, et al., 2006, Meechan \& Blair, 1993, Peñarrocha, et al., 2001 Peñarrocha, et al., 2006, Seymour, et al., 1986).

Únicamente Iqbal et al., encontraron, en esta clase cirugías, que los pacientes de menor edad padecían más dolor que los pacientes mayores (Iqbal, et al., 2007).

Por lo que respecta a los tratamientos quirúrgicos periodontales, Canacki et al., encontraron diferencias estadísticamente significativas, entre los pacientes de menor y mayor edad. Estos autores observaron, que el dolor sufrido por los pacientes después de los 


\section{Capitulo 1: Introducción}

citados tratamientos, disminuía a medida que iba aumentado la edad de los mismos (Canakçi \& Canakçi, 2007).

\section{Tabaco}

Los pacientes fumadores, tienen más riesgo de sufrir fracaso implantológico, debido a la vasoconstricción periférica y al aumento de bacterias anaeróbicas en la microflora oral y de la placa bacteriana, como han demostrado varios autores (Bain \& Moy, 1993, Baig \& Rajan, 2007, DeLuca, et al., 2006, Hinode, et al., 2006).

En la mayoría de los artículos publicados no se han encontrado diferencias significativas entre los pacientes fumadores y el aumento del dolor o la inflamación postquirúrgica (Dionne, 1999).

Estos resultados se pueden deber a que la nicotina, además de tener un efecto vasoconstrictor, también lo tiene antinociceptivo, por lo que no debería existir aumento del dolor postquirúrgico en pacientes fumadores (Jamner, et al., 1998, Pomerleau, 1986).

Así, Creekmore et al., y Marco et al., obtuvieron, en sus respectivos estudios, que los pacientes fumadores a los que se les instó a dejar de fumar, sufrieron mayor dolor y tomaron mayor número de analgésicos, que los pacientes a los que no se les prohibió fumar (Creekmore, et al., 2004, Marco, et al., 2005).

En cirugía implantológica, son pocos los estudios que han relacionado el tabaco con el postoperatorio sufrido por estos pacientes. Urban et al., en su trabajo, encontraron que los pacientes fumadores sufrieron más dolor desde el primer día después de la intervención, hasta los tres días posteriores. Sin embargo, no obtuvieron diferencias en la inflamación postquirúrgica entre fumadores y no fumadores, durante todo el postoperatorio (Urban \& Wenzel, 2010).

Otros artículos publicados sobre este tema, no encontraron ninguna diferencia en el postoperatorio implantológico entre pacientes fumadores y no fumadores (Al-Khabbaz, et al., 2007, Guarinos, et al., 1998). 


\section{VNIVERSIDAD}

BSALAMANCA

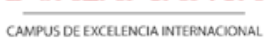

Al-Khabbaz et al., no encontraron diferencias significativas en el dolor padecido por estos pacientes, pero sus resultados mostraron mayor dolor en pacientes fumadores que en no fumadores, tanto a las 24 horas de la intervención como una semana más tarde (AlKhabbaz, et al., 2007).

En cuanto a la cirugía de los terceros molares inferiores incluidos Capuzzi et al., no encontraron diferencias significativas en el dolor y la inflamación en pacientes fumadores (Capuzzi, et al., 1994). Lo mismo les sucedió a Lopez-Carriches et al., y Larrazábal et al., aunque en este último estudio, el tabaco sí produjo mayor dolor 24 horas después de la cirugía. En este mismo trabajo, también se observó que la inflamación sufrida por los pacientes que fumaban 20 cigarrillos o más al día, fue mayor que en cualquier otro paciente (Larrazábal, et al., 2010, López, et al., 2006).

Por otra parte, existen estudios respecto a los terceros molares inferiores incluidos, que demostraron que los pacientes fumadores, sufrieron más dolor que los no fumadores, siendo estos resultados estadísticamente significativos (García, et al., 2007, Grossi, et al., 2007).

Respecto a la cirugía periapical, en el artículo publicado por Peñarrocha et al., no se encontraron diferencias significativas en el dolor y la inflamación padecidos por los pacientes fumadores y no fumadores, después de este tipo de intervenciones (Peñarrocha, et al., 2006). Por el contrario, un estudio de García et al., encontró que los pacientes que fumaban antes de someterse a dicha cirugía, sufrían mayores valores de dolor postoperatorio que los pacientes no fumadores, sin embargo, fumar o no después de la cirugía, era irrelevante respecto al postoperatorio (García, et al., 2007).

En 2008, García et al., llevaron a cabo una revisión de toda la literatura sobre este tipo de cirugías y su postoperatorio, no encontrando diferencias entre fumadores y no fumadores (García, et al., 2008).

En cuanto al tratamiento quirúrgico periodontal, no se encontraron diferencias significativas entre fumadores y no fumadores, después de un tratamiento periodontal, respecto al dolor y la inflamación postoperatoria (Canakçi \& Canakçi, 2007). 


\section{Capitulo 1: Introducción}

\section{Higiene}

De todos los artículos revisados sobre el postoperatorio implantológico, sólo uno estudió la relación entre el mismo y el grado de higiene que presentaban los pacientes, antes y después de la cirugía. Estos autores encontraron, que los pacientes que mejoraron su higiene después de la cirugía implantológica padecieron menos dolor a las 12 horas después de dicha intervención (Guarinos, et al., 1998).

Respecto a la cirugía de extracción de terceros molares inferiores incluidos, Saez et al., encontraron que los pacientes con peor higiene antes de la cirugía, sufrieron mayor dolor a las 6 horas de la intervención (Sáez, et al., 1999). Peñarrocha et al., estudiaron 100 molares extraídos, determinando que el dolor era mayor cuanto peor era la higiene del paciente, aunque no encontraron relación con la inflamación (Peñarrocha, et al., 2001). En una revisión posterior de Larrazábal et al., el dolor aumentaba cuanto menor era el cepillado del paciente, antes y durante la primera semana después de la cirugía (Larrazábal, et al., 2010).

En cirugía periapical, Peñarrocha et al., en su estudio del año 2006, encontraron que la higiene no presentó una relación significativa con el dolor y la inflamación, pero sí que los pacientes con buena higiene, tuvieron una disminución más rápida del dolor y la inflamación sufridos los 2 primeros días después de la intervención (Peñarrocha, et al., 2006). Este mismo autor, en otro artículo publicado en 2007, encontró que los pacientes con mejor higiene dental padecían menos dolor e inflamación durante los 7 primeros días del postoperatorio (García, et al., 2007).

\section{Ansiedad}

Son pocos los estudios que relacionan ansiedad y dolor postquirúrgico tras la colocación de implantes dentales. No obstante, la presencia de ansiedad es determinante en la percepción del dolor postoperatorio.

Varios estudios experimentales han demostrado que la ansiedad, las experiencias previas, las expectativas del paciente, el stress y el ambiente, pueden influir en la percepción del dolor (Brand, et al., 1995, Eli, et al., 1997, González, et al., 2010, Lindsay \& Jackson, 1993, Kent, 1997, Rubin, et al., 1988, Soh \& Yu, 1992).

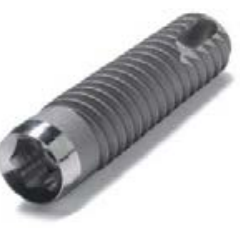




\section{VNiVERSiDAD}

osalamanca

El $85-90 \%$ de la población, cuando acude a una consulta dental, exhibe cierta clase de temor o ansiedad antes y durante el tratamiento. Rubin et al., definen la ansiedad como una reacción a un peligro desconocido. Su fuente se localiza en el inconsciente. Puede describirse como aprensión intensa y malestar difuso, no formulado, reflejado en una combinación peculiar de alteraciones visceromotoras y tensiones esqueléticas (Rubin, et al., 1988).

Numerosos estudios han demostrado que entre el 5\% y el 20\% de la población adulta, tienen problemas graves de ansiedad en la consulta odontológica (Lindsay \& Jackson, 1993) y que la principal causa, es el dolor y la experiencia traumática que los pacientes creen que van a vivir (Kent, 1997).

Está demostrado que la cirugía oral es el procedimiento odontológico que más ansiedad produce al paciente. Y dentro de este campo, la cirugía implantológica es la que más la provoca (Brand, et al., 1995, Eli, et al., 1997, Soh \& Yu, 1992, Wong \& Lytle, 1991).

Además, esta ansiedad, tiene una íntima relación con el dolor que experimenta el paciente después de la intervención. Así Torabinejad et al., encontraron una correlación positiva entre el dolor postoperatorio y la ansiedad (Torabinejad, 1994).

Llorca et al., estudiaron los niveles perceptivos del dolor y su relación con las alteraciones sobre el umbral doloroso. Éste se ve reducido con ansiedad, depresión, experiencias previas negativas, cansancio, etc. La corrección o eliminación de estos factores, incrementarían este umbral (LLorca, et al., 1989).

Hashem et al., obtuvieron como resultados de un estudio sobre ansiedad y el postoperatorio quirúrgico, después de la colocación de implantes dentales, que la cirugía implantológica produce dolor y ansiedad entre medio y moderados (Hashem, et al., 2006).

En relación al sexo del paciente, algunos estudios encontraron que las mujeres mostraron mayor ansiedad que los hombres en este tipo de intervenciones (Edwards, et al., 1999, Frazer \& Hampson, 1988, Fillingim, et al., 1999, Smyth, 1993). Sin embargo, Jones et 


\section{Capitulo 1: Introducción}

al., en su estudio sobre ansiedad relacionada con el sexo de los pacientes, la encontraron mayor en hombres que en mujeres (Jones, et al., 2003).

Para Eli et al., la relación entre sexo y ansiedad en implantología es difícil de analizar. Para ellos, los estudios anteriores demuestran diferencias entre hombres y mujeres porque las intervenciones quirúrgicas a estudiar eran de menor importancia, pero cuando se trata de la colocación de implantes dentales, la ansiedad se dispara y es casi igual en hombres y mujeres (Eli, et al., 2003).

Por edades, Stabbholz et al., encuentran niveles más altos de ansiedad en pacientes entre 35 y 49 años (Stabholz \& Peretz, 1999).

Cuando se trata de afrontar este problema en la consulta, Wardle et al., dicen que mantener al paciente informado del tratamiento que va a recibir, ayuda a reducir la ansiedad y disminuye el dolor postoperatorio (Wardle, 1983).

Corah et al., analizaron los factores que afectan a la disminución de la ansiedad en base a la opinión del paciente. El cambio en la ansiedad durante el tratamiento, se relacionó, de forma relevante, con diez conductas percibidas por el dentista. Éstas serían:

1. Explicar los procedimientos antes de comenzar.

2. Dar información específica durante los procedimientos.

3. Indicar al paciente que esté tranquilo.

4. Advertir de la posibilidad de dolor.

5. Apoyar verbalmente al paciente, darle seguridad.

6. Ayudar al sujeto a redefinir la experiencia para disminuir la amenaza al mínimo.

7. Dar a la persona cierto control sobre los procedimientos y el dolor.

8. Intentar enseñar al individuo a superar la angustia.

9. Proporcionar distracción y alivio de la tensión.

10. Tratar de generar confianza en el paciente. Trato cálido y amable.

Lo más importante en este trabajo, concomitante con la disminución de la ansiedad, fue la dedicación explícita del odontólogo a evitar infringir dolor o, al menos, que así lo perciba el paciente (Corah, et al., 1988). 
El hecho de aliviar la ansiedad por medios no farmacológicos como tranquilizar al paciente, darle explicaciones adecuadas y otros apoyos, se relaciona con una menor necesidad de medicamentos postoperatorios. Por el contrario, con la ansiedad aumenta la posibilidad de interpretar estímulos no nocivos como dolor, experimentando éste con mucha mayor intensidad. Aquí radica la importancia de la ansiedad en el tratamiento (Stimmel, 1985).

\section{B) Factores relacionados con la cirugía}

\section{Número de implantes}

Un mayor número de implantes, significa un mayor grado de agresión tisular pues inevitablemente, se debe practicar colgajo y ostectomía de mayor diámetro y, por consiguiente, una cirugía de mayor duración (Peñarrocha, et al., 2001).

En el estudio de González et al., a mayor número de implantes, mayor era el dolor y la inflamación que padecían sus pacientes, coincidiendo con otros autores (González, et al., 2005). Para éstos, es lógico pensar que si la intervención es más traumática, se producirá más dolor e inflamación (Guarinos, et al., 1998, Peñarrocha, et al., 2001).

Al-Khabbaz et al., también encontraron en su estudio, diferencias significativas entre el dolor padecido por pacientes que sólo recibieron un implante y aquellos a los que se les implantó más de uno, siendo éste mayor cuando en la cirugía se colocó más de un implante (Al-Khabbaz, et al., 2007).

\section{Duración de la intervención}

La duración de la intervención está relacionada, directamente, con el grado de dificultad de la misma y con el número de implantes que se van a colocar, pues a mayor número de éstos, inevitablemente, mayor será la duración de la cirugía. 


\section{Capitulo 1: Introducción}

En implantología, Guarinos et al., no encontraron diferencias significativas entre el dolor y la inflamación padecidos por el paciente después de la cirugía, en relación con la duración de la misma (González, et al., 2005, Guarinos, et al., 1998).

La mayoría de los autores establecen que, en cirugía de extracción de terceros molares inferiores incluidos, a mayor duración de la intervención mayor será el dolor y la inflamación postquirúrgicos que sufrirá el paciente (Bello, et al., 2011, Benediktsdottir, et al., 2004, García, et al., 1997). En este sentido Lombardía et al., y Olmedo et al., encontraron relación entre la duración de la intervención en la extracción de terceros molares mandibulares incluidos y un aumento del dolor y la inflamación postquirúrgicos (Lombardía, et al., 1989, Olmedo, et al., 2002).

Sin embargo, Peñarrocha et al., en su estudio sobre cirugía periapical, sólo observaron relación entre la inflamación y una mayor duración de la intervención, pues en su estudio no hubo un aumento del dolor postquirúrgico (Peñarrocha, et al., 2006). En este mismo campo Seymour et al., tampoco encontraron relación alguna (Seymour, et al., 1986).

\section{Experiencia del cirujano}

Respecto a la experiencia del cirujano, hay bastante controversia, debido a que, en la literatura actual, no se dispone de suficiente bibliografía que evalúe este aspecto en el campo de la implantología.

Así Al-khabbaz et al., encontraron en su estudio que pacientes a los que les fue practicada la cirugía por estudiantes de postgrado (menos de 24 años), sufrieron mayor dolor que aquellos que fueron operados por cirujanos con más experiencia. No obstante, deja claro que esta diferencia puede deberse a un aspecto psicológico, pues la juventud de los cirujanos podría haber sido la causa del aumento del dolor, ya que sí está demostrado que la percepción del dentista por el paciente, produce mayor ansiedad y aumento del dolor y la inflamación postquirúrgicos (Al-Khabbaz, et al., 2007).

En cuanto a la cirugía de extracción del tercer molar inferior incluido, Capuzzi et al., encontraron mayor dolor postquirúrgico en pacientes que fueron intervenidos por cirujanos con menor experiencia (Capuzzi, et al., 1994).

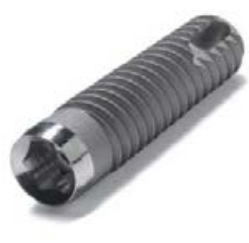




\section{VNIVERSIDAD}

BSALAMANCA

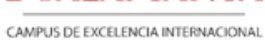

Sin embargo, otros autores no han encontrado diferencia alguna a este respecto (Berge \& Bøe, 1994, Infante, et al., 1995, Olmedo, et al., 1995).

\section{Cirugía combinada}

La dificultad de la intervención, guarda una estrecha relación con el dolor y la inflamación postquirúrgicos. La cirugía implantológica se puede acompañar, en el mismo acto quirúrgico, de una extracción dentaria previa, una regeneración ósea, una elevación sinusal directa o indirecta, etc.

Normalmente, una cirugía de mayor dificultad, produce una agresión tisular mayor que una convencional, por lo que se acompaña de mayor grado de dolor e inflamación.

Al-khabbaz et al., observaron que los pacientes a los que se les practicó alguna clase de cirugía adicional, como las mencionadas anteriormente, padecieron mayor dolor 24 horas después de la intervención, con respecto a los que sólo fueron sometidos a cirugía implantológica convencional (Al-Khabbaz, et al., 2007).

En este sentido, González et al., encontraron en su estudio que todas sus intervenciones con regeneración ósea o elevación sinusal, mostraron un aumento significativo de la inflamación postquirúrgica (González, et al., 2005). Del mismo modo que Guarinos et al., encontraron mayor inflamación en casos con elevación sinusal (Guarinos, et al., 1998).

\section{C) Factores psicológicos del paciente}

En la clínica, no pueden separarse las bases fisiológicas del dolor de los factores psicológicos, debemos tenerlos presentes para realizar un tratamiento o una prevención eficaz del mismo (Okeson, 2006).

El dolor es un mecanismo de defensa, de supervivencia, que dirige la energía al alejamiento del estímulo nocivo. Según el National Institute of Health, "El dolor no ocurre de forma aislada sino en un ser humano específico, en contextos psicosociales, económicos 


\section{Capitulo 1: Introducción}

y culturales que modifican el significado, la experiencia y la expresión verbal del dolor" (Health, 1986).

Para Rugh, las experiencias del dolor y la conducta a causa del mismo, dependen o las modifican una serie de factores que incluyen:

1. El daño hístico.

2. La ansiedad.

3. La depresión.

4. El control percibido: el dolor se percibe como menos intenso y es más tolerado, si las personas creen que tienen control sobre él. De ahí la importancia de contar con instrucciones específicas acerca de analgésicos, la disposición a examinarlos cuando sea preciso, etc.

5. La atención: es posible alterar el umbral del dolor dirigiendo, simplemente, la atención de los sujetos a otra cosa que no sea el estímulo. No es conveniente reducir las actividades, con lo que toda la atención del paciente se concentre en su situación dolorosa.

6. Antecedentes con los profesionales del cuidado de la salud: aquí se incluirían los tratamientos médicos, sobre todo dentales, el trato y la atención recibidos, el dolor, etc.

7. Experiencias anteriores con el dolor: asimilado tanto en su aspecto positivo como negativo.

8. Las características de su personalidad: los perfeccionistas desarrollan más ansiedad y frustración, los inseguros también y los extrovertidos son más aptos para expresar el dolor que los introvertidos.

9. Factores culturales y étnicos: los hombres muestran, invariablemente, más tolerancia a una amplia variedad de estímulos dolorosos y de hecho, buscan el cuidado médico y dental con menor frecuencia que las mujeres. Algunos autores sugieren que tales diferencias entre sexo, ocurren por creencias y expectativas personales sobre la conducta adecuada del papel sexual (Otto \& Dougher, 1985).

10. Los antecedentes de refuerzo.

11. Creencias sobre el dolor y su origen. Cuando se transmite al paciente un diagnóstico que alivia la ansiedad y los temores, alteramos la percepción y la tolerancia frente al dolor. El dolor molesta menos cuando se conoce su origen, de aquí la importancia 
de proporcionar al paciente una explicación del dolor en términos comprensibles. Este aspecto es crítico en el control del dolor.

Los procesos cognitivos y el sistema emocional afectivo, alteran el reconocimiento y la tolerancia ante un estímulo nocivo, así por ejemplo, la ansiedad y la depresión pueden aumentar o disminuir los impulsos nerviosos desde los nociceptores periféricos y por tanto, cambiar, notablemente, la percepción individual del dolor (sistema sensorioperceptual). Las personas más ansiosas tienen un umbral doloroso más bajo. La depresión modifica también la sensibilidad al dolor y el deseo de tolerarlo. El tratamiento de la depresión en muchas ocasiones disminuye el grado de dolor (Rugh, 1987).

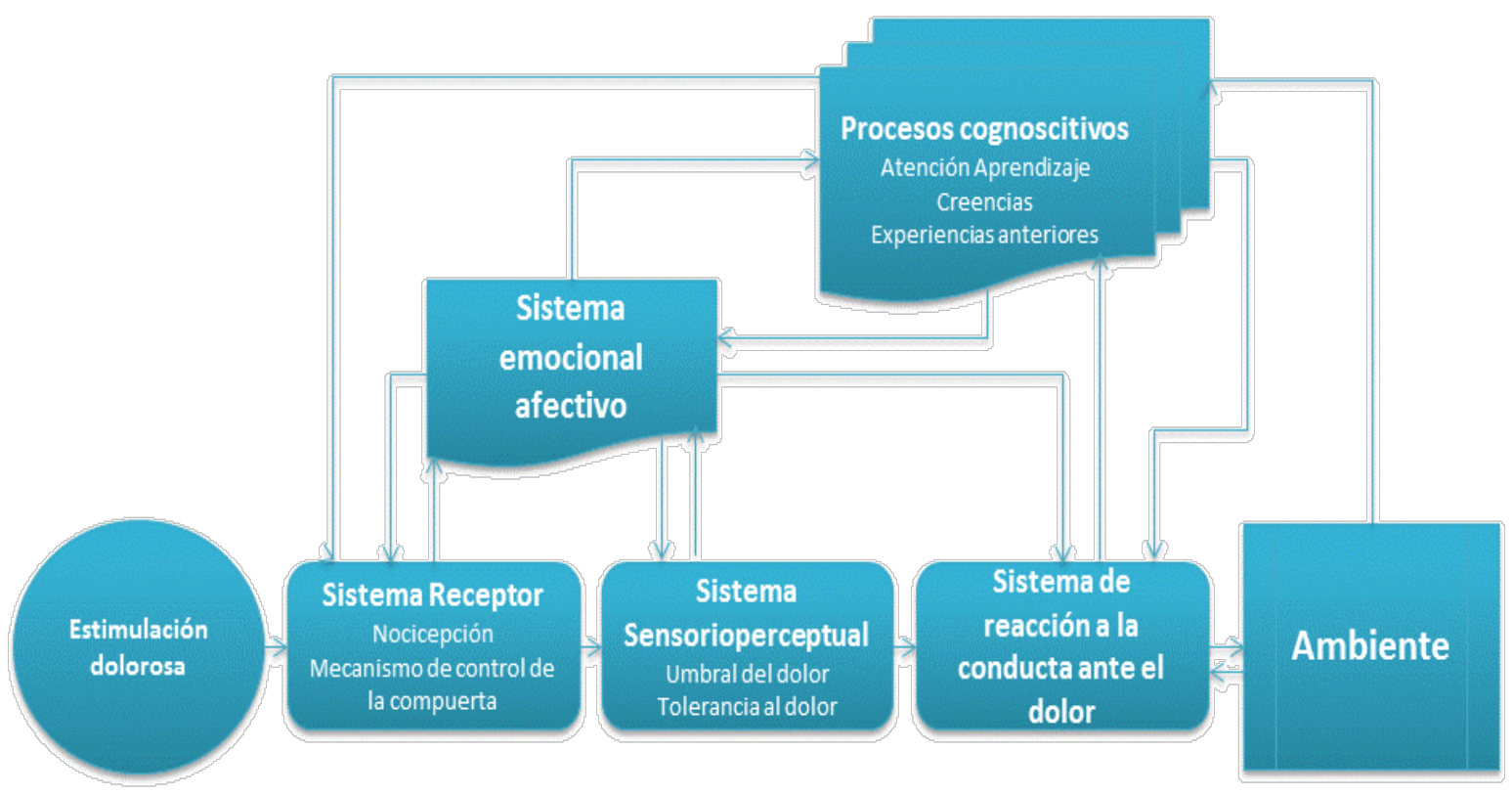

Figura 26: Interacciones que alteran el sistema de reacción ante el dolor (Tomado de Rugh, 1987).

El proceso cognitivo es un elemento clave en la experiencia del dolor. Quienes se preocupan del dolor e imaginan consecuencias negativas, comunican más dolor, más ansiedad y son menos tolerantes (Rugh, 1987).

Llorca et al., desde la psicología médica, han estudiado los niveles perceptivos del dolor y su relación con las alteraciones sobre el umbral doloroso. Éste se ve reducido con síntomas de insomnio, cansancio y ansiedad. Lo mismo sucede con depresión, introversión 


\section{Capitulo 1: Introducción}

o aislamiento. Las experiencias previas, si son negativas, también lo afectan. La corrección o eliminación de estos factores, aumentarían el umbral del dolor (LLorca, et al., 1989).

Para Muriel et al., el dolor postoperatorio tiene dos componentes: la percepción de la sensación dolorosa y la reacción al dolor.

- La percepción del dolor como cualquier otra sensación de percepción (tacto, temperatura, etc.), es un proceso neurofisiológico que tiene propiedades especiales de tipo estructural, funcional, y perceptivas; que se consigue por mecanismos relativamente simples, se puede medir y es constante; puede ser modificado por medio de drogas y factores psíquicos o puede ser eliminado por interrupción de sus vías, bien por acción química (bloqueos) o por medios quirúrgicos.

- La reacción al dolor es un complejo proceso físico-psicológico que comprende funciones cognitivas del individuo. Representa la expresión emocional y fisiológica resultante de la percepción del dolor. Es lo que el sujeto hace, siente y piensa acerca de la experiencia que está sufriendo (Muriel, et al., 1989).

Según Muriel et al., en el dolor postoperatorio, el factor más importante quizá sea la duración del estímulo nocivo. Un estímulo breve, aunque sea de gran intensidad, da lugar a una reacción menor que un estímulo prolongado, aun siendo de mediana intensidad. Para este autor, el dolor postoperatorio se reduciría con una preparación psicológica previa, premedicación adecuada, una buena técnica quirúrgica y un buen cuidado postoperatorio (Muriel, et al., 1989).

Un estudio muy importante de Touyz et al., analizó el comportamiento postoperatorio de los pacientes, a los que se les hacían llamadas periódicas desde la consulta para comprobar su estado, obteniendo como resultado mucho menos dolor postoperatorio y menor consumo de analgésicos en los pacientes que fueron llamados periódicamente, respecto a los que no fueron llamados (Touyz \& Marchand, 1998). 


\subsection{PREVENCIÓN Y TRATAMIENTO DEL DOLOR EN IMPLANTOLOGÍA}

Reducir al máximo los síntomas que se producen después de la cirugía implantológica, sin interferir en el proceso fisiológico de la inflamación debe ser el objetivo principal de cualquier cirujano oral (Romero, et al., 2006).

Los conceptos sobre el control de los síntomas postoperatorios han sufrido importantes modificaciones a lo largo de los últimos años, conforme ha avanzado el conocimiento de las bases fisiopatológicas del dolor y la inflamación, así como el mecanismo de acción y la farmacodinámica de los analgésicos y antiinflamatorios utilizados en su tratamiento (Ruiz, et al., 2003).

Como ya se ha descrito, existen factores que no se pueden controlar, como el sexo, la edad del paciente, el número de implantes que hay que colocar, pero, sin embargo, sí se pueden adoptar muchas medidas que mejorarán, considerablemente, el postoperatorio del paciente. Éstas se pueden tomar antes o después de la cirugía (Romero, et al., 2006).

\subsubsection{Antes de la cirugía}

Éstas no son tan importantes como las medidas que se pueden tomar después de la misma, pero un manejo correcto de estas opciones, mejorará considerablemente, el postoperatorio (Romero, et al., 2006).

La administración de un anestésico local o un opioide previo a la intervención quirúrgica, da como resultado un retraso en el establecimiento del dolor. La eficacia del anestésico local cuando se utiliza antes o después del tratamiento quirúrgico, es la misma siempre y cuando se administre antes de que aparezca el dolor (Dionne, 2001, Martorell, et al., 2004). 


\section{Capitulo 1: Introducción}

\section{A) Antibióticos}

No existe unanimidad de criterio sobre la administración preventiva de antibióticos en cirugía bucal para evitar la aparición de infecciones postquirúrgicas, siendo un tema que continúa generando controversias (Peñarrocha, et al., 2001).

La mayoría de los estudios hasta la fecha sobre profilaxis antibiótica en implantología, no han encontrado diferencias significativas en la supervivencia ni en las complicaciones de dichos implantes, entre pacientes que fueron medicados con antibióticos antes de la cirugía y los que no fueron premedicados (Binahmed, et al., 2005, Gynther, et al., 1998, Mark \& Granquist, 2008, Morris, et al., 2004, Quirynen, et al., 2002, Romero, et al., 2006)

Romero et al., llevaron a cabo una revisión de la literatura de la que se desprende que, en cirugía de implantes, no hay evidencia científica adecuada para recomendar ni para desaconsejar, el uso profiláctico de antibióticos sistémicos que prevengan las complicaciones y el fracaso de los implantes dentales (Romero, et al., 2006). De hecho, hasta la fecha, existen muy pocos ensayos clínicos controlados y aleatorizados, con un seguimiento mínimo de tres años, que comparen la administración profiláctica de antibióticos frente a un grupo sin tratamiento o con placebo.

Son pocos los autores que sí han encontrado una mayor supervivencia de los implantes, en pacientes que fueron medicados con antibióticos antes de la cirugía. Así Laskin et al., analizaron 3132 implantes colocados en 702 pacientes y compararon un grupo de control que no recibió antibiótico antes de la cirugía y otro que si lo recibió. El antibiótico administrado, en este último caso, dependió de cada cirujano. Los resultados fueron que los pacientes premedicados, presentaron mayor supervivencia implantológica que los no premedicados (Laskin, et al., 2000).

En cirugía general, se aconseja el uso de profilaxis cuando el índice de infecciones postoperatorias supera el 15-25\% (herida contaminada). En cirugía bucal, este índice siempre es inferior, por lo que en principio, la profilaxis antibiótica no estaría indicada, de manera rutinaria en los tratamientos quirúrgicos, salvo en determinadas circunstancias que se citan a continuación (Corah, et al., 1988, Dent, et al., 1997, Romero, et al., 2006).

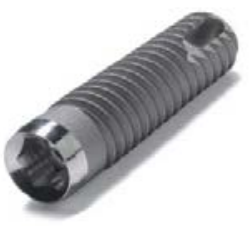


- Estaría indicada en pacientes en los que el riesgo de infección postoperatoria fuera alto, como en aquellos con riesgo de endocarditis bacteriana, insuficiencia renal, insuficiencia hepática, diabetes mal controlada, pacientes con déficit inmunitario (granulocitopenia por leucemias agudas, anemia aplásica o quimioterapia, tratamiento inmunosupresor $\mathrm{u}$ otras inmunodeficiencias), portadores de by-pass arteriales recientes ( $<6$ meses), candidatos a diálisis, pacientes con hidrocefalia con shunts ventriculoatriales, portadores de prótesis articulares -especialmente de rodilla o cadera- o pacientes adictos a drogas por vía parenteral (ADVP) (Espósito, et al., 2003).

- Igualmente se aconseja la profilaxis antibiótica en las intervenciones quirúrgicas prolongadas (duración superior a 45 minutos-1 hora), y en aquellos casos de cirugía traumática como grandes ostectomías, elevaciones abiertas del seno maxilar, transposiciones del nervio dentario, grandes injertos de hueso, etc. (Arteagoitia, et al., 2005, Gutiérrez, 2004).

Por lo tanto, la tendencia habitual consiste en no administrar profilaxis antibiótica a ningún paciente, salvo aquellos en los que el riesgo de infección sea elevado (endocarditis bacteriana, insuficiencia renal, etc.). En estos casos, el antibiótico de elección debe ser amoxicilina/ácido clavulánico: dos gramos una hora antes de la intervención por vía oral, mientras que, en caso de alérgicos a la penicilina se prescribirá eritromicina (Gay \& Berini, 1997).

\section{B) Analgésicos y Antiinflamatorios}

Los conocimientos actuales sobre la fisiopatogenia del proceso inflamatorio y los datos derivados de la evidencia científica, han apoyado la idea de administrar la medicación antes de que se liberen los mediadores implicados y de que desaparezca el efecto analgésico del anestésico utilizado (Romero, et al., 2006).

Hoy en día, sigue existiendo gran controversia respecto a la utilización preventiva de antiinflamatorios, pues si algunos autores demuestran que son eficaces, otros en cambio 


\section{Capitulo 1: Introducción}

concluyen que se obtienen similares resultados, que administrados sólo después de la cirugía (Aznar, et al., 2012, Kelly, et al., 2001, Kissin, 2000, Møiniche, et al., 2002, Woolf \& Chong, 1999).

Existen autores por tanto, que apoyan la administración preventiva de antiinflamatorio, unas horas antes de la cirugía, para conseguir niveles plasmáticos altos en sangre que actúen contra los mediadores de la inflamación desde su liberación, evitando ingerir el fármaco después de la cirugía, cuando ya han pasado unas horas tras la operación (Dionne, 2000, Farris \& Fiedler, 2001).

Así Romero et al., en su estudio de revisión, aconsejan el tratamiento de manera sistemática con antiinflamatorio no esteroideo (AINE) antes de la intervención, concretamente, derivados del ácido propiónico como ibuprofeno (400-600 mg.), que es el fármaco sobre el que existe mayor evidencia científica, el dexketoprofeno (25 mg.) o el dexibuprofeno (400 mg.) (Romero, et al., 2006).

También existen estudios, que tratan de evaluar si es más efectiva la administración preoperatoria o inmediatamente después de la cirugía, concluyendo que la eficacia es idéntica cuando se administra 30-60 minutos antes o justo después de la intervención (Allen \& Grover, 1990, Dahl \& Kehlet, 1993).

Otros autores han obtenido en sus estudios, que los analgésicos y antiinflamatorios que se administran antes de la cirugía no disminuyen el dolor postoperatorio del paciente, por lo que son totalmente innecesarios, aunque sí recomiendan su utilización lo antes posible después de la cirugía (Jung, et al., 2005, Vogel, et al., 1992).

\section{C) Antisépticos}

Existe bastante evidencia científica que demuestra que la clorhexidina disminuye notoriamente la colonización bacteriana en la cavidad oral (Gjermo, 1989, Heitz, et al., 2004, Lang, et al., 1982, Löe \& Schiott, 1970), y que además, es superior a cualquier otro agente químico en el control de la placa bacteriana (Amini, et al., 2009, Siegrist, et al., 1986). 


\section{VNiVERSIDAD}

BSALAMANCA

\section{canpus of Excelencan anterenaconat}

El control de la placa bacteriana es especialmente importante para obtener éxito en la colocación de implantes dentales (Lang, et al., 2000, Quirynen, et al., 2002). De hecho, un estudio de Van Steenberghe et al., demostró un aumento del fracaso implantológico y de las complicaciones que derivan del mismo, en pacientes con altos niveles de placa bacteriana (Van Steenberghe, et al., 1990).

Esposito et al., sugieren que, aunque las infecciones bacterianas no son la principal causa del fracaso implantológico, una buena pauta de control de la placa bacteriana es imprescindible los primeros días después de la cirugía (Esposito, et al., 1998).

También se ha estudiado la forma de administrar clorhexidina, pues se puede aplicar en spray con una concentración del $0,2 \%$ o en forma de enjuague con una concentración de 0,12\%. En ambos casos, los resultados son similares según varios autores (Francetti, et al., 2000, Francetti, et al., 2004).

En cuanto a su administración prequirúrgica Romero et al., encontraron en sus estudios evidencia de que el uso de clorhexidina en forma de colutorio reduce, significativamente, la incidencia de complicaciones infecciosas en la cirugía bucal en general. Por este motivo, aconseja el uso de enjuagues bucales de clorhexidina al 0,12\%, de dos a tres veces al día, desde el día antes de la intervención hasta dos o tres días después de la misma (Romero, et al., 2001, Romero, et al., 2006).

\subsubsection{Despúes de la cirugía}

El período postoperatorio es en el que clásicamente se ha insistido, a la hora de aplicar distintos tratamientos para controlar los síntomas postoperatorios, aunque en la actualidad, la tendencia es tratar estos síntomas de manera profiláctica.

\section{A) Antibióticos}

El uso de antibióticos sistémicos después de la cirugía implantológica, no está bien documentado hoy en día, debido a que existe gran variabilidad en los resultados y no se ha 


\section{Capitulo 1: Introducción}

demostrado que el uso de antibióticos postquirúrgicos, produzca claros beneficios tanto para la integración del implante como para mejorar el postoperatorio del paciente (Romero, et al., 2006).

Médicamente la cirugía dentoalveolar, entre la que se encuentra la colocación de implantes dentales, está clasificada dentro de las cirugías Clase II. Al contrario que la mayoría de las cirugías, ésta supone una media de infección menor al 5\% y, muy raras veces supone para el paciente graves consecuencias (Dent, et al., 1997, Lawler, et al., 2005).

La mayoría de los autores, no ha encontrado diferencias significativas en el uso de antibióticos sistémicos, para reducir la posible infección de los implantes colocados (Binahmed, et al., 2005, Gynther, et al., 1998, Morris, et al., 2004, Peterson, 1996).

Mazzocchi et al., colocaron 736 implantes dentales sin administrar antibiótico alguno, ni antes ni después de la cirugía, obteniendo una tasa de éxito muy similar a la de implantes que fueron colocados con antibióticos pre y postoperatorios (Mazzocchi, et al., 2007).

Hay autores, para los que es más importante el resto de factores que pueden alterar la integración y el postoperatorio implantológico, como una adecuada higiene, no fumar, realizar enjuagues con clorhexidina antes y después de la cirugía, no beber alcohol, etc., que la administración profiláctica o postoperatoria de antibióticos sistémicos (Coulthard, et al., 2003, Lawler, et al., 2005, Quirynen, et al., 2002).

\section{B) Analgésicos y antiinflamatorios}

Es imprescindible prescribir medicación analgésica y antiinflamatoria después de una intervención implantológica. Lo habitual en estas cirugías, es pautar un antiinflamatorio no esteroideo (AINE), pues la etiopatogenia del dolor postquirúrgico está, íntimamente relacionada con el proceso inflamatorio, asociándole a éste algún fármaco analgésico, si es preciso (Levrini, et al., 2008, Romero, et al., 2006).

Algunos estudios han comparado la administración de antiinflamatorios no esteroideos (AINES), con antiinflamatorios esteroideos (metilprednisona), indicando que 
los AINES poseen una acción analgésica inicial mayor que los esteroideos pero que, por el contrario, los esteroideos muestran mayor supresión de la inflamación (Troullos, et al., 1990). Por lo tanto, las acciones analgésicas de los AINES son relevantes en las primeras fases del dolor, mientras que las actividades del paracetamol y los analgésicos opioides, sólo son valiosas en la última fase (Urquarth, 1994).

Algunos autores han demostrado que una administración conjunta de AINES y metilprednisona, produce una acción analgésica mayor que cuando ambos fármacos actúan por separado (Schultze-Mosgau, et al., 1995, Sisk \& Bonnington, 1985, Troullos, et al., 1990).

El AINE más utilizado en cirugía oral es el ibuprofeno, debido a que muchos autores han demostrado su eficacia y tolerabilidad (Cooper, et al., 1993, Derry, et al., 2009, Mehlisch, et al., 2010, Jeske \& Zahrowski, 2010). Otros AINES eficaces en el manejo del dolor postquirúrgico, son el ketoprofeno y el dexketoprofeno (Akural, et al., 2009, Barden, et al., 2009, Jiménez, et al., 2004).

En muchas ocasiones, es suficiente el AINE pautado para mantener al paciente asintomático o con síntomas tolerables. Sin embargo, cuando esto no ocurre, se debe recurrir a otros fármacos que complementen el efecto analgésico del AINE e incrementen la eficacia clínica, sin que aparezcan efectos indeseables.

Existe una amplia gama de analgésicos que se utilizan como complemento de los AINES, pero los más utilizados son el paracetamol y el metamizol (Romero, et al., 2006).

El acetaminofén (paracetamol) es un analgésico que tiene efecto antipirético pero no antiinflamatorio, por ello suele ir siempre asociado a un AINE. Es un fármaco muy seguro, con mínimos efectos adversos y ampliamente probado en cirugía oral (Dodson, 2007, Romero, et al., 2001, Romero, et al., 2001, Weil, et al., 2007).

Para Daniels et al., la combinación de ibuprofeno y paracetamol es la mejor combinación posible. De hecho, en su trabajo comprobaron que la administración de ibuprofeno de $200 \mathrm{mg}$. y paracetamol de 500 mg., producía una analgesia muy eficaz, 


\section{Capitulo 1: Introducción}

comparable con cualquier otra combinación empleada para dolor severo (Daniels, et al., 2011). Varios autores han demostrado, que la utilización conjunta de ibuprofeno y paracetamol, produce mayor efecto que cualquier analgésico administrado por separado (Jiménez, et al., 2004, Moore, et al., 2011, Mehlisch, et al., 2010, Ong, et al., 2010). Otro estudio de referencia, fue el de Mehlisch et al., en el que demostraron que $400 \mathrm{mg}$. de ibuprofeno tienen el mismo efecto analgésico que 1 gr. de paracetamol (Mehlisch, et al., 2010).

El metamizol, es un analgésico antipirético como el paracetamol pero más potente. Tiene características muy parecidas a los AINES y, al igual que el paracetamol, presenta mínimos efectos adversos. Se suele utilizar para dolores severos (Edwards, et al., 2001, Romero, et al., 2001, Villa, et al., 1999). Este anágesico es el más utilizado en España, aunque llama la atención, que este prohibido en países como Estados Unidos o el Reino Unido.

El metamizol de 1 gr. posee el mismo efecto analgésico que el ibuprofeno de 600 $\mathrm{mg}$, aunque si la dosis de metamizol se eleva a 2 gr. produce un efecto analgésico mucho mayor que el ibuprofeno (Planas, et al., 1998).

Por otro lado, Calatayud et al., compararon la eficacia del metamizol y el paracetamol tras la cirugía del tercer molar inferior incluido, demostrando que 1 gr. de metamizol es más eficaz que 1 gr. de paracetamol (Calatayud, et al., 1992).

Algunos profesionales suelen administrar después de la cirugía implantológica, diclofenaco o ketorolaco (Dionne, 1999). Está demostrado que estos dos fármacos producen similares resultados que el metamizol de 1 gr. (Walton, et al., 1993).

\section{C) Opioides}

Los opioides, actúan a nivel central y, en algunas ocasiones, se puede plantear su utilización para reducir el postoperatorio quirúrgico. Siempre se administran cuando se prevén dolores severos. 


\section{VNiVERSIDAD}

BSALAMANCA

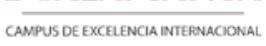

La codeína es, a menudo, considerada el prototipo de opioide usado en odontología. A dosis de $60 \mathrm{mg}$ es efectiva, pero su poder analgésico es mucho menor que cualquiera de los descritos anteriormente. Por ello, habitualmente, se administra en combinación con otros analgésicos donde si posee un efecto deseable. La combinación más frecuente es 60 mg. de codeína más 1 gramo de paracetamol, debido a que se ha demostrado su efectividad para controlar el dolor moderado y severo (Mehlisch, 2002, Moore, et al., 1997, Moore, et al., 2000, Toms, et al., 2009, Zhang \& Li Wan Po, 1996).

Otro opioide utilizado en odontología, es la oxicodona. Ésta es entre 2 y 3 veces más potente que la codeína y posee un efecto analgésico similar a los AINES.

La oxicodona se puede administrar sola, pero su efectividad aumenta cuando se asocia con otro analgésico. Algunos autores, han estudiado la administración conjunta de paracetamol y oxicodona, llegando a la conclusión de que su administración es muy efectiva y segura contra dolor severo (Cooper, et al., 1980, Gaskell, et al., 2009, Litkowsk, et al., 2005).

La oxicodona también se puede asociar con AINES. Van Dyke et al., encontraron en su estudio, que la administración de ibuprofeno de $400 \mathrm{mg}$. más oxicodona de $5 \mathrm{mg}$., producía una analgesia rápida y segura para pacientes con dolor severo después de la cirugía oral, mucho mayor que cuando se administraba oxicodona de $5 \mathrm{mg}$. en solitario (Van Dyke, et al., 2004). Dionne et al., también encontraron en su estudio, que la asociación de ibuprofeno y oxicodona producía una analgesia más rápida pero, sin embargo, sus pacientes mostraron más reacciones secundarias (Dionne, 1999). El principal problema que presenta la oxicodona es que es potencialmente adictivo.

Es importante señalar, que en el estudio de Van Dyke, donde no hubo efectos adversos, la dosis de oxicodona administrada fue de $5 \mathrm{mg}$., mientras que, en el estudio de Dionne la dosis fue el doble, $10 \mathrm{mg}$. por paciente.

Algunos autores, recomiendan la inyección de fentanilo en combinación con anestésicos, como la mepivacaina, debido a que aumenta y prolonga el efecto anestésico en 


\section{Capitulo 1: Introducción}

áreas con inflamación. Ello conlleva una reducción de los requerimientos analgésicos postquirúrgicos (Anderson, 2000, Martorell, et al., 2004).

Actualmente, existe tendencia a utilizar opioides de manera tópica, para recudir los efectos secundarios de los mismos. El tartrato de butorphanol (Stadol $®)$, se administra por vía intranasal y produce un buen efecto análgesico durante 4 horas aproximadamente.

\section{D) Corticoides}

Son, sin duda, los fármacos con mayor potencia antiinflamatoria con los que contamos actualmente, aunque con el inconveniente de que pueden presentar numerosos efectos potenciales indeseables que aparecen, generalmentalmente, cuando se administran a ciertas dosis pero durante un tiempo prolongado (Romero, et al., 2006).

Existe suficiente evidencia científica de que los corticoides, administrados a dosis medias o elevadas y durante pocos días, consiguen minimizar, de manera significativa, los síntomas postoperatorios en el modelo de extracción de los cordales incluidos, siendo más efectivos que los fármacos utilizados habitualmente para este fin.

Sin embargo, el temor a los efectos adversos sumado a un desconocimiento del manejo de éstos fármacos, ha provocado que muchos profesionales sean reticentes a utilizarlos en el campo de la cirugía oral, a pesar de las grandes ventajas que su uso racional puede aportar al paciente, cuando es necesaria su administración.

Está demostrada la utilidad del uso de corticoides en cirugía bucal, si bien no debe usarse de manera rutinaria, quedando reducido a aquellos casos concretos en los que vaya a producirse un trauma quirúrgico severo o riesgo de edema importante, como colocación de varios implantes de manera simultánea, elevaciones de seno, regeneraciones óseas, etc. (Alexander \& Throndson, 2000, Gersema \& Baker, 1992, Kim, et al., 2009, Markiewicz, et al., 2008, Romero, et al., 2006).

En la mayoría de estudios que han analizado el dolor y la inflamación, después de cirugía implantológica, no se utilizaron corticoides, controlando de manera muy efectiva el 
dolor y la inflamación postquirúrgicos (González, et al., 2005, Guarinos, et al., 1998, Peñarrocha, et al., 2002).

En odontología, los corticoides más utilizados son los de acción intermedia, como prednisolona o metilprednisolona, aunque en alguna ocasión, se pueden administrar los de acción larga, como la dexametasona o la betametasona.

De muchos estudios se desprende que la metilprednisolona es muy eficaz en el control del dolor y la inflamación postquirúrgicos (Bystedt \& Nordenram, 1985, Esen, et al., 1999, Holland, 1987, Laureano, et al., 2008, Micó, et al., 2006, Ustün, et al., 2003). Ésta se puede administrar por vía oral, intravenosa o intramuscular, aunque en la clínica dental, lo normal es administrarla siempre por vía oral. En este caso, la dosis recomendada es entre 15 y $20 \mathrm{mg}$. (Beirne \& Hollander, 1986).

La asociación de metilprednisolona con AINES, fue estudiada por Schultze-Mosgau et al., obteniendo una reducción del 56\% de la inflamación, después de la extracción del tercer molar mandibular (Misch, 2006, Schultze-Mosgau, et al., 1995).

La prednisolona también ha sido utilizada en cirugía oral, demostrándose que una dosis de entre 20 y $30 \mathrm{mg}$. disminuye con eficacia, el dolor y la inflamación postquirúrgicos (Buyukkurt, et al., 2006, Tiigimae-Saar, et al., 2010).

Otro corticoide utilizado en cirugía bucal es la dexametasona. Casi todos los estudios sobre él, avalan el buen control sobre la inflamación y el dolor postquirúrgico, se administre por vía oral o intramuscular (Antunes, et al., 2011, Graziani, et al., 2006, Hooley \& Francis, 1969, Schmelzeisen \& Frölich, 1993). Sin embargo, Laureano Filho et al., comprobaron en su trabajo, que aunque la dexametasona es capaz de hacer un buen control de la inflamación y el edema después de la cirugía, no es tan eficaz reduciendo el dolor postquirúrgico (Laureano, et al., 2008).

Por último, otro corticoide que ha sido utilizado en cirugía oral es la betametasona, pero éste corticoide de acción prolongada, suele ser excesivo para el tipo de intervenciones 


\section{Capitulo 1: Introducción}

que se practican en un gabinete dental. Es muy efectivo pero, normalmente se utilizan los descritos anteriormente (Hooley \& Francis, 1969, Nathanson \& Seifert, 1964). 

Capítulo 2

OBJETIVOS 



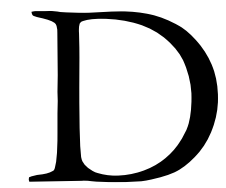
espués de la colocación de implantes dentales el paciente presenta durante unos días, diferentes grados de dolor, inflamación y hematoma que, en la mayoría de los casos, no dura más de una semana. En la actualidad, existen pocos trabajos basados en el estudio de la intensidad y duración de dichos síntomas, después de este tipo de intervenciones.

La principal preocupación de un paciente que acude a nuestra consulta para colocarse un implante dental es conocer si la intervención le va a originar mucho dolor y cuánto tiempo va a padecerlo.

Por lo tanto, la intención de este trabajo fue estudiar todos los síntomas experimentados por los pacientes sometidos a este tipo de intervenciones, así como la duración de los mismos y su correlación con diferentes parámetros clínicos y quirúrgicos.

Por otro lado también pretendemos analizar si el protocolo de medicación postquirúrgica adoptado en este estudio, fue suficiente para proporcionar un postoperatorio confortable a los pacientes intervenidos.

La finalidad del estudio de todos estos parámetros y variables es utilizar estos datos para poder predecir el dolor postoperatorio que van a padecer los pacientes que se someten a este tipo de cirugías, y poder por tanto, tratar correctamente a los mismos. 


\subsection{OBJETIVOS PRINCIPALES DEL ESTUDIO}

1. Conocer el grado de dolor, inflamación y hematoma que padecen los pacientes que se somenten a colocación de implantes dentales y compararlos con la bibliografía existente.

2. Comprobar que la medicación protocolaria que se administró a los pacientes después de la intervención, fue suficiente para controlar la sintomatología postoperatoria y proporcionar un postoperatorio confortable a dichos pacientes, pudiendo evitar la medicación profiláctica de los mismos.

3. Establecer qué variables de las catalogadas dentro del grupo de características generales (edad, sexo, medicación, etc.), influyen directamente en el dolor postoperatorio padecido por los pacientes implantológicos.

4. Establecer qué variables dentro del grupo de características quirúrgicas (número de implantes, situación del implante, etc.), tienen una relación significativa respecto al grado de dolor postoperatoio que padecen los pacientes sometidos a colocación de implantes dentales.

5. Comprobar que variables relacionadas con el paciente presentan una relación directa con el postoperatorio implantológico, aunque los resultados no sean estadísticamente significativos.

6. Comprobar que variables relacionadas con la intervención presentan una relación directa con el postoperatorio sin llegar a ser estadísticamente significativas. 
Capítulo 3

MATERIAL Y MÉTODOS 



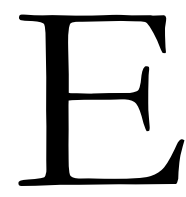

ste estudio se centra, principalmente, en la evaluación del postoperatorio que padecen los pacientes odontológicos, sometidos a cirugía de colocación de implantes dentales. En él se pretende estudiar la evolución de todos los pacientes tratados con implantes dentales, analizando la duración y severidad de los síntomas que padecen y obtener así un protocolo de tratamiento estandarizado para este tipo de pacientes.

En este capítulo se expondrá, en primer lugar, la metodología empleada en el estudio, con todos los planteamientos que conlleva, es decir, se enunciaran las variables y los instrumentos utilizados. En segundo lugar, se realizará una explicación aproximada de la técnica quirúrgica empleada, desde el diagnóstico de los pacientes candidatos a la colocación de implantes dentales hasta la descripción del acto quirúrgico.

A continuación, se explicará detalladamente la relación que existió, entre el operador, su auxiliar y el paciente, desde que se realizó el diagnóstico del caso en la primera cita, hasta que terminó el postoperatorio 7 días después de la intervención.

Posteriormente, se explicará la codificación de las variables analizadas en el estudio, las razones de selección de la población y muestra escogida y, por último, las técnicas de análisis de datos utilizadas para la obtención de los resultados.

El capítulo termina, con un resumen gráfico de todo el proceso que se ha llevado a cabo durante el estudio, desde su inicio, con el planteamiento del problema, hasta la obtención de las conclusiones extraídas del mismo. 


\subsection{METODOLOGÍA DE INVESTIGACIÓN}

En este capítulo, presentamos el proceso metodológico que diseñamos para realizar nuestra investigación. El primer paso, consiste en elegir un determinado diseño de investigación desde la perspectiva empírico-analítica adoptada. A continuación, determinaremos las variables o características sobre las que recoger la información y las herramientas que usaremos para su registro, así como la obtención de la población y la selección de la muestra sobre la que intervenir. Consideramos también necesario, exponer el esquema general de las fases del proceso seguido, con la secuencia de tiempos seguida en el trabajo.

Todos los datos fueron recogidos de la misma forma, integrándolos en única base de datos, aplicándose posteriormente, distintas técnicas estadísticas adecuadas al tratamiento de cada variable y objetivos formulados.

\subsubsection{Planteamiento del problema}

En odontología moderna cada día se utilizan más los implantes osteointegrados como solución a la ausencia de piezas dentales (Misch, 2009). Este crecimiento es progresivo, pues en 2002 se colocaron 10 veces más implantes que en 1982, esperando además, un crecimiento del 9,4\% para los próximos años (Yuasa \& Sugiura, 2004).

Está demostrado, que la población general sufre ansiedad en la consulta odontológica y que además, como se cita en el apartado Ansiedad, en la página 77, aumenta claramente cuando el paciente se va a someter a cirugía de implantes dentales (Brand, et al., 1995, Eli, et al., 1997, Soh \& Yu, 1992, Wong \& Lytle, 1991). Esto es debido a que actualmente la cirugía implantológica no es predecible en cuanto a los síntomas postoperatorios que va a padecer el paciente, debido a la existencia de escasa literatura centrada, exclusivamente, en el postoperatorio implantológico.

Por lo tanto, pensamos que si se hace una evaluación exhaustiva de los síntomas postoperatorios de esta clase de cirugía, así como de la duración de los mismos, podremos 


\section{Capitulo 3: Material y Métodos}

predecir con antelación, qué postoperatorio va a padecer cada paciente individualmente y que fármacos se deben prescribir para el alivio del dolor y la inflamación postoperatorios.

\subsubsection{Diseño de investigación}

El presente trabajo de investigación consiste en un estudio epidemiológico longitudinal prospectivo, en el que se han analizado la prevalencia del dolor, la inflamación y el hematoma postoperatorio, después de la colocación de implantes dentales, mediante muestreo probabilístico no consecutivo.

Se llevó a cabo un estudio prospectivo, considerando a todos los pacientes consecutivos de una clínica de odontología general, en la que se practica cirugía de manera habitual. Los estudios retrospectivos, ofrecen menor probabilidad de prejuicios y en ellos se pueden obtener mayor número de datos, pero en los prospectivos, obtenemos mejor estandarización y uniformidad de evaluación. Se realizó un protocolo de diagnóstico, manteniendo el mismo criterio de trabajo durante todo el estudio.

\section{A) Definición del diseño}

Los principales objetivos de la investigación epidemiológica son, por un lado, describir la distribución de las enfermedades y eventos de salud en poblaciones humanas y, por otro, contribuir al descubrimiento y caracterización de las leyes que gobiernan o influyen en estas condiciones.

El diseño de investigación elegido fue por tanto, un "diseño epidemiológico experimental", pues se realizó la manipulación de una exposición determinada en un grupo de individuos, comparándola a su vez, con otros sometidos a la misma exposición.

Dentro de los diseños experimentales, nuestro estudio es un "ensayo clínico", el estudio experimental más frecuente. En ellos los sujetos son pacientes y se evalúan uno o más tratamientos para una enfermedad o proceso. La validez de este estudio radica, principalmente, en que el proceso aleatorio haga los grupos comparables, en las variables más relevantes en relación al problema estudiar.

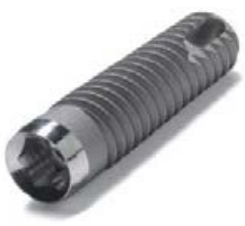


Los ensayos clínicos son los mejores estudios experimentales pero, aunque tienen muchas ventajas con respecto a otro tipo de estudios, también pueden presentar una serie de limitaciones:

Tabla 6: Ventajas y limitaciones de los ensayos clínicos.

\begin{tabular}{|c|c|}
\hline VENTAJAS & LIMITACIONES \\
\hline - Mayor control en el diseño. & $\bullet$ Coste elevado. \\
\hline $\begin{array}{c}\text { Menor posibilidad de sesgos debido a la } \\
\text { selección aleatoria de los grupos. }\end{array}$ & $\begin{array}{c}\text { - Limitaciones de tipo ético y } \\
\text { responsabilidad en la manipulación de la } \\
\text { exposición. }\end{array}$ \\
\hline Repetibles y comparables con otras \\
experiencias. & $\begin{array}{c}\text { Dificultades en la generalización debido } \\
\text { a la selección y/o la propia rigidez de la } \\
\text { intervención. }\end{array}$ \\
\hline
\end{tabular}

\section{B) Elementos del diseño}

Hipótesis. Como hipótesis principales del estudio experimental, se propusieron comprobar las siguientes:

- El grado de dolor, inflamación y hematoma que sufren los pacientes sometidos a cirugía de colocación de implantes dentales.

- Qué factores tienen una relación directa con el postoperatorio que padecen los pacientes sometidos a este tipo de intervención.

- Si la medicación que se prescribió a los pacientes fue suficiente para controlar el postoperatorio quirúrgico.

- Qué variables de todas las estudiadas presentan una relación importante con el dolor, la inflamación y el hematoma postoperatorio, aunque ésta no sea estadísticamente significativa. 


\section{Capitulo 3: Material y Métodos}

Diseño. El diseño de investigación seleccionado para responder a las hipótesis anteriores, fue de tipo experimental con un único grupo de estudio.

Variables e instrumentos. Desde un punto de vista metodológico, las variables consideradas en el estudio experimental se denominan variables dependientes, independientes e intervinientes o de control:

- Dependientes: constituyen el objeto de la investigación, siendo la característica sobre la que se espera que se produzcan los cambios o los efectos de la variable independiente. En nuestro caso, será el postoperatorio que padecen los pacientes sometidos a cirugía implantológica.

- Independientes: son aquellas sobre las que se interviene y que modificarán a las dependientes, sobre las cuales se observará la incidencia producida. Nuestro trabajo cuenta como variable independiente, la colocación de implantes dentales.

- De control: es un tipo de variable independiente que no se manipula, sino que se mantiene constante para neutralizar sus efectos sobre la variable dependiente.

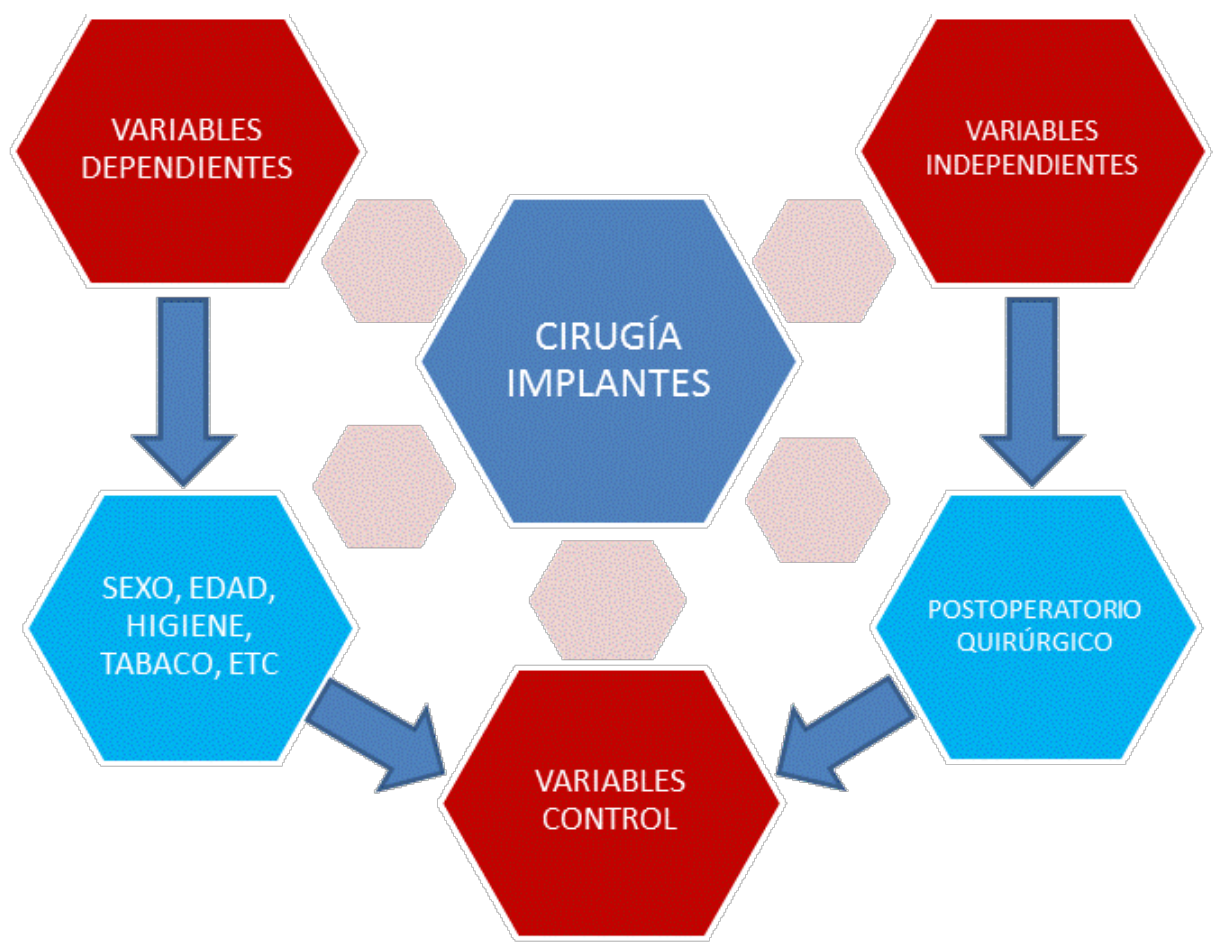

Figura 27: Variables implicadas en el estudio. 
Instrumentos de recogida de datos. Las variables dependientes se recogieron por medio de cuestionarios de datos, que se rellenaron antes y después de la cirugía.

El estudio se diseñó para realizar un seguimiento a través de un protocolo de recogida de datos, en el que recogimos información acerca del paciente y de la cirugía a la que se iba a someter (Anexo 2. Datos generales y preoperatorios).

En este cuestionario, se recogieron todos los datos de filiación que eran de interés para el estudio, como:

- Edad: al paciente se le pidió la fecha de nacimiento y se anotó su edad en el momento de la cirugía.

- Sexo: se anotó si era hombre una "H" y si era mujer una "M".

- Fumador: este apartado se dividió en tres grupos: el primero de ellos era el de los no fumadores que se englobaron en el apartado "NO", si el paciente era fumador de 10 o menos cigarrillos al día quedaba anotado en el grupo de " $\leq 10$ ", mientras que si fumaba más de 10 cigarrillos al día se englobaba en el grupo ">10".

- Higiene: aquí también se establecieron tres grupos: si el paciente se cepillaba los dientes tres veces al día con regularidad, se colocó en el grupo de "Buena", si lo hacía dos veces al día se anotó en el grupo de "Regular" y si era menos de dos veces al día se reflejó en el grupo de "Mala".

- Enfermedades actuales: en este apartado se anotaron las enfermedades que padecían los pacientes en el momento de la cirugía.

- Medicación actual: aquí se anotó qué medicamentos estaban tomando los pacientes en el momento de la intervención.

- Alergias: por último se anotó si el paciente padecía alguna alergia.

En el mismo cuestionario se recogieron, también, todos los datos sobre la cirugía a la que se iba a someter el paciente y que eran relevantes para el análisis posterior.

- Tipo de edentulismo: en primer lugar se anotó si los implantes fueron colocados en un extremo, sin que hubiera dientes posteriores a dichos implantes, en este 


\section{Capitulo 3: Material y Métodos}

caso se apuntaron en el grupo "extremo libre"; en un segundo apartado se anotaron los implantes colocados entre dos o más piezas dentarias, en el grupo de "espacio interdental" y, por último, si los implantes se colocaron en una arcada sin piezas dentarias, se apuntaban en el grupo de "completo".

- Número de implantes: en este apartado se apuntaban el número de implantes que se iban a colocar al paciente y, además, la anchura, longitud y marca comercial del implante.

- Localización: aquí en primer lugar se apuntaba si el implante se colocaba en la parte superior de la arcada "Maxilar superior" o si se hacía en la parte inferior "Mandibular". Por otro lado, la arcada se dividía en anterior, cuando el implante era colocado del segundo premolar en adelante incluyendo dicha pieza, anotándose en este caso "Ant." y si, por el contrario, iba colocado del segundo premolar hacia detrás se anotaba como "Post.".

- Colgajo: se anotó también, si se precisó la realización de un colgajo de despegamiento en la cirugía.

- Sedación: se reflejó si al paciente se le aplicó sedación consciente.

- Regeneración ósea: en este apartado se anotaba si, además de la colocación del implante, se iba a practicar alguna técnica de regeneración ósea, para aumentar el volumen óseo disponible.

- Elevación de seno: aquí se marcaba si al paciente se le iba a practicar elevación sinusal directa o indirecta.

En último lugar, se registraba la medicación que se administrada al paciente después de la cirugía.

A los pacientes se les explicó antes de salir del gabinete que debían rellenar un cuestionario durante los 7 días posteriores a la cirugía (Anexo 4. Datos postoperatorios).

Este cuestionario estaba formado por cuatro partes:

En la primera, figuraba una escala E.V.A. (Escala Visual Analógica) de 0 a 10, siendo 0 (sin dolor) y 10 (dolor extremo), donde los pacientes tenían que anotar, durante los siete días posteriores a la intervención, qué grado de dolor habían padecido.

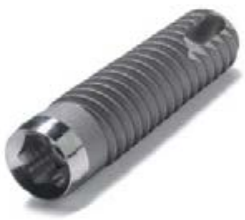


Posteriormente debajo de esta escala los tres apartados restantes, correspondían a dolor, inflamación y hematoma. En todas ellos existía un recuadro donde los pacientes tenían que marcar, con un aspa, qué grado de dolor, inflamación y hematoma habían sufrido a las $12,24,48$ horas y en el $3^{\circ}, 5^{\circ}$ y $7^{\circ}$ día, posteriores a la intervención. Los pacientes disponían de cuatro opciones para valorar el dolor, la inflamación y el hematoma que eran: ausencia, ligero, moderado o fuerte.

Población y muestra. La población estudiada se compuso de 200 pacientes, a los que les fueron colocados 470 implantes dentales, entre Enero de 2008 y Diciembre de 2011.

Análisis de datos. Los análisis estadísticos idóneos para esta clase de información son de carácter descriptivo (medidas de tendencia central y de desviación) e inferenciales (pruebas no paramétricas, pues la muestra no se comportó de manera normal), en base a los objetivos específicos de esta fase del estudio. Se utilizó el programa estadístico SPSS 21.0. 
Capitulo 3: Material y Métodos

\subsection{TÉCNICA QUIRÚRGICA}

Para la colocación de implantes dentales se tuvieron en cuenta dos momentos temporales muy importantes.

Una primera fase preoperatoria, en la que se realizó el diagnóstico del caso, estableciendo criterios básicos como necesidad de regeneración ósea previa o simultánea a la colocación de los implantes dentales, número de ellos, medidas de los mismos, etc.

Y una segunda en la que se estudió el procedimiento quirúrgico a seguir con cada paciente intervenido, para prevenir adecuadamente las complicaciones que se pudieran derivar de la cirugía, así como para la preparación del material requerido con cada paciente.

El procedimiento quirúrgico que se sigue para colocar un implante dental no es complejo, pero intervienen muchos factores que se deben controlar antes de la cirugía y durante la misma, para evitar complicaciones mayores que las del propio acto quirúrgico.

\subsubsection{Diagnóstico}

Historia médica y odontológica. El primer paso que seguimos en todos los pacientes a los que se les se colocaron implantes dentales, fue comprobar su estado de salud general y bucodental. Los pacientes que presentaban algún problema bucodental fueron remitidos al odontólogo general para su tratamiento y conseguir con ello un estado bucodental correcto antes de la cirugía (Anexo 5. Historia médica y odontológica).

En este punto, fue muy importante valorar si el paciente era fumador y, en caso de serlo, conocer el número de cigarrillos que fumaba al día, así como el grado de higiene que presentaba antes de la cirugía, pues son dos aspectos importantes respecto a la integración y postoperatorio implantológicos.

En nuestro estudio, todos los pacientes sometidos a la colocación de implantes dentales fueron tratados, una semana antes, con una profilaxis dental para mantener lo más higiénica posible la cavidad oral antes de la intervención. 


\section{VNiVERSIDAD \\ BSALAMANCA

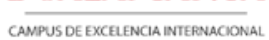

Diagnóstico implantológico. Después de la revisión médica y odontológica del paciente, se procedió al estudio de todas las variables que intervienen en el tratamiento implantológico como son: la cantidad y calidad ósea remanente en la zona a intervenir, espacio para la corona protésica, análisis de las angulaciones de dientes vecinos, cantidad de carga que van a recibir los implantes, estudio de estructuras anatómicas adyacentes a la zona de la intervención, etc.

La gran mayoría de los pacientes fueron sometidos a un escáner dental, para valorar el grado de soporte óseo remanente en la zona donde se iban a colocar los implantes dentales. En este punto, se valoró el tipo de implante que se iba a colocar (longitud, anchura, etc.), y si el paciente precisaba regeneración ósea o elevación de seno, bien previa a la colocación de los implantes o bien simultánea a la misma.

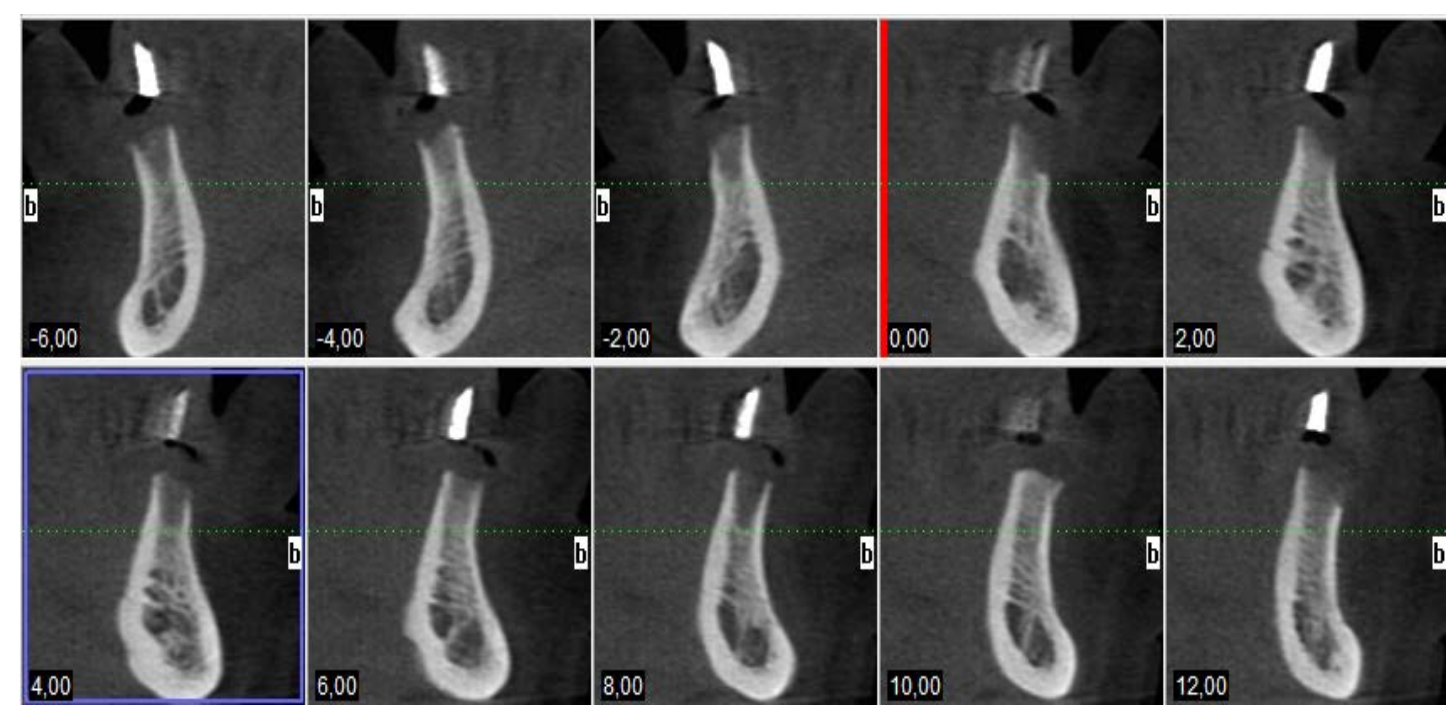

Figura 28: Cortes de un escáner dental para colocar un implante en posición 42.

Una vez comprobados estos aspectos, se procedió a realizar la férula quirúrgica que iba a servir de guía durante la colocación de los implantes dentales. Ésta sólo se practicó para casos con buena disponibilidad ósea, pues los casos complejos requirieron una visión directa de la zona intervenida. 
Capitulo 3: Material y Métodos

\subsubsection{Acto quirúrgico}

Preparación del campo quirúrgico. Todas las cirugías para la colocación de implantes dentales se realizaron en un ambiente aséptico siguiendo los principios de la técnica quirúrgica limpia descrita en el apartado A) Preparación del campo quirúrgico, en la página 36.

El cirujano y las auxiliares que participaron, activamente, en la cirugía usaron guantes, gorro, bata y mascarilla estériles y desechables, mientras que todo el material que se utilizó en la cirugía como la pieza de mano, bisturí, periostótomos, fresas de ostectomía, etc., se encontraban a su vez, limpios y estériles.

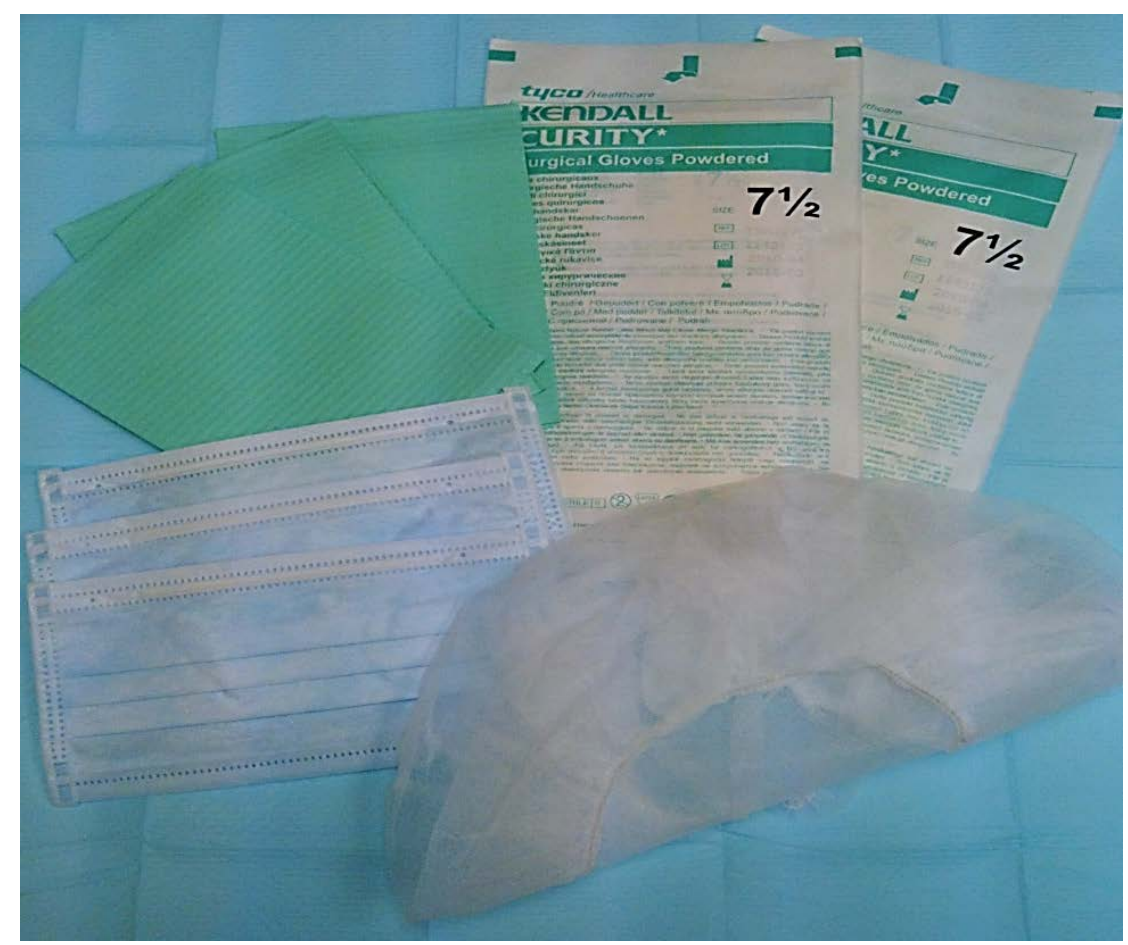

Figura 29: Set quirúrgico para implantología oral (gorros, guantes, mascarilla y baberos estériles).

$\mathrm{Al}$ paciente se instó a rellenar el consentimiento informado y se le practicó, previa a la cirugía, una asepsia extraoral mediante la colocación de gorro y babero estéril y también intraoral, aplicándole enjuagues de clorhexidina al $0,12 \%$, dos o tres veces antes de la intervención (Anexo 6. Consentimiento informado).

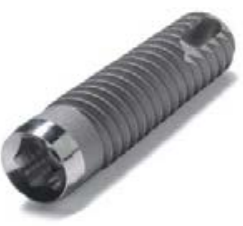




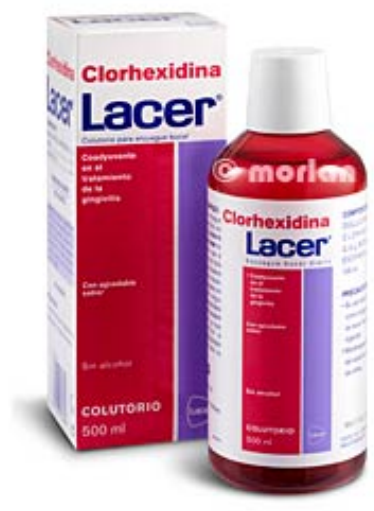

Figura 30: Colutorio oral con clorhexidina para asepsia intraoral.

Anestesia. Todos los pacientes intervenidos, fueron anestesiados con una solución de articaína hidrocloruro con epinefrina al 0,5\% (Ultracain ${ }^{\circledR}$ ). La dosis de anestésico inyectado varió en función de la cantidad de implantes colocados, así, se utilizó un carpule y medio de anestésico por cada implante a colocar, siendo 7 u 8 carpules el máximo de anestésico utilizado por paciente.

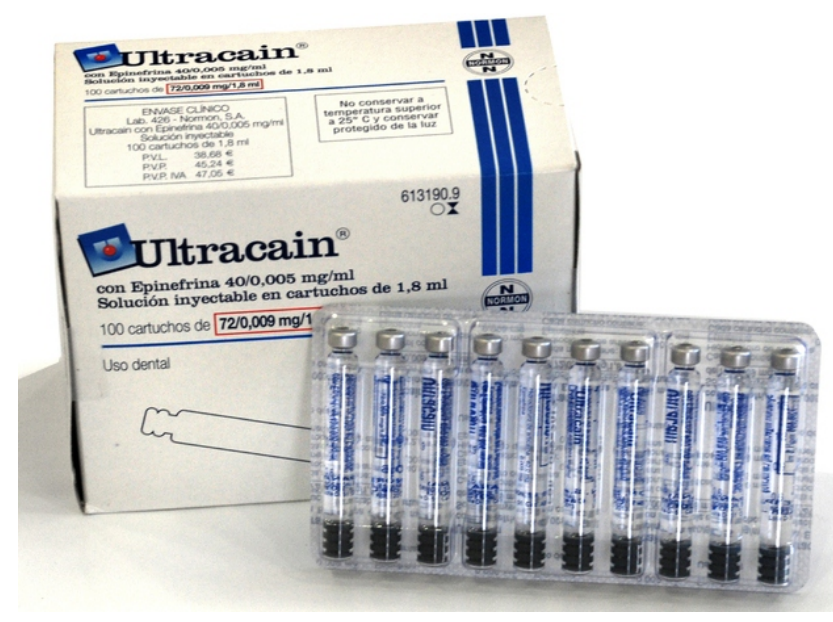

Figura 31: Anestésico utilizado para la colocación de implantes dentales.

Incisión. Todas las incisiones realizadas en las cirugías se llevaron a cabo con hoja de bisturí número 15 (recta), con bisturí circular o con hoja de bisturí número 12 (curva). 
Capitulo 3: Material y Métodos

Como se describe en el apartado C) Incisión, en la página 39, dependiendo de la disponibilidad ósea y del estado de los tejidos blandos se practicaron distintios tipos de incisiones; mínimamente invasiva (bisturí circular), incisión paracrestal sin descargas (hoja número 15) e incisiones paracrestales con descargas mesiales y distales (hojas de bisturí 15 y 12).

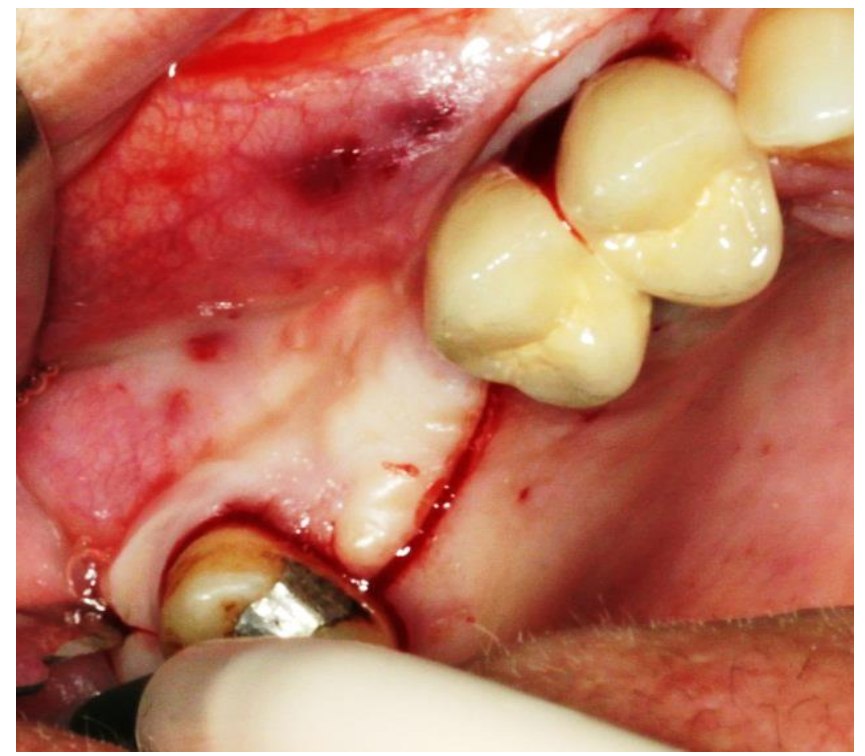

Figura 32: Incisión paracrestal con descargas mesiales y distales.

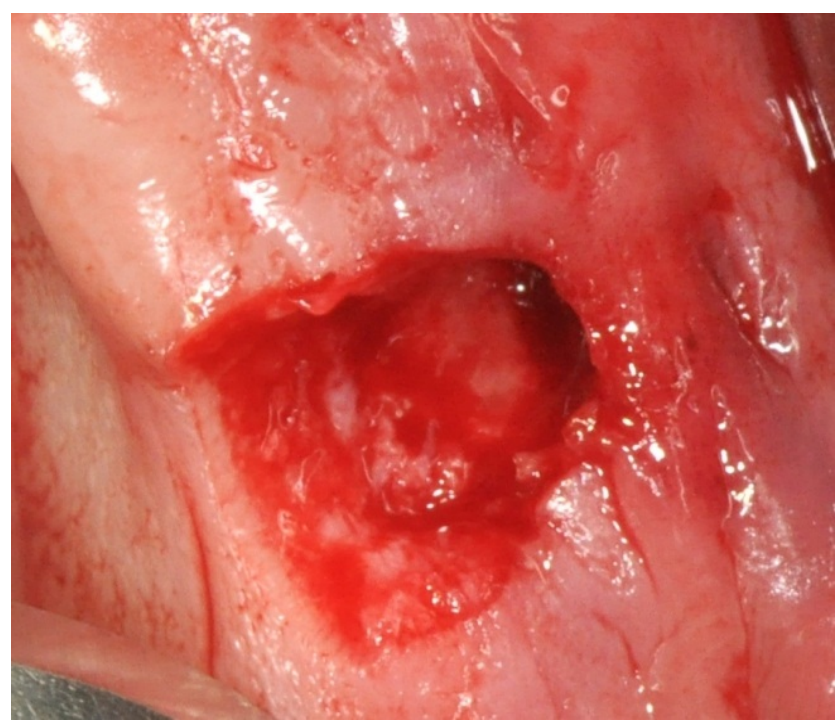

Figura 33: Incisión mínimamente invasiva con el bisturí circular.

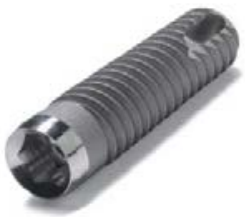


Ostectomía. Se realizó la incisión y separación del colgajo y se colocó, en la boca del paciente la férula o guía quirúrgica. Una vez ubicada ésta en la posición correcta se precedió al fresado óseo con la fresa piloto o inicial a una velocidad de $1200 \mathrm{rpm}$ y abundante irrigación. A continuación, se usó la secuencia de fresas de la caja quirúrgica. Todas las fresas se insertaron a la misma longitud que la del implante a colocar, aumentado la anchura progresivamente, hasta conseguir una anchura ligeramente inferior a la del implante que se pretendía colocar.

Tabla 7: Secuencia de fresado para la clocación de implantes dentales.

\begin{tabular}{|c|c|c|c|c|c|c|}
\hline \multicolumn{5}{|c|}{ SECUENCIA DE FRESADO } & $\begin{array}{c}\text { DIÁMETRO } \\
\text { IMPLANTE }\end{array}$ \\
\hline Piloto & $2,3 \mathrm{~mm}$. & $2,3 \mathrm{~mm}$. & - & - & - & Implante 3,3 mm. \\
\hline Piloto & $2,3 \mathrm{~mm}$. & $2,3 \mathrm{~mm}$. & $3,4 \mathrm{~mm}$. & - & - & Implante 3,7 mm. \\
\hline Piloto & $2,3 \mathrm{~mm}$. & $2,3 \mathrm{~mm}$. & $3,4 \mathrm{~mm}$. & $3,8 \mathrm{~mm}$. & - & Implante 4,1 mm. \\
\hline Piloto & $2,3 \mathrm{~mm}$. & $2,3 \mathrm{~mm}$. & $3,4 \mathrm{~mm}$. & $3,8 \mathrm{~mm}$. & $4,3 \mathrm{~mm}$. & Implante 4,7 mm. \\
\hline
\end{tabular}

Colocación del implante. Terminado el fresado del lecho óseo, se irrigó la zona con abundante suero salino y se aspiró para eliminar posibles restos de tejido óseo. La colocación de los implantes se realizó siempre de manera mecánica, mediante un micromotor con una fuerza de 50 newton, aunque la mayoría de los implantes fueron introducidos en su parte final, de manera manual, usando una carraca quirúrgica. 
Capitulo 3: Material y Métodos

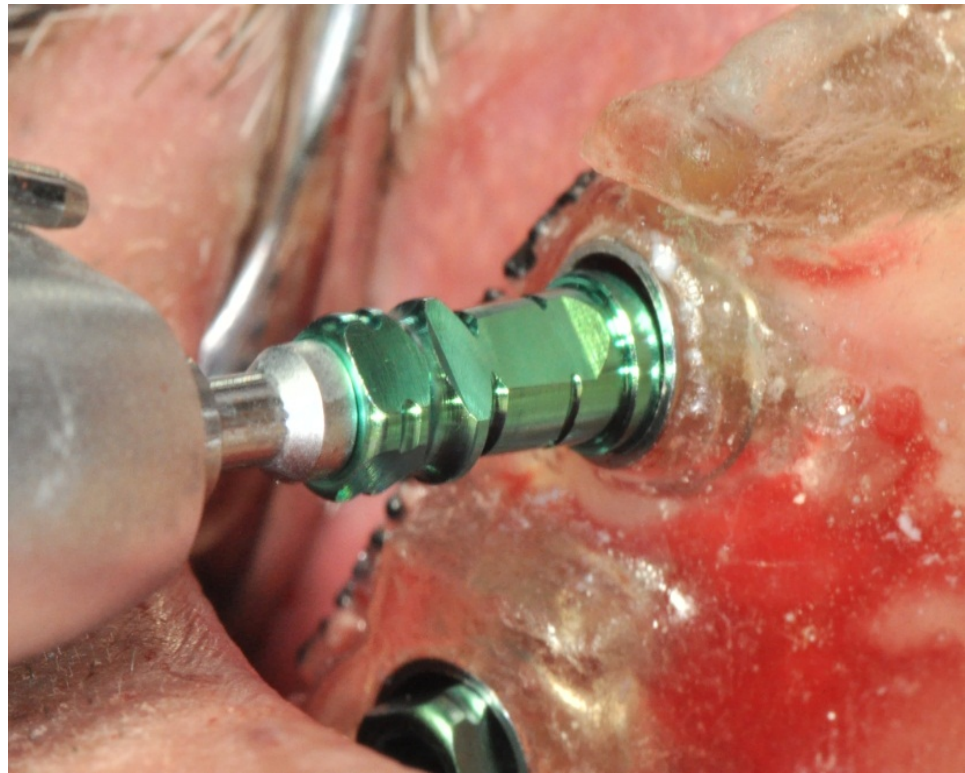

Figura 34: Colocación de un implante dental mediante micromotor.

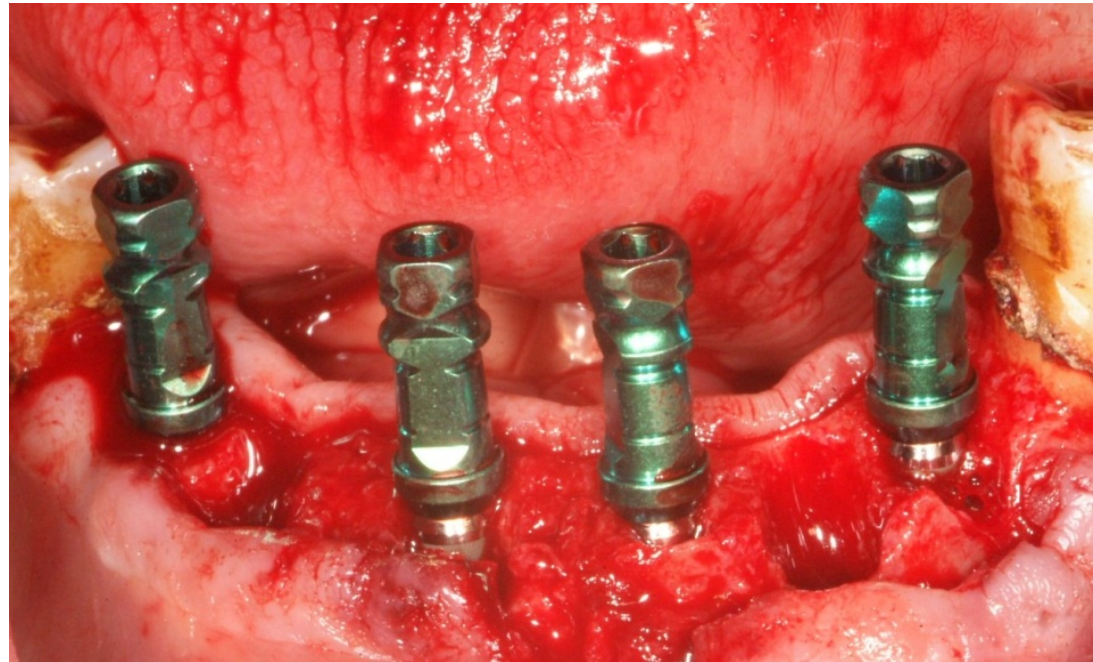

Figura 35: Implantes colocados de manera manual en caninos e incisivos inferiores.

Sutura. Todos los colgajos se cerraron con puntos simples utilizando seda trenzada de 3 y 4 ceros, salvo en casos en los que se combinaron la colocación de implantes dentales con técnicas de regeneración ósea, pues en éstos se utilizó seda trenzada y sutura reabsorbible, siendo el ácido poliglicólico la sutura de elección. 


\section{VNiVERSIDAD \\ BSALAMANCA \\ CAMPUS DE EXCELENCIA INTEPNACIONAL}

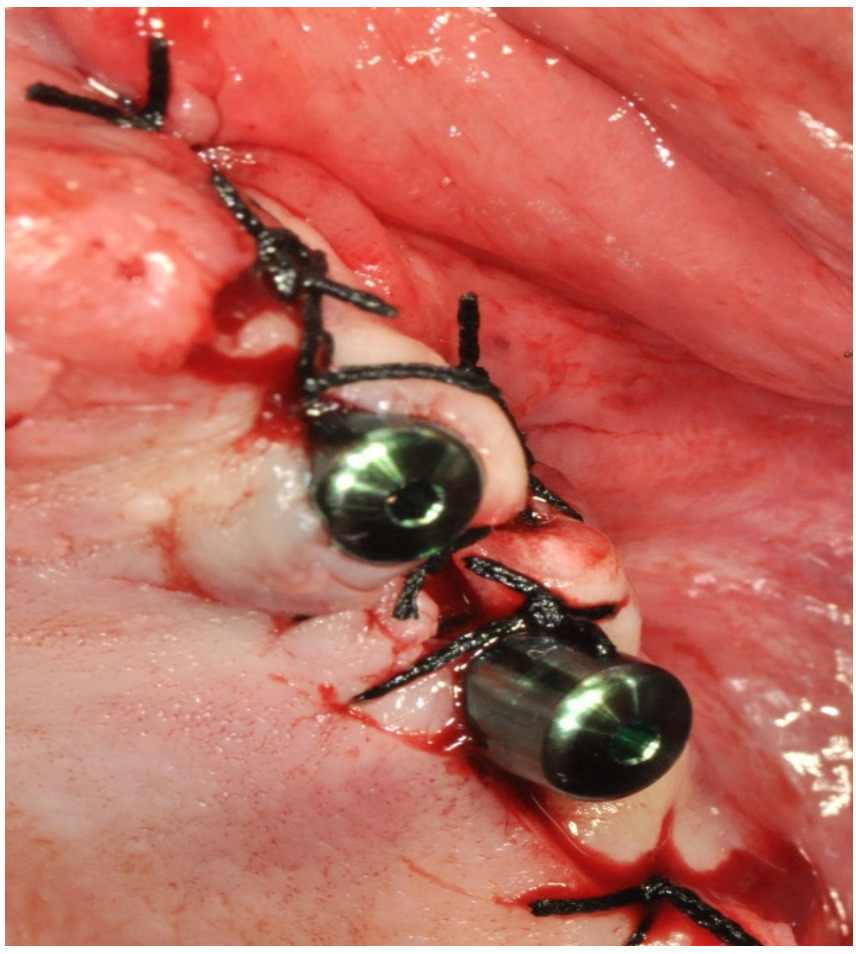

Figura 36: Colgajo suturado con seda de 3 ceros.

Comprobación radiográfica. Después de la cirugía, se realizó una radiografía periapical o panorámica para comprobar la correcta colocación de los implantes dentales.

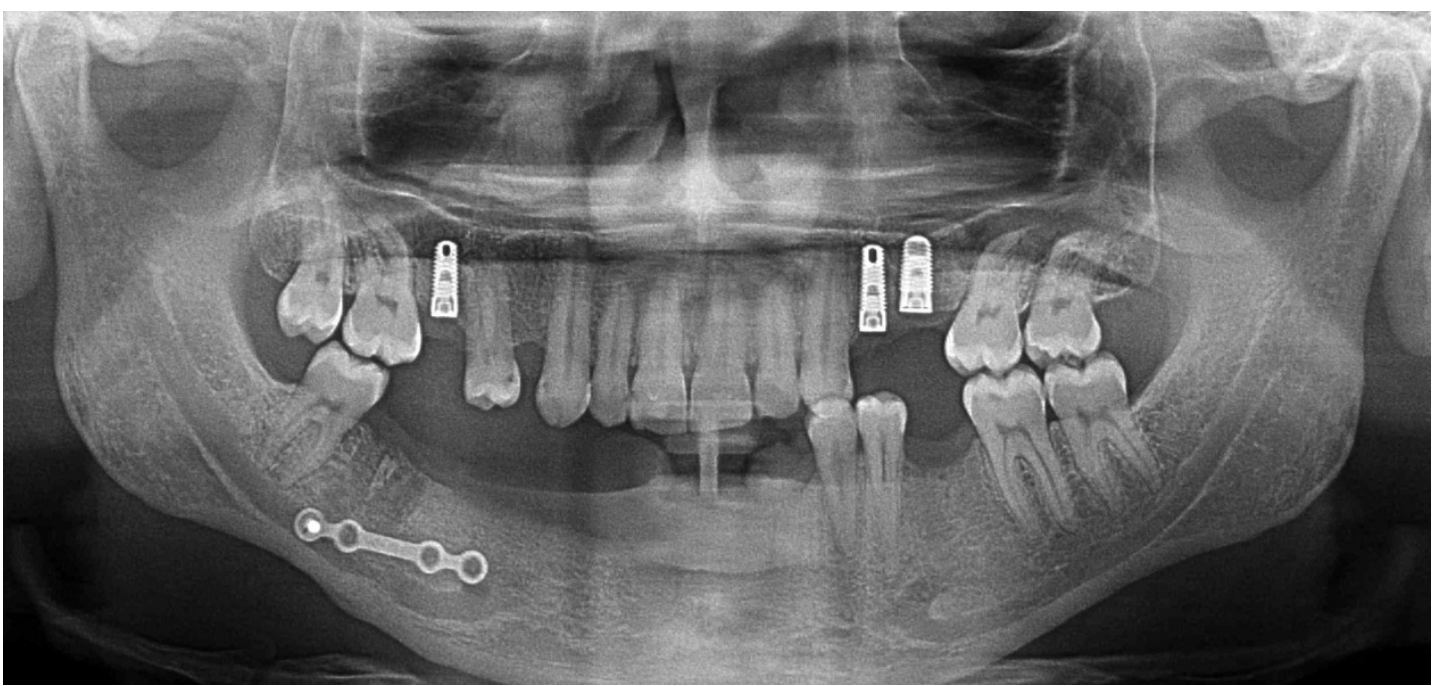

Figura 37: Implantes colocados en posición 16, 24 y 25 con elevación sinusal indirecta. 


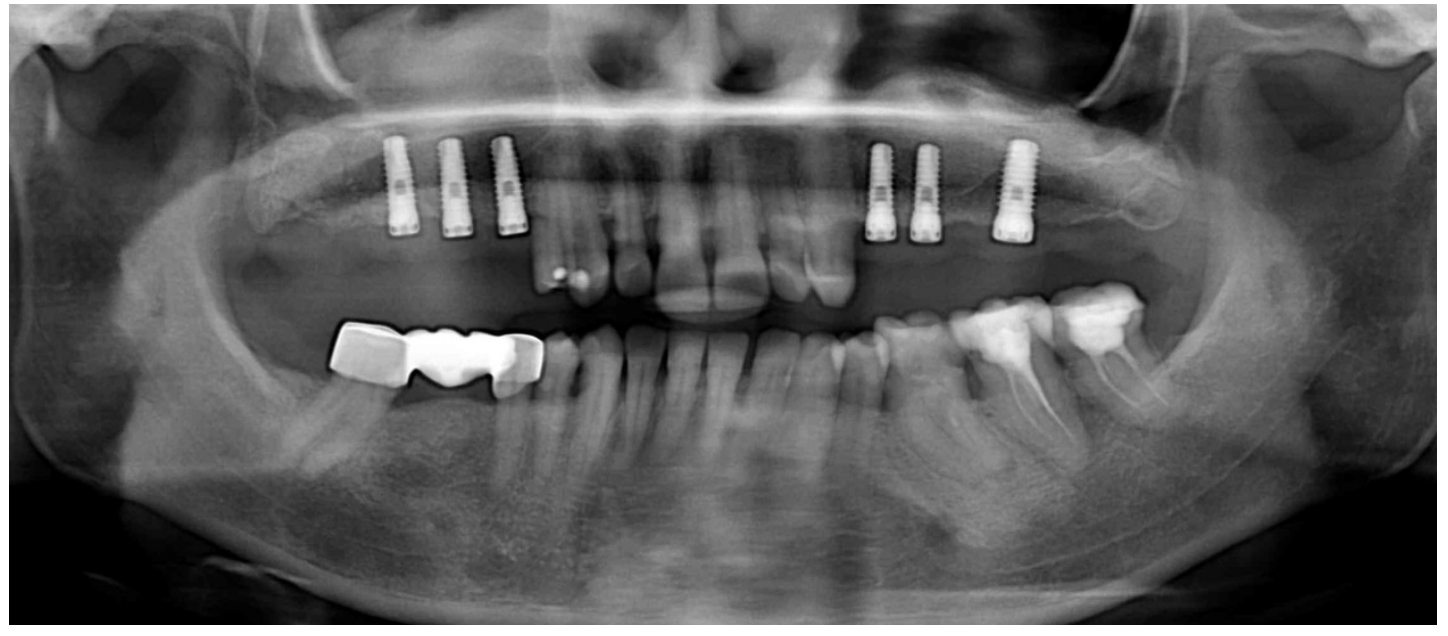

Figura 38: Implantes colocacdos en posición 15, 16, 17, 24, 25 y 27 con elevación sinusal directa bilateral.

Medidas prequirúrgicas y postquirúrgicas. Antes de la cirugía, se practicó a todos los pacientes una profilaxis dental para eliminar la placa bacteriana.

Existe evidencia científica sobre el beneficio de la administración de clorhexidina por medio de enjuague, gel o spray en el postoperatorio, sin embargo, su aplicación prequirúrgica no está tan estudiada, por lo que en nuestros pacientes se redujo su administración a dos enjuagues, 10 minutos antes de la cirugía.

Después de la cirugía se prescribió a todos los pacientes antibiótico, antiinflamatorio y analgésico. El antibiótico de elección fue amoxicilina más ácido clavulánico de $500 \mathrm{mg}$. y eritromicina de $500 \mathrm{mg}$. en alérgicos a la penicilina, el antiinflamatorio elegido fue ibuprofeno de $600 \mathrm{mg}$. y el analgésico fue metamizol de $575 \mathrm{mg}$., todos ellos administrados por vía oral, cada 8 horas durante los 7 días posteriores a la intervención.

El tratamiento antiinflamatorio y analgésico comenzó, en todos los casos, inmediatamente después de la cirugía, administrando ibuprofeno de $600 \mathrm{mg}$. En nuestro caso y debido a la bibliografía consultada no se prescribió analgésico ni antiinflamatorio antes de la cirugía. 
Para finalizar, después de esta primera medicación se les explicó y entregó por escrito a todos los pacientes las instrucciones que debían seguir para realizar un postoperatorio correcto (Anexo 3. Instrucciones postquiríryicas). 


\subsection{OPERATIVIZACIÓN DE LAS VARIABLES}

A continuación, se presenta la tabla con la definición operativa de las variables utilizadas en el estudio.

Tabla 8: Operativización de las variables utilizadas.

\begin{tabular}{|c|c|c|c|}
\hline \multicolumn{4}{|c|}{ OPERATIVIZACIÓN DE LAS VARIABLES } \\
\hline Denominación & Nombre & Etiqueta & $\begin{array}{l}\text { Descripción } \\
\text { Categórica }\end{array}$ \\
\hline \multicolumn{4}{|c|}{ DATOS GENERALES DEL PACIENTE } \\
\hline $\begin{array}{c}\text { Variable } \\
\text { Independiente }\end{array}$ & EDAD & Edad & $\begin{array}{c}\text { Variable numérica } \\
\text { entre } 22 \text { y } 82 \text { (ambos } \\
\text { inclusive) }\end{array}$ \\
\hline $\begin{array}{c}\text { Variable } \\
\text { Independiente }\end{array}$ & SEXO & Sexo & $\begin{array}{c}\text { Variable nominal } \\
\text { con } 2 \text { alternativas } \\
\text { excluyentes: } \\
1 \text { Hombre } \\
2 \text { Mujer }\end{array}$ \\
\hline $\begin{array}{c}\text { Variable } \\
\text { Independiente }\end{array}$ & HIGIENE & Higiene & $\begin{array}{c}\text { Variable nominal } \\
\text { con } 3 \text { alternativas } \\
\text { excluyentes: } \\
1 \text { Vez al día } \\
2 \text { Veces al día } \\
3 \text { Veces al día }\end{array}$ \\
\hline $\begin{array}{c}\text { Variable } \\
\text { Independiente }\end{array}$ & FUMADOR & Fumador & $\begin{array}{c}\text { Variable nominal } \\
\text { con } 3 \text { alternativas } \\
\text { excluyentes: } \\
0 \text { No fumador } \\
1 \text { Fumador } \leq 10 \\
2 \text { Fumador }>10\end{array}$ \\
\hline
\end{tabular}




\begin{tabular}{|c|c|c|c|}
\hline $\begin{array}{c}\text { Variable } \\
\text { Independiente }\end{array}$ & $\begin{array}{c}\text { ENFERMEDADES } \\
\text { ACTUALES }\end{array}$ & $\begin{array}{l}\text { Enfermedades } \\
\text { actuales }\end{array}$ & $\begin{array}{c}\text { Variable nominal } \\
\text { con dos alternativas } \\
\text { excluyentes: } \\
0 \mathrm{No} \\
1 \mathrm{Si}\end{array}$ \\
\hline $\begin{array}{c}\text { Variable } \\
\text { independiente }\end{array}$ & $\begin{array}{l}\text { MEDICACIÓN } \\
\text { ACTUAL }\end{array}$ & $\begin{array}{l}\text { Medicamentos que } \\
\text { toma actualmente }\end{array}$ & $\begin{array}{c}\text { Variable nominal } \\
\text { con } 2 \text { alternativas } \\
\text { excluyentes: } \\
0 \mathrm{No} \\
1 \mathrm{Si}\end{array}$ \\
\hline $\begin{array}{c}\text { Variable } \\
\text { independiente }\end{array}$ & ALERGIAS & Alergias & $\begin{array}{c}\text { Variable nominal } \\
\text { con } 3 \text { alternativas } \\
\text { excluyentes: } \\
0 \mathrm{No} \\
1 \mathrm{Si}\end{array}$ \\
\hline \multicolumn{4}{|c|}{ DATOS PREOPERATORIOS DEL PACIENTE } \\
\hline $\begin{array}{l}\text { Variable } \\
\text { Independiente }\end{array}$ & $\begin{array}{c}\text { TIPO DE } \\
\text { EDENTULISMO }\end{array}$ & Tipo de edentulismo & $\begin{array}{c}\text { Variable nominal } \\
\text { excluyente con } 3 \\
\text { alternativas: } \\
1 \text { Extremo libre } \\
2 \text { Espacio interdental } \\
3 \text { Completo }\end{array}$ \\
\hline $\begin{array}{l}\text { Variable } \\
\text { Independiente }\end{array}$ & $\begin{array}{l}\text { NÚMERO DE } \\
\text { IMPLANTES }\end{array}$ & $\begin{array}{l}\text { Número de } \\
\text { implantes }\end{array}$ & $\begin{array}{l}\text { Variable numérica } \\
\text { entre } 1 \text { y } 8 \text { (ambos } \\
\text { inclusive) }\end{array}$ \\
\hline
\end{tabular}




\begin{tabular}{|c|c|c|c|}
\hline $\begin{array}{c}\text { Variable } \\
\text { Independiente }\end{array}$ & LOCALIZACIÓN & Localización & $\begin{array}{c}\text { Variable nominal } \\
\text { con } 4 \text { alternativas: } \\
1 \text { Maxilar } \\
2 \text { Mandibular } \\
1 \text { Anterior } \\
2 \text { Posterior }\end{array}$ \\
\hline $\begin{array}{c}\text { Variable } \\
\text { Independiente }\end{array}$ & $\begin{array}{c}\text { REGENERACIÓN } \\
\text { ÓSEA }\end{array}$ & Regeneración ósea & $\begin{array}{c}\text { Variable nominal } \\
\text { con } 2 \text { alternativas } \\
\text { excluyentes: } \\
0 \mathrm{No} \\
1 \mathrm{Si}\end{array}$ \\
\hline $\begin{array}{c}\text { Variable } \\
\text { Independiente }\end{array}$ & $\begin{array}{c}\text { ELEVACIÓN DE } \\
\text { SENO }\end{array}$ & Elevación de seno & $\begin{array}{c}\text { Variable nominal } \\
\text { con dos alternativas } \\
\text { excluyentes: } \\
0 \mathrm{No} \\
1 \mathrm{Si}\end{array}$ \\
\hline $\begin{array}{c}\text { Variable } \\
\text { independiente }\end{array}$ & SEDACIÓN & Sedación & $\begin{array}{c}\text { Variable nominal } \\
\text { con } 2 \text { alternativas } \\
\text { excluyentes: } \\
0 \mathrm{No} \\
1 \mathrm{Si}\end{array}$ \\
\hline $\begin{array}{c}\text { Variable } \\
\text { independiente }\end{array}$ & COLGAJO & Colgajo & $\begin{array}{c}\text { Variable nominal } \\
\text { con } 2 \text { alternativas } \\
\text { excluyentes: } \\
0 \mathrm{No} \\
1 \mathrm{Si}\end{array}$ \\
\hline \multicolumn{4}{|c|}{ DATOS POSTOPERATORIOS DEL PACIENTE } \\
\hline $\begin{array}{c}\text { Variable } \\
\text { Independiente }\end{array}$ & $\begin{array}{c}\text { ESCALA VISUAL } \\
\text { ANALÓGICA } \\
\text { (E.V.A.) }\end{array}$ & $\begin{array}{c}\text { Escala visual } \\
\text { analógica (E.V.A.) }\end{array}$ & $\begin{array}{c}\text { Variable numérica } \\
\text { entre } 0 \text { y } 10\end{array}$ \\
\hline
\end{tabular}




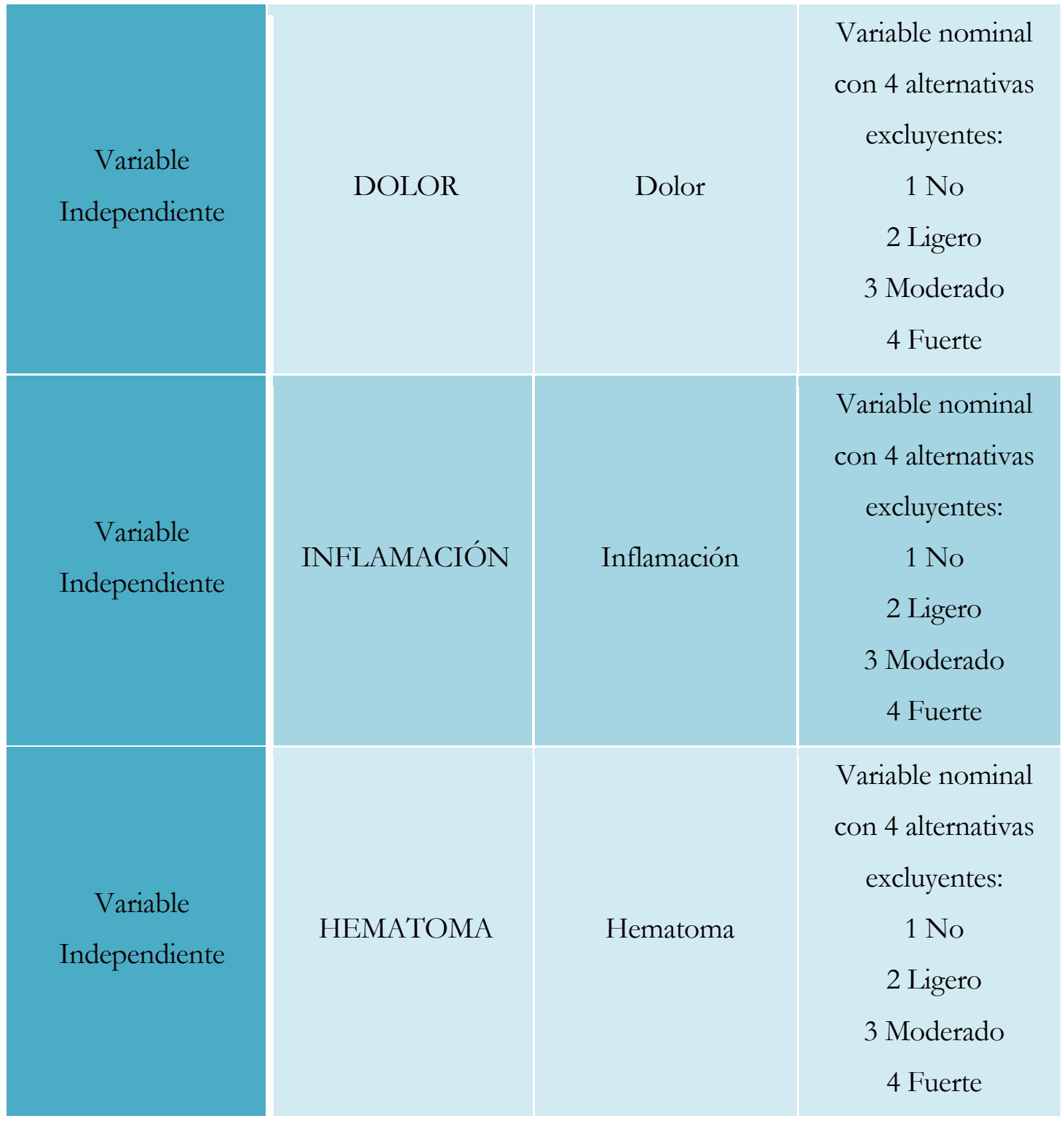


Capitulo 3: Material y Métodos

\subsection{POBLACIÓN Y MUESTRA}

Se define la población objeto de estudio, como el conjunto de pacientes que acudieron a la clínica dental privada entre Enero de 2008 y Diciembre de 2011.

Además, la muestra queda conformada con las siguientes características que limitan el número total de intervinientes en el estudio:

- Los integrantes de la muestra tenían edades entre 22 y 82 años ambos inclusive.

- Todos presentaban buen estado bucodental previo a la intervención.

- Ninguno padecía enfermedades de gravedad previas.

Se estudiaron 213 pacientes, de los que 13 se descartaron por no cumplir los criterios de inclusión del estudio. Se les colocaron 470 implantes durante un período de 3 años. A todos se les pidió el consentimiento informado por escrito (Anexo 6. Consentimiento informado).

Los implantes dentales fueron colocados en el mismo gabinete dental, por el mismo especialista con la ayuda del mismo auxiliar y, siempre se siguió el mismo protocolo quirúrgico.

Tabla 9: Datos de la muestra.

\begin{tabular}{c|c|}
\cline { 2 - 2 } Lugar & Clínica Dental Albucasis \\
\hline Período & $2008-2011$ \\
\hline Pacientes incluidos & 200 \\
\hline Pacientes excluidos & 13 \\
\hline Implantes colocados & 470
\end{tabular}




\subsection{ANÁLISIS EXPERIMENTAL}

En este punto se describen las interacciones existentes entre el cirujano y su auxiliar con el grupo experimental, en el trascurso y desarrollo de la intervención, desde la toma de contacto inicial, antes de la cirugía, hasta su última visita 7 días después de la intervención.

En primer lugar, se exploró a todos los pacientes comprobando que su salud general y bucodental, eran adecuados para realizar cirugía de colocación de implantes dentales.

Una vez comprado su estado general y bucodental, se les explicaba la intervención, el postoperatorio y la duración aproximada de ambos.

Antes de comenzar se rellenaba el cuestionario de datos preoperatorios (Anexo 2. Datos generales y preoperatorios) y una vez terminada la cirugía, se le entregaba a cada paciente el cuestionario de recogida de datos postoperatorios y se les explicaba como debían rellenarlo (Anexo 4. Datos postoperatorios).

Después la auxiliar les citaba para comprobar su evolución a los 3 días de la intervención y luego a los 7 días. En este momento, se retiraban los puntos de sutura y se recogía el cuestionario completado por el paciente. 
Capitulo 3: Material y Métodos

\subsection{TÉCNICAS DE ANÁLISIS DE DATOS}

La información obtenida en las distintas fases de la investigación y la contenida en los cuestionarios de estudio, se han conjuntado e incluido en el programa estadístico SPSS 21.0. con licencia perteneciente a la Universidad de Salamanca. Este proceso fue realizado con la colaboración de la profesora Dña. $\mathrm{M}^{\mathrm{a}}$ Purificación Galindo Villardón, directora del Departamento de Estadística, Facultad de Medicina, Universidad de Salamanca.

En esta fase de la investigación, el análisis estadístico de los datos tiene por objeto proporcionar respuestas a las hipótesis planteadas, mediante técnicas analíticas estadísticas, en un paradigma cuantitativo, trasformando los datos en resultados.

Con ello se quiere decir, que los resultados obtenidos de las técnicas estadísticas aplicadas, no sólo han de ser estadísticamente significativos, sino que han de tener significación sustantiva y dar respuesta a las cuestiones planteadas.

\section{MÉTODOS ESTADÍSTICOS}

\section{MÉTODOS UNI Y BIVARIANTES}

- Técnicas descriptivas: se realizó un análisis descriptivo de la muestra completa y de los diferentes grupos, utilizando como medida de tendencia central la media aritmética simple y como medidas de dispersión la desviación típica y/o el error estándar, para analizar la representatividad de la muestra. En los casos en los que los datos no se ajustaron a una ley normal, se utilizó la mediana al efectuar los correspondientes contratses no paramétricos como explicaremos más adelante.

- Técnicas inferenciales (experimentales): se realizaron para estudiar la relación entre las variables explicativas y la respuesta. La elección del estadístico de contraste más adecuado y el modelo teórico al cual se ajusta esta variable aleatoria, se hace tras analizar la normalidad y/o homocedasticidad de las muestras, así como los correspondientes tamaños muestrales y si los datos eran independientes o apareados. Este análisis aporta la explicación del comportamiento o el efecto de las variables independientes sobre las dependientes. 


\section{VNIVERSIDAD}

BSALAMANCA

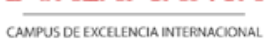

Diferenciaremos el tratamiento según que las dos variables de estudio sean cuantitativas, las dos cualitativas o una cualitativa y la otra cuantitativa. En este caso, distinguiremos además si la variable cualitativa es dicotómica o multicotómica.

En todos los casos se tomaron como significativos, p-valores menores de 0,05.

La normalidad de los datos se estudió con el test de Kolmogorov-Smirnov y la homocedasticidad/heterocedasticidad con el test de Levenne.

- Kolmogorov-Smirnov. La prueba de Kolmogorov-Smirnov se utiliza para el análisis de una muestra mediante un procedimiento de bondad de ajuste, es decir, permite la medición del grado de concordancia existente entre la distribución de un conjunto de datos y una distribución teórica específica. También nos da a conocer si la muestra se distribuye de modo normal, lo cual nos permitirá elegir, posteriormente, los contrastes a utilizar.

Si los datos se ajustaban a un modelo normal y la variable independiente era diotócmica y la dependiente cuantitativa, se utilizó el test " $\mathrm{t}$ " de Student.

- Test " $t$ "-Student. En probabilidad y estadística, la distribución- $t$ o distribución t de Student, es una medida de probabilidad que surge del problema de estimar la media de una población, normalmente distribuida, cuando el tamaño de la muestra es pequeño. Esta situación se plantea cuando se están comparando dos grupos con relación a una variable cuantitativa. Técnicamente se puede describir la prueba $\mathrm{T}$ de Student como aquella que se utiliza en un modelo en el que una variable explicativa (variable independiente) dicotómica, intenta explicar una variable respuesta (variable dependiente) dicotómica. La "t" de Student se basa, como todos los estadísticos de contraste, en el cálculo de estadísticos descriptivos previos: el número de observaciones, la media y la desviación típica de cada grupo. A través de ellos se calcula el estadístico de contraste experimental. Posteriormente, con la ayuda de unas tablas se obtiene a partir de dicho estadístico, el p-valor. Si el valor de p es menor de $0,05(\mathrm{p}<0,05)$, se concluye que existe diferencia entre las dos variables estudiadas. 
Capitulo 3: Material y Métodos

La fórmula utilizada es, por tanto, la siguiente:

$$
t=\frac{\bar{X}_{1}-\bar{X}_{2}}{S_{X_{1} X_{2}} \cdot \sqrt{\frac{2}{n}}}
$$

Donde

$$
S_{X_{1} X_{2}}=\sqrt{\frac{1}{2}\left(S_{X_{1}}^{2}+S_{X_{2}}^{2}\right)}
$$

Las hipótesis para poder aplicar la t de student es, que en cada grupo la variable estudiada siga una distribución normal y que la dispersión en ambos grupos, sea homogénea. Por lo tanto, la hipótesis nula (Ho) se dará, cuando las diferencias observadas entre las variables de estudio se deban al azar, mientras que la hipótesis alterna $(\mathrm{Ha})$ se dará, cuando existan diferencias entre las dos variables estudiadas.

En cuanto al nivel de significación, se concluyen dos aspectos:

- Para todo valor de probabilidad igual o menor que 0,05 , se acepta la Ha y se rechaza la Ho.

- Para todo valor de probabilidad mayor que 0.05 , se acepta Ho y se rechaza Ha.

Como nuestros datos no se ajustaban a una ley normal se utilizó la correspondiente versión no paramétrica de la "t" de Student, concretamente la U de Mann-Whitney, para datos independientes y el test de Wilcoxon para datos apareados, los cuales comparan medianas en lugar de medias.

- U-Mann Whitney. En estadística, la prueba de U-Mann Whitney o de MannWilcoxon-Whitney, es una medida no paramétrica con la cual se identifican diferencias entre dos poblaciones basadas en el análisis de dos muestras independientes, cuyos datos han sido medidos en una escala ordinal. Esta prueba es la versión no paramétrica de la prueba, "t" de Student. 
La prueba calcula el denominado estadístico $U$, cuya distribución, para muestras con más de 20 observaciones, se aproxima bastante bien a la distribución normal. La aproximación a la normal, ₹ cuando tenemos muestras lo suficientemente grandes, viene dada por la expresión:

$$
z=\left(U-m_{U}\right) / \sigma_{U}
$$

Donde $\mathrm{m}_{\mathrm{U}} \mathrm{y} \sigma_{\mathrm{U}}$ son la media y la desviación estándar de $U$, si la hipótesis nula es cierta, y vienen dadas por las siguientes fórmulas:

$$
\begin{gathered}
m_{U}=n_{1} n_{2} / 2 \\
\sigma_{U}=\sqrt{\frac{n_{1} n_{2}\left(n_{1}+n_{2}+1\right)}{12}}
\end{gathered}
$$

La hipótesis nula (Ho) se dará, cuando las diferencias observadas entre las variables de estudio se deban al azar, mientras que la hipótesis alterna $(\mathrm{Ha})$ se dará, cuando existan diferencias entre las dos variables estudiadas.

Nivel de significación: para todo valor de probabilidad igual o menor que 0,05, se acepta Ha y se rechaza Ho.

Zona de rechazo: para todo valor de probabilidad mayor que 0,05 , se acepta Ho y se rechaza Ha.

Si la variable independiente era multicotómica y la dependiente cuantitativa, se utilizó el Analisis de la Varianza, para garantizar el control del error tipo I (rechazo indebido de la hipótesis nula de independencia), o su correspondiente versión no paramétrica, el test de Kruskal-Wallis, cuando los datos no se ajustaban a un modelo normal.

- Análisis de la varianza (ANOVA). El análisis de la varianza (ANOVA) es una técnica estadística de contraste de hipótesis. El análisis de la varianza (o Anova: Analysis of variance) es un método para comparar dos o más medias, que es necesario, porque 


\section{Capitulo 3: Material y Métodos}

cuando se quiere comparar más de dos medias, es incorrecto utilizar repetidamente el contraste basado en la t de Student.

Para utilizar ANOVA de forma satisfactoria, deben cumplirse tres tipos de hipótesis, aunque se aceptan ligeras desviaciones de las condiciones ideales:

1. Cada conjunto de datos debe ser independiente del resto.

2. Los resultados obtenidos para cada conjunto deben seguir una distribución normal

3. Las varianzas de cada conjunto de datos no deben diferir de forma significativa.

Esencialmente, el diseño para el análisis simple de la varianza consistirá, en obtener muestras aleatorias e independientes del valor de $\mathrm{Y}$ asociado a cada uno de los distintos niveles del factor X1, X2,..., Xn. Entonces podremos determinar, si los diferentes niveles del factor, tienen un efecto significativo sobre el valor de la variable dependiente.

El funcionamiento de la técnica ANOVA simple es, a grandes rasgos, el siguiente: a fin de comparar las medias de $\mathrm{Y}$ asociadas a los distintos niveles del factor $(\mathrm{X} 1, \mathrm{X} 2, \ldots, \mathrm{Xn})$, compararemos una medida de la variación entre diferentes niveles (MS-factor), con una medida de la variación dentro de cada nivel (MS-error). Si el MS-factor es significativamente mayor que el MS-error, concluiremos que las medias asociadas a diferentes niveles del factor son distintas. Esto significa que el factor influye significativamente sobre la variable dependiente Y. Si, por el contrario, el MS-factor no es significativamente mayor que el MS-error, no rechazaremos la hipótesis nula de que todas las medias asociadas a diferentes niveles del factor, coinciden.

- Kruskal Wallis. La prueba de Kruskal-Wallis no requiere distribuciones normales. Por ello es la que se adecúa a la distribución de nuestras variables. Es una prueba no paramétrica que utiliza rangos de datos muestrales de tres o más poblaciones independientes. Se utiliza para probar la hipótesis nula de que las muestras independientes provienen de poblaciones con medianas iguales; la hipótesis 
alternativa es la aseveración de que las poblaciones tienen medianas que no son iguales.

H0: Las muestras provienen de poblaciones con medianas iguales.

H1: Las muestras provienen de poblaciones con medianas que no son iguales.

En el caso de que las dos variables de estudio fueran cuantitativas se utilizó el coeficiente de correlación de Pearson y/o el coeficiente Rho de Spearman (versión no paramétrica para casos de no normalidad). Igual que en el caso anterior, se tomaron como significativos, p-valores menores de 0,05 .

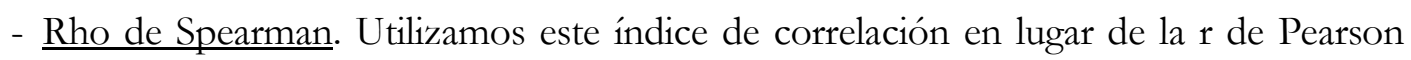
como aproximación no paramétrica, pues las variables de nuestra muestra no se distribuyen de forma normal. El coeficiente de correlación (sea o no paramétrico) es un valor adimensional que oscila entre $-1 \mathrm{y}+1$. El valor cero se da cuando no existe ninguna correlación entre las variables analizadas; el valor -1 implica una correlación perfecta de carácter inverso (o indirecto) y el valor +1 una correlación perfecta de tipo directo (cuando una crece también lo hace la otra).

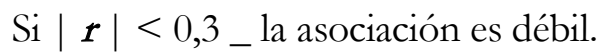

Si $0,30_{-}|\boldsymbol{r}|{ }_{-} 0,70_{-}$la asociación es moderada.

Si $|\boldsymbol{r}|>0,70 \_$la asociación es fuerte.

Cuando las dos variables eran categóricas se utilizó el test Chi-cuadrado. El grado de asociación se evaluó con el Coeficiente de Contingencia.

- Chi-cuadrado. La prueba de independencia Chi-cuadrado, nos permite determinar si existe una relación entre dos variables categóricas. Es necesario resaltar que esta prueba nos indica si existe o no una relación entre las variables, pero no el grado o el tipo de relación; es decir, no indica el porcentaje de influencia de una variable sobre la otra o la variable que causa la influencia. 
Capitulo 3: Material y Métodos

La prueba chi-cuadrado de contingencia, sirve para comprobar la independencia de frecuencias entre dos variables aleatorias.

Las hipótesis contrastadas en la prueba son:

- Hipótesis nula: las dos variables son independientes.

- Hipótesis alternativa: las dos variables no son independientes (no importa cuál sea la relación que mantengan ni el grado de ésta).

La fórmula utilizada en este caso es la siguiente:

$$
\sum_{i j} \frac{\left(O_{i j}-E_{i j}\right)^{2}}{E_{i j}} \approx \chi^{2}
$$

Todos estos tests pueden consultarse en "Bioestadística para las Ciencias de la Salud" de A. Martín y en "Estadística multivariante y no paramétrica. Aplicación a las ciencias de la salud" de R. Álvarez. Por tratarse de tests básicos, muy conocidos, entendemos que no requieren más explicación (Álvarez, 1995, Martín \& Luna, 2004).

\section{MÉTODOS MULTIVARIANTES}

Los métodos multivariantes son menos conocidos, por eso explicaremos con cierto nivel de detalle el Método en Componentes Principales, que hemos utilizado en esta investigación.

Comenzamos justificando el ínteres del uso de este método.

En el postoperatorio disponemos de información relativa a dolor, inflamación y hematoma, todas y cada una de estas variables evaluadas a las 12, 24, 48 horas y 3,5 y 7 días.

Evidentemente, podíamos optar por efectuar tantos contrates por parejas como fuera posible, siguiendo el método tradicional, pero el elevado número de comparaciones nos llevaría, sin duda, a declarar contrastes estadísticamente significativos que en realidad responden a incrementos en el riesgo Tipo 1. Por esta razón, realizamos un análisis

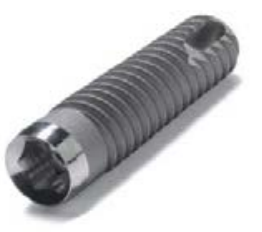


multivariante con el objetivo de simplificar la dimensionalidad del problema, es decir, construir variables latentes, combinaciones lineales de las de partida que recojan la información más relevante y nos permitan encontrar los patrones de dolor, inflamación y hematoma.

El Análisis Factorial Exploratorio (EFA) es una técnica estadística que examina una matriz de correlaciones entre las variables observables, como punto de partida para intentar identificar grupos de variables que verifiquen que hay fuerte correlación entre ellas y baja correlación con las variables de los otros grupos. De esta menera, es posible cambiar muchas variables observables por unas pocas variables latentes, combinación lineal de las de partida que capturan la mayor parte de la información y nos permiten simplificar el problema.

\section{El modelo factorial lineal}

Dadas las variables $\mathrm{X}_{1}, \ldots, \mathrm{X}_{\mathrm{n}}$ buscamos $n+m$ variables incorreladas (con $m$ mínima, $m<n$ siempre), $\mathrm{F}_{1}, \ldots, \mathrm{F}_{\mathrm{m}}$ (factores comunes) y $\mathrm{U}_{1}, \ldots, \mathrm{U}_{\mathrm{n}}$ (factores únicos) de modo que:

$$
\left(\begin{array}{c}
X_{1} \\
\vdots \\
X_{n}
\end{array}\right)=\left(\begin{array}{ccc}
a_{11} & \square & a_{1 m} \\
\vdots & \ddots & \vdots \\
a_{n 1} & \cdots & a_{n m}
\end{array}\right) \cdot\left(\begin{array}{c}
F_{1} \\
\vdots \\
F_{m}
\end{array}\right)+\left(\begin{array}{c}
d_{1} U_{1} \\
\vdots \\
d_{n} U_{n}
\end{array}\right)
$$

donde:
$a_{i j} \quad$ saturación de $X_{i}$ en $F_{j}$
$\mathrm{a}_{\mathrm{ij}}^{2}$ contribución de $\mathrm{F}_{\mathrm{j}}$ a la variabilidad total de $\mathrm{X}_{\mathrm{i}}$
$\mathrm{d}_{\mathrm{i}}^{2}$ contribución de $\mathrm{U}_{\mathrm{i}}$ a la variabilidad total de $\mathrm{X}_{\mathrm{i}}$
$\mathrm{h}_{\mathrm{i}}^{2} \quad$ comunalidad de $\mathrm{X}_{\mathrm{i}}(=\quad 2 \mathrm{a}$ 
Capitulo 3: Material y Métodos

El objetivo es buscar la matriz $A=\left(a_{i j}\right)$, para lo cual hay varias técnicas, entre las que cabe citar:

1. Método del factor principal.

2. Análisis en Componentes Principales.

3. Método de Máxima Verosimilitud.

En nuestro caso hemos utilizado como método de estimación de la matriz factorial el Análisis en Componentes Principales, el cual prescinde de las unicidades y captura sólo la información común.

Esto equivale a calcular los valores y vectores propios directamente de la matriz de correlaciones de las variables originales, pues este método no exige estimar las comunalidades, ya que todas valen uno.

Los vectores propios de la matriz de correlaciones son las componentes principales (nuevas variables latentes, incorreladas y con máxima capacidad informativa) y los valores propios permiten cuantificar la variabilidad de esas nuevas variables latentes.

Cada valor propio dividido por la suma de todos los valores propios nos permite conocer la importancia de cada eje factorial.

La suma de los dos primeros valores propios, dividida por la suma total de todos ellos, multiplicada por cien, nos informa sobre la cantidad de inercia (termino físico utilizado en este contexto para hablar de la capacidad informativa), explicada por el primer plano principal. Con análogo razonamiento podemos evaluar la cantidad de información recogida en cualquier otro plano.

\section{Interpretación de los ejes factoriales}

Es muy frecuente, que la solución encontrada en el análisis factorial no sea fácilmente interpretable. Los investigadores generalmente someten la solución a una rotación para conseguir otra que sea más interpretable. Hay muchas alternativas en la

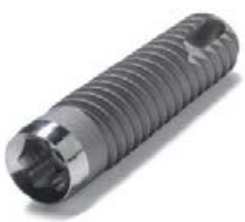


literatura y cualquier programa informático contempla varias. En nuestro caso, hemos optado por la rotación Varimax que proporciona variables latentes incorreladas, por ser ésta la más frecuentemente utilizada.

Los ejes, una vez rotada la solución, se interpretan a través de las saturaciones, que juegan un papel similar al coeficiente d correlación, pero en este caso traducen correlaciones entre las varuables observables y las latentes.

Los factores de carga indican la importancia de las variables en cada eje factorial, pues representan la correlación entre éstas y los factores.

\section{Número de factores a retener}

Una de las cuestiones más importantes en la práctica es decidir el número de variables latentes (también llamados factores o ejes), que debemos retener para captar la información más relevante.

Hay muchos procedimientos estadísticos para determinar el número de factores. Algunos de los usados más frecuentemente son los que señalamos a continuación (Gorsuch, 1974).

- Valores propios mayores que uno. El número de factores estará determinado por el número de valores propios mayores que uno.

- $\quad$ Regla del 75\% de la varianza. El número de factores estará determinado por la absorción de inercia. Se tomarán tantos valores propios como sean necesarios para conseguir un $75 \%$ de inercia absorbida. Por supuesto, se puede trabajar con porcentajes diferentes.

consiste en representar gráficamente los valores propios en orden descendente y dibujar una recta imaginaria a través de los componentes con los valores propios más bajos. Se retienen los componentes que se corresponden con los autovalores que quedan por encima de la línea. 
Capitulo 3: Materialy Métodos

- Especificación del usuario. Es posible especificar personalmente el número de factores. Usualmente no será mayor que el número de variables dividido por dos. En el caso en que se sobrestime este valor, el número será ajustado por el ordenador. 


\subsection{DIAGRAMA DEL PROCESO INVESTIGADOR}

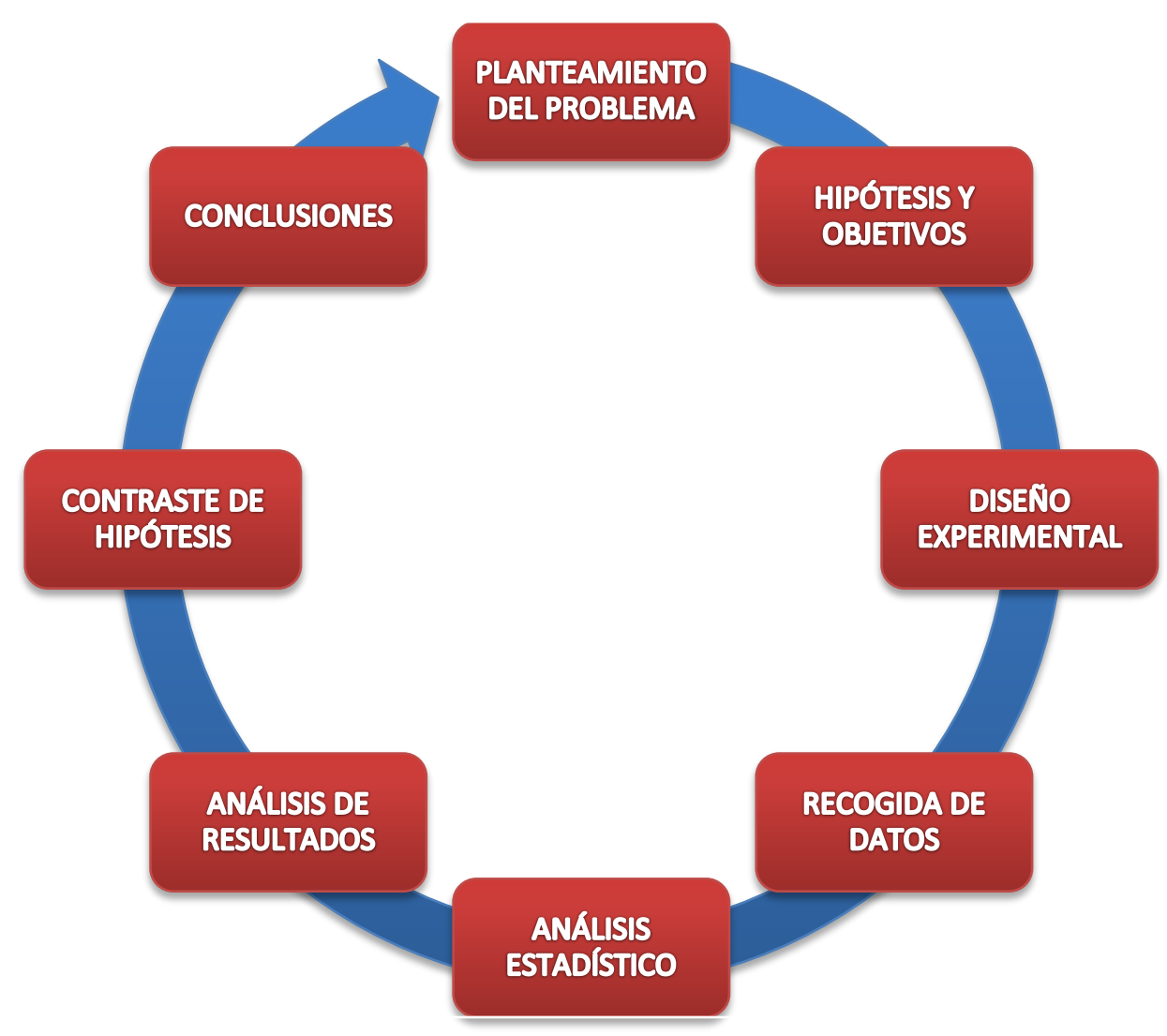

Figura 39: Diagrama del proceso investigador. 


\section{Capítulo 4}

\section{RESULTADOS}



na vez aplicado el diseño experimental sobre el grupo a estudiar e introducidos los datos obtenidos en la aplicacaión estadística SPSS 21.0., se procedió al análisis de los resultados.

Éste se llevó a cabo en distintas fases:

En primer lugar, se transformaron las matrices de datos recogidas de los pacientes para su tratamiento, aplicando cambios en las variables para obtener resultados interpretables. Este proceso, así como, el análisis estadístico completo, fue realizado con la colaboración de la profesora Dña. M $M^{a}$ Purificación Galindo Villardón, directora del Departamento de Estadística, Facultad de Medicina, Universidad de Salamanca.

En segundo lugar, se analizaron los resultados obtenidos del análisis de las características de la población de estudio. En este apartado, se estudiaron los factores que afectan al postoperatorio quirúrgico por parte del paciente y los relacionados con la cirugía. También se valoraron los resultados en cuanto al dolor, inflamación y hematoma sufridos por los pacientes tras la colocación de implantes dentales.

En el tercer apartado, se realizó la comparación de la variable "Dolor E.V.A." con todas las variables estudiadas, para observar cómo se comportaban las mismas, en relación con el dolor padecido por los pacientes durtante el postoperatorio.

Posteriormente, se realizó el análisis del Test no paramétrico Kolmogorov-Smirnov, para determinar qué tipo de prueba estadística era la adecuada para la muestra de estudio. A continuación, con el objetivo de comprobar cómo se comportan las variables del postoperatorio "Dolor", "Inflamación” y "Hematoma", todas ellas a las 12, 24, 48 horas y 3, 5 y 7 días, y establecer la relación entre las variables "Dolor", "Edad" y "Sexo", se realizó un análisis en componentes principales y factorial, respectivamente.

En el último apartado del capítulo, se analizaron los resultados obtenidos de la comparación entre las variables "Dolor", "Inflamación” y "Hematoma" con el resto de ellas. 


\subsection{ADECUACIÓN DE LAS BASES DE DATOS PARA EL ANÁLISIS}

A continuación, se explican las modificaciones realizadas en las bases de datos "Variable de cada implante dental" y "Variables generales y postoperatorias", que se incluyeron en la denominada "Base para trabajar".

Para obtener información sobre la situación del implante, (anterior/posterior y maxilar/mandibular), se crearon siete variables en la base de datos "Variables generales y postoperatorias", con la información procedente de la otra base. La primera, denominada "Situación del implante", que describe, en cada paciente, la ubicación de los implantes: "Mandibular", "Maxilar" o "Ambos"; la segunda, denominada "Anterior o Posterior" que describe la zona de ubicación con categorías: "Anterior", "Posterior", o "Ambos"; las demás variables generadas fueron: "Elevación”, "Regeneración”, "Sedación", "Postextracción” y "Colgajo", todas ellas categorizadas por "Sî" y "No", teniendo en cuenta que si la variable ocurría para al menos uno de los implantes, la respuesta se catalogaba como "Sî".

La edad de los pacientes, se dividió en: "Menor de 50" y "Mayor o igual a 50", utilizando 50 años como punto de corte, por ser el valor más próximo entre la mediana (49 años) y la media $(50,39 \pm 12,781$ años). Se recogió esta información en la variable denominada "InterEdad".

La variable "Dolor E.V.A.” se recodificó creando intervalos, por presentar una clara asimetría negativa. Por este motivo, se creó la variable "DolorEvaInter" en la cual, se incluyeron aquellos pacientes que manifiestaron dolor de 0 a 2 en la escala E.V.A., como "Dolor Tenue" y a los que marcaron 3 o más, se les englobó en el grupo de "Dolor Intenso".

Por último, se dividió también la muestra respecto de la variable "Número de implantes", creando la variable "NumImpInter" y generando tres categorías: "1 implante", "2 implantes" y "3 o más implantes". 


\subsection{ANÁLISIS DESCRIPTIVO}

\subsubsection{Características de los pacientes}

En este apartado, se analizaron las variables relacionadas con los pacientes que fueron sometidos a la colocación de implantes dentales. En primer lugar, se estudiaron las características generales de los pacientes, teniendo en cuenta los resultados obtenidos en las siguientes variables: "Sexo", "Edad", "Fumador", "Higiene", "Enfermedades actuales", "Medicación” y “Alergias” y, en segundo, se estudiaron las características postoperatorias de los pacientes, teniendo en cuenta las siguientes variables: "Número de implantes", "Marca del implante", "Localización del implante”, "Anchura y longitud del implante”, “Tipo de edentulismo", "Regeneración”, “Elevación”, "Postextracción” y “Colgajo”.

\section{A) Características generales}

Los resultados obtenidos, en cuanto a las características generales de los pacientes del estudio, fueron recogidos en este apartado analizando, el sexo, la edad, si eran fumadores o no, el grado de higiene que presentaban, si padecían alguna enfermedad o alergia y si tomaban algún tipo de medicación en el momento de la intervención. Estos resultados fueron los siguientes:

- Sexo: de los 200 pacientes analizados, la proporción de mujeres fue mayor que la de hombres, como muestra la siguiente tabla.

Tabla 10: Frecuencia de la variable "Sexo".

\begin{tabular}{c|c|c|}
\cline { 2 - 3 } & Frecuencia & $\%$ \\
\hline Hombre & 71 & 35,5 \\
\hline Mujer & 129 & 64,5 \\
\hline Total & 200 & 100 \\
\hline
\end{tabular}

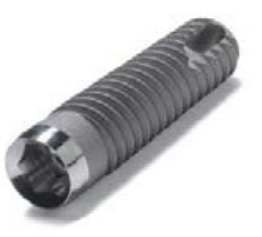


- Edad: el rango de edad de los pacientes incluidos en el estudio se comprendió entre 22 y 82 años, siendo mayor el número de ellos de mediana edad. En la Tabla 11, se puede apreciar que la media de edad fue de 50,39 años, siendo el grupo de entre 40 y 48 años el más numeroso.

Tabla 11: Frecuencia de la variable "Edad".

\begin{tabular}{c|c|c|}
\cline { 2 - 3 } Intervalo Edad & Frecuencia & $\%$ \\
\hline 20-29 años & 11 & 5,5 \\
\hline 30-39 años & 30 & 15,0 \\
\hline $40-49$ años & 59 & 29,5 \\
\hline 50-59 años & 53 & 26,5 \\
\hline 60-69 años & 33 & 16,5 \\
\hline $70-79$ años & 11 & 5,5 \\
\hline 80-89 años & 3 & 1,5 \\
\hline Total & 200 & 100 \\
\cline { 2 - 3 }
\end{tabular}

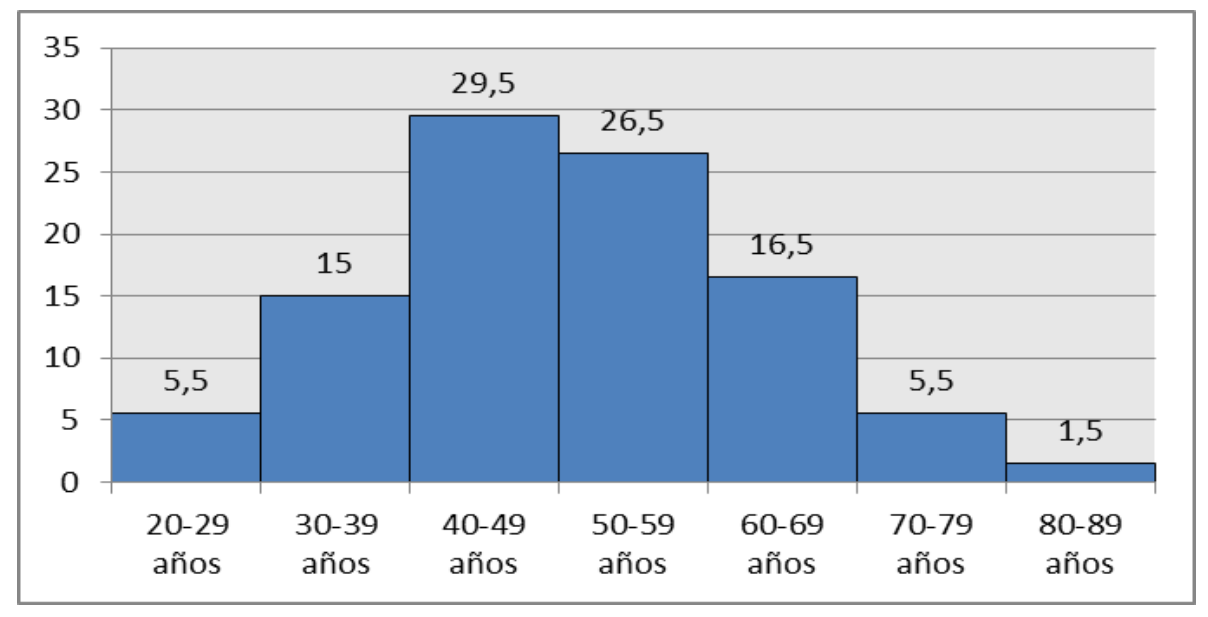

Figura 40: Variable "Edad" por intervalos. 
Capitulo 4: Resultados

- Fumador: los resultados obtenidos en la Tabla 12, reflejan que el 73,5\% de los pacientes no fumaban, el 17,5\% lo hacía de manera moderada (10 o menos cigarrillos al día) y tan sólo un $9 \%$ fumaba más de 10 cigarrillos diarios.

Tabla 12: Frecuencia de la variable "Fumador".

\begin{tabular}{c|c|c|}
\cline { 2 - 3 } Tabaco & Frecuencia & $\%$ \\
\hline No fuma & 147 & 73,5 \\
\hline Fuma 10 o menos cigarrillos al día & 35 & 17,5 \\
\hline Fuma más de 10 cigarrillos al día & 18 & 9,0 \\
\hline Total & 200 & 100 \\
\hline
\end{tabular}

- Higiene: la mayoría de los pacientes estudiados presentaba buena higiene (cepillado 3 veces/día) o higiene regular (cepillado 2 veces/día). En la Tabla 13 , se puede observar que la muestra presentaba en un $62,5 \%$ de los casos buena higiene, el 30,5\% higiene regular y que el grupo con menor número de pacientes fue el de mala higiene, con un 7,5\% de los casos.

Tabla 13: Frecuencia de la variable "Higiene".

\begin{tabular}{c|c|r|}
\cline { 2 - 3 } Higiene & Frecuencia & $\%$ \\
\hline Buena & 124 & 62 \\
\hline Regular & 61 & 30,5 \\
\hline Mala & 15 & 7,5 \\
\hline Total & 200 & 100 \\
\hline
\end{tabular}




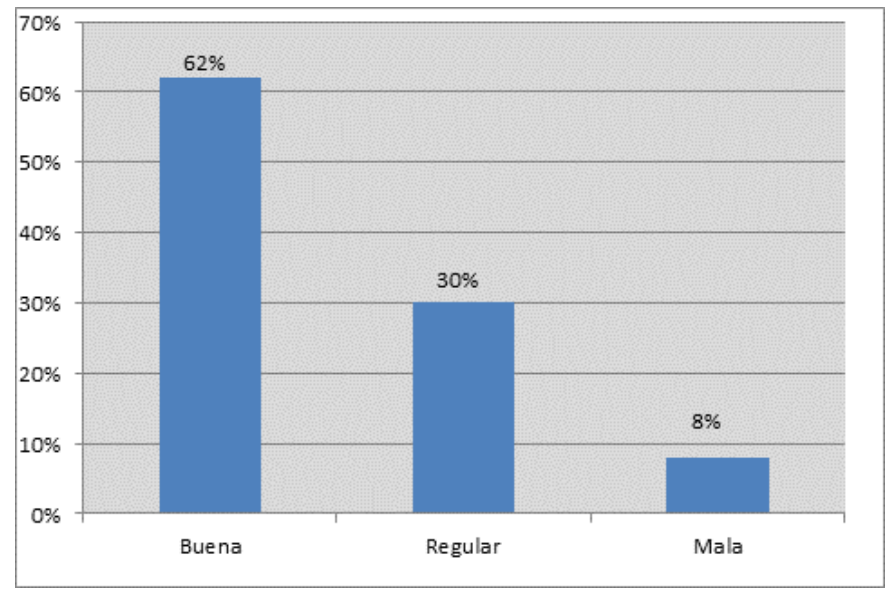

Figura 41: Distribución de la variables "Higiene".

- Enfermedades, medicación y alergias: la gran mayoría de los pacientes estudiados no padecían enfermedades (82\%). El 18\% padecía algún tipo de enfermedad, el $23 \%$ se encontraba en tratamiento con medicación y sólo el $13,5 \%$, sufría algún tipo de alergia.

Tabla 14: Frecuencia de la variable "Enfermedades Actuales".

\begin{tabular}{c|c|c}
\cline { 2 - 3 } Enf. Actuales & Frecuencia & $\%$ \\
\hline Padece & 164 & 82 \\
\hline No padece & 36 & 18 \\
\hline Total & 200 & 100 \\
\hline
\end{tabular}

Tabla 15: Frecuencia de la variable "Medicación".

\begin{tabular}{c|c|c|}
\cline { 2 - 3 } Medicación & Frecuencia & $\%$ \\
\hline Toma & 154 & 77 \\
\hline No toma & 46 & 23 \\
\hline Total & 200 & 100 \\
\hline
\end{tabular}


Tabla 16: Frecuencia de la variable "Alergias".

\begin{tabular}{c|c|c|}
\cline { 2 - 3 } Alergia & Frecuencia & $\%$ \\
\hline Sí & 173 & 86,5 \\
\hline No & 27 & 13,5 \\
\hline Total & 200 & 100 \\
\hline
\end{tabular}

\section{B) Características de la cirugía}

Los datos obtenidos durante la cirugía a la que se sometía el paciente, fueron recogidos en este apartado, analizando el número de implantes que se colocó a cada uno, la marca de los implantes colocados, la localización de los mismos, si el paciente necesitó o no sedación consciente, el tipo de edentulismo que padecía el paciente, si necesitó regeneración ósea o elevación de seno, si se le practicó colgajo o si el implante fue colocado postextracción.

- Número de implantes: se colocaron entre uno y ocho implantes a los 200 pacientes estudiados. En la Tabla 17, se puede observar que la cirugía que más se practicó fue la de colocación de un sólo implante (38,5\%), mientras que la segunda, consistió en la colocación de dos implantes con una proporción del $31,5 \%$. La cirugía que menos veces se realizó, fue la de colocación de siete implantes.

Tabla 17: Frecuencia de la variable "Número de implantes".

\begin{tabular}{c|c|c|}
\cline { 2 - 3 } Número Impl. & Frecuencia & $\%$ \\
\hline 1 implante & 77 & 38,5 \\
\hline 2 implantes & 63 & 31,5 \\
\hline 3 implantes & 18 & 9 \\
\hline 4 implantes & 18 & 9 \\
\hline
\end{tabular}




\begin{tabular}{c|c|c|}
\hline 5 implantes & 8 & 4 \\
\hline 6 implantes & 9 & 4,5 \\
\hline 7 implantes & 1 & 0,5 \\
\hline 8 implantes & 6 & 3 \\
\hline Total & 200 & 100 \\
\hline
\end{tabular}

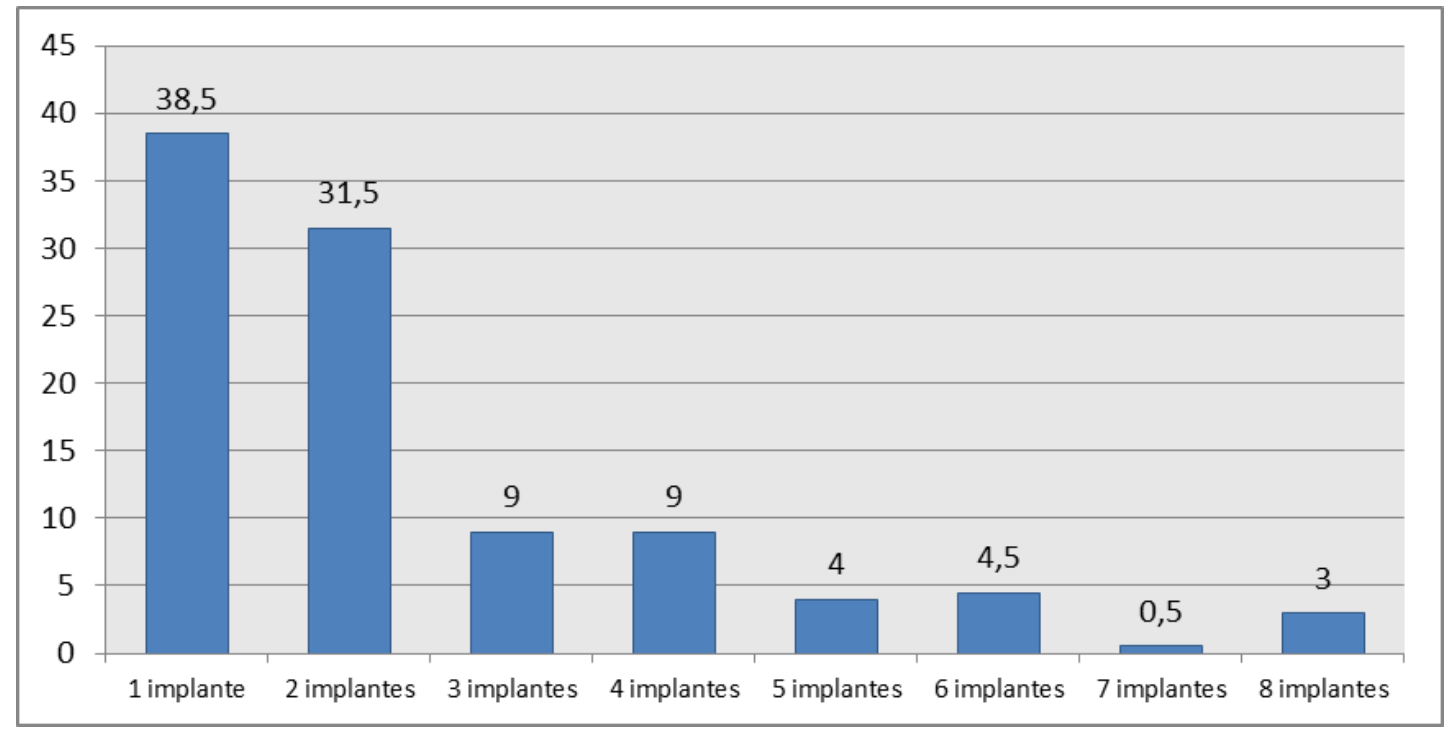

Figura 42: Distribución de la variable "Número de implantes".

- Marca del implante: se utilizaron varias marcas de implantes dentales, colocando con mayor prevalencia Zimmer y Bioner.

Tabla 18: Frecuencia de la variable "Marca del implante".

\begin{tabular}{c|c|c|}
\cline { 2 - 3 } Marca Impl. & Frecuencia & $\%$ \\
\hline Zimmer & 300 & 63,8 \\
\hline Bioner & 143 & 30,4 \\
\hline Bti & 21 & 4,5 \\
\hline
\end{tabular}


Capitulo 4: Resultados

\begin{tabular}{c|c|c|}
\hline Integra & 4 & 0,9 \\
\hline Straumann & 2 & 0,4 \\
\hline Total & 470 & 100,0 \\
\cline { 2 - 3 }
\end{tabular}

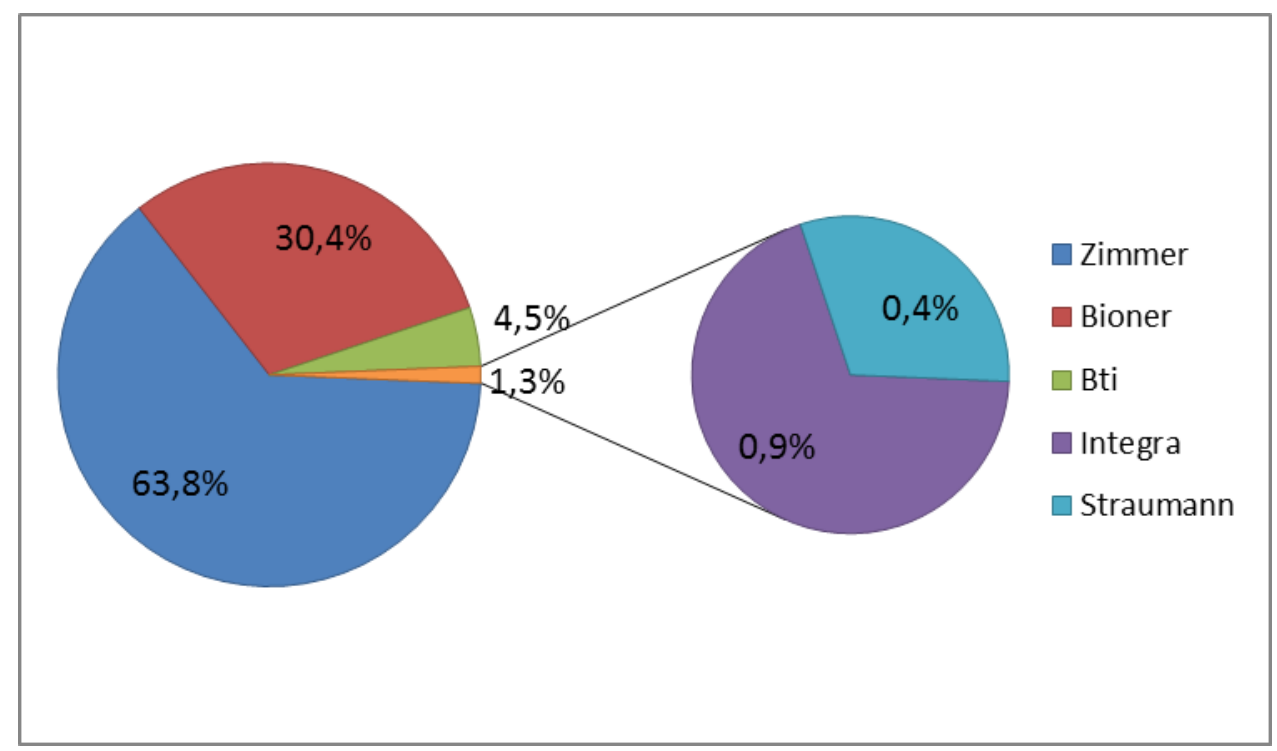

Figura 43: Distribución de la variable "Marca del implante".

- Localización del implante: los resultados obtenidos mostraron que los implantes dentales fueron colocados el mismo número de veces en la parte superior e inferior y que se ubicaron más en la parte anterior que en la posterior.

Tabla 19: Frecuencia de las variables "Maxilar o Mandibular" y "Anterior o Posterior".

\begin{tabular}{c|c|c|}
\cline { 2 - 3 } Localización & Frecuencia & $\%$ \\
\hline Anterior & 276 & 58,7 \\
\hline Posterior & 194 & 41,3 \\
\hline Total & 470 & 100,0 \\
\cline { 2 - 3 } & &
\end{tabular}

\begin{tabular}{c|c|r}
\cline { 2 - 3 } Localizacion & Frecuencia & $\%$ \\
\hline Maxilar & 235 & 50,0 \\
\hline Mandibular & 235 & 50,0 \\
\hline Total & 470 & 100,0 \\
\cline { 2 - 3 }
\end{tabular}


- Anchura y longitud de implante: se colocaron implantes de longitudes entre 7 y $16 \mathrm{~mm}$. y de anchuras entre 3,25 y $6 \mathrm{~mm}$. Los resultados se muestran en la Tabla 20, donde se puede observar que la anchura del implante que más veces se colocó fue la de 4,1 mm. (33,4\%), y la longitud más empleada fue la de $13 \mathrm{~mm}$. (37,4\%).

Tabla 20: Frecuencia de anchuras y longitudes de implantes colocados.

\begin{tabular}{c|c|c|c|c|c|}
\cline { 2 - 6 } Anchura & Frecuencia & $\%$ & Longitud & Frecuencia & $\%$ \\
\hline $3,25 \mathrm{~mm}$. & 3 & 0,6 & $7,00 \mathrm{~mm}$. & 2 & 0,4 \\
\hline $3,30 \mathrm{~mm}$. & 53 & 11,3 & $7,50 \mathrm{~mm}$. & 2 & 0,4 \\
\hline $3,50 \mathrm{~mm}$. & 6 & 1,3 & $8,00 \mathrm{~mm}$. & 7 & 1,5 \\
\hline $3,70 \mathrm{~mm}$. & 93 & 19,8 & $8,50 \mathrm{~mm}$. & 6 & 1,3 \\
\hline $3,75 \mathrm{~mm}$. & 54 & 11,5 & $10,00 \mathrm{~mm}$. & 100 & 21,3 \\
\hline $3,80 \mathrm{~mm}$. & 17 & 3,3 & $11,50 \mathrm{~mm}$. & 164 & 34,9 \\
\hline $4,00 \mathrm{~mm}$. & 28 & 6,0 & $12,00 \mathrm{~mm}$. & 1 & 0,2 \\
\hline $4,10 \mathrm{~mm}$. & 157 & 33,4 & $13,00 \mathrm{~mm}$. & 176 & 37,4 \\
\hline $4,20 \mathrm{~mm}$. & 20 & 4,3 & $15,00 \mathrm{~mm}$. & 7 & 1,5 \\
\hline $4,25 \mathrm{~mm}$. & 1 & 0,2 & $16,00 \mathrm{~mm}$. & 5 & 1,1 \\
\hline $4,30 \mathrm{~mm}$. & 4 & 0,9 & $/$ & $/$ & $/$ \\
\hline $4,70 \mathrm{~mm}$. & 21 & 4,5 & $/$ & $/$ & $/$ \\
\hline $5,00 \mathrm{~mm}$. & 11 & 2,3 & $/$ & $/$ & $/$ \\
\hline $6,00 \mathrm{~mm}$. & 2 & 0,4 & $/$ & $/ 100,0$ \\
\hline Total & 470 & 100,0 & Total & $/$ & $/$ \\
\hline
\end{tabular}


- Tipo de edentulismo: los pacientes que más se sometieron a cirugía de colocación de implantes fueron los que padecían un edentulismo completo, en un $46 \%$ de los casos totales. Después, los que padecían edentulismo parcial entre dos dientes, en un 38,1\%, mientras que los menos intervenidos fueron los pacientes con extremos libres, en un 16\% de los casos.

Tabla 21: Frecuencia de la variable "Tipo de edentulismo".

\begin{tabular}{c|c|c|}
\cline { 2 - 3 } Tipo de Edentulismo & Frecuencia & $\%$ \\
\hline Extremo libre & 75 & 16 \\
\hline Espacio interdental & 179 & 38 \\
\hline Completo & 216 & 46 \\
\hline Total & 470 & 100 \\
\hline
\end{tabular}

- Regeneración ósea y elevación de seno: en algunos casos, a la vez que se colocaban los implantes dentales, se realizó algún otro tipo de intervención de manera simultánea. En el 7\% de los pacientes intervenidos, se practicó regeneración ósea, mientras que en el 3,4\% de ellos se realizó elevación de seno simultánea para poder colocar correctamente el implante dental.

- Colgajo: el 79,8\% de los pacientes tratados, precisó la apertura de colgajo a espesor total con descargas, para llevar a cabo la correcta colocación del implante, mientras que el 20,2\% necesitó sólo una incisión paracrestal para ello.

- Implante postextracción: el 95,7\%, o bien ya presentaba ausencia de la pieza dentaria que se quería reponer mediante un implante dental, o debió esperar 3-4 meses después de la extracción de la pieza para la completa cicatrización del tejido blando y duro. Al 4,3\% de los pacientes, se les colocó el implante dental justo después de extraer la pieza dentaria. 
- Sedación: la gran mayoría de los pacientes fue operada bajo el efecto de la anestesia local (89,4\%), mientras que sólo se utilizó sedación consciente en el $10,6 \%$ de ellos.

Tabla 22: Frecuencia de las variables "Regeneración", "Elevación de seno", "Colgajo", "Postextracción" y "Sedación".

\begin{tabular}{r|c|c|c|c|c|}
\cline { 2 - 6 } & Regeneración & Elevación seno & Colgajo & Postextracción & Sedación \\
\hline Sí & $7,0 \%$ & $3,4 \%$ & $79,8 \%$ & $4,3 \%$ & $10,6 \%$ \\
\hline No & $93,0 \%$ & $96,6 \%$ & $19,2 \%$ & $95,7 \%$ & $89,4 \%$ \\
\hline \multirow{2}{*}{ Total } & $100 \%$ & $100 \%$ & $100 \%$ & $100 \%$ & $100 \%$ \\
\cline { 2 - 6 } & & & &
\end{tabular}

\section{C) Características postoperatorias}

En el siguiente apartado, se analizaron las variables postoperatorias evaluadas: el dolor recogido mediante Escala Visual Analógica (E.V.A.) y el dolor, la inflamación y el hematoma recogidos por los pacientes a lo largo de los 7 días posteriores a la cirugía.

- Escala Visual Analógica (E.V.A.): los pacientes seleccionaron el nivel de dolor que padecieron en esta escala, obteniéndose los siguientes resultados: ningún paciente consideró que el dolor padecido durante esos días fuera de grado 9 o $10(0 \%)$, mientras que el valor que más veces marcaron en la E.V.A. fue el grado 0 de dolor, en un $37 \%$ de las ocasiones. 
Tabla 23: Frecuencia de los valores de E.V.A.

\begin{tabular}{c|c|c|}
\cline { 2 - 3 } Valor E.V.A. & Frecuencia & $\%$ \\
\hline 0 & 74 & 37,0 \\
\hline 1 & 35 & 17,5 \\
\hline 2 & 40 & 20,0 \\
\hline 3 & 30 & 15,0 \\
\hline 4 & 10 & 5,0 \\
\hline 5 & 2 & 1,0 \\
\hline 6 & 5 & 2,5 \\
\hline 7 & 3 & 1,5 \\
\hline 8 & 1 & 0,5 \\
\hline 9 & 0 & 0,0 \\
\hline 10 & 0 & 0,0 \\
\hline Total & 200 & 100,0 \\
\hline
\end{tabular}

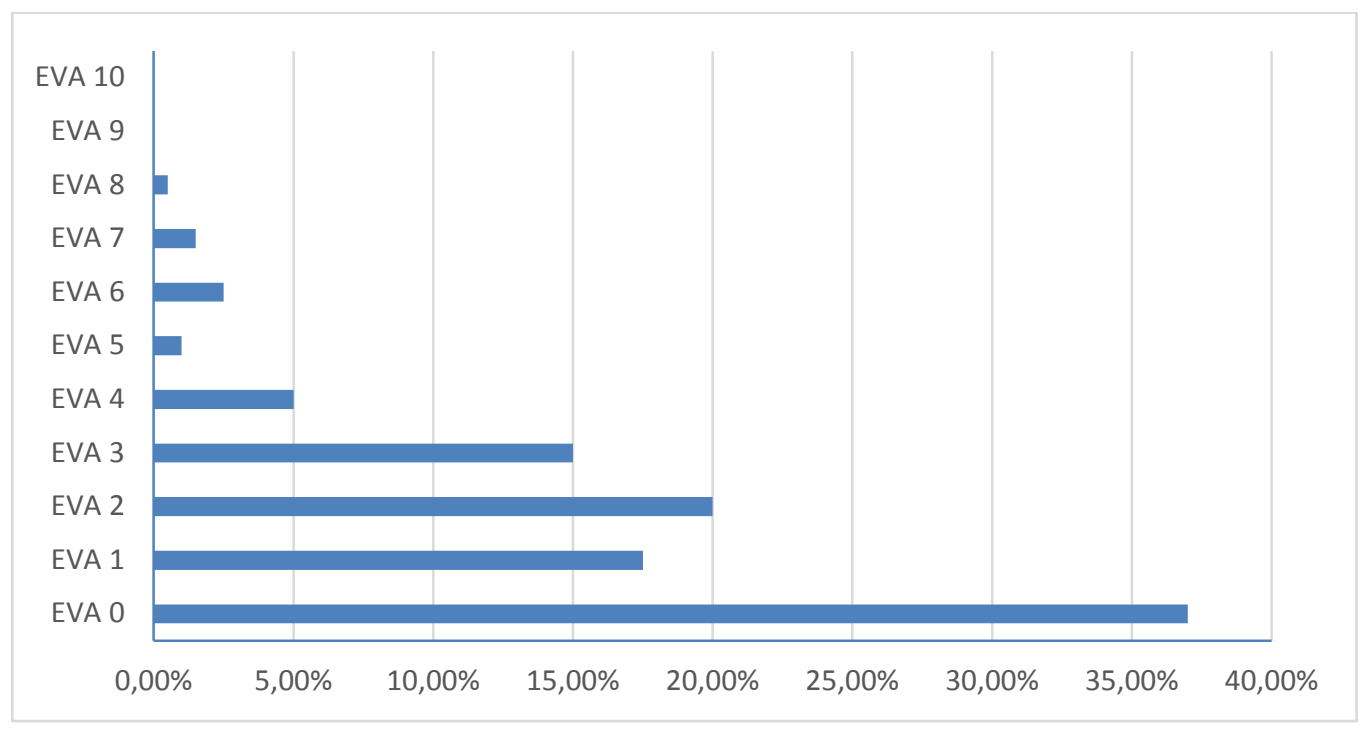

Figura 44: Frecuencia de la variable E.V.A. 
- Dolor: es el síntoma, junto con la inflamación, que más aparece en el postoperatorio implantológico. El dolor sufrido por los pacientes durante los 7 días posteriores a la cirugía mostró los siguientes resultados:

Tabla 24: Distribución y evolución temporal del dolor postoperatorio.

\begin{tabular}{c|r|r|r|r|r|r|}
\cline { 2 - 7 } Dolor & 12 horas & 24 horas & 48 horas & 3 días & 5 días & 7 días \\
\hline No & $55.5 \%$ & $52.5 \%$ & $64.5 \%$ & $81.0 \%$ & $90.5 \%$ & $94.0 \%$ \\
\hline Ligero & $34.0 \%$ & $34.5 \%$ & $22.5 \%$ & $14.0 \%$ & $7.0 \%$ & $4.5 \%$ \\
\hline Moderado & $10.0 \%$ & $12.5 \%$ & $11.0 \%$ & $3.5 \%$ & $1.5 \%$ & $1.0 \%$ \\
\hline Fuerte & $0.5 \%$ & $0.5 \%$ & $2.0 \%$ & $1.5 \%$ & $1.0 \%$ & $0.5 \%$ \\
\hline Total & $100 \%$ & $100 \%$ & $100 \%$ & $100 \%$ & $100 \%$ & $100 \%$ \\
\hline
\end{tabular}

\section{Síntomas de dolor en el tiempo}

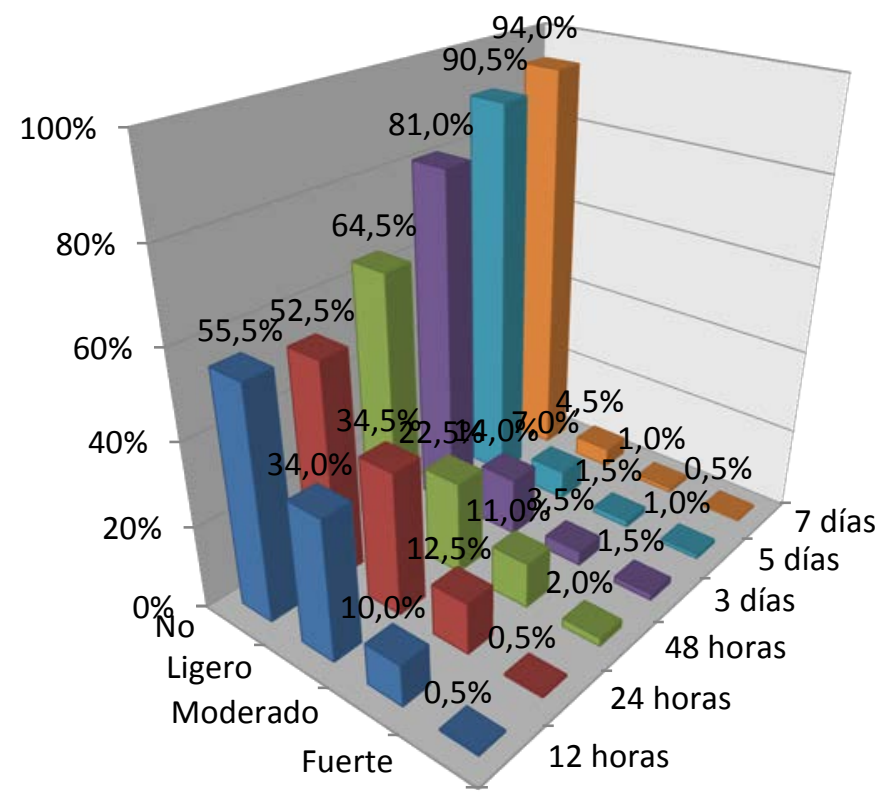

12 horas

$\square 24$ horas

$\square 48$ horas

$\square$ días

$\square 5$ días

$\square 7$ días

Figura 45: Síntomas de dolor en el tiempo. 
- Inflamación: los datos de la inflamación postoperatoria se recogieron también durante los 7 días posteriores a la intervención, obteniéndose los siguientes resultados:

Tabla 25: Distribución y evolución temporal de la inflamación postoperatoria.

\begin{tabular}{c|r|r|r|r|r|r|}
\cline { 2 - 7 } Inflamación & 12 horas & 24 horas & 48 horas & 3 días & 5 días & 7 días \\
\hline No & $59.5 \%$ & $50.0 \%$ & $55.0 \%$ & $68.0 \%$ & $86.5 \%$ & $94.5 \%$ \\
\hline Ligera & $33.0 \%$ & $36.5 \%$ & $32.5 \%$ & $23.5 \%$ & $10 \%$ & $4.0 \%$ \\
\hline Moderada & $7.0 \%$ & $12.0 \%$ & $10.5 \%$ & $8.0 \%$ & $3.0 \%$ & $1.0 \%$ \\
\hline Fuerte & $0.5 \%$ & $1.5 \%$ & $2.0 \%$ & $0.5 \%$ & $0.5 \%$ & $0.5 \%$ \\
\hline Total & $100 \%$ & $100 \%$ & $100 \%$ & $100 \%$ & $100 \%$ & $100 \%$ \\
\cline { 2 - 7 } & & & & & &
\end{tabular}

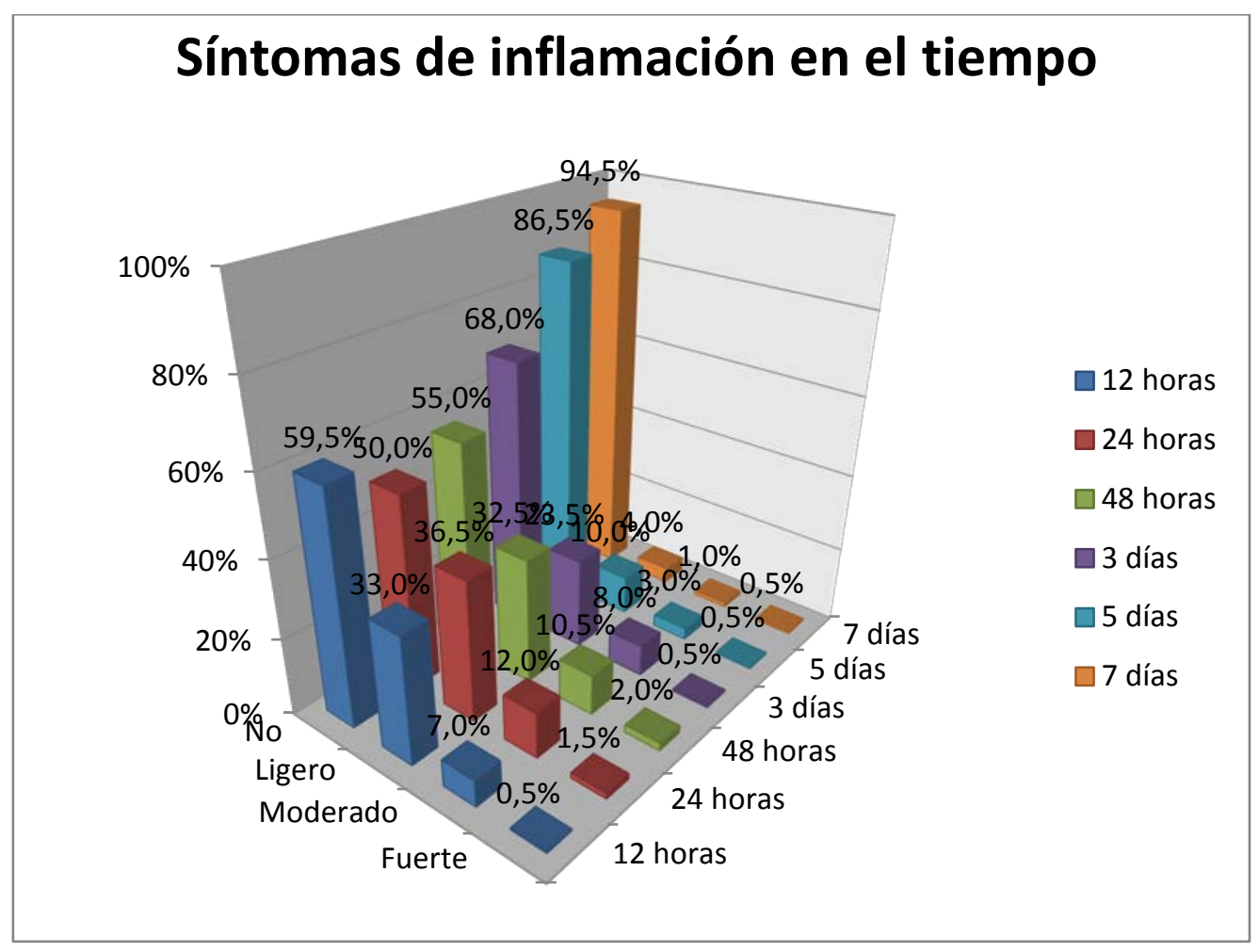

Figura 46: Síntomas de inflamación en el tiempo. 
- Hematoma: en este estudio apenas se registraron pacientes con hematoma postoperatorio. Los resultados encontrados fueron los siguientes:

Tabla 26: Distribución y evolución temporal del hematoma postoperatorio.

\begin{tabular}{c|r|r|r|r|r|r|}
\cline { 2 - 7 } Hematoma & 12 horas & 24 horas & 48 horas & 3 días & 5 días & 7 días \\
\hline No & $93.0 \%$ & $89.0 \%$ & $87.0 \%$ & $90 \%$ & $92.5 \%$ & $94.5 \%$ \\
\hline Ligero & $6.0 \%$ & $9.0 \%$ & $8.5 \%$ & $6.0 \%$ & $4.5 \%$ & $4.0 \%$ \\
\hline Moderado & $0.0 \%$ & $0.5 \%$ & $2.0 \%$ & $2.0 \%$ & $2.0 \%$ & $1.0 \%$ \\
\hline Fuerte & $1.0 \%$ & $1.5 \%$ & $2.5 \%$ & $2.0 \%$ & $1.0 \%$ & $0.5 \%$ \\
\hline Total & $100 \%$ & $100 \%$ & $100 \%$ & $100 \%$ & $100 \%$ & $100 \%$ \\
\hline
\end{tabular}

\section{Síntomas de hematoma en el tiempo}

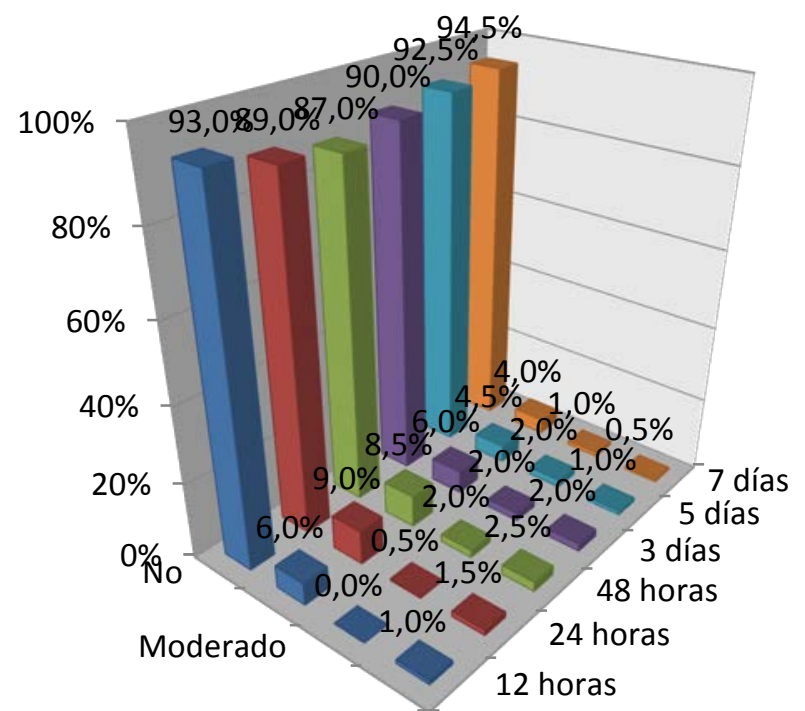

$\square 12$ horas

$\square 24$ horas

$\square 48$ horas

$\square 3$ días

$\square 5$ días

$\square 7$ días

Figura 47: Síntomas de hematoma en el tiempo. 
Capitulo 4: Resultados

\subsubsection{Análisis de la variable "Dolor E.V.A."}

La variable "Dolor E.V.A." como se explica en el capítulo 4.1 ADECUACIÓN DE LAS BASES DE DATOS PARA EL ANÁLISIS, en la página 144, se ha recodificado creando intervalos. Así dicha variable queda definida como "DolorEvaInter", que a su vez consta de dos grupos: "Dolor Tenue", para aquellos pacientes que marcaron el dolor E.V.A. de 0 a 2 y "Dolor Intenso", para los que marcaron éste como 3 o más.

La variable "DolorEVAInter" es la dependiente, es decir, la que se pretende explicar.

Se ha realizado un análisis descriptivo para la variable "DolorEVAInter" (variable "Dolor E.V.A." recodificada), como se ha explicado anteriormente. Se ha llevado a cabo el estudio de las siguientes variables: "Sexo", "Edad", "Fumador", "Alergias", "Enfermedades Actuales", "Número de implantes", "Situación implante", "Anterior/Posterior", “Elevación”, "Regeneración”, “Sedación”, "Postextracción” y “Colgajo”. La Figura 48, pone de manifiesto que el grupo de pacientes que manifestaron "Dolor Tenue" durante el postoperatorio, fue el $74 \%$ de los estudiados y el $26 \%$ restante presentaron "Dolor Intenso". 


\section{Dolor EVA}

$\square$ No Dolor $\square 3 \square 4 \square 5 \square 6 \square 7 \square 8$

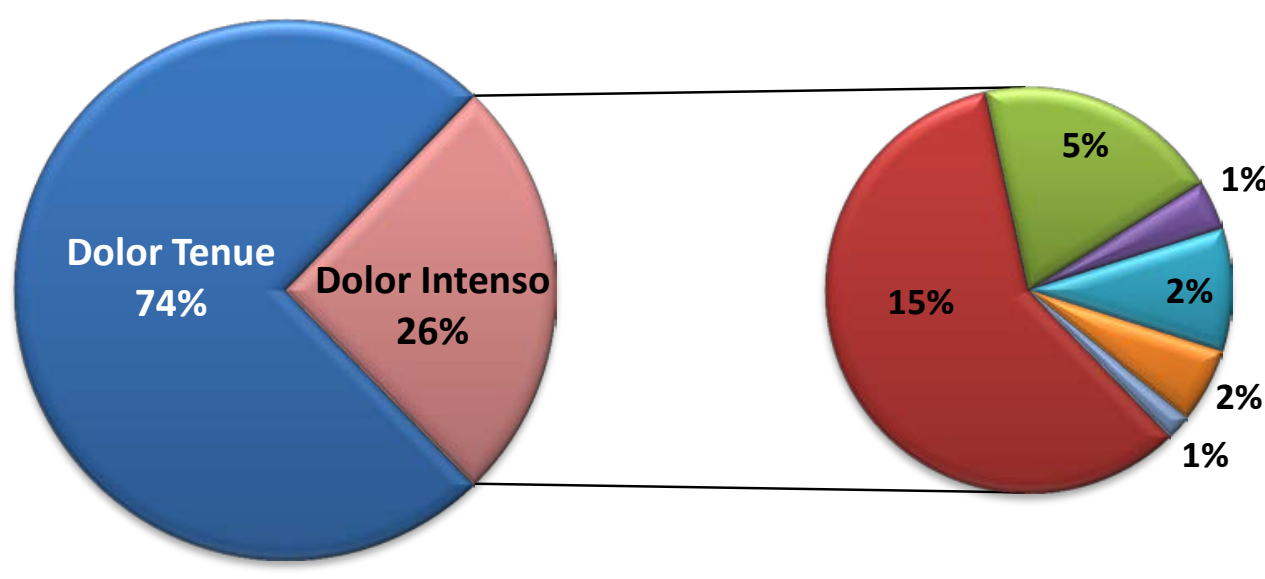

Figura 48: Distribución de la E.V.A. en la muestra en la que: "Dolor Tenue" = 0,1,2 y "Dolor Intenso" $=3,4,5,6,7$ y 8 en la E.V.A.

Un análisis más detallado de este conjunto de pacientes, pone de manifiesto que dentro de los que marcaron 3 o más en la E.V.A. (Dolor Intenso), el 15\%, es decir, más de la mitad seleccionaron el 3, mientras que el 11\% restante marcaron 4 o más. Ningún paciente marcó el máximo nivel de dolor (10).

Este primer resultado, tiene gran importancia debido a que sólo 52 de los 200 pacientes estudiados $(26 \%)$, presentaron dolor intenso.

\section{A) Relación de la variable "Dolor" con la de "Sexo"}

A continuación, se presenta cómo se distribuye la muestra según el dolor, segmentado por "Sexo" y viceversa. 
Capitulo 4: Resultados

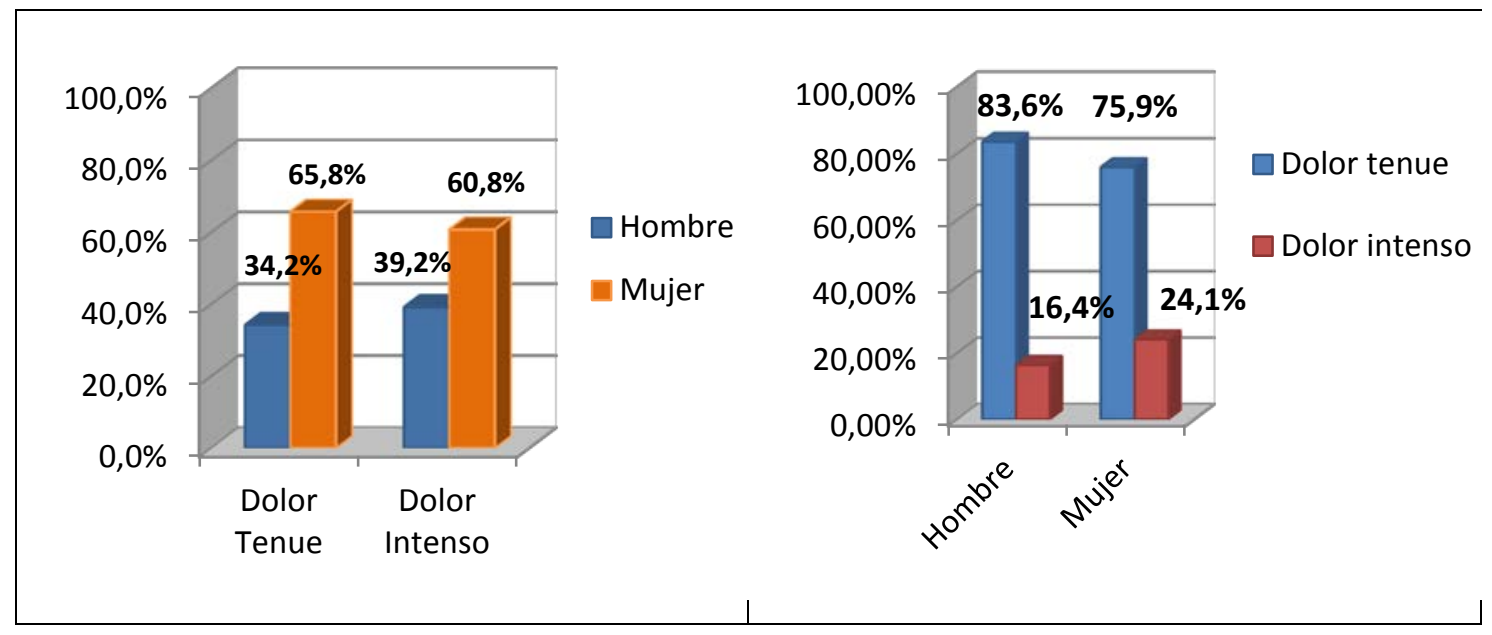

Figura 49: Distribución del dolor en relación a la variable "Sexo".

La Figura 49 contiene dos diagramas de barras, el primero de ellos representa el grado de dolor que mostraron hombres y mujeres. En él se aprecia cómo las mujeres presentaron valores mayores, tanto para dolor tenue como para el intenso, (65,8\% y 60,8\%), mientras que los hombres mostraron valores sensiblemente inferiores, (34,2\% y 39,2\%), respectivamente.

El segundo de diagrama, representa la distribución del dolor en función del sexo, obteniendo, también, que son más las mujeres que marcaron 3 o más en la E.V.A., (24,1\%), respecto a los hombres (16,4\%). Aun así, se vuelve a constatar que la mayoría de los pacientes no sufrieron un nivel de dolor superior a 3 en la E.V.A., pues los porcentajes de dolor tenue fueron muy elevados para ambos grupos, $83,6 \%$ y $75,9 \%$.

\section{B) Relación de la variable "Dolor" con la de "Fumador"}

A continuación, se representa cómo se distribuye la muestra según el dolor, segmentado por "Fumador" y viceversa. 


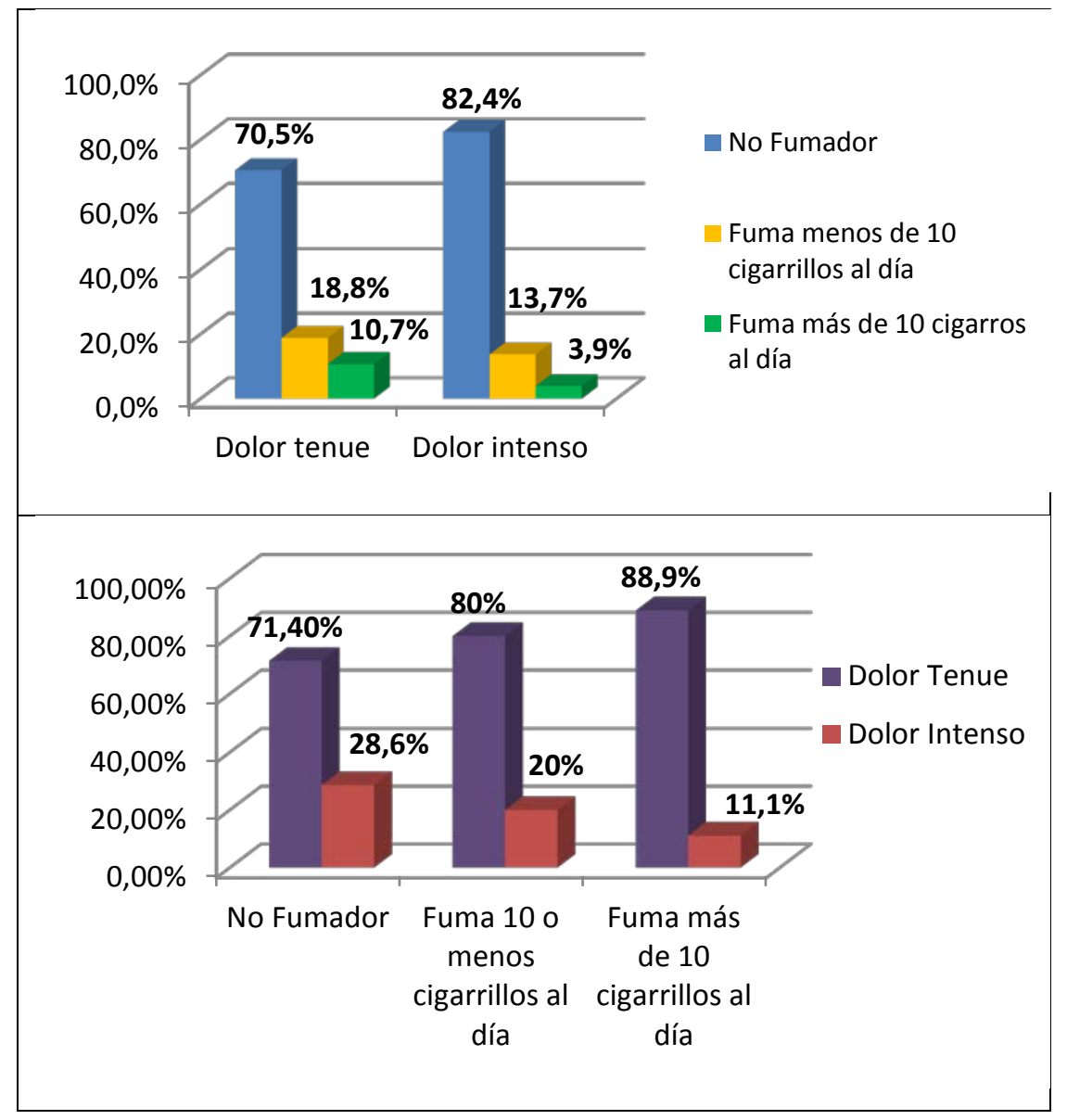

Figura 50: Distribución del dolor en relación a la variable "Fumador".

El primer diagrama de la Figura 50, muestra que los pacientes no fumadores obtuvieron porcentajes mayores de dolor tenue e intenso, respecto a los fumadores.

En el segundo diagrama encontramos que los pacientes no fumadores padecieron más dolor intenso $(28,6 \%)$ que los fumadores $(20 \%$ y $11,1 \%$ ) y que cuanto más fumaban, menor era dicho porcentaje de dolor.

\section{C) Relación de la variable "Dolor" con la de "Higiene"}

A continuación, se representa cómo se distribuye la muestra según el dolor, segmentado por "Higiene" y viceversa. 


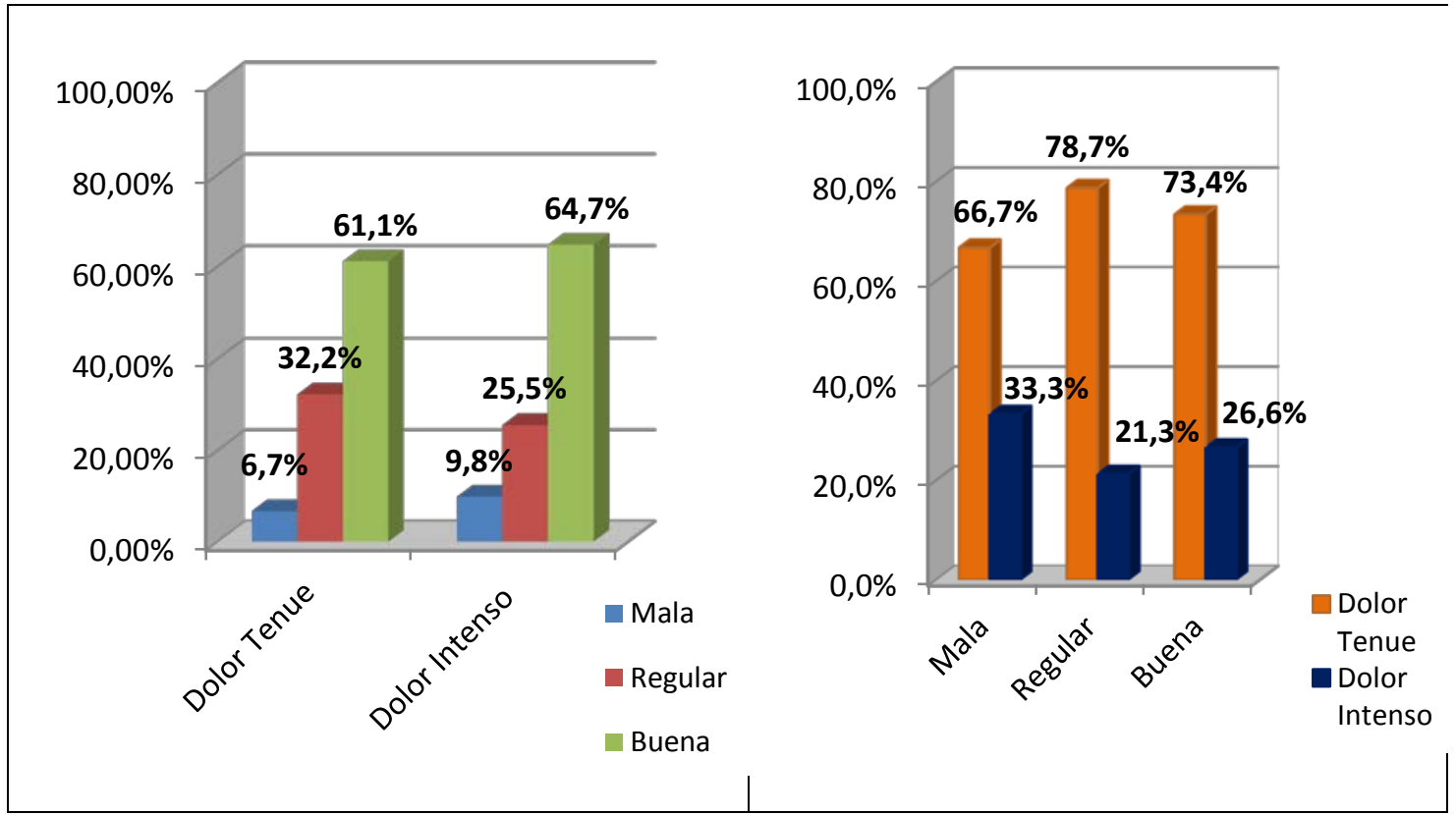

Figura 51: Distribución del dolor en relación a la variable "Higiene".

La Figura 51 muestra en el primer diagrama, la distribución de los pacientes según el dolor que manifestaron dependiendo del grado de higiene, encontrando resultados muy similares, tanto para los que padecieron dolor tenue, como para los que padecieron dolor intenso.

El segundo diagrama muestra que, de los pacientes clasificados con mala higiene, el $33,3 \%$ de ellos afirmaron haber padecido dolor intenso, en comparación a los pacientes con regular y buena higiene, que mostraron valores más bajos, $21,3 \%$ y 26,6\%, respectivamente. Se puede observar que el porcentaje de pacientes con dolor intenso que presentaban una higiene regular, fue inferior al de los pacientes con buena higiene, aunque la diferencia fue pequeña.

\section{D) Relación de la variable "Dolor" con la de "Enfermedades actuales"}

A continuación, se representa cómo se distribuye la muestra según el dolor, segmentado por "Enfermedades actuales" y viceversa.

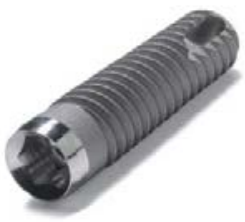




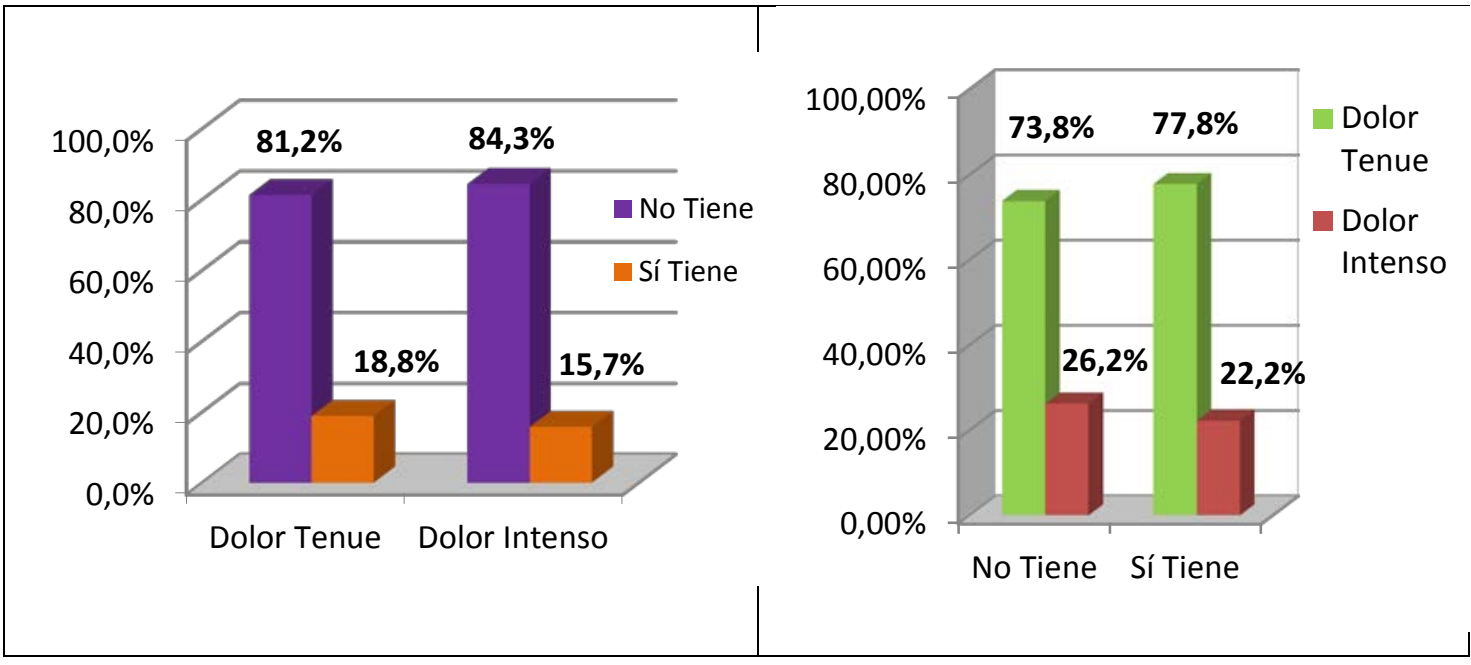

Figura 52: Distribución del dolor en relación a la variable "Enfermedades actuales".

La Figura 52, pone de manifiesto que no existen diferencias aparentes entre pacientes que padecen enfermedades y los que no, respecto al nivel de dolor marcado en la E.V.A., pues la diferencia existente entre ambos grupos respecto de las categorías del dolor, es de tan sólo un 3\%.

\section{E) Relación de la variable "Dolor" con la de "Alergias"}

A continuación, se representa cómo se distribuye la muestra según el dolor, segmentado por "Alergias" y viceversa.

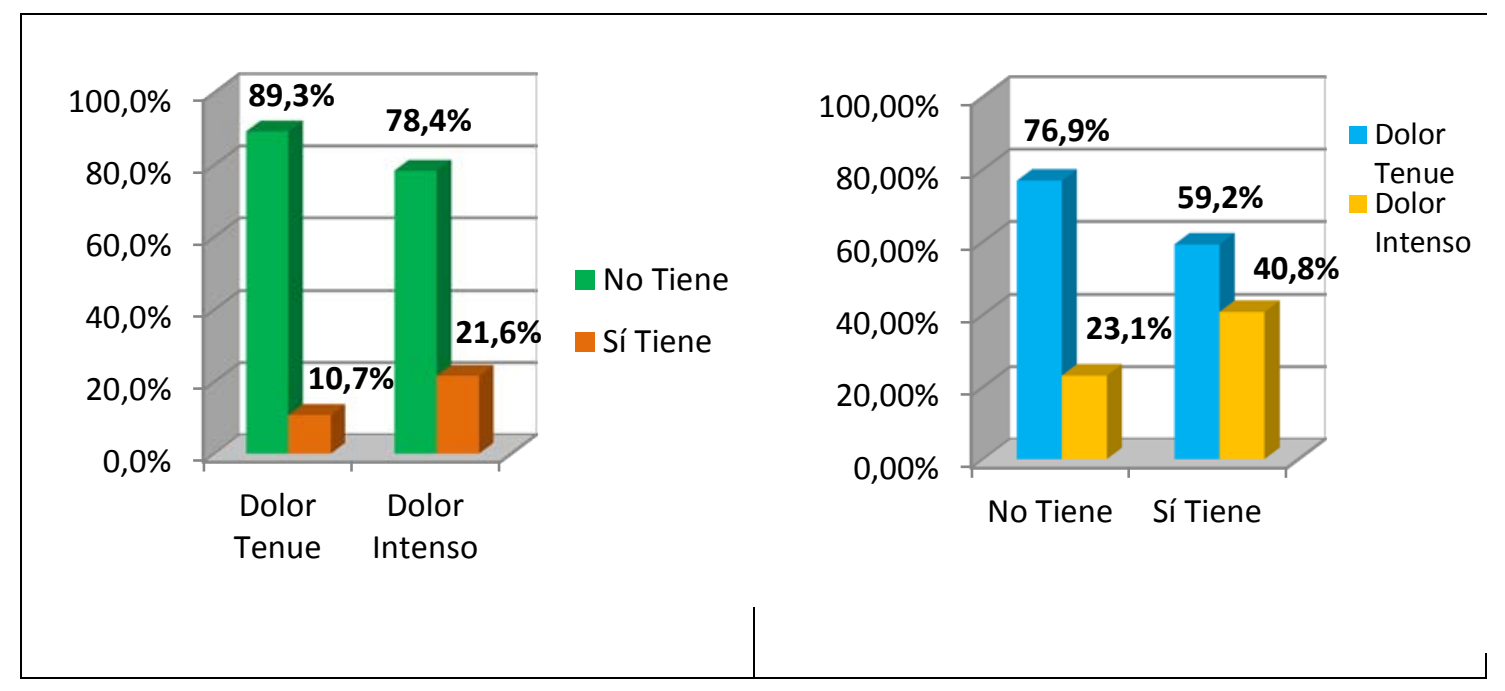


Capitulo 4: Resultados

Figura 53: Distribución del dolor en relación a la variable "Alergias".

Como se observa en la Figura 53, es llamativa la relación existente entre los pacientes con alergia y sin alergia respecto al dolor. Dentro de los pacientes que afirmaron haber sufrido dolor intenso, casi el doble de ellos padecía algún tipo de alergia, con lo cual, aparentemente, se puede afirmar que existe una relación directa entre padecer algún tipo de alergia y haber marcado 3 o más en la E.V.A.

\section{F) Relación de la variable "Dolor" con la de "Medicamentos"}

A continuación, se representa cómo se distribuye la muestra según el dolor, segmentado por "Medicamentos" y viceversa.

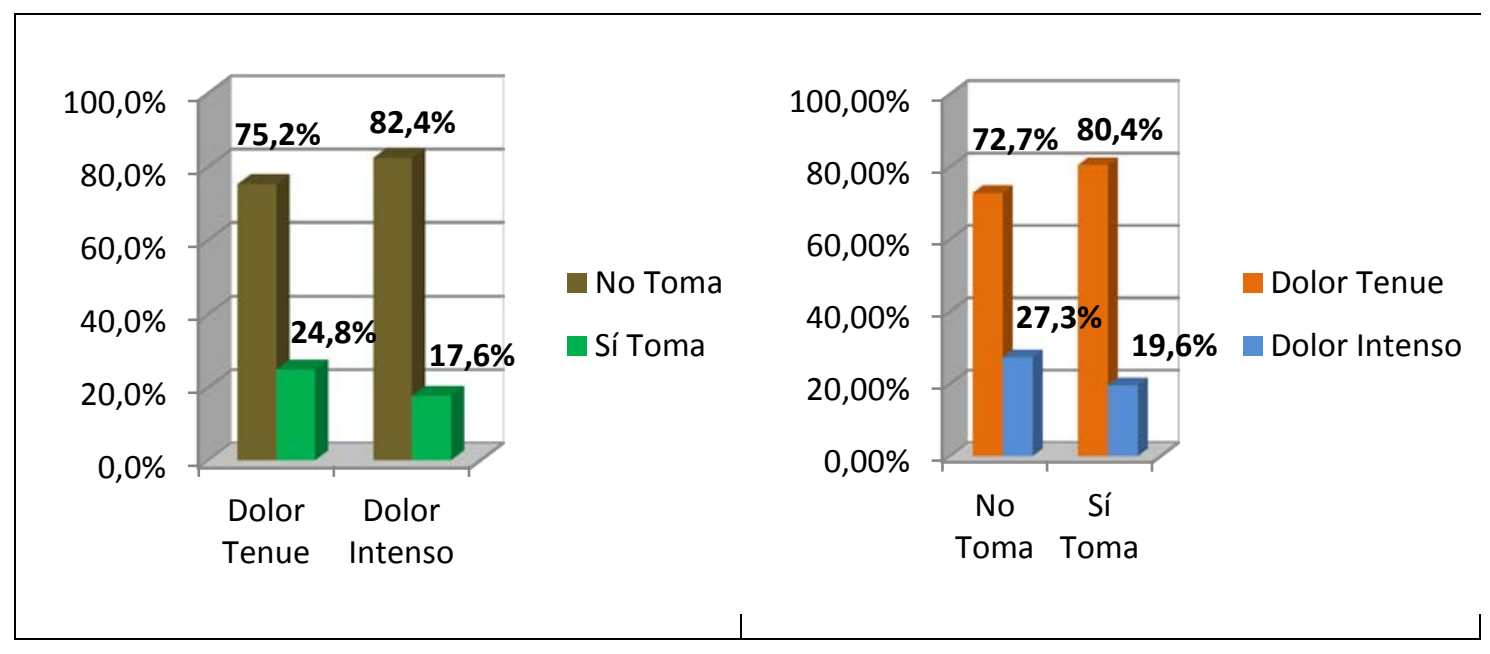

Figura 54: Distribución del dolor en relación a la variable "Medicamentos".

La Figura 54, pone de manifiesto que no existen diferencias aparentes entre pacientes que sí toman medicamentos y los que no lo hacen, respecto al nivel de dolor marcado en la E.V.A., pues la diferencia existente entre ambos grupos respecto de las categorías del dolor, es de tan sólo un 7\%.

\section{G) Relación de la variable "Dolor" con la de "Número de implantes"}

A continuación, se representa cómo se distribuye la muestra según el dolor, segmentado por "Número de Implantes" y viceversa.

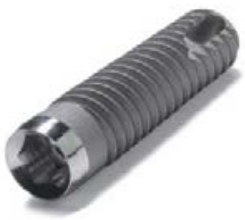




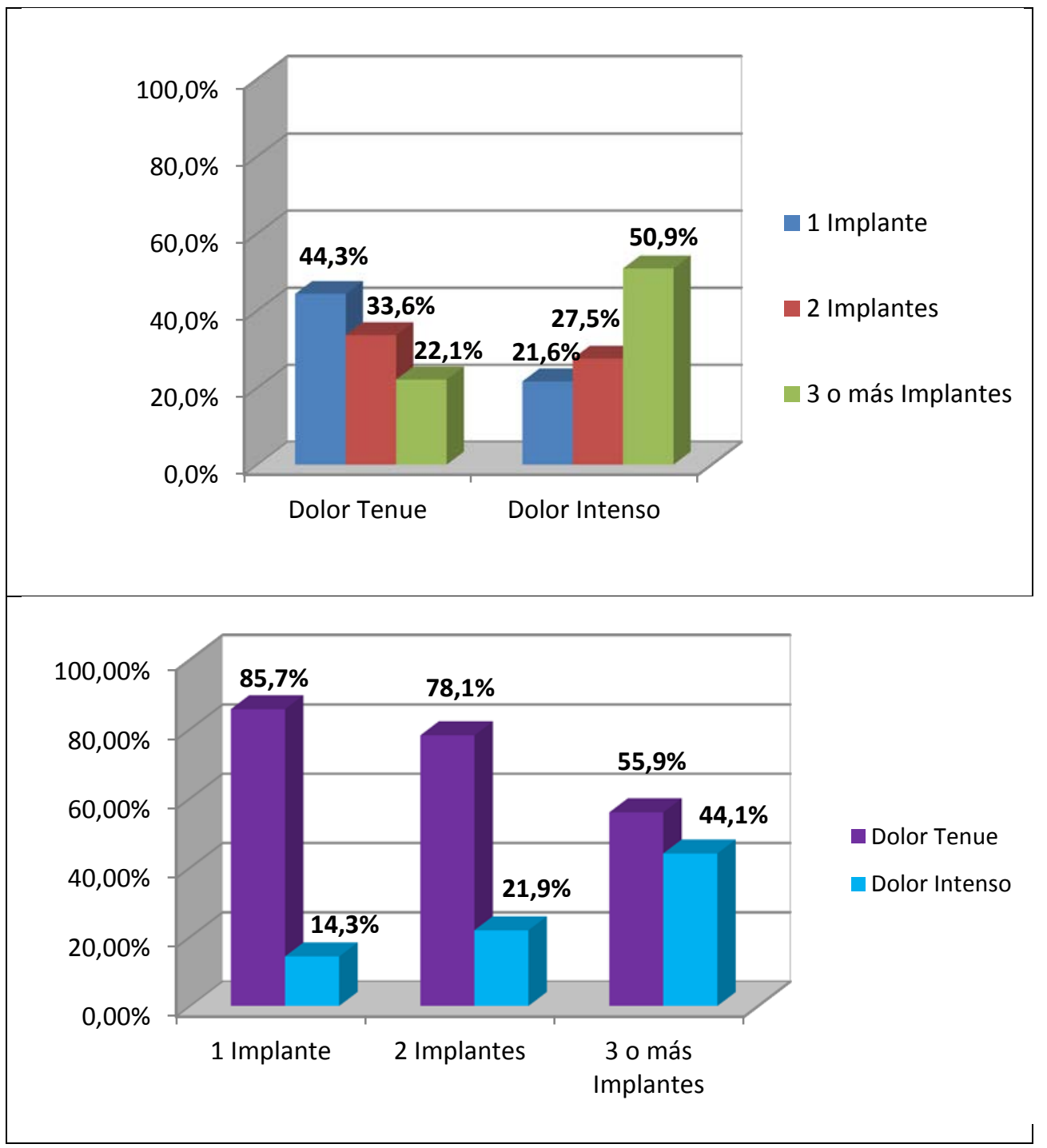

Figura 55: Distribución del dolor en relación a la variable "Número de implantes".

En la parte superior de la Figura 55, se puede observar, con respecto al dolor tenue, cómo la línea de tendencia disminuye conforme aumenta el número de implantes colocados, mientras que por el contrario el dolor intenso aumenta.

El diagrama inferior de esta figura muestra que, a mayor número de implantes, mayor es el nivel de dolor marcado en la E.V.A. Además, se puede observar que en el grupo de pacientes con 3 o más implantes, la proporción de los que percibieron el dolor como tenue y los que lo hicieron como intenso son muy parecidos (55,9\% y 44,1\% 


\section{Capitulo 4: Resultados}

respectivamente), sin embargo, los pacientes a los que se les colocó un solo implante, un $85,7 \%$, percibieron el dolor como tenue.

\section{H) Relación de la variable "Dolor" con la de "Situación del implante"}

A continuación, se representa cómo se distribuye la muestra según el dolor, segmentado por "Situación del implante" y viceversa.

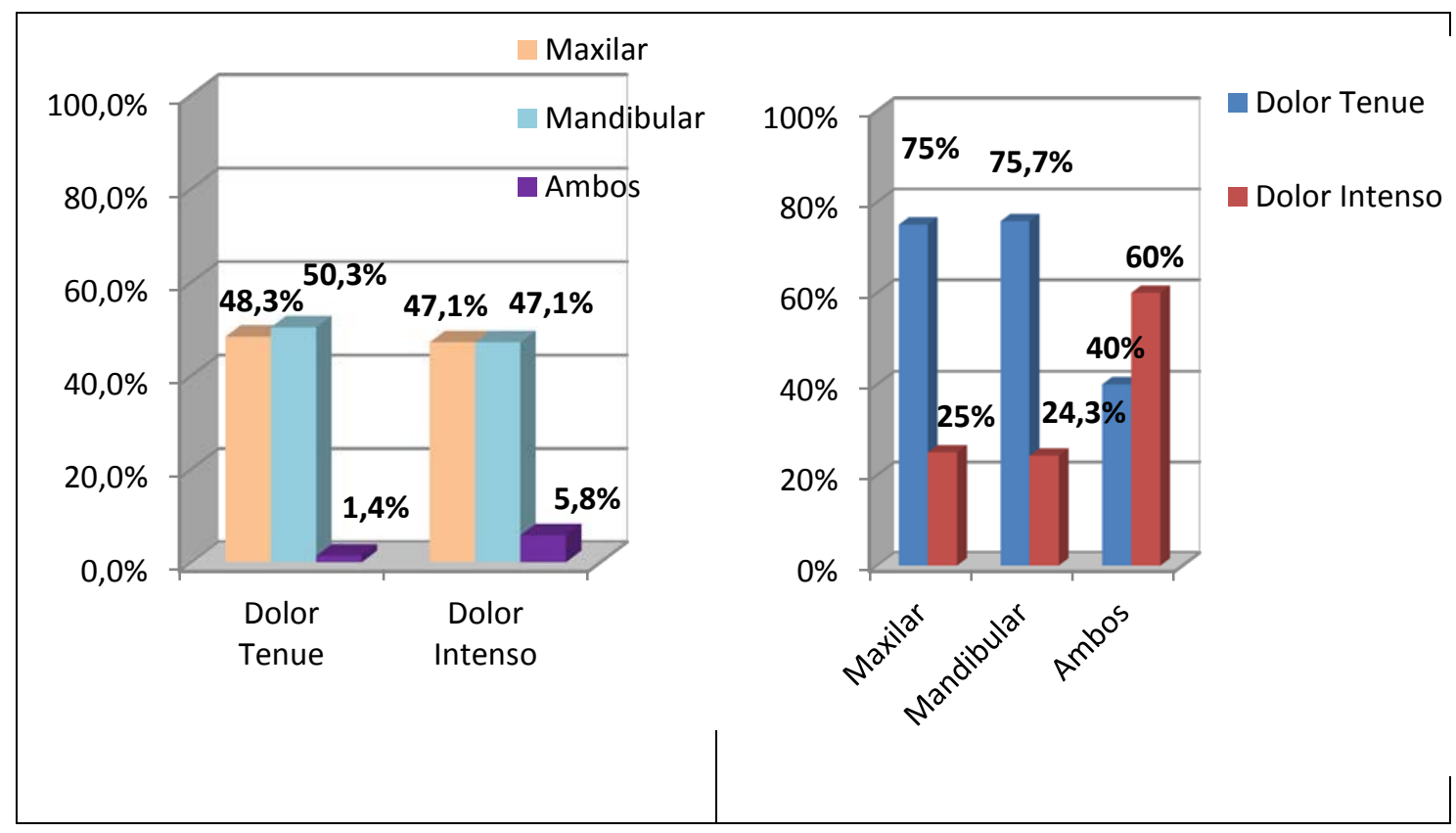

Figura 56: Distribución del dolor en relación a la variable "Situación del implante".

La Figura 56, muestra la relación entre el grado de dolor (tenue o intenso) y la situación de los implantes (maxilar, mandibular o ambos), puediéndose observar que, en todos los casos, los valores de dolor tenue e intenso fueron similares.

En el segundo gráfico de esta misma figura, se observa que la distribución del dolor tenue e intenso fue prácticamente igual en los pacientes a los que se les colocaron los implantes en el maxilar superior y en el inferior. Sin embargo, se aprecia cómo los pacientes a los que se les colocó implantes en ambos maxilares en el mismo acto quirúrgico, sufrieron más dolor intenso (60\%) que los otros dos grupos (25\% y $24,3 \%$ ), respectivamente. 


\section{I) Relación de la variable "Dolor" con la de "Anterior/Posterior"}

A continuación, se representa cómo se distribuye la muestra según el dolor, segmentado por "Anterior/Posterior" y viceversa.

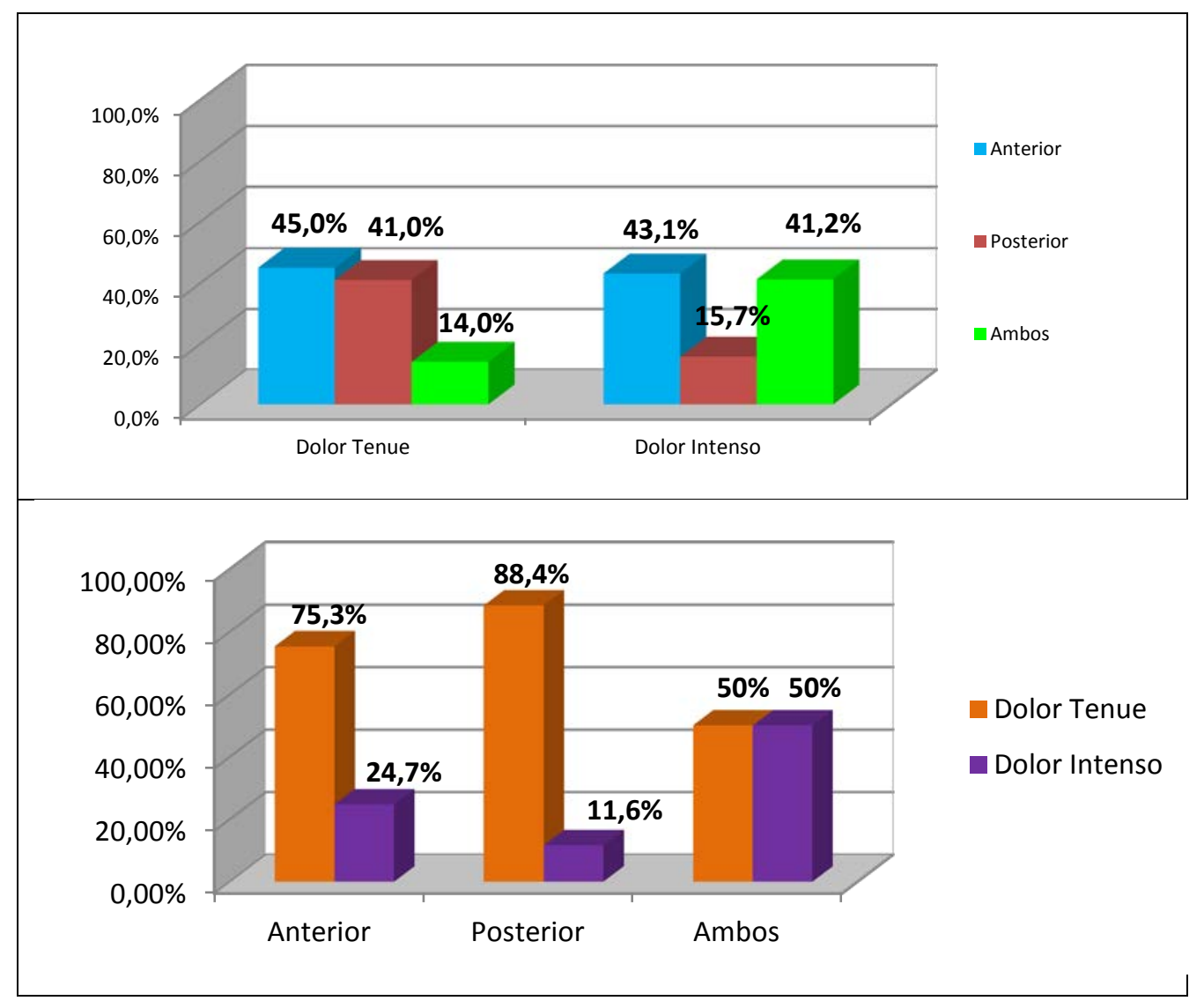

Figura 57: Distribución del dolor en relación a la variable “Anterior/Posterior".

En la Figura 57 podemos observar que de los pacientes con dolor intenso, al 43,1\% se les colocó el implante en la parte anterior y al 41,2\%, se les colocaron en ambas situaciones. Igualmente, en el grupo de pacientes que marcaron el dolor como tenue, siguen siendo mayoritarios aquéllos con implantes en la parte anterior.

No obstante, en la parte inferior de esta figura, se observa que dentro del total de pacientes con implantes en la zona posterior, el 11,6\% marcaron el dolor como intenso, 


\section{Capitulo 4: Resultados}

mientras que a nivel anterior este porcentaje fue del $24,7 \%$, lo que pone de manifiesto que los pacientes a los que los implantes les fueron colocados a nivel anterior, padecieron más dolor que los que fueron colocados en la zona posterior. Por último, hay que destacar que si el implante fue colocado en ambas zonas, la proporción de pacientes con dolor tenue e intenso fue la misma.

\section{J) Relación de la variable "Dolor" con la de "Elevación de seno"}

A continuación, se representa cómo se distribuye la muestra según el dolor, segmentado por "Elevación de seno" y viceversa.

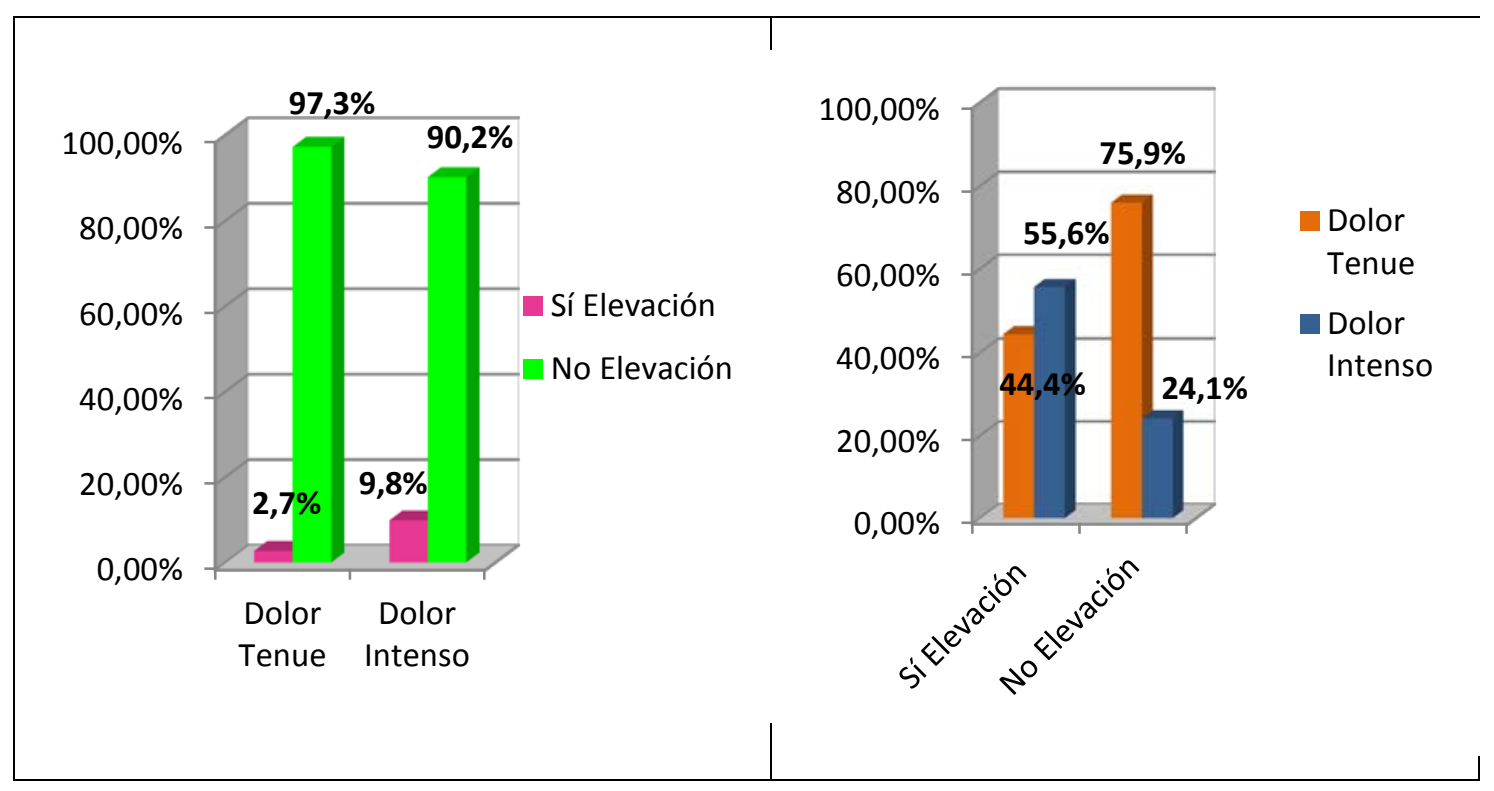

Figura 58: Distribución del dolor en relación a la variable "Elevación de seno".

Como se observa en la Figura 58, a la mayoría de los pacientes no se les practicó elevación de seno. Dentro de los que se sometieron a elevación de seno, el 55,6\% marcaron el dolor como intenso (3 o más en la E.V.A.).

Además, como cabe esperar, de los pacientes a los que no se les practicó elevación sinusal (191 casos), más del 75\%, valoraron su dolor como tenue. 


\section{K) Relación de la variable "Dolor" con la de "Regeneración"}

A continuación, se representa cómo se distribuye la muestra según el dolor, segmentado por "Regeneración” y viceversa.

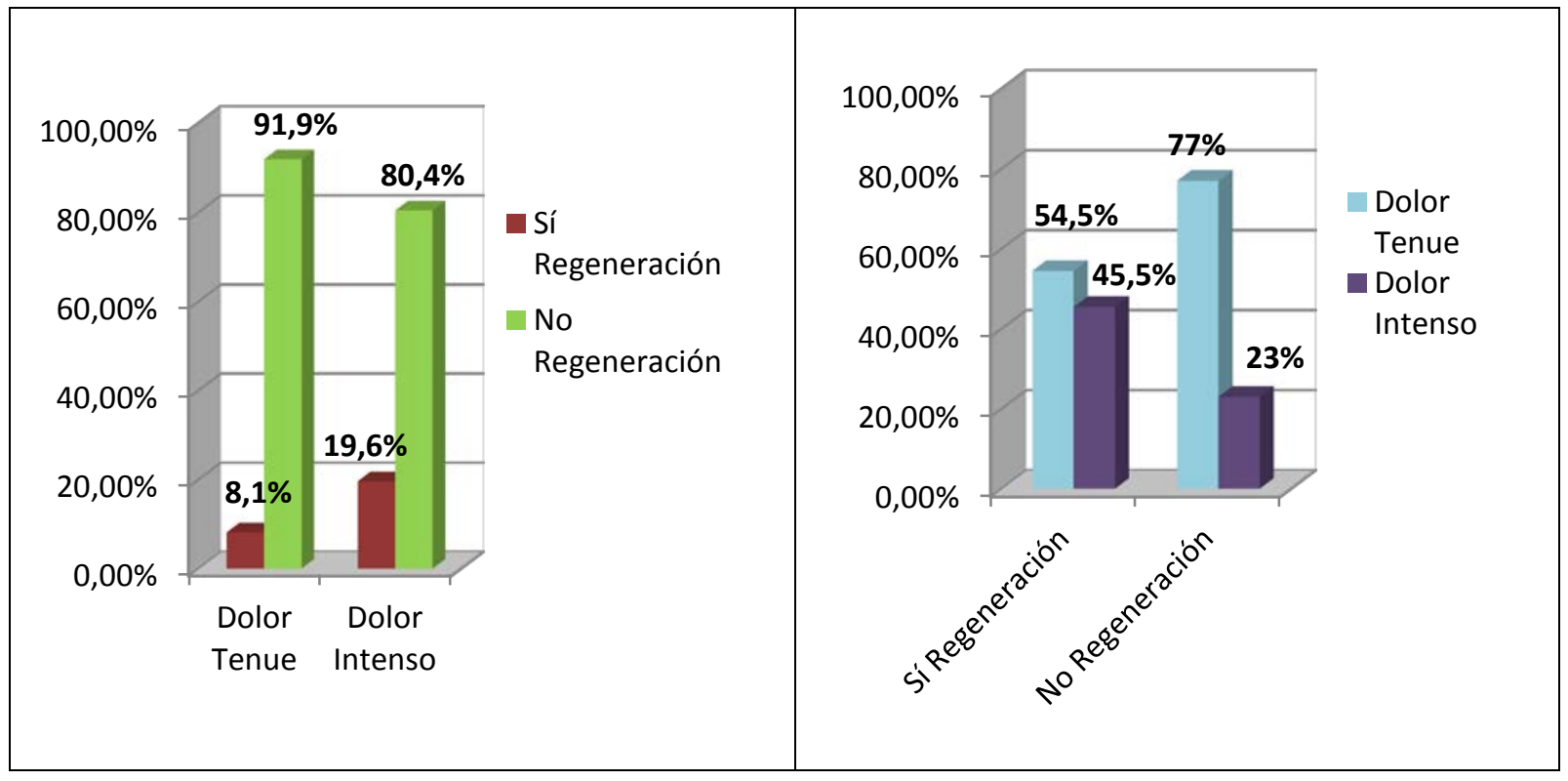

Figura 59: Distribución del dolor en relación a la variable "Regeneración".

De nuevo, en la Figura 59 se observa que a la mayor parte de los pacientes no se les realizó regeneración ósea. Aun así, atendiendo al dolor sufrido, el diagrama de barras muestra que dentro de los que sí se les practicó, el 19,6\% marcaron el dolor como intenso (3 o más en la E.V.A).

Por otro lado, también, se aprecia que los pacientes a los que no se les practicó regeración ósea durante la colocación de los implantes, padecieron menos dolor intenso (23\%), que los pacientes a los que sí se les realizó (45,5\%).

\section{L) Relación de la variable "Dolor" con la de "Sedación"}

A continuación, se representa cómo se distribuye la muestra según el dolor, segmentado por "Sedación” y viceversa. 
Capitulo 4: Resultados

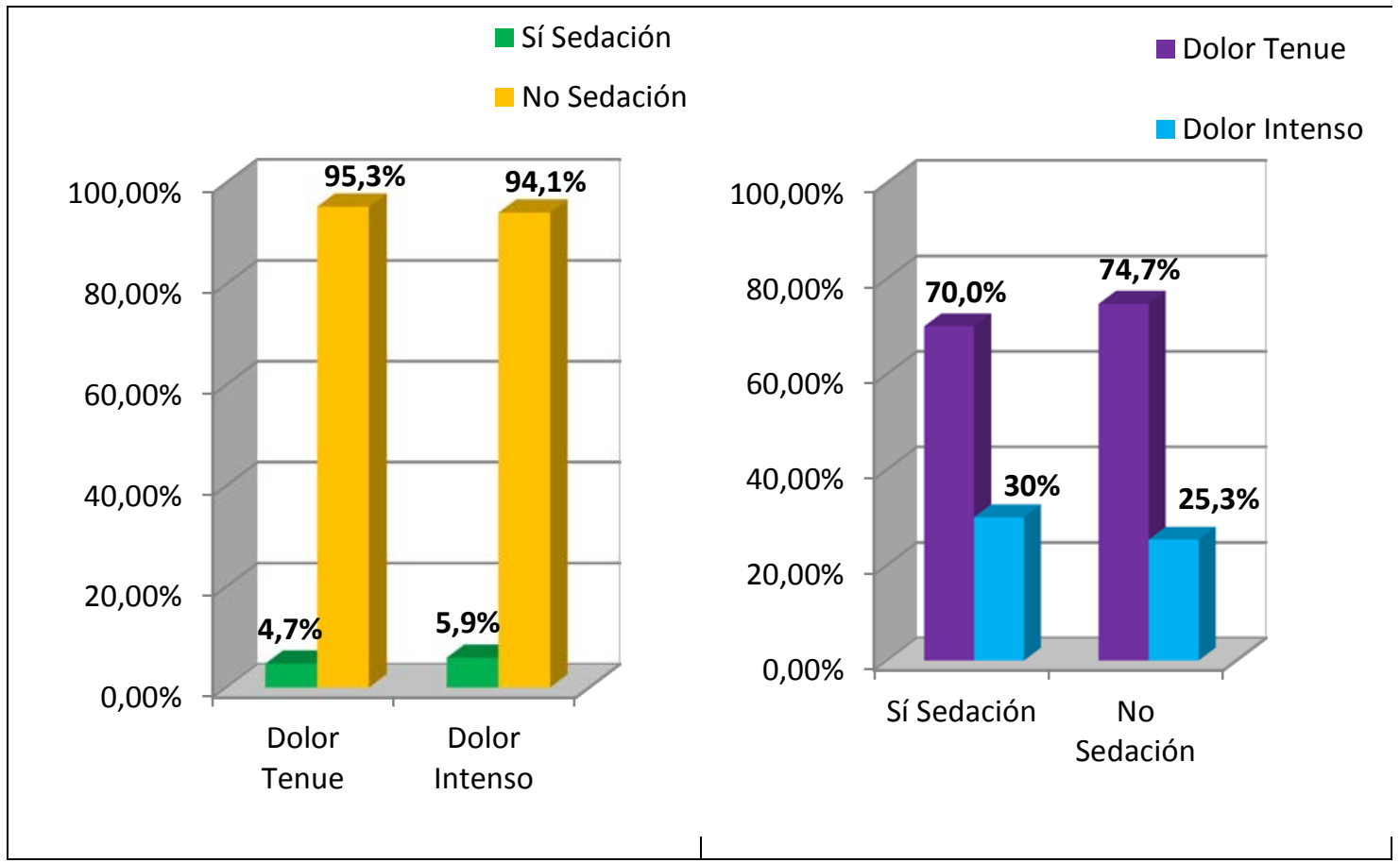

Figura 60: Distribución del dolor en relación a la variable "Sedación".

Como se puede deducir al observar la Figura 60, no hay diferencias significativas entre haber empleado sedación o no a la hora de colocar los implantes dentales, dado que los dos gráficos son prácticamente iguales en cuanto a proporciones. No obstante, el número de pacientes sedados fue muy reducido.

\section{M) Relación de la variable "Dolor" con la de "Postextracción"}

A continuación, se representa cómo se distribuye la muestra según el dolor, segmentado por "Postextracción” y viceversa. 


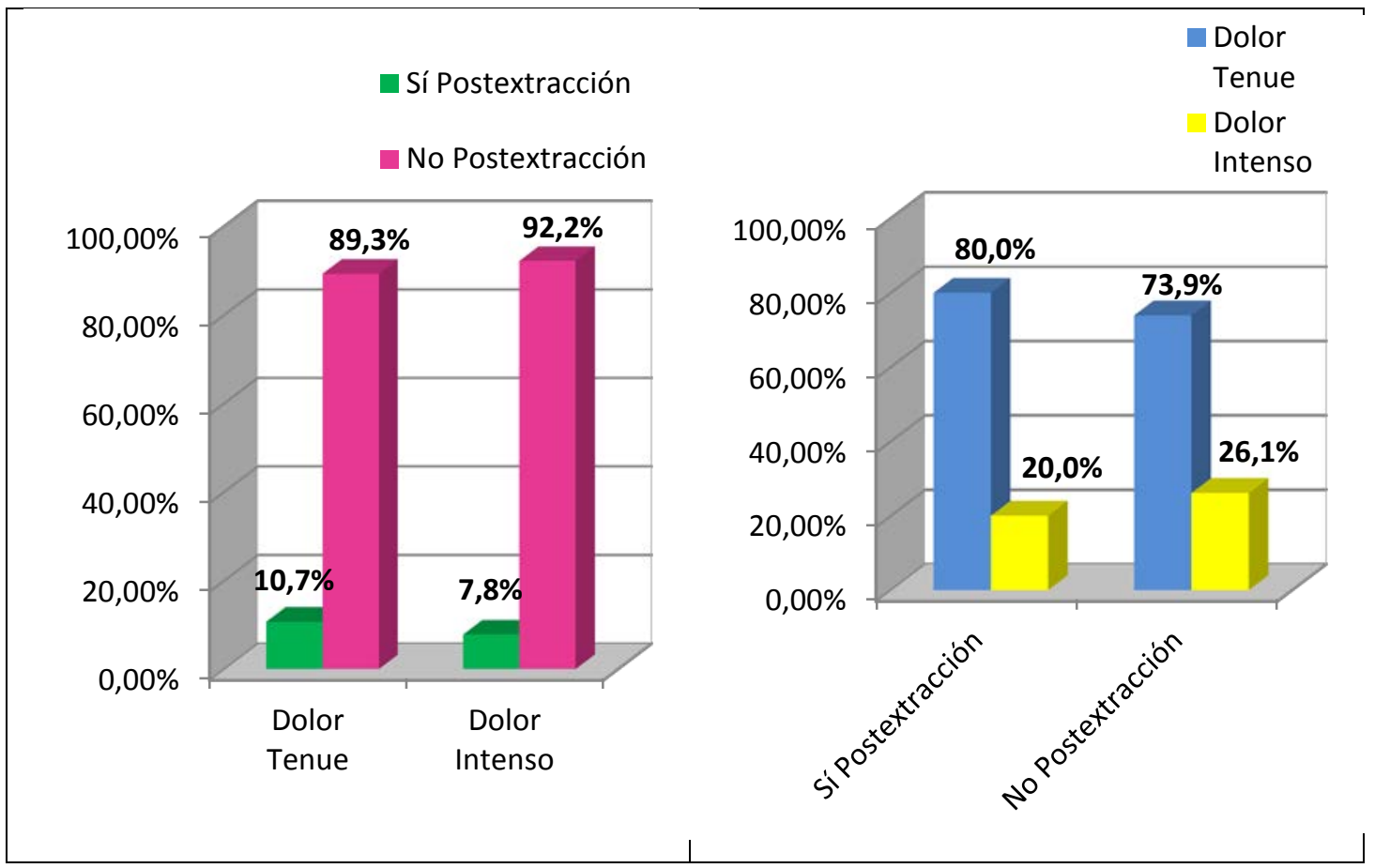

Figura 61: Distribución del dolor en relación a la variable "Postextracción".

La Figura 61, pone de manifiesto que en la mayoría de los pacientes, los implantes fueron colocados de manera convencional (sobre tejido cicatrizado y edéntulo), dejando los casos postextracción para pacientes muy concretos.

Además, se puede observar que el grado de dolor intenso padecido por los pacientes a los que se les colocaron los implantes de manera convencional, fue superior $(26,1 \%)$ respecto al de los que les fueron colocados postextracción (20\%).

\section{N) Relación de la variable "Dolor" con la de "Colgajo"}

A continuación, se representa cómo se distribuye la muestra según el dolor, segmentado por "Colgajo" y viceversa. 


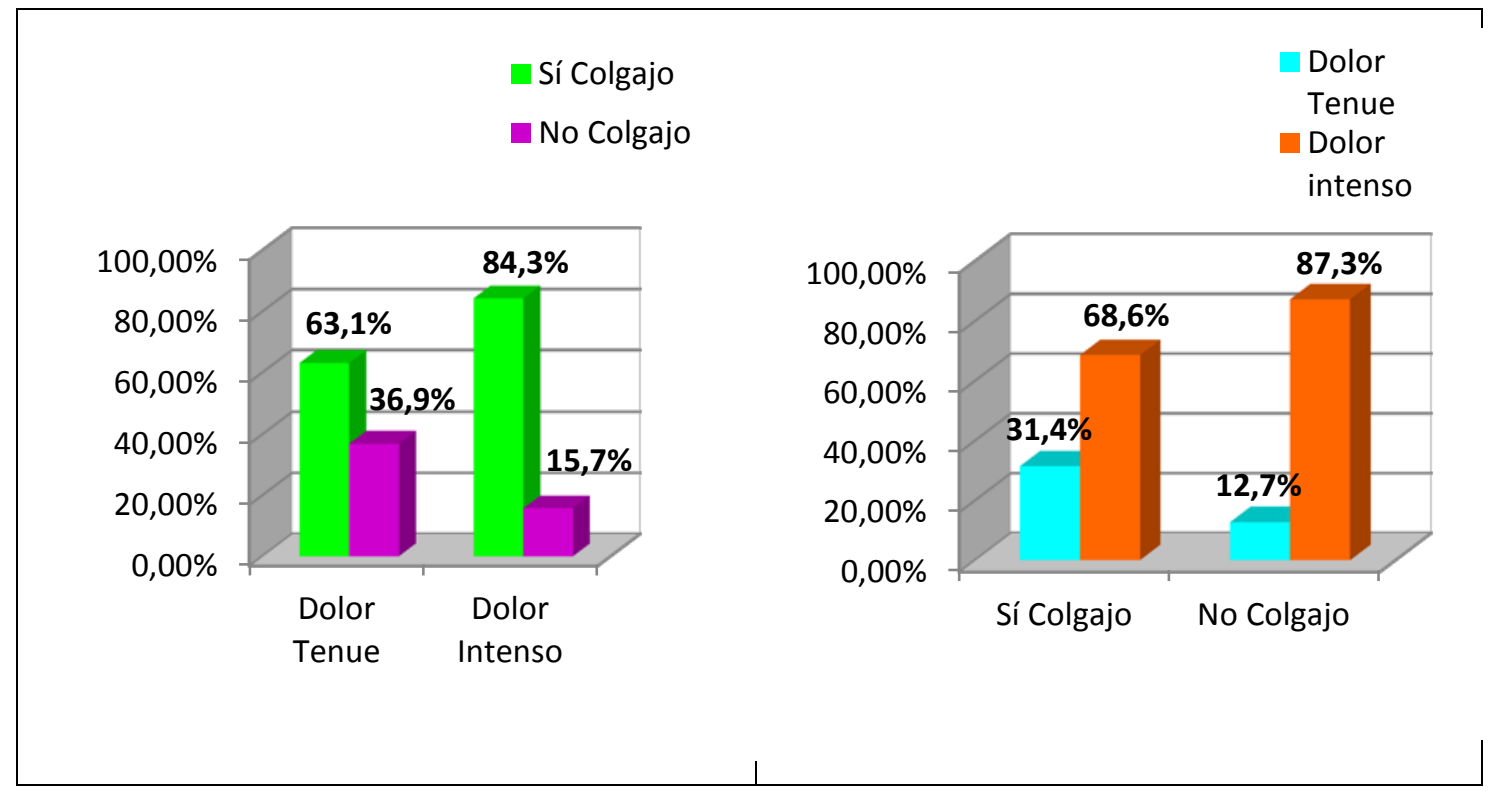

Figura 62: Distribución del dolor en relación a la variable "Colgajo".

En la Figura 62, se observan diferencias entre los pacientes a los que sí se les abrió colgajo con descargas durante la cirugía, con respecto a los que no, puesto que la proporción de los pacientes que marcaron el dolor como intenso es, aproximadamente, el triple en los pacientes con colgajo con respecto a los que no. De los 137 pacientes con colgajo, el 31,4\% marcaron el dolor como intenso, mientras que de los 63 a los que no se les practicó colgajo, sólo el 12,7\% marcaron éste como intenso.

\subsubsection{Contrastes no paramétricos para comparar dos muestras}

En esta sección, se llevarán a cabo las comparaciones de las distintas categorías de las variables generales, respecto de la Escala Visual Analógica del dolor.

En primer lugar, vamos a comprobar que la variable "Dolor E.V.A." no se distribuye normalmente. Para ello, se contrastará la hipótesis nula de que la variable "Dolor E.V.A.” es normal mediante el Test no paramétrico Kolmogorov-Smirnov de normalidad. 
Tabla 27: Prueba K-S de normalidad para la variable "Dolor E.V.A.".

\begin{tabular}{|c|c|c|}
\hline \multicolumn{2}{|c|}{ K-S DE UNA MUESTRA } & $\begin{array}{c}\text { Dolor } \\
\text { E.V.A. }\end{array}$ \\
\hline \multirow{2}{*}{ N } & 200 \\
\hline \multirow{2}{*}{ Parámetros normales } & Media & 1,57 \\
\cline { 2 - 3 } & Desviación típica & 1,697 \\
\hline Z de Kolmogorov-Smirnov & 2,723 \\
\hline \multicolumn{2}{|c|}{ Sig. asintót. (bilateral) } &, 000 \\
\hline
\end{tabular}

Como refleja la Tabla 27, la prueba K-S de normalidad para una muestra, ofrece un p-valor inferior a 0,05 y 0,01 , luego se rechaza la hipótesis nula de normalidad, concluyendo que la variable "Dolor E.V.A." no es normal, por lo tanto, en los sucesivos análisis, se descartan las pruebas paramétricas, como la $\mathrm{T}$ de Student, y se aplicarán pruebas no paramétricas como la prueba U de Mann Whitney o el Test de Kruskal Wallis.

Para comparar la escala "Dolor E.V.A." para las distintas variables generales, se ha de tener en cuenta el número de categorías de estas variables, porque si se trabaja con variables cualitativas nominales dicotómicas, se aplicará la Prueba U de Mann Whitney para datos independientes y, si se hace con variables cualitativas politómicas, se aplicará el Test de Kruskal-Wallis. Para las variables de escala "Edad" y "Número de Implantes", se estudiarán las correlaciones no paramétricas.

En primer lugar, se realizarán los contrastes para las variables nominales dicotómicas, éstas son: "Sexo", "Enfermedades Actuales", “Alergias” y "Medicación”. Los resultados se han recogido en la siguiente tabla. 


\section{Capitulo 4: Resultados}

Tabla 28: Prueba no paramétrica "U-Mann Whitney" para "Dolor EVA" con variables nominales dicotómicas.

\begin{tabular}{|c|c|c|c|c|}
\cline { 2 - 5 } \multicolumn{1}{c|}{} & SEXO & ENF. ACTUALES & ALERGIAS & MEDICACIÓN \\
\hline U-Mann Whitney & 4340 & 2666,5 & 2072 & 2443,5 \\
\hline $\mathbf{Z}$ & $-0,633$ & $-0,940$ & $-0,976$ & $-0,296$ \\
\hline p-valor (bilateral) & 0,527 & 0,347 & 0,329 & 0,767 \\
\hline
\end{tabular}

Como queda reflejado en la Tabla 28, no aparecen p-valores significativos para ninguna de las variables objeto de estudio. Se deduce de ello, que no hay evidencias suficientes para reconocer una relación entre las variables "Sexo", "Enfermedades actuales", “Alergias" y "Medicación", con la variable "Dolor E.V.A.". El resto de variables dicotómicas estudiadas tampoco mostraron resultados estadísticamente significativos.

A continuación, se presenta la prueba Kruskal-Wallis para contrastar la relación del "Dolor E.V.A." con las variables nominales politómicas: "Fumador", "Higiene", "Número de Implantes por intervalo", "Situación del implante" y "Anterior/Posterior".

Tabla 29: Prueba no paramétrica "Kruskal-Wallis" para contrastar la relación de "Dolor E.V.A." con las variables nominales politómicas.

\begin{tabular}{|c|c|c|c|c|c|}
\cline { 2 - 6 } \multicolumn{1}{c|}{} & Fumador & Higiene & $\begin{array}{r}\text { Número } \\
\text { Implantes } \\
\text { Intervalos }\end{array}$ & $\begin{array}{r}\text { Localización } \\
\text { Implante }\end{array}$ & $\begin{array}{c}\text { Anterior/ } \\
\text { Posterior }\end{array}$ \\
\hline Chi-Cuadrado & 0,268 & 3,353 & 19,506 & 2,685 & 20,151 \\
\hline G.L. & 2 & 2 & 2 & 2 & 2 \\
\hline $\begin{array}{c}\text { p-valor } \\
\text { (Significación) }\end{array}$ & 0,875 & 0,187 & 0,000 & 0,261 & 0,000 \\
\hline
\end{tabular}


Atendiendo a los p-valores reflejados en la Tabla 29, las variables "Número de Implantes" y "Anterior/Posterior" están altamente relacionadas con "Dolor E.V.A.”, dado que el p-valor de ambas es menor de 0,05 y de 0,01, como se podía deducir, respectivamente, de las Figura 55 y 57.

El resto de variables, no presentan evidencias suficientes para hablar de relación entre ellas y la variable "Dolor E.V.A.", puesto que el p-valor obtenido con la prueba Kruskal-Wallis es superior a 0,05.

Por último, se presenta la matriz de correlaciones no paramétricas para las variables en escala "Edad" y "Número de implantes", midiendo su relación con la variable "DolorE.V.A.".

Tabla 30: Correlaciones no paramétricas de "Dolor E.V.A." y "Edad".

\begin{tabular}{|c|l|c|c|c|}
\cline { 3 - 4 } \multicolumn{2}{l|}{} & \multirow{2}{*}{ Rho de Spearman } & Dolor E.V.A. & Edad \\
\cline { 3 - 5 } & \multirow{2}{*}{ Edad } & Coefic. de correlación & 1,000 &, $204^{* *}$ \\
\cline { 3 - 5 } & Sig. (bilateral) & $\cdot$ &, 004 \\
\cline { 3 - 5 } & & Coefic. de correlación &, $204^{* *}$ & 1,000 \\
\cline { 3 - 5 } & \multicolumn{2}{|c|}{ Sig. (bilateral) } &, 004 & $\cdot$ \\
\hline
\end{tabular}

Se observa que la correlación entre "Dolor E.V.A." y "Edad" es altamente significativa, dado que el p-valor es, en ambas, menor que 0,05 y que 0,01 (Tabla 30).

Tabla 31: Correlaciones no paramétricas de "Dolor EVA" y "Número de implantes".

\begin{tabular}{|c|c|c|c|c|}
\hline & \multirow{3}{*}{\begin{tabular}{|c|}
$\mathbf{N}^{\mathbf{o}}$ implantes \\
1,000
\end{tabular}} & \multirow{3}{*}{\begin{tabular}{|c|} 
Dolor E.V.A. \\
, $320^{* *}$
\end{tabular}} \\
\hline & & & & \\
\hline \multirow{4}{*}{ Rho de Spearman } & \multirow{2}{*}{ DolorE.V.A. } & Coefic. de correlación & & \\
\hline & & Sig. (bilateral) & . & ,000 \\
\hline & \multirow{2}{*}{$\mathbf{N}^{\circ}$ implantes } & Coefic. de correlación &, $320^{* *}$ & 1,000 \\
\hline & & Sig. (bilateral) & ,000 & . \\
\hline
\end{tabular}




\begin{tabular}{|c|c|c|c|c|}
\hline & \multirow{3}{*}{$\frac{\mathbf{N}^{\mathbf{o}} \text { implantes }}{1,000}$} & \multirow{3}{*}{\begin{tabular}{|c|} 
Dolor E.V.A. \\
$320^{* *}$
\end{tabular}} \\
\hline & & & & \\
\hline \multirow{4}{*}{ Rho de Spearman } & \multirow{2}{*}{ DolorE.V.A. } & Coefic. de correlación & & \\
\hline & & Sig. (bilateral) & . & ,000 \\
\hline & \multirow{2}{*}{$\mathbf{N}^{\circ}$ implantes } & Coefic. de correlación & $320^{* *}$ & 1,000 \\
\hline & & Sig. (bilateral) & 000 & . \\
\hline & La correlacic & in es significativa al nis & 10,01 (bilateral). & \\
\hline
\end{tabular}

En este caso, se aprecia, de nuevo, una alta significación en la correlación entre las variables "Dolor E.V.A.” y "Número de implantes", al ser los p-valores también menores que 0,05 y 0,01 .

Si comparamos los coeficientes de correlación de la variable "Dolor E.V.A." con las variables "Edad" y "Número de implantes", podemos observar que, en ambos casos, dichos coeficientes no son muy elevados y la relación es directa, pues los coeficientes son positivos. No obstante, en el caso de la variable "Número de implantes" se aprecia una mayor correlación.

\subsubsection{Análisis factorial para las variables del postoperatorio}

Con la finalidad de comprobar cómo se comportan las variables del postoperatorio "Dolor", "Inflamación" y "Hematoma", todas ellas a las 12, 24, 48 horas y 3, 5 y 7 días, se ha realizado un análisis factorial con el objeto de reducir las dimensiones de todas esas variables y ver cómo covarían todas entre sí. Para ello, después de un primer análisis exploratorio, se ha tomado la decisión de reducir la dimensionalidad a 3, por el hecho de que estos tres factores van a explicar, de la mejor manera posible, el comportamiento de las variables del postoperatorio.

En primer lugar, vemos la Tabla 32 que nos muestra la varianza total explicada por los tres factores, utilizando el método de extracción de análisis de componentes principales. La primera dimensión hace referencia al dolor y la inflamación desde las 48 horas de la

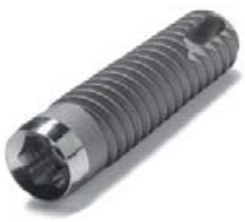


intervención hasta los 7 días, la segunda se refiere a todos los valores de la variable hematoma y la tercera al dolor y la inflamación padecidos las primeras 24 horas después de la cirugía.

Tabla 32: Método de extracción: Análisis de componentes principales.

\begin{tabular}{|c|c|c|c|c|c|c|c|c|c|c|}
\hline \multicolumn{11}{|c|}{ VARIANZA TOTAL EXPLICADA } \\
\hline \multirow{2}{*}{\multicolumn{2}{|c|}{ Componente }} & \multicolumn{3}{|c|}{ Autovalores iniciales } & \multicolumn{3}{|c|}{$\begin{array}{l}\text { Sumas de las saturaciones al } \\
\text { cuadrado de la extracción }\end{array}$} & \multicolumn{3}{|c|}{$\begin{array}{c}\text { Suma de las saturaciones al } \\
\text { cuadrado de la rotación }\end{array}$} \\
\hline & & Total & $\begin{array}{l}\% \text { de la } \\
\text { varianza }\end{array}$ & $\begin{array}{c}\% \\
\text { acumulado }\end{array}$ & Total & $\begin{array}{l}\% \text { de la } \\
\text { varianza }\end{array}$ & $\begin{array}{c}\% \\
\text { acumulado }\end{array}$ & Total & $\begin{array}{l}\% \text { de la } \\
\text { varianza }\end{array}$ & $\begin{array}{c}\% \\
\text { acumulado }\end{array}$ \\
\hline \multirow{3}{*}{ Dimensión } & 1 & 7,654 & 42,523 & 42,523 & 7,654 & 42,523 & 42,523 & 4,273 & 23,740 & 23,740 \\
\hline & 2 & 2,742 & 15,234 & 57,757 & 2,742 & 15,234 & 57,757 & 4,157 & 23,093 & 46,832 \\
\hline & 3 & 1,664 & 9,245 & 67,002 & 1,664 & 9,245 & 67,002 & 3,631 & 20,170 & 67,002 \\
\hline
\end{tabular}

A partir de esta tabla, podemos afirmar que los tres factores extraídos durante el proceso, tienen una absorción de inercia del 67\%, lo que quiere decir, que del 100\% de la variabilidad existente en los datos, los tres factores extraídos explicarán el 67\%. Este resultado se puede considerar como bueno, pudiendo aceptar las conclusiones que se extraigan de análisis posteriores.

A continuación se detallan, finalmente, los resultados obtenidos en el análisis factorial a partir de la matriz de componentes rotados. 
Tabla 33: Matriz de componentes rotados.

\begin{tabular}{|c|c|c|c|}
\cline { 2 - 4 } \multicolumn{1}{c|}{} & \multicolumn{3}{c|}{ Componente } \\
\cline { 2 - 4 } & 1 & 2 & 3 \\
\hline Dolor 12H & & &, 487 \\
\hline Dolor 24H & & &, 664 \\
\hline Dolor 48H &, 650 & & \\
\hline Dolor 3 Días &, 848 & & \\
\hline Dolor 5 Días &, 878 & & \\
\hline Dolor 7 Días &, 731 & & \\
\hline Inflamación 12H & & &, 653 \\
\hline Inflamación 24H & & &, 831 \\
\hline Inflamación 48H &, 450 & & \\
\hline Inflamación 3 Días &, 552 & & \\
\hline Inflamación 5 Días &, 648 & & \\
\hline Inflamación 7 Días &, 575 & & \\
\hline Hematoma 12H & &, 531 & \\
\hline Hematoma 24H & &, 670 & \\
\hline Hematoma 48H & &, 830 & \\
\hline Hematoma 3 Días & &, 911 & \\
\hline Hematoma 5 Días & &, 894 & \\
\hline Hematoma 7 Días & &, 861 & \\
\hline Método de extracción: Análisis de componentes principales. \\
Método de rotación: Normalización Varimax con Kaiser. \\
\hline
\end{tabular}

Como se puede comprobar en la matriz de componentes rotados, las variables del postoperatorio que hacen referencia a "Hematoma" para cualquier intervalo de tiempo, se comportan de manera diferente a las variables de "Inflamación" y "Dolor" pues, como se observa, cargan todas en el segundo factor.

En el caso de "Dolor" e "Inflamación" se observan diferencias entre las variables 12 y 24 horas frente al resto, cargando éstas en el tercer factor, mientras que las demás cargan

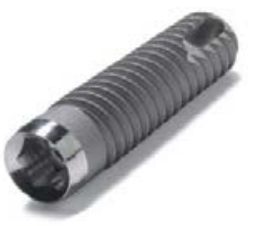


en el primero. Por tanto, se puede afirmar que tanto a las 12 como a las 24 horas, la variabilidad en las respuestas de los pacientes difiere, significativamente, de las respuestas obtenidas a partir de las 48 horas para las variables "Dolor" e "Inflamación".

\subsubsection{Análisis trifactorial para las variables "Dolor", "Edad"y "Sexo" en busca de posibles interacciones}

En este apartado, se pretende contrastar la hipótesis de que no existe relación entre las variables "Dolor", "Sexo" y "Edad".

Para contrastar las siguientes hipótesis:

$\left\{\begin{array}{l}\mathrm{H}_{0}: \text { Dolor, Sexo y Edad son independientes conjuntamente. } \\ \mathrm{H}_{\AA}: \text { Existe relación entre Dolor, Sexo y Edad. }\end{array}\right.$

Se tienen que dar las siguientes relaciones:

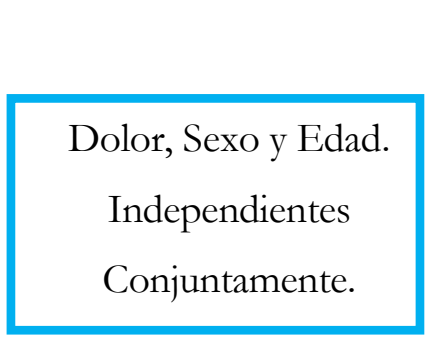

Dolor es independiente del Sexo para cualquier intervalo de Edad.

olor, Sexo y Edad.

pendientes

Dolor es independiente de la Edad para cualquier Sexo.

Conjuntamente.

\section{Y}

Edad es independiente del Sexo para cualquier nivel Dolor.

En primer lugar, se contrasta la hipótesis nula de que "Dolor" es independiente del "Sexo" para cualquier intervalo de edad. 
Capitulo 4: Resultados

Tabla 34: Prueba Chi-Cuadrado de independencia condicionada por edad, entre dolor y sexo.

\begin{tabular}{|cc|c|c|c|}
\hline InterEdad & Valor & gl & P-valor \\
\hline \multirow{2}{*}{ Menores de $\mathbf{5 0}$} & Chi-cuadrado de Pearson &, 052 & 1 & \\
& N de casos válidos & 100 & & \\
\hline \multirow{2}{*}{ Mayores de 50 } & Chi-cuadrado de Pearson &, 374 & 1 & \\
& N de casos válidos & 100 & & \\
\hline & SUMA & 0,426 & 2 & $\mathbf{0 , 8 0}$ \\
\hline
\end{tabular}

Como $0,80>0,05$, no hay evidencias para rechazar la hipótesis nula y, por tanto, se puede decir que dolor es independiente del sexo para cualquier intervalo de edad.

En segundo lugar, se contrasta la hipótesis de que edad y sexo son independientes, en cualquiera de los niveles de dolor.

Tabla 35: Prueba de Chi-Cuadrado de independencia condicionada por dolor, entre sexo y edad.

\begin{tabular}{|cc|c|c|c|}
\hline & DolorEvaInter & Valor & gl & P-Valor \\
\hline $\begin{array}{c}\text { Dolor } \\
\text { Tenue }\end{array}$ & Chi-cuadrado de Pearson &, 007 & 1 & \\
\hline $\begin{array}{c}\text { Dolor } \\
\text { Intenso }\end{array}$ & N de casos válidos & 149 & & \\
\hline & N de casos válidos & 51 & & \\
\hline
\end{tabular}

Como 0,98>0,05 no hay evidencias para rechazar la hipótesis nula y se puede decir que el sexo y la edad son independientes para cualquier dolor.

Por último, se contrasta la hipótesis de que el nivel de dolor es independiente de la edad, en ambos sexos. 
Tabla 36: Prueba de Chi-Cuadrado de independencia condicionada por sexo, entre edad y dolor.

\begin{tabular}{|cc|c|c|c|}
\hline \multirow{3}{*}{ Hombre } & Sexo & Valor & gl & P-Valor \\
\hline \multirow{2}{*}{ Mujer } & Chi-cuadrado de Pearson & 4,148 & 1 & \\
& N de casos válidos & 71 & & \\
\hline & Chi-cuadrado de Pearson & 5,365 & 1 & \\
& N de casos válidos & 129 & & \\
\hline
\end{tabular}

Como 0,009<0,05, hay evidencias suficientes para rechazar la hipótesis nula y se puede decir que el dolor está relacionado con la edad en alguno de los sexos.

Como conclusión, se demuestra que no hay independencia completa entre las variables "Dolor", "Sexo" y "Edad", pero existe evidencia de una independencia múltiple. Considerando el nivel de dolor en los estratos de edad, no se detectan resultados diferentes en los dos sexos, lo que implica que el dolor no depende del sexo.

Puesto que se ha demostrado la existencia de una relación entre las variables "Edad" y "Dolor”, se comprueba, a continuación, qué tipo de relación existe entre dichas variables.

Tabla 37: Tabla de contingencia para edad y dolor.

\begin{tabular}{|c|c|c|c|}
\cline { 3 - 4 } \multicolumn{2}{c|}{} & \multicolumn{2}{c|}{ Intervalo Dolor E.V.A. } \\
\cline { 3 - 4 } \multicolumn{2}{c|}{} & Dolor Tenue & Dolor Intenso \\
\hline \multirow{3}{*}{ Intervalo Edad } & Menores de 50 & $\mathbf{4 2 , 0 \%}$ & $\mathbf{8 , 0 \%}$ \\
\cline { 2 - 4 } & Mayores de 50 & $\mathbf{3 2 , 5 \%}$ & $\mathbf{1 7 , 5 \%}$ \\
\hline
\end{tabular}


Capitulo 4: Resultados

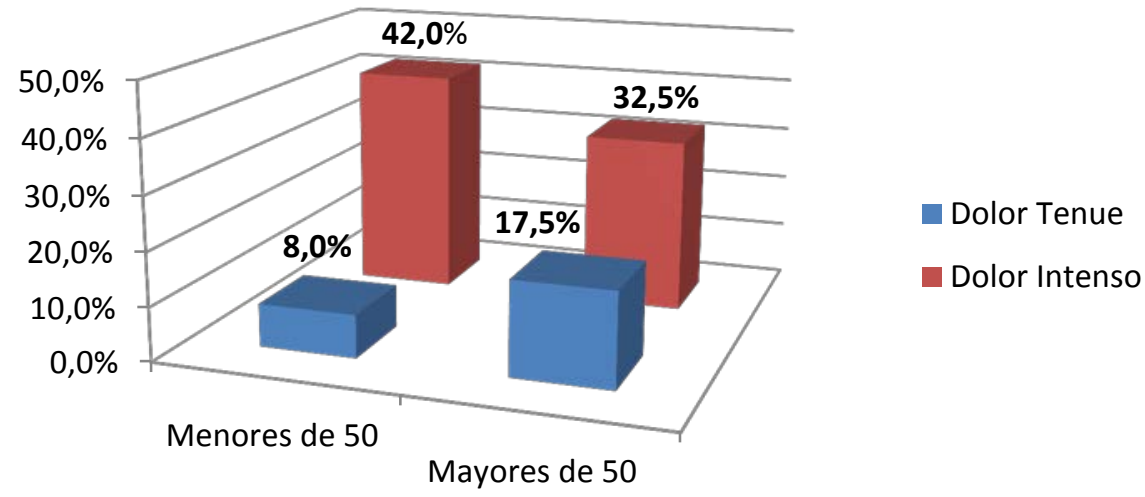

Figura 63: Comportamiento del dolor según la edad.

Estos resultados muestran la relación existente entre dolor y edad: a mayor edad, se observa que crece la proporción de pacientes con dolor postoperatorio más intenso, es decir, las personas menores de 50 presentan un mejor postoperatorio.

A continuación, se muestra el gráfico con la escala de la variable "Dolor E.V.A." para cada individuo con su edad, y la relación lineal que demuestra la tendencia creciente del dolor E.V.A. conforme aumenta la edad:

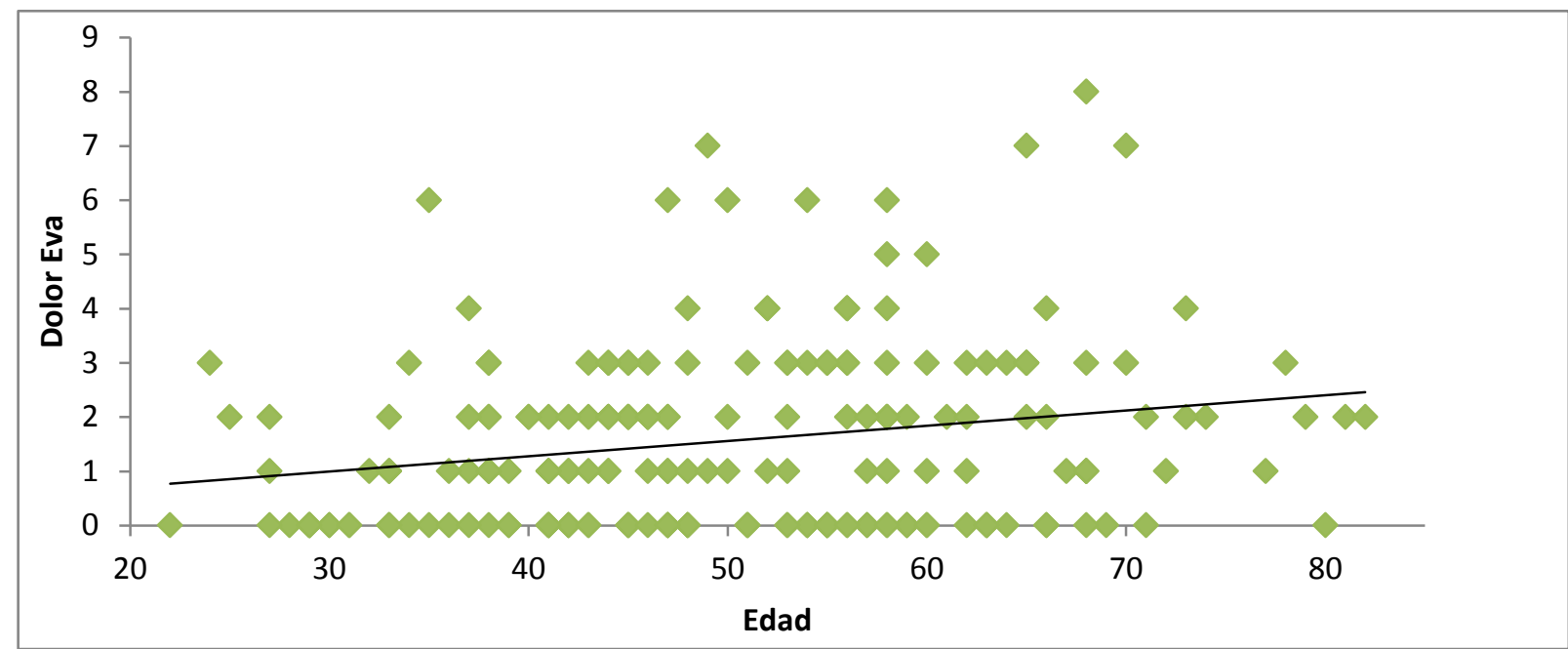

Figura 64: Dispersión de la variable "Edad" frente a la variable "DolorE.V.A.". 


\subsubsection{Relación entre las variables}

A continuación, se muestran las tablas con la información correspondiente a los contrastes Chi-Cuadrado, para la comparación de las variables "Dolor" "Inflamación" y "Hematoma" con el resto de variables.

En cada casilla se muestra el valor del coeficiente y el p-valor asociado.

Se marcan en verde, aquellas variables que han mostrado una relación significativa, y en azul, las que lo han hecho pero con más de un 50\% de las casillas con baja frecuencia (menor o igual que 5).

Aquellos p-valores marcados con superíndice ${ }^{1}$, son los correspondientes a las tablas que tenían más del $50 \%$ de casillas con baja frecuencia pero cuyos contrastes no han resultado significativos, por lo que el resultado no se ve alterado por estas frecuencias bajas.

\section{A) Relación entre las variables generales y la variable "Dolor"}

Tabla 38: Contrastes Chi-Cuadrado de independencia entre las variables generales y la variable "Dolor".

\begin{tabular}{|c|c|c|c|c|c|c|}
\hline & $\begin{array}{c}\text { Dolor } \\
12 \mathrm{H} .\end{array}$ & $\begin{array}{c}\text { Dolor } \\
24 \mathrm{H} .\end{array}$ & $\begin{array}{c}\text { Dolor } \\
48 \mathrm{H} .\end{array}$ & $\begin{array}{c}\text { Dolor } \\
\text { 3D. }\end{array}$ & $\begin{array}{c}\text { Dolor } \\
\text { 5D. }\end{array}$ & $\begin{array}{c}\text { Dolor } \\
\text { 7D. }\end{array}$ \\
\hline Sexo & $\begin{array}{c}1,043 \\
\mathrm{p}=0,791\end{array}$ & $\begin{array}{c}1,929 \\
\mathrm{p}=0,587\end{array}$ & $\begin{array}{c}0,323 \\
\mathrm{p}=0,956\end{array}$ & $\begin{array}{c}3,372 \\
\mathrm{p}=0,338^{1}\end{array}$ & $\begin{array}{c}0,497 \\
\mathrm{p}=0,920^{1}\end{array}$ & $\begin{array}{c}5,374 \\
\mathrm{p}=0,146^{1}\end{array}$ \\
\hline Fumador & $\begin{array}{c}1,992 \\
\mathrm{p}=0,920\end{array}$ & $\begin{array}{c}9,958 \\
p=0,126\end{array}$ & $\begin{array}{c}8,054 \\
p=0,2341\end{array}$ & $\begin{array}{c}4,068 \\
\mathrm{p}=0,6671\end{array}$ & $\begin{array}{c}3,281 \\
\mathrm{p}=0,773^{1}\end{array}$ & $\begin{array}{c}3,287 \\
\mathrm{p}=0,772^{1}\end{array}$ \\
\hline Higiene & $\begin{array}{c}2,515 \\
\mathrm{p}=0,867\end{array}$ & $\begin{array}{c}17,744 \\
\mathrm{p}=0,007\end{array}$ & $\begin{array}{c}8,931 \\
\mathrm{p}=0,178\end{array}$ & $\begin{array}{c}4,557 \\
\mathrm{p}=0,602^{1}\end{array}$ & $\begin{array}{c}7,238 \\
\mathrm{p}=0,299^{1}\end{array}$ & $\begin{array}{c}14,873 \\
\mathrm{p}=0,021\end{array}$ \\
\hline Enfermedades act. & $\begin{array}{c}3,806 \\
\mathrm{p}=0,283\end{array}$ & $\begin{array}{c}0,305 \\
\mathrm{p}=0,959\end{array}$ & $\begin{array}{c}1,227 \\
\mathrm{p}=0,747\end{array}$ & $\begin{array}{c}2,044 \\
\mathrm{p}=0,563\end{array}$ & $\begin{array}{c}2,170 \\
\mathrm{p}=0,538^{1}\end{array}$ & $\begin{array}{c}5,285 \\
\mathrm{p}=0,152^{1}\end{array}$ \\
\hline Alergias & $\begin{array}{c}13,584 \\
p=0,004\end{array}$ & $\begin{array}{c}13,418 \\
p=0,004\end{array}$ & $\begin{array}{c}7,721 \\
p=0,052\end{array}$ & $\begin{array}{c}7,443 \\
\mathrm{p}=0,059^{1}\end{array}$ & $\begin{array}{c}11,671 \\
\mathrm{p}=0,009\end{array}$ & $\begin{array}{c}8,106 \\
p=0,044\end{array}$ \\
\hline Medicación & $\begin{array}{c}0,982 \\
\mathrm{p}=0,806\end{array}$ & $\begin{array}{c}1,363 \\
p=0,714\end{array}$ & $\begin{array}{c}3,333 \\
\mathrm{p}=0,343\end{array}$ & $\begin{array}{c}5,441 \\
\mathrm{p}=0,142\end{array}$ & $\begin{array}{c}3,882 \\
\mathrm{p}=0,2741\end{array}$ & $\begin{array}{c}4,681 \\
\mathrm{p}=0,1971\end{array}$ \\
\hline
\end{tabular}


Capitulo 4: Resultados

\begin{tabular}{|c|c|c|c|c|c|c|}
\hline Número de Impl. & $\begin{array}{c}27,036 \\
\mathrm{p}=0,170^{1}\end{array}$ & $\begin{array}{c}41,929 \\
p=0,004\end{array}$ & $\begin{array}{c}42,502 \\
p=0,004\end{array}$ & $\begin{array}{c}30,081 \\
\mathrm{p}=0,090^{1}\end{array}$ & $\begin{array}{c}38,700 \\
\mathrm{p}=0,011\end{array}$ & $\begin{array}{c}33,498 \\
p=0,041\end{array}$ \\
\hline Intervalos Edad & $\begin{array}{c}9,366 \\
p=0,025\end{array}$ & $\begin{array}{c}4,932 \\
p=0,177\end{array}$ & $\begin{array}{c}6,506 \\
p=0,089\end{array}$ & $\begin{array}{c}4,824 \\
\mathrm{p}=0,185^{1}\end{array}$ & $\begin{array}{c}10,410 \\
\mathrm{p}=0,015\end{array}$ & $\begin{array}{c}3,196 \\
\mathrm{p}=0,362^{1}\end{array}$ \\
\hline Dolor EVA Intervalos & $\begin{array}{c}46,352 \\
p=0,000\end{array}$ & $\begin{array}{c}65,639 \\
\mathrm{p}=0,000\end{array}$ & $\begin{array}{c}90,593 \\
p=0,000\end{array}$ & $\begin{array}{c}59,461 \\
\mathrm{p}=0,000\end{array}$ & $\begin{array}{c}45,624 \\
\mathrm{p}=0,000\end{array}$ & $\begin{array}{c}23,061 \\
p=0,000\end{array}$ \\
\hline Número Implantes Interv. & $\begin{array}{c}10,717 \\
\mathrm{p}=0,098\end{array}$ & $\begin{array}{c}18,556 \\
\mathrm{p}=0,005\end{array}$ & $\begin{array}{c}17,926 \\
\mathrm{p}=0,006\end{array}$ & $\begin{array}{c}8,528 \\
\mathrm{p}=0,202^{1}\end{array}$ & $\begin{array}{c}17,746 \\
\mathrm{p}=0,007\end{array}$ & $\begin{array}{c}3,835 \\
\mathrm{p}=0,699^{1}\end{array}$ \\
\hline Situación del Implante & $\begin{array}{c}8,941 \\
\mathrm{p}=0,177^{1}\end{array}$ & $\begin{array}{c}7,892 \\
\mathrm{p}=0,246^{1}\end{array}$ & $\begin{array}{c}4,000 \\
\mathrm{p}=0,6771\end{array}$ & $\begin{array}{c}8,466 \\
\mathrm{p}=0,206^{1}\end{array}$ & $\begin{array}{c}10,288 \\
\mathrm{p}=0,113^{1}\end{array}$ & $\begin{array}{c}4,438 \\
p=0,618^{1}\end{array}$ \\
\hline Anterior/Posterior & $\begin{array}{c}3,423 \\
p=0,754\end{array}$ & $\begin{array}{c}19,164 \\
p=0,004\end{array}$ & $\begin{array}{c}13,018 \\
\mathrm{p}=0,043\end{array}$ & $\begin{array}{c}13,428 \\
p=0,036\end{array}$ & $\begin{array}{c}9,559 \\
\mathrm{p}=0,145^{1}\end{array}$ & $\begin{array}{c}9,951 \\
\mathrm{p}=0,127^{1}\end{array}$ \\
\hline Elevación & $\begin{array}{c}4,782 \\
\mathrm{p}=0,188^{1}\end{array}$ & $\begin{array}{c}1,689 \\
\mathrm{p}=0,6391\end{array}$ & $\begin{array}{c}2,347 \\
\mathrm{p}=0,504^{1}\end{array}$ & $\begin{array}{c}2,395 \\
\mathrm{p}=0,495^{1}\end{array}$ & $\begin{array}{c}0,466 \\
\mathrm{p}=0,926^{1}\end{array}$ & $\begin{array}{c}0,602 \\
\mathrm{p}=0,896^{1}\end{array}$ \\
\hline Regeneración & $\begin{array}{c}0,626 \\
p=0,890\end{array}$ & $\begin{array}{c}3,096 \\
\mathrm{p}=0,377\end{array}$ & $\begin{array}{c}6,926 \\
\mathrm{p}=0,074^{1}\end{array}$ & $\begin{array}{c}8,095 \\
\mathrm{p}=0,044\end{array}$ & $\begin{array}{c}2,220 \\
p=0,528^{1}\end{array}$ & $\begin{array}{c}1,578 \\
\mathrm{p}=0,664^{1}\end{array}$ \\
\hline Sedación & $\begin{array}{c}1,255 \\
p=0,740\end{array}$ & $\begin{array}{c}1,281 \\
\mathrm{p}=0,734^{1}\end{array}$ & $\begin{array}{c}4,823 \\
\mathrm{p}=0,185^{1}\end{array}$ & $\begin{array}{c}3,008 \\
\mathrm{p}=0,390^{1}\end{array}$ & $\begin{array}{c}0,399 \\
\mathrm{p}=0,940^{1}\end{array}$ & $\begin{array}{c}0,672 \\
\mathrm{p}=0,880^{1}\end{array}$ \\
\hline Postextracción & $\begin{array}{c}2,650 \\
p=0,749\end{array}$ & $\begin{array}{c}4,608 \\
p=0,203\end{array}$ & $\begin{array}{c}4,098 \\
\mathrm{p}=0,251^{1}\end{array}$ & $\begin{array}{c}1,984 \\
\mathrm{p}=0,576^{1}\end{array}$ & $\begin{array}{c}3,642 \\
\mathrm{p}=0,303^{1}\end{array}$ & $\begin{array}{c}1,865 \\
\mathrm{p}=0,601^{1}\end{array}$ \\
\hline Colgajo & $\begin{array}{c}10,790 \\
p=0,013\end{array}$ & $\begin{array}{c}6,953 \\
\mathrm{p}=0,073\end{array}$ & $\begin{array}{c}10,144 \\
p=0,017\end{array}$ & $\begin{array}{c}7,576 \\
\mathrm{p}=0,056^{1}\end{array}$ & $\begin{array}{c}7,999 \\
\mathrm{p}=0,046\end{array}$ & $\begin{array}{c}1,817 \\
\mathrm{p}=0,611^{1}\end{array}$ \\
\hline
\end{tabular}

Como se observa en la Tabla 38, las variables: "Sexo", "Fumador", "Enfermedades Actuales", "Medicación", "Situación del implante”, "Elevación”, "Sedación” y "Postextracción" no presentan relación alguna con las distintas variables de dolor.

Las variables menos relacionadas son "Higiene", que se relaciona sólo con el dolor a las 24h, e "Intervalos de Edad" que se relaciona sólo con el dolor a las 12h.

De igual manera, las variables que presentan mayor relación con el dolor son: "Alergias", relacionada con dolor a las 12 y 24h, "Dolor E.V.A. Intervalos", ampliamente relacionada con dolor, "Número Implantes Intervalos", relacionada con el dolor a las $24 \mathrm{y}$ 48h, "Anterior o Posterior", relacionada con dolor a las 24 y $48 \mathrm{~h}$ y "Colgajo" relacionada con dolor a las 12 y $48 \mathrm{~h}$. 
Por lo general, existe mayor relación de las variables con el dolor en las primeras 48 horas y, a partir del tercer día, no se puede afirmar nada con los contrastes chi-cuadrado de independencia anteriores, dado que la mayor parte de los pacientes, a partir de ese día, se incluyen en las celdas de "Dolor Tenue", dejando las celdas correspondientes al "Dolor Intenso" con frecuencias muy bajas o vacías.

\section{B) Relación entre las variables generales y la variable "Inflamación"}

Tabla 39: Contrastes Chi-Cuadrado de independencia entre las variables generales y la variable "Inflamación".

\begin{tabular}{|c|c|c|c|c|c|c|}
\hline & $\begin{array}{c}\text { Inflam. } \\
12 \mathrm{H} \text {. }\end{array}$ & $\begin{array}{l}\text { Inflam. } \\
24 \mathrm{H} \text {. }\end{array}$ & $\begin{array}{c}\text { Inflam. } \\
48 \mathrm{H} \text {. }\end{array}$ & $\begin{array}{c}\text { Inflam. } \\
3 \text { D. }\end{array}$ & $\begin{array}{c}\text { Inflam. } \\
5 \mathrm{D} .\end{array}$ & $\begin{array}{c}\text { Inflam. } \\
\text { 7D. }\end{array}$ \\
\hline Sexo & $\begin{array}{c}1,385 \\
\mathrm{p}=0,709\end{array}$ & $\begin{array}{c}4,003 \\
p=0,261\end{array}$ & $\begin{array}{c}2,211 \\
\mathrm{p}=0,530\end{array}$ & $\begin{array}{c}1,243 \\
\mathrm{p}=0,743\end{array}$ & $\begin{array}{c}0,744 \\
\mathrm{p}=0,863^{1}\end{array}$ & $\begin{array}{c}1,138 \\
p=0,768^{1}\end{array}$ \\
\hline Fumador & $\begin{array}{c}2,307 \\
\mathrm{p}=0,889\end{array}$ & $\begin{array}{c}6,865 \\
p=0,334\end{array}$ & $\begin{array}{c}5,994 \\
\mathrm{p}=0,424\end{array}$ & $\begin{array}{c}4,840 \\
\mathrm{p}=0,565^{1}\end{array}$ & $\begin{array}{c}7,985 \\
\mathrm{p}=0,239^{1}\end{array}$ & $\begin{array}{c}6,547 \\
p=0,365^{1}\end{array}$ \\
\hline Higiene & $\begin{array}{c}1,270 \\
\mathrm{p}=0,973^{1}\end{array}$ & $\begin{array}{c}4,801 \\
p=0,570\end{array}$ & $\begin{array}{c}5,243 \\
\mathrm{p}=0,513\end{array}$ & $\begin{array}{c}1,646 \\
\mathrm{p}=0,949^{1}\end{array}$ & $\begin{array}{c}8,133 \\
\mathrm{p}=0,229^{1}\end{array}$ & $\begin{array}{c}4,885 \\
\mathrm{p}=0,559^{1}\end{array}$ \\
\hline Enfermedades act. & $\begin{array}{c}3,391 \\
\mathrm{p}=0,335\end{array}$ & $\begin{array}{c}2,257 \\
p=0,521\end{array}$ & $\begin{array}{c}1,504 \\
p=0,681\end{array}$ & $\begin{array}{c}3,291 \\
\mathrm{p}=0,349\end{array}$ & $\begin{array}{c}0,282 \\
\mathrm{p}=0,963^{1}\end{array}$ & $\begin{array}{c}0,924 \\
\mathrm{p}=0,820^{1}\end{array}$ \\
\hline Alergias & $\begin{array}{c}8,485 \\
p=0,037\end{array}$ & $\begin{array}{c}18,111 \\
\mathrm{p}=0,000\end{array}$ & $\begin{array}{c}3,702 \\
\mathrm{p}=0,296\end{array}$ & $\begin{array}{c}7,805 \\
\mathrm{p}=0,050\end{array}$ & $\begin{array}{c}16,200 \\
p=0,001\end{array}$ & $\begin{array}{c}7,730 \\
\mathrm{p}=0,052^{1}\end{array}$ \\
\hline Medicación & $\begin{array}{c}0,553 \\
\mathrm{p}=0,907\end{array}$ & $\begin{array}{c}6,960 \\
p=0,073\end{array}$ & $\begin{array}{c}9,786 \\
\mathrm{p}=0,020\end{array}$ & $\begin{array}{c}6,392 \\
p=0,094\end{array}$ & $\begin{array}{c}5,552 \\
\mathrm{p}=0,136^{1}\end{array}$ & $\begin{array}{c}4,452 \\
p=0,217^{1}\end{array}$ \\
\hline Número de Impl. & $\begin{array}{c}31,095 \\
\mathrm{p}=0,072^{1}\end{array}$ & $\begin{array}{c}44,812 \\
p=0,002\end{array}$ & $\begin{array}{c}62,680 \\
p=0,000\end{array}$ & $\begin{array}{c}56,547 \\
p=0,000\end{array}$ & $\begin{array}{c}44,574 \\
p=0,002\end{array}$ & $\begin{array}{c}26,738 \\
p=0,180^{1}\end{array}$ \\
\hline Intervalos Edad & $\begin{array}{c}9,188 \\
\mathrm{p}=0,027\end{array}$ & $\begin{array}{c}11,574 \\
\mathrm{p}=0,009\end{array}$ & $\begin{array}{c}11,119 \\
\mathrm{p}=0,011\end{array}$ & $\begin{array}{c}9,664 \\
p=0,022\end{array}$ & $\begin{array}{c}12,167 \\
\mathrm{p}=0,007\end{array}$ & $\begin{array}{c}9,259 \\
\mathrm{p}=0,026\end{array}$ \\
\hline Dolor EVA Interv. & $\begin{array}{c}26,119 \\
\mathrm{p}=0,000\end{array}$ & $\begin{array}{c}44,524 \\
p=0,000\end{array}$ & $\begin{array}{c}58,409 \\
\mathrm{p}=0,000\end{array}$ & $\begin{array}{c}54,199 \\
\mathrm{p}=0,000\end{array}$ & $\begin{array}{c}28,459 \\
p=0,000\end{array}$ & $\begin{array}{c}14,623 \\
p=0,002\end{array}$ \\
\hline $\begin{array}{l}\text { Número Implantes } \\
\text { Intervalos }\end{array}$ & $\begin{array}{c}11,840 \\
\mathrm{p}=0,066\end{array}$ & $\begin{array}{c}23,998 \\
p=0,001\end{array}$ & $\begin{array}{c}31,657 \\
p=0,000\end{array}$ & $\begin{array}{c}19,600 \\
p=0,003\end{array}$ & $\begin{array}{c}19,691 \\
p=0,003\end{array}$ & $\begin{array}{c}7,748 \\
p=0,257^{1}\end{array}$ \\
\hline Situación del Impl. & $\begin{array}{c}11,379 \\
p=0,0771\end{array}$ & $\begin{array}{c}1,852 \\
\mathrm{p}=0,933^{1}\end{array}$ & $\begin{array}{c}13,191 \\
\mathrm{p}=0,040\end{array}$ & $\begin{array}{c}14,122 \\
p=0,028\end{array}$ & $\begin{array}{c}8,361 \\
p=0,213^{1}\end{array}$ & $\begin{array}{c}5,622 \\
p=0,467^{1}\end{array}$ \\
\hline
\end{tabular}


Capitulo 4: Resultados

\begin{tabular}{|c|c|c|c|c|c|c|}
\hline Anterior/Posterior & $\begin{array}{c}8,867 \\
p=0,181\end{array}$ & $\begin{array}{c}13,900 \\
p=0,031\end{array}$ & $\begin{array}{c}22,474 \\
p=0,001\end{array}$ & $\begin{array}{c}12,518 \\
\mathrm{p}=0,051\end{array}$ & $\begin{array}{c}20,654 \\
p=0,002\end{array}$ & $\begin{array}{c}6,977 \\
\mathrm{p}=0,323^{1}\end{array}$ \\
\hline Elevación & $\begin{array}{c}2,812 \\
\mathrm{p}=0,422^{1}\end{array}$ & $\begin{array}{c}7,504 \\
\mathrm{p}=0,057^{1}\end{array}$ & $\begin{array}{c}7,297 \\
\mathrm{p}=0,063^{1}\end{array}$ & $\begin{array}{c}0,764 \\
\mathrm{p}=0,858^{1}\end{array}$ & $\begin{array}{c}2,208 \\
\mathrm{p}=0,530^{1}\end{array}$ & $\begin{array}{c}10,090 \\
\mathrm{p}=0,018\end{array}$ \\
\hline Regeneración & $\begin{array}{c}1,121 \\
\mathrm{p}=0,771\end{array}$ & $\begin{array}{c}4,129 \\
p=0,248\end{array}$ & $\begin{array}{c}4,334 \\
p=0,228\end{array}$ & $\begin{array}{c}3,694 \\
p=0,297\end{array}$ & $\begin{array}{c}2,583 \\
\mathrm{p}=0,461^{1}\end{array}$ & $\begin{array}{c}1,439 \\
\mathrm{p}=0,696^{1}\end{array}$ \\
\hline Sedación & $\begin{array}{c}0,504 \\
\mathrm{p}=0,918^{1}\end{array}$ & $\begin{array}{c}6,473 \\
\mathrm{p}=0,091^{1}\end{array}$ & $\begin{array}{c}10,598 \\
p=0,014\end{array}$ & $\begin{array}{c}21,879 \\
p=0,000\end{array}$ & $\begin{array}{c}6,837 \\
\mathrm{p}=0,077^{1}\end{array}$ & $\begin{array}{c}1,128 \\
\mathrm{p}=0,770^{1}\end{array}$ \\
\hline Postextracción & $\begin{array}{c}2,995 \\
\mathrm{p}=0,392\end{array}$ & $\begin{array}{c}11,259 \\
p=0,010\end{array}$ & $\begin{array}{c}5,704 \\
p=0,127\end{array}$ & $\begin{array}{c}1,515 \\
\mathrm{p}=0,6791\end{array}$ & $\begin{array}{c}1,519 \\
\mathrm{p}=0,678^{1}\end{array}$ & $\begin{array}{c}1,293 \\
\mathrm{p}=0,731^{1}\end{array}$ \\
\hline Colgajo & $\begin{array}{c}8,776 \\
\mathrm{p}=0,032\end{array}$ & $\begin{array}{c}13,806 \\
\mathrm{p}=0,003\end{array}$ & $\begin{array}{c}19,350 \\
p=0,000\end{array}$ & $\begin{array}{c}17,423 \\
p=0,001\end{array}$ & $\begin{array}{c}11,237 \\
\mathrm{p}=0,011\end{array}$ & $\begin{array}{c}5,353 \\
\mathrm{p}=0,148^{1}\end{array}$ \\
\hline
\end{tabular}

De la Tabla 39 se deduce que las variables "Sexo", "Fumador", "Higiene", "Enfermedades Actuales" y "Regeneración", no presentan relación con las variables correspondientes a la inflamación en el postoperatorio.

Por otra parte, la variable "Alergias" está altamente relacionada con la inflamación a las 12 y 24h, la variable "Medicación" sólo presenta relación con la inflamación a las 48h y las variables "Intervalos Edad" y "Dolor E.V.A. Intervalos", presentan relación con la inflamación en los primeros 3 días.

La variable "Número Implantes Intervalos" está relacionada con la inflamación a las 24h, 48h y 3 días, y la variable "Anterior o Posterior", presenta relación con la inflamación a las 24 y 48h. Por último, se observa una alta relación de la variable "Colgajo" con la inflamación padecida durante los tres primeros días. 


\section{C) Relación entre las variables generales y la variable "Hematoma"}

Tabla 40: Contrastes Chi-cuadrado de independencia entre las variables generales y la variable

"Hematoma".

\begin{tabular}{|c|c|c|c|c|c|c|}
\hline & $\begin{array}{c}\text { Hematoma } \\
12 \mathrm{H} .\end{array}$ & $\begin{array}{l}\text { Hematoma } \\
\qquad 24 \mathrm{H} .\end{array}$ & $\begin{array}{c}\text { Hematoma } \\
48 \mathrm{H} .\end{array}$ & $\begin{array}{l}\text { Hematoma } \\
3 \text { D. }\end{array}$ & $\begin{array}{l}\text { Hematoma } \\
5 \text { D. }\end{array}$ & $\begin{array}{c}\text { Hematoma } \\
7 \text { D. }\end{array}$ \\
\hline Sexo & $\begin{array}{c}0,784 \\
p=0,676^{1}\end{array}$ & $\begin{array}{c}0,610 \\
\mathrm{p}=0,894^{1}\end{array}$ & $\begin{array}{c}3,263 \\
p=0,353^{1}\end{array}$ & $\begin{array}{c}4,661 \\
p=0,198^{1}\end{array}$ & $\begin{array}{c}2,842 \\
\mathrm{p}=0,417^{1}\end{array}$ & $\begin{array}{c}3,868 \\
\mathrm{p}=0,276^{1}\end{array}$ \\
\hline Fumador & $\begin{array}{c}1,551 \\
p=0,818^{1}\end{array}$ & $\begin{array}{c}1,840 \\
p=0,934^{1}\end{array}$ & $\begin{array}{c}3,236 \\
p=0,779^{1}\end{array}$ & $\begin{array}{c}3,050 \\
p=0,803^{1}\end{array}$ & $\begin{array}{c}2,558 \\
\mathrm{p}=0,862^{1}\end{array}$ & $\begin{array}{c}2,239 \\
\mathrm{p}=0,896^{1}\end{array}$ \\
\hline Higiene & $\begin{array}{c}2,005 \\
p=0,735^{1}\end{array}$ & $\begin{array}{c}10,265 \\
p=0,114^{1}\end{array}$ & $\begin{array}{c}9,427 \\
p=0,151^{1}\end{array}$ & $\begin{array}{c}5,083 \\
\mathrm{p}=0,533^{1}\end{array}$ & $\begin{array}{c}9,292 \\
p=0,158^{1}\end{array}$ & $\begin{array}{c}13,493 \\
\mathrm{p}=0,036^{2}\end{array}$ \\
\hline Enfermedades act. & $\begin{array}{c}0,846 \\
p=0,655^{1}\end{array}$ & $\begin{array}{c}6,551 \\
p=0,088^{1}\end{array}$ & $\begin{array}{c}6,960 \\
p=0,073^{1}\end{array}$ & $\begin{array}{c}5,254 \\
p=0,154^{1}\end{array}$ & $\begin{array}{c}9,546 \\
\mathrm{p}=0,023^{2}\end{array}$ & $\begin{array}{c}7,202 \\
\mathrm{p}=0,066^{1}\end{array}$ \\
\hline Alergias & $\begin{array}{c}3,846 \\
p=0,146^{1}\end{array}$ & $\begin{array}{c}7,771 \\
\mathrm{p}=0,051^{1}\end{array}$ & $\begin{array}{c}0,994 \\
\mathrm{p}=0,803^{1}\end{array}$ & $\begin{array}{c}2,517 \\
\mathrm{p}=0,472^{1}\end{array}$ & $\begin{array}{c}1,395 \\
\mathrm{p}=0,707^{1}\end{array}$ & $\begin{array}{c}3,448 \\
\mathrm{p}=0,328^{1}\end{array}$ \\
\hline Medicación & $\begin{array}{c}1,339 \\
\mathrm{p}=0,512^{1}\end{array}$ & $\begin{array}{c}5,646 \\
p=0,130^{1}\end{array}$ & $\begin{array}{c}7,222 \\
p=0,065^{1}\end{array}$ & $\begin{array}{c}2,560 \\
p=0,465^{1}\end{array}$ & $\begin{array}{c}7,446 \\
\mathrm{p}=0,059^{1}\end{array}$ & $\begin{array}{c}7,421 \\
\mathrm{p}=0,060^{1}\end{array}$ \\
\hline Número de Impl. & $\begin{array}{c}10,043 \\
p=0,759^{1}\end{array}$ & $\begin{array}{c}55,298 \\
\mathrm{p}=0,000^{2}\end{array}$ & $\begin{array}{c}106,670 \\
p=0,000^{2}\end{array}$ & $\begin{array}{c}118,137 \\
\mathrm{p}=0,000^{2}\end{array}$ & $\begin{array}{c}140,856 \\
\mathrm{p}=0,000^{2}\end{array}$ & $\begin{array}{c}82,704 \\
p=0,000^{2}\end{array}$ \\
\hline Intervalos Edad & $\begin{array}{c}5,344 \\
\mathrm{p}=0,069\end{array}$ & $\begin{array}{c}13,438 \\
\mathrm{p}=0,004^{2}\end{array}$ & $\begin{array}{c}15,627 \\
\mathrm{p}=0,001^{2}\end{array}$ & $\begin{array}{c}18,133 \\
\mathrm{p}=0,000^{2}\end{array}$ & $\begin{array}{c}16,216 \\
\mathrm{p}=0,001^{2}\end{array}$ & $\begin{array}{c}11,640 \\
\mathrm{p}=0,009^{2}\end{array}$ \\
\hline Dolor EVA Interv. & $\begin{array}{c}2,450 \\
p=0,294^{1}\end{array}$ & $\begin{array}{c}9,857 \\
\mathrm{p}=0,020^{2}\end{array}$ & $\begin{array}{c}8,016 \\
p=0,046^{2}\end{array}$ & $\begin{array}{c}5,676 \\
p=0,128^{1}\end{array}$ & $\begin{array}{c}2,321 \\
\mathrm{p}=0,508^{1}\end{array}$ & $\begin{array}{c}4,294 \\
\mathrm{p}=0,231^{1}\end{array}$ \\
\hline $\begin{array}{l}\text { Número Implantes } \\
\text { Intervalos }\end{array}$ & $\begin{array}{c}4,775 \\
p=0,311^{1}\end{array}$ & $\begin{array}{c}18,864 \\
\mathrm{p}=0,004^{2}\end{array}$ & $\begin{array}{c}26,140 \\
\mathrm{p}=0,000^{2}\end{array}$ & $\begin{array}{c}28,312 \\
\mathrm{p}=0,000^{2}\end{array}$ & $\begin{array}{c}26,589 \\
p=0,000^{2}\end{array}$ & $\begin{array}{c}17,679 \\
\mathrm{p}=0,007^{2}\end{array}$ \\
\hline Situación del Impl. & $\begin{array}{c}13,641 \\
\mathrm{p}=0,009^{2}\end{array}$ & $\begin{array}{c}2,676 \\
p=0,848^{1}\end{array}$ & $\begin{array}{c}9,362 \\
p=0,154^{1}\end{array}$ & $\begin{array}{c}12,654 \\
\mathrm{p}=0,049^{2}\end{array}$ & $\begin{array}{c}15,251 \\
\mathrm{p}=0,018^{2}\end{array}$ & $\begin{array}{c}4,589 \\
\mathrm{p}=0,598^{1}\end{array}$ \\
\hline Anterior/Posterior & $\begin{array}{c}3,599 \\
\mathrm{p}=0,463^{1}\end{array}$ & $\begin{array}{c}14,099 \\
\mathrm{p}=0,0292\end{array}$ & $\begin{array}{c}16,417 \\
p=0,012^{2}\end{array}$ & $\begin{array}{c}9,194 \\
\mathrm{p}=0,163^{1}\end{array}$ & $\begin{array}{c}6,604 \\
p=0,359^{1}\end{array}$ & $\begin{array}{c}11,097 \\
\mathrm{p}=0,085^{1}\end{array}$ \\
\hline Elevación & $\begin{array}{c}0,709 \\
\mathrm{p}=0,701^{1}\end{array}$ & $\begin{array}{c}1,165 \\
\mathrm{p}=0,761^{1}\end{array}$ & $\begin{array}{c}0,504 \\
p=0,918^{1}\end{array}$ & $\begin{array}{c}2,860 \\
\mathrm{p}=0,4141\end{array}$ & $\begin{array}{c}0,764 \\
\mathrm{p}=0,858^{1}\end{array}$ & $\begin{array}{c}0,548 \\
\mathrm{p}=0,908^{1}\end{array}$ \\
\hline Regeneración & $\begin{array}{c}0,652 \\
p=0,722^{1}\end{array}$ & $\begin{array}{c}1,104 \\
p=0,776^{1}\end{array}$ & $\begin{array}{c}1,166 \\
p=0,761^{1}\end{array}$ & $\begin{array}{c}2,860 \\
p=0,414^{1}\end{array}$ & $\begin{array}{c}0,765 \\
p=0,858^{1}\end{array}$ & $\begin{array}{c}1,439 \\
\mathrm{p}=0,696^{1}\end{array}$ \\
\hline
\end{tabular}


Capitulo 4: Resultados

\begin{tabular}{|c|c|c|c|c|c|c|}
\hline Sedación & $\begin{array}{c}3,735 \\
\mathrm{p}=0,1541\end{array}$ & $\begin{array}{c}12,445 \\
\mathrm{p}=0,006\end{array}$ & $\begin{array}{c}24,660 \\
\mathrm{p}=0,000\end{array}$ & $\begin{array}{c}40,468 \\
\mathrm{p}=0,000\end{array}$ & $\begin{array}{c}29,161 \\
\mathrm{p}=0,000\end{array}$ \\
$\mathrm{p}=0,000$ & 2,589 \\
\hline Postextracción & 1,673 & 2,747 & 3,052 \\
$\mathrm{p}=0,433^{1}$ & $\mathrm{p}=0,432^{1}$ & $\mathrm{p}=0,3841$ & $\mathrm{p}=0,4171$ & $\mathrm{p}=0,5251$ \\
$\mathrm{p}=0,942^{1}$ \\
\hline Colgajo
\end{tabular}

Ninguna de las significaciones obtenidas es interpretable, puesto que en las tablas de contingencia, más del $50 \%$ de las casillas presentan frecuencias observadas menores o iguales a 5 .

Esto pone de manifiesto los resultados obtenidos en el análisis factorial previo, donde las variables que hacían referencia a hematoma en el postoperatorio, aparecían en un factor diferente a las variables del dolor e inflamación. 



\title{
Capítulo 5
}

\author{
DISCUSIÓN
}





\section{Capitulo 5: Discusión}

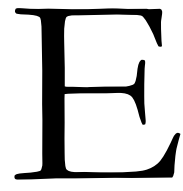

n la actualidad, el tratamiento de los espacios edéntulos mediante la colocación de implantes dentales, es la opción más empleada por los odontólogos. La

variablidad de los síntomas padecidos por los pacientes tras la colocación de estos implantes, ha generado dudas a los profesionales odontológicos sobre el postoperatorio quirúrgico que van a padecer sus pacientes y la manera de enfrentarse al mismo.

Desgraciadamente, la mayoría de los pacientes odontológicos padecen temor y ansiedad en la consulta odontológica, viéndose éstos incrementados cuando el tratamiento conlleva una intervención quirúrgica como la extracción de una pieza dentaria, extracción de un tercer molar incluido, colocación de implantes dentales, etc. Este temor al dentista, sumado al miedo a lo desconocido, como la colocación de un implante dental, ha despertado el interés de los profesionales sobre el verdadero postoperatorio que produce una intervención de esta naturaleza. Todo ello, ha originado la necesidad de buscar datos científicos para poder mostrar datos reales a nuestros pacientes y así, poder afrontar el postoperatorio con más seguridad.

Esta búsqueda científica del verdadero postoperatorio producido por la colocación de implantes dentales, y la falta de estudios y artículos centrados en la sintomatología producida por este tipo de cirugía, han motivado la realización de un trabajo exhaustivo y prolongado sobre el postoperatorio implantológico.

Son múltiples los factores que justifican un mejor conocimiento del postoperatorio sufrido por los pacientes odontológicos, después de la colocación de implantes dentales:

- El aumento en la demanda de los implantes dentales por parte de los pacientes odontológicos y su gran tasa de éxito.

- El desconocimiento general de los profesionales odontológicos sobre el grado de dolor, inflamación y hematoma que padecen estos pacientes.

- Averiguar la duración de los síntomas postoperatorios. 
- Conocer los factores internos y externos que afectan al paciente y al operador, y que pueden influir de manera directa en el postoperatorio de la cirugía implantológica.

- Comprobar si la medicación administrada es suficiente para proporcionar un postoperatorio confortable a los pacientes implantológicos.

La mayoría de los artículos sobre el postoperatorio sufrido por los pacientes odontológicos, están basados en la cirugía de extracción de terceros molares inferiores incluidos (habitualmente más agresivas que la colocación de implantes dentales), cirugía periapical (apicectomías, extracciones radiculares, etc.) y cirugía periodontal.

Esta tesis doctoral ha querido analizar, también, el resto de cirugías odontológicas que pueden producir un postoperatorio similar al de la cirugía de colocación de implantes dentales. Por ello, se revisaron en la literatura artículos sobre extracción de terceros molares incluidos, cirugía periapical, tratamientos quirúrgicos periodontales, elevaciones sinusales y regeneraciones óseas.

Igualmente este trabajo, hemos analizado el período postoperatorio sufrido por los pacientes tras la colocación de implantes dentales, basándonos en sus estimaciones mediante una escala visual analógica (E.V.A.) y en la información recogida sobre su estado durante los siete días posteriores a la intervención. Para ello, los pacientes debían registrar el dolor padecido con un valor de 0 a 10 durante ese período, mientras que en otro test, tenían que recoger datos sobre el dolor, la inflamación y el hematoma padecidos durante esos siete días. Posteriormente, se compararon los resultados obtenidos con todas las variables consideradas, para poder establecer conclusiones.

Todos los pacientes recibieron tratamiento antiálgico y antiinflamatorio los 7 días posteriores a la intervención siguiendo, un protocolo similar, al empleado en la mayoría de los artículos revisados sobre el postoperatorio en implantología oral (Al-Khabbaz, et al., 2007, González, et al., 2005, Guarinos, et al., 1998, Hashem, et al., 2006, Peñarrocha, et al., 2000, Romero, et al., 2006, Urban \& Wenzel, 2010), con la diferencia de que en nuestro 


\section{Capitulo 5: Discusión}

estudio se les administró además a todos los pacientes $600 \mathrm{mg}$ de ibuprofeno al término de la cirugía, siguiendo el protocolo propuesto por Romero-Ruiz et al. (Romero, et al., 2006). 


\subsection{METODOLOGÍA COMPARADA}

Antes de exponer las observaciones extraídas de nuestro estudio y los resultados obtenidos, es preciso realizar una breve reseña sobre el proceso metodológico seguido, su diseño, la muestra seleccionada, el tipo de instrumentos de recogida de datos y las técnicas de análisis estadístico empleadas.

En cuanto al diseño del estudio, elegimos el "epidemiológico experimental”, en el que comparamos una serie de individuos sometidos a un tratamiento determinado para cada caso en particular.

Dentro de los diseños experimentales, se utilizó el "ensayo clínico" que es a su vez, el más frecuente. En los ensayos clínicos, los sujetos son pacientes y se evalúan uno o más tratamientos para una enfermedad o proceso. En nuestro caso, los sujetos eran los pacientes y el proceso la colocación de implantes dentales. El diseño experimental es el mismo que el utilizado por otros autores que analizaron el postoperatorio implantológico (Al-Khabbaz, et al., 2007, González, et al., 2005, Guarinos, et al., 1998, Hashem, et al., 2006, Peñarrocha, et al., 2000, Romero, et al., 2006, Urban \& Wenzel, 2010).

La validez de este estudio radica fundamentalmente, en que el proceso aleatorio de análisis, proporcione grupos comparables en las variables más relevantes, en relación al tratamiento que se pretende estudiar. La validez interna, es el grado en el que la manipulación de la variable independiente es la responsable de los cambios producidos en la variable dependiente. En nuestro estudio, la validez interna viene determinada por el grado en el que, la colocación de implantes dentales, afecta a nuestros pacientes posteriormente. La validez externa, es la forma en que los resultados de un experimento pueden ser generalizados a diferentes sujetos, poblaciones, lugares, experimentadores, etc. En la validez externa radica la posibilidad de poder generalizar los resultados obtenidos en el postoperatorio de nuestros pacientes, al resto de la población.

En lo que se refiere a la selección de la muestra y población, se eligieron pacientes odontológicos que se querían someter a cirugía implantológica independientemente de su 


\section{Capitulo 5: Discusión}

edad y sexo. Todos los pacientes, antes de someterse a dicha intervención debían presentar un estado bucodental correcto. Así, la muestra de estudio quedó definida por 200 pacientes, que acudieron a una consulta dental de práctica privada en Salamanca capital, a los que les fueron colocados 470 implantes dentales, entre enero de 2008 y diciembre de 2011. Hay que mencionar que en principo, contábamos con 213 casos para el estudio pero, por no cumplir con los requisitos necesarios, 13 de ellos quedaron descartados. Los criterios de inclusión y exclusión de los pacientes que se estudiaron, fueron los mismos que los seguidos en la mayoría de artículos revisados sobre el tema (Al-Khabbaz, et al., 2007, González, et al., 2005, Guarinos, et al., 1998, Hashem, et al., 2006, Muller \& Ríos, 2001, Peñarrocha, et al., 2000, Romero, et al., 2006, Urban \& Wenzel, 2010).

El estudio fue diseñado para hacer un seguimiento a través de un protocolo de recogida de datos, en el que se recogía información acerca del paciente (datos de filiación) y de las características de la cirugía a la que se le iba a someter (número de implantes colocados, localización, etc.). En ninguno de los artículos estudiados, se recogieron tal número de datos pre y postoperatorios, tanto generales como relacionados con la cirugía, como en el nuestro, salvo en el realizado por González, et al., (González, et al., 2005). Después de la cirugía, se entregaba al paciente otro cuestionario donde tenía que valorar el dolor, la inflamación y el hematoma padecido durante los siete días poteriores a la intervención. En este último cuestionario, también se recogía la medicación que se administraba al paciente después de la cirugía. Es importante destacar, que todos los pacientes del estudio recibieron la misma medicación.

El cuestionario donde el paciente reflejaba el dolor, la inflamación y el hematoma sufridos los días posteriores a la cirugía, fue similar al que utilizaron Gónzalez et al., Muller et al., Guarinos et al. y Peñarrocha et al. (González, et al., 2005, Guarinos, et al., 1998, Muller \& Ríos, 2001, Peñarrocha, et al., 2000), pues otros estudios semejantes como los de Al-khabbad et al., Hashem et al. y Urban et al., no analizaron los resultados en períodos de tiempo tan cortos (Al-Khabbaz, et al., 2007, Hashem, et al., 2006, Urban \& Wenzel, 2010).

En relación a las técnicas de análisis estadístico, éstas se han realizado a partir de la inferencia estadística de una serie de pruebas o test con la finalidad de confirmar con cierta probabilidad, las hipótesis planteadas. Gran parte de las variables utilizadas en el

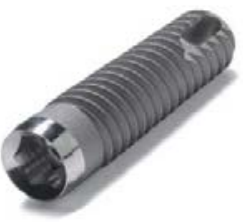


postoperatorio implantológico, no presentaban una distribución normal en la población. Bajo este supuesto, hemos utilizado pruebas estadísticas no paramétricas como $\chi^{2}$, U de Mann-Whitney, etc., en el sentido de que no se fundamentan, en ningún supuesto sobre los parámetros de la población.

En este estudio, se han realizado pruebas estadísticas similares a las utilizadas por otros autores (Al-Khabbaz, et al., 2007, González, et al., 2005, Guarinos, et al., 1998, Hashem, et al., 2006, Muller \& Ríos, 2001, Peñarrocha, et al., 2000, Romero, et al., 2006, Urban \& Wenzel, 2010).

Tras exponer algunas observaciones sobre la metodología seguida en este trabajo, es preciso interpretar los resultados obtenidos en las pruebas realizadas sobre el grupo experimental. Por ello, a continuación analizaremos los resultados obtenidos respecto a los tres síntomas estudiados y todos los factores que podrían tener influencia en nuestros resultados. 
Capitulo 5: Discusión

\subsection{SÍNTOMAS POSTOPERATORIOS}

\subsubsection{Dolor}

En cuanto al dolor padecido por nuestros pacientes, hay que destacar que durante los siete días del postoperatorio estudiado, éstos manifestaron ausencia de dolor o dolor ligero en aproximadamente, el 90\% de los casos (Tabla 24).

En la escala visual analógica (E.V.A.), los resultados encontrados confirman lo expuesto, pues el 74\% de los pacientes marcó menos de 3 en la E.V.A., y del $26 \%$ de los pacientes restantes, el 15\% registró el dolor padecido con un 3 en la misma, mientras que el 11\% restante marcaron 4 o más. Por lo tanto, sólo 52 de los 200 pacientes (26\%), presentaron dolor intenso (3 o más en la E.V.A.), durante el postoperatorio (Figura 48).

Estos resultados siguen la línea de los encontrados por Muller et al., pues en su estudio, el $45 \%$ de los pacientes refirieron dolor tras las primeras 24 horas, mientras que en nuestro caso fue el 47,5\%, aunque hay que destacar que el 34,5\% de estos pacientes, lo reflejaron como dolor ligero y desconocemos qué grado de dolor padecieron los del estudio del citado autor (Muller \& Ríos, 2001) (Tabla 24).

En el estudio de Guarinos et al., el pico máximo de dolor se presentó a las 12 horas de la intervención y con una intensidad de 3,5 en la E.V.A., mientras que Peñarrocha et al., en su trabajo sobre el dolor padecido tras la colocación implantes dentales, observaron el mayor grado de dolor a las 6 horas de la intervención, con una intensidad moderada (Guarinos, et al., 1998, Peñarrocha, et al., 2000). Estos resultados distan mucho de los obtenidos en nuestro estudio, donde el pico de dolor se encontró a las 24 horas de la intervención y con un predominio claro del dolor ligero $(34,5 \%)$, respecto al dolor moderado $(12,5 \%)$ y severo $(0,5 \%)$. Consideramos que estas diferencias se deben, básicamente, a que en nuestro trabajo se administró analgésico y antiinflamatorio al término de la cirugía, retrasando así, la apararición de los síntomas.

Uno de los artículos valorado más reciente fue el de González et al., quienes obtuvieron resultados similares a los nuestros, puesto que en la E.V.A. a las 6 horas y a las 12 horas, el dolor fue ligero en el 41,5\% y 39\% de los casos, respectivamente, mientras que

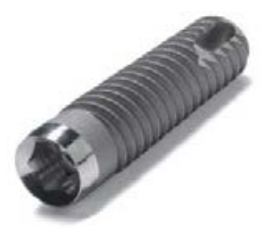


en nuestro estudio a las 12 horas el dolor fue ligero en el 34\% de los casos (González, et al., 2005). Creemos que los resultados obtenidos por estos autores se asemejan tanto a los nuestros, porque el protocolo de medicación de los pacientes intervenidos fue muy similar.

Al-Khabbaz et al., obtuvieron respecto al dolor valores superiores a los nuestros pues, a las 24 horas de la intervención sólo el 19,7\% de los pacientes mostraron ausencia de dolor respecto al 52,5\% obtenido en nuestro estudio. El dolor ligero a las 24 horas fue del $69,7 \%$ mientras que nuestros pacientes marcaron éste un 34,5\% de los casos. A los 7 días de la intervención, los valores se aproximan aunque siguen siendo inferiores, pues sus pacientes mostraron en un 39,7\% ausencia de dolor, mientras que en nuestro estudio, la ausencia de dolor se presentó en un 44,8\% (Al-Khabbaz, et al., 2007). Como en el caso descrito anteriormente, creemos que estos resultados difieren tanto de los encontrados en nuestro estudio, porque nosotros administramos análgesico y antiinflamatorio al término de la cirugía, lo que mejora el postoperatorio considerablemente.

Los resultados obtenidos en nuestro estudio sobre el dolor postoperatorio tras la colocación de implantes dentales son los más bajos de todos los artículos revisados. Esto puede deberse a que en la mayoría de nuestros pacientes $(79 \%)$, se colocaron 1,2 o 3 implantes, lo que supone cirugías sencillas y, habitualmente de corta duración, pues como describe la bibliografía existente, a mayor número de implantes mayor dolor postoperatorio (Al-Khabbaz, et al., 2007, González, et al., 2005, Guarinos, et al., 1998, Peñarrocha, et al., 2000), aunque también pensamos que pueden influir otros factores como el elevado porcentaje de pacientes que se sometieron a cirugía mínimamente invasiva, es decir, cirugías menos agresivas y más rápidas o como se ha comentado anteriormente, la administración de analgésico y antiinflamatorio en el gabinete dental, al término de la cirugía.

También podemos comparar nuestros resultados con los obtenidos en estudios sobre pacientes sometidos a otros tipos de cirugía oral, pues en nuestra opinión, y salvando las obvias diferencias, la agresión tisular que se produce en ellas, no difiere mucho de la generada en cirugía implantológica, aunque en aquéllas puedan existir otros factores que compliquen el postoperatorio como una mayor ostectomía, mayor duración de la cirugía, un posible componente infeccioso, etc. 


\section{Capitulo 5: Discusión}

Así, en la revisión sobre el postoperatorio tras cirugía periapical, Peñarrocha et al., en su estudio sobre el dolor padecido en este tipo de pacientes, obtuvieron como resultado, que éstos padecían dolor intenso a las 48 horas de la intervención en un 14,7\% de los casos, mientras que en nuestro estudio, fue del $2 \%$. Otro valor interesante fue el porcentaje de pacientes que no padecían dolor a las 12 y 24 horas de la intervención, pues este valor en el estudio de Peñarrocha et al., registró el 37,2\% y 33,6\%, respectivamente, mientras que en el nuestro, los valores fueron muy superiores, $55,5 \%$ y $52,5 \%$, respectivamente (Peñarrocha, et al., 2006).

En la mayoría de estos estudios sobre cirugía periapical, el mayor grado de dolor se registró en las primeras horas postoperatorias pero, en ninguno de ellos se encontraron valores de dolor a las 12 y 24 horas, tan bajos como los nuestros (García, et al., 2007, García, et al., 2008, Peñarrocha, et al., 2006, Seymour, et al., 1986, Tssesis, et al., 2005). Estos resultados creemos que pueden deberse, además de a otros factores como colgajos más amplios, cirugías más largas, etc., o a que, normalmente, en cirugía periapical existe un componente de origen infeccioso que puede comprometer el postoperatorio, mientras que en implantología éste no existe.

Otro tipo de postoperatorio semejante, es el sufrido después de una extracción dental simple. Cheung et al., encontraron que los pacientes a los que se les extraía alguna pieza dentaria sin complicaciones, padecían dolor de moderado a severo durante la cicatrización del alveolo (Cheung, et al., 2001). Similares resultados encontraron Adeyemo et al., quienes encontraron en su estudio que sus pacientes padecieron el mismo tipo de dolor, manteniéndose moderado hasta los 7 días posteriores a la extracción (Adeyemo, et al., 2006). García et al., exponen en su estudio que una extracción simple produce un postoperatorio más confortable que una compleja que conlleva la odontosección del diente o la ostectomía de la zona (García, et al., 1997). Nosotros, creemos lo mismo, pues cuanto menor agresión tisular se provoque, menor reacción inflamatoria se producirá y más confortable será el postoperatorio de los pacientes (Fortin, et al., 2007, García, et al., 1997, Infante, et al., 1995, Lombardía, et al., 1989, Lombardía, et al., 1987).

Siguiendo con el postoperatorio tras una extracción simple, Al-Khateeb et al., encontraron que el 38,6\% de los pacientes presentaron dolor medio a las 12 horas de la

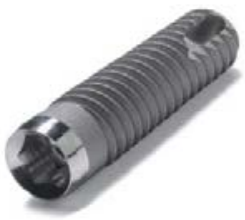


intervención mientras que en nuestro estudio, si sumamos el dolor ligero, moderado y severo, sólo un 44,5\% de los pacientes padecieron algún tipo de dolor a las 12 horas de la intervención. A los 3 días de la extracción, el 52,2\% ya no presentaba dolor mientras que en nuestro estudio, el porcentaje de pacientes sin dolor era ya del 81\%, para acabar a los 7 días de la intervención con un $94 \%$ de pacientes sin dolor respecto al $78 \%$ de los pacientes sin dolor registrado por estos autores 7 días después de la extracción (Al-Khateeb \& Alnahar, 2008).

Hay que destacar, que en los artículos sobre el postoperatorio tras una extracción simple, no se administró medicación para mejorar el postoperatorio de los pacientes, lo que indudablemente, explica que los valores referidos al dolor postoperatorio encontrados en nuestro estudio sean tan inferiores. En nuestra opinión la colocación de un implante dental, en un lugar favorable debería producir un postoperatorio muy similar al de una extracción dental simple, si ambos fueran tratados de la misma manera.

Sin embargo, lo más habitual es que la colocación de implantes dentales entrañe mayor complejidad con la necesidad de apertura de colgajos amplios con descargas, cirugías más largas y frecuentemente, acompañadas de regeneraciones óseas, elevaciones sinusales, etc. Esta es la causa, en nuestra opinión, de que estas cirugías se asocien más a la extracción del tercer molar inferior incluido que a las extracciones dentales simples.

Diversos autores obtuvieron como resultados de sus estudios sobre la extracción de terceros molares que el pico de dolor postextracción se alcanzó a las 8 horas de la intervención y que éste suele ser duradero y de grado moderado (Antila, et al., 1992, Dionne \& Gordon, 1994, Happonen, et al., 1990, Seymour, et al., 1985). Otros autores, sin embargo, encontraron el pico máximo a las 24 horas de la intervención, siendo éste de gran intensidad (Bello, et al., 2011, Capuzzi, et al., 1994, De Boer, et al., 1995, García, et al., 1997, Olmedo, et al., 2002). Por ejemplo, en el artículo de Yuasa et al., el dolor de los pacientes sometidos a la extracción de terceros molares inferiores a las 24 horas de la intervención fue de intensidad severa en el 50\% de los casos, mientras que en nuestro trabajo, éste fue del 0,5\%. En nuestro estudio, el $94 \%$ de los pacientes no padeció dolor alguno a los 7 días de haber colocado los implantes dentales (Yuasa \& Sugiura, 2004). 


\section{Capitulo 5: Discusión}

Estos resultados son lógicos, debido a que la extracción de un molar inferior incluido, normalmente, es más compleja que la mayoría de las cirugías implantológicas. Sostenemos que no se puede comparar el postoperatorio de un tercer molar complejo, con la colocación de uno o dos implantes, pues el grado de ostectomía, la apertura del colgajo, la duración de la cirugía, el grado de agresión tisular producido y otros muchos factores hacen que la extracción de un tercer molar inferior incluido, sólo se pueda comparar con cirugías implantológicas complejas como la colocación de 6 o más implantes, colocación de implantes con grandes regeneraciones óseas, elevaciones sinusales, etc., en el que todos los factores expuestos anteriormente, se equiparan.

\subsubsection{Inflamación.}

La inflamación postoperatoria de nuestros pacientes, fue en aumento progresivo hasta las 24 horas de la intervención, disminuyendo posteriormente, hasta desaparecer casi por completo a los 7 días de la intervención (94.5\%) (Tabla 25).

El mayor grado de inflamación sufrida por nuestros pacientes fue de intensidad ligera a las 24 horas de la intervención (36,5\%). Hay que señalar, que los resultados obtenidos mostraron que la inflamación a las 12 y 24 horas, al igual que el dolor, fueron las opciones más contestadas por los pacientes (Tabla 25).

Nuestros datos concuerdan con los obtenidos por otros autores que también encontraron el pico de inflamación a las 24 horas de la intervención (Guarinos, et al., 1998, Muller \& Ríos, 2001, Peñarrocha, et al., 2000, Urban \& Wenzel, 2010)

En el artículo de González et al., en el que se siguió un procolo similar al nuestro, los pacientes reportaron un pico máximo de inflamación, con intensidad moderada, a las 48 horas de la intervención (48,8\%), mientras que en nuestro estudio, el pico máximo de inflamación con intensidad moderada ocurrió a las 24 horas (12\%), siendo del 10\% a las 48 horas de la intervención (González, et al., 2005).

Estos resultados son superiores a los encontrados en nuestro estudio y consideramos que podría ser debido a que en el 25\% de nuestros pacientes, la cirugía practicada fue mínimamente invasiva o postextracción, lo que reduce considerablemente, la

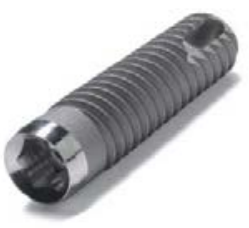


agresión tisular provocando menor inflamación. También pensamos que tiene gran influencia, el hecho de que a nuestros pacientes se les administró el medicamento antiinflamatorio justo después de la cirugía en el mismo gabinete dental, mejorando el postoperatorio y produciendo menor inflamación. Como en el caso del dolor postoperatorio, otro factor de gran influencia es que la mayoría de los pacientes (79\%), se sometió a cirugía sencilla de colocación de 1, 2 o 3 implantes, lo que conlleva menor inflamación que intervenciones más complejas.

Como en el caso del dolor, consideramos también que se pueden comparar nuestros resultados, con estudios que analizan la inflamación con otras clases de cirugía oral.

Así, en el artículo de Peñarrocha et al., sobre pacientes sometidos a cirguía periapical observamos que el pico máximo de inflamación se produjo a las 24 horas de la intervención, siendo éste de intensidad moderada (49,6\%). Hay que señalar también, que a los 3 días de la intervención, sólo el 12,4\% no padecía inflamación mientras que en nuestro estudio, el porcentaje fue del 68\% (Peñarrocha, et al., 2006).

Tsesis et al., y García et al., encontraron también mayor inflamación a las 24 horas de la intervención, disminuyendo progresivamente desde ese momento (García, et al., 2007, García, et al., 2008, Tsesis, et al., 2003).

Los artículos revisados sobre cirugía periapical, reportan como nosotros, el máximo grado de inflamación a las 24 horas y de intensidad moderada, pero todos en porcentajes entre 45 y 66\%, mientras que en nuestro estudio, fue del 12\% (García, et al., 2007, Kvist \& Reit, 2000, Lin, et al., 2006, Peñarrocha, et al., 2006, Tsesis, et al., 2003).

Consideramos que estas diferencias pueden ser debidas a que la cirugía periapical conlleva la apertura de colgajos amplios, un componente infeccioso, ostectomías agresivas para poder limpiar la zona, etc. Todos estos factores, acompañados de que en nuestro estudio el mayor número de intervenciones consistieron en la colocación de pocos implantes, lo que implicó colgajos más conservadores, medicación antiinflamatoria al término de la cirugía, etc., son los responsables de la gran diferencia entre la inflamación en cirugía periapical y la encontrada en nuestro trabajo. 


\section{Capitulo 5: Discusión}

En relación a la extracción de piezas dentarias simples que no presentan ningún tipo de inflamación antes de la misma, Al-Khateeb, Ruta, et al., y Slade, et al., encontraron que el postoperatorio de estos pacientes fue mucho mejor que aquellos pacientes que fueron sometidos a extracciones más complicadas con inflamación previa, odontosección, terceros molares incluidos, etc. (Al-Khateeb \& Alnahar, 2008, Ruta, et al., 2000, Slade, et al., 2004).

Basándonos en estos resultados y los obtenidos en nuestro estudio, deducimos que los pacientes sometidos a extracciones simples, presentan menor inflamación que aquéllos a los que se les colocan implantes dentales, aunque si la cirugía implantológica consta de la colocación de pocos implantes, el postoperatorio se equipara considerablemente.

En el caso de la extracción de terceros molares inferiores incluidos, existe amplio consenso en los resultados encontrados, pues la mayoría de los autores observaron la máxima inflamación postoperatoria a las 24 horas de la intervención, aunque al igual que en el caso de cirugía periapical, fue muy superior a la encontrada en nuestro estudio.

Hay que señalar, que la mayoría de los artículos revisados, reportaron la intensidad de la inflamación moderada, mientras que en nuestro estudio fue leve. (Bello, et al., 2011, De Boer, et al., 1995, García, et al., 1997, Grossi, et al., 2007, Infante, et al., 1995, Olmedo, et al., 2002, Peñarrocha, et al., 2001).

Estas diferencias en la intensidad de la inflamación entre la extracción de terceros molares inferiores incluidos y la colocación de implantes dentales, consideramos que pueden ser debidas a varios factores. En primer lugar, el grado de lesión tisular producido por una intervención de larga duración, compleja y que requiere practicar gran ostectomía, es mucho mayor que el producido en la colocación de pocos implantes dentales, como ocurrió en la mayoría de los pacientes de este estudio. Por otro lado, estas extracciones suelen realizarse cuando ya existe cierto grado de inflamación o incluso algún componente infeccioso por lo que, inevitablemente, la inflamación posterior será más duradera y marcada, mientras que en la colocación de implantes dentales, nunca existe este componente. Por último, creemos que puede influir en gran medida el hecho de que nuestros pacientes fueron tratados con antiinflamatorios al término de la intervención para prevenirla, al contrario que en la extraccion de molares incluidos donde, habitualmente, el paciente presenta inflamación el día de la cirugía.

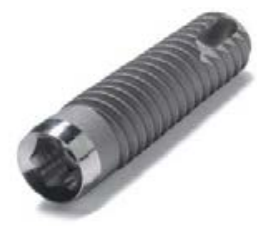




\subsubsection{Hematoma y equimosis}

El ultimo síntoma estudiado en este trabajo, fue el hematoma padecido por los pacientes después de la colocación de implantes dentales. En nuestro estudio, se registraron valores muy bajos en este sentido, obteniendo el pico máximo de hematoma a las 24 horas en el $9 \%$ de las casos, mientras que a las 48 horas fue 8,5\% y a los 3 días el 6\% (Tabla 26).

Más del 90\% de los pacientes sometidos a la colocación de implantes dentales, no padeció hematoma postoperatorio.

En el estudio de Muller et al., en el que se analiza el postoperatorio implantológico observaron hematoma en el $12 \%$ de los pacientes 24 horas después de la intervención, mientras que a los 7 días, ninguno de los pacientes presentaba hematoma (Muller \& Ríos, 2001). En nuestro estudio, el hematoma a las 24 horas de la intervención fue del 11\%, mientras que a los 7 días este valor fue del 5,5\%.

Consideramos que estos resultados son lógicos, porque no se puede controlar el grado de hematoma que presenta un paciente farmacológicamente, como sucede con el dolor y la inflamación, por lo que este síntoma depende en gran medida de las características del paciente.

El hematoma es una complicación menor y que no ocurre en todos los pacientes, siendo más frecuente en aquéllos con piel más lábil. Este síntoma depende sustancialmente del tipo de cirugía que se lleve cabo, si se ha practicado colgajo con descargas o no, número de implantes colocados, duración de la cirugía, tipo de coagulación del paciente, etc (González, et al., 2006).

Estamos de acuerdo con González et al., pues como se puede apreciar en la Tabla 26, muy pocos pacientes presentaron hematoma. Esta complicación es tan poco frecuente, que de los artículos revisados sobre el postoperatorio implantológico sólo Muller et al., analizaron el hematoma, centrándose el resto de autores se en el estudio del dolor y la inflamación. 
Capitulo 5: Discusión

\subsection{FACTORES RELACIONADOS CON EL PACIENTE.}

\subsubsection{Sexo}

Si analizamos los resultados obtenidos en el estudio de la relación entre la variable "Sexo" y el resto de variables temporales de dolor, se observa que no existen diferencias estadísticamente significativas para ninguna de dichas variables, como se puede comprobar en la Tabla 38. Si comparamos los resultados obtenidos respecto a la variable "Dolor E.V.A.” podemos afirmar igual que en el caso anterior, que el dolor no depende del sexo, como se demuestra en la Tabla 36.

No obstante, si analizamos el comportamiento de la muestra respecto al sexo, observamos que las mujeres padecieron más dolor que los hombres en la E.V.A., pues marcaron un 10\% más la casilla de dolor intenso (3 o más en la E.V.A.) (Figura 49), existiendo por lo tanto, una clara tendencia de las mujeres a padecer más dolor que los hombres aunque estos resultados no fueran estadísticamente significativos.

Estos resultados concuerdan con otros autores que tampoco encontraron diferencias estadísticamente significativas, entre el dolor y el sexo de los pacientes después de haberse colocado implantes dentales (Eli, et al., 2003, González, et al., 2005, Guarinos, et al., 1998 Hashem, et al., 2006, Peñarrocha, et al., 2000).

Sin embargo, también existen varios autores cuyos resultados difieren de los nuestros, pues encontraron mayor dolor en mujeres que en hombres después de la colocación de implantes dentales. En el estudio más cercano al nuestro en cuanto a tamaño de la muestra y proporción de hombres y mujeres, Al-khabbad et al., encontraron diferencias estadísticamente significativas, ya que las mujeres padecieron mayor grado de dolor a las 24 horas de la intervención, aunque a partir de este punto los valores obtenidos se equiparaban entre ambos sexos. Siguiendo esta línea Urban et al., también observaron mayor dolor en mujeres que en hombres, aunque éste, era más patente el segundo día después de la cirugía (Al-Khabbaz, et al., 2007, Urban \& Wenzel, 2010). 


\section{VNIVERSIDAD}

BSALAMANCA

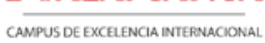

Si relacionamos el dolor postoperatorio y la ansiedad, Eli et al., encontraron en su estudio que las mujeres padecían mayor ansiedad y dolor que los hombres, después de colocarse implantes dentales (Eli, et al., 2000).

Observamos que existen resultados dispares en la relación entre el dolor postoperatorio y el sexo, sin embargo, esta disparidad se basa en que no existen diferencias significativas entre hombres y mujeres respecto al dolor y si existen, son muy ligeras y con tendencia a que las mujeres lo padezcan más.

Consideramos que esta ligerísima diferencia que encontramos podría ser debida a que las mujeres son más sensibles al dolor y a que en estos resultados también influye el factor ansiedad que como se emplica en el apartado Ansiedad, en la página 77, afecta más a mujeres que a hombres, (Eli, et al., 2003, Jones, et al., 2003, Stabholz \& Peretz, 1999) aunque debemos tener en cuenta que influidos por expectativas sociales, los hombres suelen manifestar menos el dolor.

Por lo tanto, coincidimos con la mayoría de los artículos revisados, pues aunque nuestros resultados no son estadísticamente significativos, sí encontramos una tendencia clara de las mujeres a ser más sensibles al dolor que los hombres.

Si comparamos nuestros resultados con los obtenidos en otro tipo de cirugías odontológicas como la extracción de terceros molares inferiores incluidos, éstos son también muy similares a los obtenidos en nuestro estudio, pues el postoperatorio quirúrgico fue igual para hombres y mujeres en la mayoría de los estudios (Capuzzi, et al., 1994, Collins, et al., 1997, Lombardía, et al., 1989, Hansson, et al., 1989, Infante, et al., 1995, Sáez, et al., 1999, Taenzer, et al., 1986). Aunque, sin embargo, existen varios autores que obtuvieron un mayor grado de dolor en mujeres después de dichas cirugías (Berge \& Bøe, 1994, Fisher, et al., 1988, Olmedo, et al., 2002, Sanchez, et al., 1995, Seymour, et al., 1985).

En el resto de cirugías odontológicas, no se han encontrado diferencias significativas en el dolor postoperatorio sufrido por hombres y mujeres (Brown, et al., 1990, Canakçi \& Canakçi, 2007, García, et al., 2007, Iqbal, et al., 2007, Lin, et al., 2006, Meechan \& Blair, 1993, Peñarrocha, et al., 2006, Seymour, et al., 1986, Tsesis, et al., 2003). 


\section{Capitulo 5: Discusión}

En cuanto a la inflamación postoperatoria, tampoco se encontraron diferencias estadísticamente significativas entre hombres y mujeres (Tabla 39). Estos resultados al igual que sucedía con el dolor postoperatorio, coinciden con la mayoría de los autores (González, et al., 2005, Guarinos, et al., 1998), aunque también existen estudios que reportan mayor inflamación en mujeres (Peñarrocha, et al., 2000).

En cirugía de extracción de terceros molares inferiores incluidos y otra clase de cirugías odontológicas la mayoría de los autores no encontraron diferencias significativas entre la inflamación padecida por hombres y mujeres (Capuzzi, et al., 1994, García, et al., 2007, Infante, et al., 1995, Iqbal, et al., 2007, Lin, et al., 2006, Meechan \& Blair, 1993, Peñarrocha, et al., 2006, Sáez, et al., 1999, Seymour, et al., 1986, Taenzer, et al., 1986, Tsesis, et al., 2003), aunque al igual que en el dolor, existe cierta tendencia de la mujer a sufrir mayor inflamación como demostraron varios autores en sus estudios (Berge \& Bøe, 1994, Fisher, et al., 1988, Olmedo, et al., 2002, Sanchez, et al., 1995).

Consideramos que estos resultados pueden deberse también, a expectativas sociales, debido a que las zonas de inflamación visibles en la cara afectan de manera directa a la estética facial, siendo las mujeres las que más preocupación muestran en este sentido y, por tanto, las que valoran dicha inflamación como más grave. También creemos que como se ha citado anteriormente, los hombres están influidos por esas mismas expectativas sociales manifestando como menos grave el dolor y la inflamación postoperatorios.

El hematoma postoperatorio no mostró resultados significativos entre hombres y mujeres (Tabla 40). Esto se debe, a que muy pocos pacientes sufrieron hematoma después de la cirugía por lo que es improbable que los resultados fueran significativos.

\subsubsection{Edad}

El dolor postoperatorio tiene una correlación altamente significativa respecto a la edad de los pacientes, como se refleja en la Tabla 30.

También, se estudió la relación entre la variable "Edad" y "Dolor E.V.A.", encontrando como se muestra en la Tabla 36, que dicha relación es estadisticamente significativa. Para el estudio de esta relación, se dividió la variable "Edad" en dos grupos,

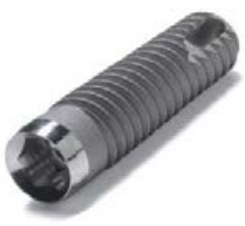


utilizando como punto de corte la edad media de la muestra (50,8 años). Los resultados obtenidos muestran que los pacientes mayores de 50 años padecieron más dolor que los menores de esa edad (Figura 63). Estos resultados difieren de los obtenidos por Urban et al., que dividieron su muestra utilizando el mismo punto de corte (50 años), obteniendo sin embargo, que los pacientes menores de 50 años fueron los que más dolor padecieron. Estos resultados pueden deberse a que en este trabajo, el postoperatorio sólo se analizó durante 3 días después de la cirugía, observándose cómo en el tercer día del postoperatorio tanto los mayores como los menores de 50 años, presentando valores similares respecto al dolor, lo que podría significar que si se hubiera estudiado hasta los 7 días, los valores se podrían haber igualado e incluso superado por los pacientes mayores de 50 años. Creemos también, que estos resultados difieren tanto de los nuestros porque su muestra fue sensiblemente inferior, las técnicas utilizadas fueron distintas y todos los implantes fueron colocados postextracción.

En nuestro trabajo, encontramos una relación significativa entre la edad de los pacientes y el dolor medido en la escala temporal, pues aunque ésta sólo se observó a las 12 horas y a los 5 días, el resto de valores estuvieron muy próximos a ser significativos (Tabla 38). Estos resultados confirman que en nuestro caso, existe una clara relación entre la edad de los pacientes y el dolor postoperatorio.

El resto de los autores no encontraron diferencias significativas entre la edad de los pacientes y el dolor padecido tras la colocación de implantes dentales (Al-Khabbaz, et al., 2007, González, et al., 2005, Guarinos, et al., 1998, Muller \& Ríos, 2001, Peñarrocha, et al., 2000). Creemos que puede ser debido a que en todos los casos, salvo en el estudio de AlKhabbaz et al., la muestra de estudio fue sensiblemente inferior a la nuestra.

Con respecto a la cirugía de extracción de terceros molares inferiores incluidos hallamos también resultados dispares, pues muchos autores no encuentran diferencias significativas entre la edad de los pacientes y el dolor postoperatorio (Fisher, et al., 1988, Gillies, et al., 1987, Kalkman, et al., 2003, López, et al., 2006, Martínez, et al., 1995, Peñarrocha, et al., 2001, Sáez, et al., 1999, Seymour, et al., 1985). Sin embargo, otros autores sí obtuvieron resultados similares a los nuestros, porque los pacientes de mayor edad 


\section{Capitulo 5: Discusión}

padecieron más dolor que los más jóvenes (Bello, et al., 2011, Bruce, et al., 1980, Bui, et al., 2003, Capuzzi, et al., 1994, Chuang, et al., 2007, Chuang, et al., 2008, De Boer, et al., 1995, Fisher, et al., 1988, Infante, et al., 1995, Olmedo, et al., 2002).

Coincidimos con estos autores en que el incremento del dolor en los pacientes mayores, se asocia a la peor vascularización que tienen, la mayor densidad ósea que poseen y a que su ligamento periodontal es más estrecho, por lo que generalmente, las intervenciones son más largas y cruentas.

En el caso de cirugías pericapicales, los resultados son similares pues en la mayoría de los estudios no se encontraron diferencias estadisticamente significativas (Brown, et al., 1990, Chong \& Pitt Ford, 2005, García, et al., 2007, Lin, et al., 2006, Meechan \& Blair, 1993, Peñarrocha, et al., 2001 Peñarrocha, et al., 2006, Seymour, et al., 1986).

En relación a la inflamación, nuestros resultados muestran una gran relación con la edad de los pacientes intervenidos, pues como se puede observar en la Tabla 39, fueron estadísticamente significativos para todos los valores temporales de la inflamación.

Estos resultados concuerdan con los encontrados por Gónzalez et al., quienes observaron que sus pacientes padecieron mayor inflamación a medida que aumentaba la edad de los mismos (González, et al., 2005).

Sin embargo, nuestros resultados difieren ampliamente, de los encontrados en el resto de los estudios analizados, pues ninguno observó diferencias estadísticamente significativas (Al-Khabbaz, et al., 2007, Guarinos, et al., 1998, Muller \& Ríos, 2001, Peñarrocha, et al., 2000).

También coincidimos con la mayoría de estudios sobre cirugías del tercer molar inferior incluido, pues en ellos se encontró que los pacientes de mayor edad padecieron más inflamación (Bello, et al., 2011, Bruce, et al., 1980, Capuzzi, et al., 1994, Chuang, et al., 2007, Chuang, et al., 2008, De Boer, et al., 1995, Fisher, et al., 1988, Infante, et al., 1995, Olmedo, et al., 2002), aunque también hay autores que no encontraron diferencias significativas (Fisher, et al., 1988, López, et al., 2006, Peñarrocha, et al., 2001, Sáez, et al., 1999). 


\section{VNiVERSIDAD}

BSALAMANCA

$\mathrm{Al}$ igual que ocurre con el dolor postoperatorio, consideramos que estos resultados tienen sentido, pues en pacientes de mayor edad, el tejido óseo es más compacto, la vascularización es menor, al igual que el ligamento periodontal, etc, lo que conlleva una cirugía de mayor duración, ostectomías mas agresivas y mayor inflamación postoperatoria.

Los resultados obtenidos en nuestro estudio, difieren con los encontrados por otros autores, respecto a la inflamación tras la cirugía periapical, puesto que éstos no encontraron diferencias entre la inflamación padecida y la edad de los pacientes (Iqbal, et al., 2007, Kvist \& Reit, 2000, Lin, et al., 2006 Meechan \& Blair, 1993, Peñarrocha, et al., 2001, Peñarrocha, et al., 2006). Como en el dolor postoperatorio, estas diferencias pueden deberse a que este tipo de cirugías suelen ser más localizadas, con menor agresión tisular y de menor duración, por lo que la inflamación es siempre menor que en el caso de la cirugía implantológica o de extracción de terceros molares incluidos.

En cuanto al hematoma postoperatorio, también se encontraron resultados significativos pero ninguno de ellos es interpretable, pues como la mayoría de los pacientes no padecieron hematoma, no se puede establecer esta relación como estadísticamente significativa, aunque existe tendencia en las personas de mayor edad a padecer más hematoma (Tabla 26). Creemos que puede ser debido a que, las personas de mayor edad, tienen la piel más frágil y peor vascularización, por lo que son más propensas a padecer este síntoma postoperatorio.

La mayoría de los estudios sobre cirugía implantológica, no estudiaron el hematoma padecido por los pacientes después de dichas intervenciones basándose, únicamente, en el estudio del dolor y la inflamación posoperatorios (Al-Khabbaz, et al., 2007, Eli, et al., 2003, González, et al., 2005, Hashem, et al., 2006, Guarinos, et al., 1998, Muller \& Ríos, 2001, Peñarrocha, et al., 2000).

\subsubsection{Tabaco}

En nuestro estudio, existe una clara relación entre los pacientes no fumadores y el grado de dolor padecido tras la colocación de implantes dentales. En la Figura 50, se puede 


\section{Capitulo 5: Discusión}

obsevar como los pacientes no fumadores padecieron más dolor que los pacientes fumadores. También podemos apreciar como dentro del grupo de los pacientes fumadores, los que más fumaban fueron los que menos dolor padecieron.

Sin embargo, estos resultados no fueron estadísticamente significativos, por lo que coincidimos con otros autores que tampoco encontraron diferencias significativas entre fumadores y no fumadores (Al-Khabbaz, et al., 2007, Guarinos, et al., 1998).

Por otro lado Urban et al., encontraron que los pacientes fumadores padecieron más dolor que los no fumadores durante los 3 primeros días de la intervención, aunque luego los valores en la E.V.A. se igualaban (Urban \& Wenzel, 2010). Coinciden, por tanto, con Al-Khabbaz et al., quienes aunque no encontraron resultados estadísticamente signifivativos observaron también, que los pacientes fumadores padecían más dolor que los no fumadores (Al-Khabbaz, et al., 2007).

Como se puede apreciar, los resultados en cuanto al tabaco y el dolor postoperatorio son dispares. Desde nuestro punto de vista, existen varios factores que afectan al dolor sufrido por estos pacientes, por un lado, como se explica en el apartado Tabaco, en la página 75, la nicotina tiene efecto antinociceptivo, por lo que no debería existir aumento del dolor postquirúrgico en pacientes fumadores, aunque por otro lado, también tiene efecto vasoconstrictor, lo que conlleva una peor cicatrización y la posibilidad de producir dolor durante más tiempo hasta que se completa el cierre de la herida.

En cirugía de extracción de terceros molares inferiores incluidos, varios autores obtuvieron los mismos resultados que nosotros, es decir, que no existe relación entre el tabaco y el dolor postquirúrgico (Capuzzi, et al., 1994, Larrazábal, et al., 2010, López, et al., 2006), aunque también existen autores que reportaron más dolor en fumadores que en no fumadores (García, et al., 2007, Grossi, et al., 2007).

Consideramos que esta diferencia respecto a los pacientes implantológicos, puede deberse a varios aspectos: zonas quirúrgicas de gran tamaño, el efecto vasoconstrictor de la nicotina que retrasa la cicatrización, colonización del área intervenida por bacterias, deficit de higiene postoperatoria debido a la localización posterior de la herida quirúrgica, etc, al 
contrario de lo que sucede en cirugía implantológica donde los tejidos se reponen siempre a su posición original y no se dejan espacios vacios que puedan ser colonizados por bacterias.

Respecto a la cirugía periapical, hay autores como Peñarrocha et al., que no encontraron diferencias significativas en el dolor postoperatorio entre pacientes fumadores y no fumadores (Peñarrocha, et al., 2006), sin embargo, otros autores como García et al., observaron que los pacientes fumadores padecieron más dolor que los no fumadores (García, et al., 2007). Consideramos que estos resultados difieren de los obtenidos en cirugía implantológica por los mismos motivos que en cirugía de extracción de terceros molares inferiores incluidos.

En relación a la inflamación postoperatoria, tampoco encontramos resultados estadísticamente significativos entre pacientes fumadores y no fumadores, como se puede observar en la Tabla 39.

En este caso, existe consenso en los resultados encontrados por los autores que investigaron el postoperatorio implantológico, pues coincidimos en que la inflamación postquirúrgica no tiene relación con la variable "Tabaco" (Guarinos, et al., 1998, Urban \& Wenzel, 2010). Consideramos que la colocación de implantes dentales no es una cirugía de gran envergadura para que el postoperatorio quirúrgico sea diferente entre fumadores y no fumadores. A diferencia del dolor, donde si se pueden sacar conclusiones, la inflamación padecida por nuestros pacientes fue muy leve, por lo que no se pudieron establecer diferencias notables entre fumadores y no fumadores.

El hematoma postquirúrgico mostró resultados estadísticamente significativos a las 24 y 48 horas pero, como sucede con la variable "Edad", no son interpretables, pues como la mayoría de los pacientes no padecieron hematoma, no se puede establecer esta relación como estadísticamente significativa (Tabla 26). 


\section{Capitulo 5: Discusión}

\subsubsection{Higiene}

Los resultados obtenidos sobre la relación entre la variables "Higiene" y "Dolor E.V.A.”, muestran que los pacientes con mala higiene padecieron más dolor intenso que los pacientes que presentaban una higiene regular o buena (Figura 51).

En el análisis temporal de esta variable, se observa que la relación es estadísticamente significativa para el dolor padecido por los pacientes a las 24 horas de la intervención. Estos resultados pueden deberse a que es en ese momento cuando se produce el pico de dolor, por lo que mantener la zona intervenida limpia puede mejorar el grado de dolor padecido por dichos pacientes, siendo los de peor higiene los que padecen un pico de dolor más alto.

Nuestros resultados se encuentran en línea con los obtenidos por Guarinos et al., quienes reportaron que los pacientes con buena higiene padecieron menos dolor a las 12 horas de la intervención (Guarinos \& Peñarrocha, 1994).

Por lo tanto creemos que cuanta mejor higiene presente el paciente, mejor será el postoperatorio, siendo ésta más importante las primeras 48 horas, pues es cuando la herida quirúrgica está reciente y es más importante el cuidado de la misma, perdiendo importancia cuanto más tiempo pase y mejor cicatrizada se encuentre dicha herida.

En la extracción de terceros molares inferiores incluidos y en cirugía periapical, los árticulos revisados muestran los mismos resultados que los de nuestro estudio, pues cuanto mejor es la higiene del paciente, menor es el dolor postoperatorio (García, et al., 2007, Larrazábal, et al., 2010, Peñarrocha, et al., 2001, Peñarrocha, et al., 2006, Sáez, et al., 1999). Estos resultados están en línea con los encontrados en cirugía implantológica, pero son aún más evidentes pues la herida quirúrgica suele ser de mayor tamaño y la posible presencia de bacterias antes de la intervención, hacen que la higiene juegue, desde nuestro punto de vista, un papel fundamental.

No se encontraron resultados estadísticamente significativos entre la variable "Higiene" y la inflamación en ninguno de los momentos temporales estudiados. Estos resultados concuerdan con la mayoría de los artículos revisados para cualquier clase de

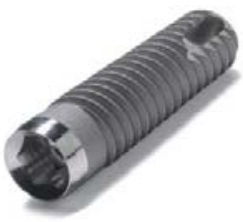




\section{VNiVERSIDAD}

BSALAMANCA

cirugía oral en los que tampoco se observaron diferencias significativas entre la higiene del paciente y la inflamación padecida tras la cirugía (Peñarrocha, et al., 2001, Peñarrocha, et al., 2006).

Hay que mencionar el estudio de García et al., sobre cirugía periapical, en el que encontraron que cuanto mejor era la higiene del paciente, menor inflamación padecía después de la cirugía (García, et al., 2007).

Creemos que nuestros resultados, aunque no sean estadísticamente significativos siguen esta línea, pero al ser muy pocos los pacientes que presentaban mala higiene antes y después de la cirugía (sólo un 8\%), no se han podido extraer resultados más concluyentes.

Por último, y como cabía esperar, el hematoma postquirúgico tampoco presentó una relación estadísticamente significativa respecto al grado de higiene del paciente, pues como se ha comentado anteriormente, muy pocos pacientes sufrieron hematoma.

\subsubsection{Enfermedades Actuales}

El dolor sufrido por los pacientes que padecían alguna enfermedad en el momento de la cirugía y los que no la padecían, fue muy similar como se observa en la Figura 52.

No se encontraron diferencias estadísticamente significativas para el dolor, la inflamación y el hematoma en ninguno de los momentos temporales analizados, por lo que se puede afirmar que padecer una enfermedad en el momento de colocarse implantes dentales, no tiene relación con el postoperatorio quirúrgico (Tabla 38, 39 y 40).

Consideramos que estos resultados se deben a que la mayoría de los pacientes que padecen alguna enfermedad en el momento de la operación, se encuentran bajo tratamiento y con la medicación adecuada establecida, por lo que no hay motivos para que sufran un peor postoperatorio.

Ninguno de los artículos revisados estableció una relación entre padecer enfermedades en el momento de la intervención, con respecto al postoperatorio sufrido tras la colocación de implantes dentales. 
Capitulo 5: Discusión

\subsubsection{Medicación}

El dolor padecido por los pacientes que estaban en tratamiento farmacológico previo a la intervención y los que no recibían ninguna medicación fue similar, existiendo una ligera tendencia de estos últimos a padecer más dolor intenso, como se puede observar en la Figura 54.

No obstante, no se encontraron resultados estadísticamente significativos entre el dolor y los pacientes con o sin medicación previa a la colocación de implantes dentales (Tabla 38). Estos resultados pueden deberse al bajo porcentaje de pacientes de la muestra con medicación $(23 \%$, ) en el momento de la cirugía o a que como muestran los resultados, el dolor postoperatorio fue bajo para todos los pacientes, lo que demuestra que la medicación que se administró como protocolo, controló muy bien el postoperatorio, provocando que la medicación previa del paciente no influyera en el mismo.

La inflamación y el hematoma tampoco mostraron resultados estadísticamente significativos para ninguna de las variables temporales estudiadas, salvo para la variable "Inflamación a las 48h".

Al igual que con la variable "Enfermedades Actuales" no se encontró ningún artículo que valorara la relación entre el postoperatorio implantológico y la medicación previa que estaban tomando los pacientes para el tratamiento de las enfermedades que padecían en el momento de la cirugía y cómo podían afectar dichos medicamentos al postoperatorio implantológico.

\subsubsection{Alergias}

Nuestros resultados muestran una gran relación entre la variable "Alergias" y el dolor padedido tras la colocación de implantes dentales. Así, como se expone en el Figura 53, observamos que los pacientes con alergias padecieron el doble de dolor intenso que los que no las padecían.

Además, esta variable muestra resultados estadísticamente significativos para varios de los momentos temporales estudiados como: "Dolor a las 12 horas", "Dolor a las 24

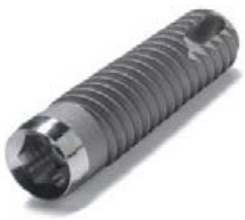


horas", "Dolor a los 5 días" y "Dolor a los 7 días", lo que confirma que los pacientes que padecen algún tipo de alergia durante la cirugía padecen más dolor en el postoperatorio (Tabla 38).

No se ha encontrado ningun resultado parecido en la bibliografía revisada, por lo que no sabemos explicar esta relación tan fuerte entre el dolor postoperatorio y los pacientes que padecen alergias durante el tratamiento con implantes dentales.

La inflamación postquirúrgica también mostró resultados estadísticamente significativos para las variables: "Inflamación a las 12 horas", "Inflamación a las 24 horas" e "Inflamación a los 5 días" (Tabla 39). Desconocemos que origina estos resultados y como sucede con el dolor postoperatorio tampoco hemos encontrado autores que estudiaran esta relación.

El hematoma postoperatorio no mostró resultados estadísticamente significativos para ninguna de las variables estudiadas por lo que no se establece relación entre padecer alguna alergia y un mayor hematoma postoperatorio. Estos resultados, como en el caso de otras variabales, pueden deberse a que hubo pocos pacientes que padecieron hematoma, por lo que no se pueden extraer resultados concluyentes respecto a esta variable.

Ninguno de los artículos revisados, hace mención a la relación de padecer alguna alergia en el momento de la intervención, con el postoperatorio sufrido tras la colocación de implantes dentales. 
Capitulo 5: Discusión

\subsection{FACTORES RELACIONADOS CON LA CIRUGÍA}

\subsubsection{Número de implantes}

Existe una clara relación entre el dolor padecido por los pacientes después de someterse a cirugía implantológica, respecto al número de implantes que se colocan en dicha intervención. En la Figura 55, se puede apreciar cómo el aumento del dolor postquirúrgico es directamente proporcional al número de implantes.

La Tabla 31, refleja la existencia de una relación directa entre el número de implantes colocados y el valor del dolor marcado por los pacientes en la E.V.A.

En cuanto al análisis temporal del dolor respecto al número de implantes colocados, se observa también, una evidente relación entre ambas variables, pues los resultados son estadísticamente significativos para: "Dolor a las 24 horas", "Dolor a las 48 horas", "Dolor a los 5 días" y "Dolor a los 7 días" (Tabla 38). Por lo tanto, podemos afirmar que a mayor número de implantes colocados en la cirugía, más dolor padece el paciente durante el postoperatorio.

En este sentido coincidimos con los artículos revisados, pues todos ellos encontraron que a mayor número de implantes colocados, más dolor padecían sus pacientes (Al-Khabbaz, et al., 2007, González, et al., 2005, Guarinos, et al., 1998, Peñarrocha, et al., 2000).

Es lógico suponer que la colocación de mayor número de implantes conlleva una mayor duración de la cirugía, la realización de colgajos más grandes, mayores ostectomías, etc, provocando que la intervención sea más traumática y produzca más dolor postoperatorio.

Respecto a la inflamación postquirúrgica, se encontraron también, resultados estadísticamente significativos para las siguientes variables: "Inflamación a las 24 horas", "Inflamación a las 48 horas", "Inflamación a los 3 días" e "Inflamación a los 5 días" (Tabla 39). 
En este aspecto coincidimos con Gónzalez et al., Guarinos et al., y Peñarrocha et al., que encontraron mayor inflamación en los pacientes a los que se colocaron mayor número de implantes (González, et al., 2005, Guarinos, et al., 1998, Peñarrocha, et al., 2000).

Como se ha mencionado anteriormente, podemos afirmar que cuantos más implantes se coloquen, mayor agresión tisular se produceirá y por ello, mayor inflamación postquirúrgica padecerá el paciente.

Al igual que en el caso del dolor y la inflamación postoperatorios, el hematoma también tiene gran relación con el número de implantes colocados pues, salvo para la variable "Hematoma a las 12 horas", el resto de ellas mostraron datos estadísticamente significativos (Tabla 40).

Consideramos que estos resultados son lógicos, pues a las 12 horas de la intervención es pronto para que se desarrolle hematoma postquirúrgico, sin embargo, pasadas 24 horas puede comenzar a aparecer. Como sucede con el dolor y la inflamación postoperatorios, creemos que cuantos más implantes se coloquen, mayor es la agresión tisular y más probabilidades existen de padecer hematoma.

\subsubsection{Situación del implante}

La localización de los implantes colocados en la cirugía, muestra que no influye que el implante sea colocado en el maxilar superior o en el inferior, respecto al dolor que padecen nuestros pacientes. Sin embargo, cuando los implantes son colocados en ambas zonas, es decir, en el maxilar superior y a nivel mandibular, los pacientes perciben más dolor que cuando se colocan en una sola (Figura 56).

No obstante, no se aprecia una relación estadísticamente significativa entre el dolor E.V.A. y el dolor medido temporalmente, con respecto a la situación del implante dental (Tabla 38).

Estos resultados concuerdan con los encontrados por González et al., que en su análisis del postoperatorio implantológico, no encontraron mayor dolor en implantes que 


\section{Capitulo 5: Discusión}

fueron colocados en el maxilar superior (González, et al., 2005). Otros autores como Alkhabbaz et al., y Urban et al., obtuvieron los mismos resultados en sus estudios (AlKhabbaz, et al., 2007, Urban \& Wenzel, 2010).

Como muestran los resultados de nuestro estudio y los de otros autores, no hay razón para que se produzca mayor dolor cuando la intervención se lleve a cabo en el maxilar superior o en el inferior. Sin embargo, en nuestro estudio ponen de manifiesto que cuando se colocan en ambos maxilares, los pacientes padecen más dolor puesto que son dos zonas quirúrgicas distintas, hay que realizar dos colgajos, la cirugía es de mayor duración, se colocan como mínimo dos implantes, etc, lo que puede provocar que el paciente padezca más dolor que cuando se colocan en una sola zona. En este caso, consideramos que nuestros resultados no se deben a que la localización del implante sea maxilar o mandibular sino a que son dos zonas quirúrgicas distintas.

Respecto a la inflamación, únicamente se encontraron resultados significativos en las variables: "Inflamación a las 48 horas" e "Inflamación a los 3 días", ambas con frecuencias muy bajas, por lo que no existe una fuerte relación entre la zona donde se ha colocado el implante y la inflamación postquirúrgica.

Estos resultados concuerdan con los encontrados por González et al., y Urban et al., pero, sin embargo, difieren de los obtenidos por Guarinos et al., que observaron mayor inflamación en las zonas mandibulares posteriores (González, et al., 2005, Guarinos, et al., 1998, Urban \& Wenzel, 2010). Al igual que González et al., no compartimos estos resultados pues lo habitual, es que la inflamación se muestre más en la zona anterior bien sea en el maxilar superior o en el inferior, debido a que son áreas en las que el hueso presenta mayor curvatura y se precisan colgajos más amplios, cirugías más largas, etc, lo que conlleva mayor inflamación. Además, estéticamente, las inflamaciones anteriores son más visibles, por lo que tienen más repercusión psicosocial y los pacientes suelen considerarlas más graves que las que se producen en la zona posterior.

En cuanto al hematoma sufrido despues de la cirugía implantológica, se encontraron también, resultados estadísticamente significativos para las variables: "Hematoma a las 12 horas, "Hematoma a los 3 días" y "Hematoma a los 5 días" pero, como en el caso de la 
inflamación, las frecuencias son muy bajas, por lo que no se puede establecer una relación clara entre ambas variables (Tabla 40).

Ninguno de los artículos revisados, estudió la relación entre el hematoma postoperatorio y la localización de los implantes pero parece obvio pensar, que si no existe relación entre el dolor y la inflamación, respecto a la localización de los implantes tampoco existirá en este caso.

\subsubsection{Anterior o Posterior}

Los resultados de nuestro estudio muestran que los pacientes a los que se les colocaron los implantes dentales en la zona anterior, entre el segundo premolar derecho y el segundo premolar izquierdo, bien fuera en el maxilar superior o en el inferior, sufrieron más dolor cuando se colocaron a nivel posterior (Figura 57).

La relación entre el dolor medido en la E.V.A. y la localización del implante anterior o posterior, es estadísticamente significativa por lo que podemos afirmar, que los pacientes a los que se les colocaron los implantes a nivel anterior, padecieron más dolor que aquéllos a los que se les practicaron en la zona posterior (Tabla 28).

En relación al momento temporal del dolor y la situación anterior o posterior de los implantes dentales, se encontraron también, resultados estadísticamente significativos para las variables: "Dolor a las 24 horas", "Dolor a las 48 horas" y "Dolor a los 3 días" (Tabla $38)$.

No se han encontrado artículos que evalúen el dolor respecto a la colocación anterior o posterior de implantes dentales, sin embargo, nuestros resultados son muy concluyentes a este respecto, como se ha expuesto anteriormente. Ésto puede ser debido a que en la zona anterior, tanto superior como inferior, el hueso es más estrecho y presenta una inclinación que no es tan marcada a nivel posterior, por lo que las cirugías suelen requerir colgajos más amplios y mayor duración. Consideramos que otro factor importante es la anatomía de la cabeza, pues las zonas anteriores, tanto maxilar como mandibular, 


\section{Capitulo 5: Discusión}

contienen más terminaciones nerviosas, lo que puede producir al paciente mayor dolor que si es intervenido en zonas posteriores.

La inflamación resultó, también, estadísticamente significativa para las variables: "Inflamación a las 48 horas" e "Inflamación a los 3 días" (Tabla 39). Estos resultados pueden ser debidos a que, estéticamente, las inflamaciones a nivel posterior no tienen tanta repercusión psicosocial como las que se producen en la zona anterior, por lo que los pacientes consideran más graves las inflamaciones en la zona anterior, debido a que éstas pueden influir en su vida diaria.

El hematoma mostró, también, resultados significativos para las variables: "Hematoma a las 24 horas y "Hematoma a las 48 horas" (Tabla 40). Ésto puede ser debido, a que la zona anterior se encuentra más irrigada por pequeños vasos que se pueden romper durante la cirugía y provocar más hematomas que en las zonas posteriores, con menor irrigación. Al igual que ocurre con la inflamación, otro factor importante es la éstetica y la respercusión social, pues no es lo mismo un hematoma en la zona anteiror que en la posterior.

\subsubsection{Elevación de seno}

Los pacientes a los que se les practicó elevación de seno, simultáneamente a la colocación de implantes dentales, presentaron más del doble de dolor intenso que aquéllos a los que no se les practicó (Figura 58).

No se ha encontrado relación estadísticamente significativa entre la variable "Dolor E.V.A.” y los pacientes que se sometieron a este tipo de intervención (Tabla 38). Estos resultados son similares a los encontrados por Urban et al., que en aquellos casos en los que produjo una perforación del suelo sinusal, no observaron aumento del dolor postquirúrgico (Urban \& Wenzel, 2010).

Sin embargo, en nuestro estudio, los pacientes a los que se les practicó elevación de seno, padecieron más dolor que los que no fueron sometidos a la misma. Consideramos que estos resultados no son significativos, porque muy pocos pacientes de los estudiados fueron sometidos a este tipo de intervención, sin embargo, si la muestra fuera superior,

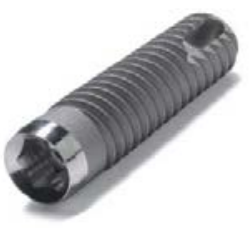


probablemente sí lo serían. Ésto se debe a que los pacientes a los que se les practica este tipo de cirugía, sufren intervenciones de mayor duración, se les realizan colgajos más agresivos, se les implantan biomateriales, etc, por lo que, generalmente, el dolor postoperatorio es mayor que en otros casos.

Así, autores como González et al., y Guarinos et al., encontraron que los pacientes sometidos a elevación sinusal, padecieron más dolor que los que no fueron sometidos a ella (González, et al., 2005, Guarinos, et al., 1998).

La inflamación tampoco mostró resultados estadísticamente significativos, en los momentos temporales de inflamación estudiados, como refleja la Tabla 39. Sin embargo, como en el caso del dolor, consideramos que es debido al escaso número de pacientes que se sometieron a este tipo de intervención pues, generalmente, estos pacientes presentan mayor inflamación por lo expuesto anteriormente.

El hematoma postoperatorio tampoco mostró relación estadísticamente significativa respecto a la elevación de seno (Tabla 40). Como en los casos de dolor e inflamación, consideramos que estos resultados se deben al escaso número de pacientes que fueron sometidos a este tipo de intervención.

\subsubsection{Regeneración ósea}

Los pacientes que fueron sometidos a regeneración ósea simultánea a la colocación de implantes dentales, sufrieron más dolor que aquéllos a los que no se les practicó este tipo de intervención (Figura 59).

Como en el caso de la elevación de seno, estos resultados, aunque nos marcan una clara línea de tendencia, no fueron estadísticamente significativos para la variable "Dolor E.V.A", ni para los diferentes momentos temporales en los que se analizó el dolor (Tabla 38), aunque en este último grupo, la variable "Dolor a los 3 días", sí mostró ser significativa.

En este sentido, nuestros resultados concuerdan con los encontrados por AlKhabbaz et al., y Urban et al., que en sus respectivos estudios, tampoco encontraron 


\section{Capitulo 5: Discusión}

diferencias estadísticamente significativas, entre los pacientes a los que se les practicaron técnicas de aumento óseo y los que no, aunque sí una tendencia de los primeros a padecer más dolor.

Consideramos que si el número de regeneraciones óseas hubiera sido mayor, los resultados encontrados habrían sido significativos pues, al igual que en las elevaciones sinusales, la regeneracion ósea precisa un tiempo de cirugía mayor, la apertura de colgajos más amplios y agresivos, colocación de biomateriales, etc, todos ellos factores que conllevan mayor agresión y, por tanto, más complicaciones postoperatorias.

En lo que se refiere a la inflamación, nuestros resultados tampoco muestran una relación estadísticamente significativa respecto a esta variable, como se puede observar en la Tabla 39.

En este sentido, González et al., encontraron que los pacientes que fueron sometidos a regeneración ósea, padecieron mayor inflamación 48 horas después de la intervención que los que no fueron sometidos a la misma (González, et al., 2005). Del mismo modo que con el dolor postoperatorio, consideramos que si la muestra de estos pacientes fuera mayor, nuestros resultados también serían significativos.

El hematoma postoperatorio, no mostró resultados significativos con respecto a los pacientes que fueron sometidos a regeneración ósea simultánea a la colocación de implantes (Tabla 40).

\subsubsection{Sedación}

Los pacientes sedados para la colocación de implantes dentales, sufrieron dolor similar a los que no lo fueron, como se puede apreciar en la Figura 60.

Los resultados obtenidos respecto a esta variable, no fueron estadísticamente significativos para ninguna de las variables estudiadas: la variable "Dolor E.V.A." y el resto de variables temporales del dolor (Tabla 38).

Para esta misma variable, tampoco se encontraron resultados significativos en el caso de la inflamación y el hematoma postoperatorios (Tabla 39 yTabla 40).

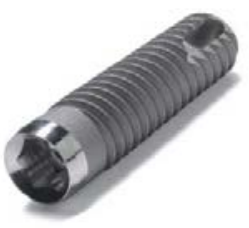


Consideramos que los resultados son coherentes, pues la sedación consciente no tiene por qué influir en el postoperatorio implantológico.

\subsubsection{Postextracción}

Los pacientes a los que se les colocaron los implantes inmediatamente después de extraerles la pieza dentaria, sufrieron dolor similar a aquéllos a los que el implante se les colocó en una zona edéntula cicatrizada (Figura 61).

Para esta variable, no se encontraron resultados estadísticamente significativos respecto a la variable "Dolor E.V.A." y los diferentes momentos temporales del dolor (Tabla 38).

Consideramos que estos resultados son lógicos, debido a las ventajas que conlleva un implante postextracción que no precisa la apertura de colgajo, con menor ostectomía para la colocación del implante y menor duración de la cirugía, pueden quedar contrarrestradas por el posible componente infeccioso y la mayor agresión que se produce en la extracción dental.

La inflamación y el hematoma postoperatorios, tampoco mostraron resultados estadísticamente significativos, como puede observarse en las Tabla 39 y 40.

\subsubsection{Colgajo}

Los pacientes a los que se les colocaron implantes dentales practicando colgajo, padecieron más dolor que los pacientes en los que la apertura del tejido blando fue más conservadora (Figura 62).

Los resultados de esta variable respecto a la variable "Dolor E.V.A.", no fueron estadísticamente significativos, sin embargo, si lo fueron respecto a la valoración temporal del dolor para los siguientes momentos: "Dolor a las 12 horas", "Dolor a las 48 horas" y "Dolor a los 5 días" (Tabla 38). Por lo tanto, podemos afirmar que existe una clara relación entre la variable "Colgajo" y el dolor que padecen los pacientes después de la cirugía. 


\section{Capitulo 5: Discusión}

Coincidimos con Al-khabbaz et al., quienes observaron que a las 24 horas de la intervención, los pacientes a los que se les aumentó el tejido óseo y por tanto precisaron colgajos más amplios, padecieron más dolor que cuando no fue así (Al-Khabbaz, et al., 2007). Sin embargo, disentimos de los resultados encontrados por González et al., Guarinos et al., y Peñarrocha et al., quienes no observaron diferencias significativas respecto al tipo y tamaño de la incisión (González, et al., 2005, Guarinos, et al., 1998, Peñarrocha, et al., 2000).

Consideramos que nuestros resultados son coherentes, pues no se produce la misma agresión tisular cuando se realiza una simple incisión paracrestal, que cuando se practica colgajo con descargas mesiales y distales y despegamiento del periostio.

Corroborando nuestra teoría, se encuentran los resultados obtenidos respecto a la inflamación pues, como se muestra en la Tabla 39, salvo la variable "Inflamación a los 7 días", el resto de variables temporales estudiadas mostraron resultados estadísticamente significativos, respecto al tipo de colgajo que se practicó en la cirugía.

Nuestros resultados concuerdan con los encontrados por González et al., y Guarinos et al., quienes observaron mayor inflamación cuando los colgajos practicados fueron más grandes y agresivos (González, et al., 2005, Guarinos, et al., 1998).

Consideramos que estos resultados se deben a que la reacción inflamatoria que se produce después de la apertura de colgajo con descargas y despegamiento del periostio, es mucho mayor que cuando, simplemente, se practica una incisión paracrestal en la zona que se va a intervenir, debido a que la agresión tisular producida es mucho menor.

Existe también una amplia relación entre el hematoma postquirúrgico y el colgajo realizado en la intervención, pues se encontraron resultados estadísticamente significativos para las siguientes variables: "Hematoma a las 12 horas", "Hematoma a las 24 horas", "Hematoma a las 48 horas" y "Hematoma a los 3 días" (Tabla 40).

Como ocurre con el dolor y la inflamación, también consideramos que cuanto mayor es el colgajo realizado, mayor es la probabilidad de sufrir pequeñas hemorragias y, por lo tanto, de padecer hematoma después de la intervención. 


\subsection{ANÁLISIS EN COMPONENTES PRINCIPALES}

Cuando se recoge la información de una muestra de datos, lo más frecuente es considerar el mayor número posible de variables. Sin embargo, si tomamos demasiadas variables sobre un conjunto de objetos, como ocurre en nuestro estudio, habrá que tener en cuenta múltiples coeficientes de correlación; para 20 variables, dicho número asciende a 180.

Evidentemente, en este caso es difícil visualizar relaciones entre las variables. Otro problema que se plantea, es la fuerte correlación que, frecuentamente, se presenta entre las variables: si consideramos demasiadas variables, lo normal es que estén relacionadas o que midan lo mismo bajo distintos puntos de vista. Se hace necesario pues, reducir el número de variables (Jolliffe, 2002).

Es importante resaltar el hecho de que el concepto de mayor información, se relaciona con el de mayor variabilidad o varianza. Cuanto mayor sea la variabilidad de los datos (varianza), se considera que existe mayor información (Jolliffe, 2002).

La reducción dimensional realizada mediante este análisis, ha puesto de manifiesto que con únicamente tres factores, se puede explicar la varianza asociada al comportamiento de 18 variables del postoperatorio en un 67\% (Tabla 32).

Estos tres factores aparecen claramente diferenciados. El primero de ellos, representa el dolor y la inflamación a partir del segundo día de la intervención y conlleva el $42,5 \%$ de la variabilidad existente en los datos. Estos resultados muestran que los síntomas que más información recogieron, fueron el dolor y la inflamación a partir de las 24 horas de la intervención. Coincidimos con estos resultados porque durante el primer día postoperatorio, la información que aporta el paciente no es muy fiable, debido a los síntomas estudiados pueden estar enmascarados por el inicio temprano de la medicación, la persistencia de la anestesia en el área intervenida, la aplicación de frío en la zona, etc.

El segundo factor obtenido, que representa una varianza superior al 15\%, obtiene información únicamente referida a la variable "Hematoma". Estos resultados muestran que 


\section{Capitulo 5: Discusión}

esta variable en todos sus momentos temporales fue la segunda que más información recogió sobre el postoperatorio. Consideramos que, psicológicamente, la aparición de hematoma en la zona intervenida tiene mucha repercusión para los pacientes, por lo que, aunque este síntoma casi no apareció, es lógico pensar que en los casos en los que se manifestó, éstos lo calificaran como muy importante.

El tercer factor incluye el dolor y la inflamación del primer día, con un 9,2\% de la varianza aportada por las 18 variables iniciales del postoperatorio. Por lo tanto, este último factor nos informa de que el dolor y la inflamación a las 12 y 24 horas, explican un bajo porcentaje de los resultados obtenidos. Como hemos mencionado anteriormente, es normal que estas variables no sean muy explícitas, pues la intervención es muy reciente y existen muchos factores como la medicación inmediata tras la cirugía, la duración de la anestesia, etc, que pueden enmascarar los síntomas que van a padecer nuestros pacientes.

Por lo tanto, podemos afirmar que, respecto al estado del paciente tras la colocación de implantes dentales, las variables que más información recogieron fueron el dolor y la inflamación a partir de las 24 horas de la intervención, en segundo lugar, todas las variables sobre el hematoma y en tercer lugar, y en menor medida, el dolor y la inflamación en las primeras 24 horas tras la intervención. 


\subsection{REPERCUSIÓN CLÍNICA DE LOS RESULTADOS}

Los resultados de nuestro estudio muestran que la mayoría de los pacientes sometidos a la colocación de implantes dentales padecieron dolor tenue según la E.V.A. y dolor ligero, si éste era medido mediante la escala temporal. El pico máximo de dolor fue de intensidad ligera y se alcanzó a las 24 horas de la intervención (34,5\%), aunque su valor fue muy parecido al obtenido a las 12 horas (34\%). Los valores de dolor obtenidos en nuestro trabajo son inferiores al resto de estudios analizados, mientras que el pico de dolor máximo alcazado fue sensiblemente posterior, pues en todos los artículos revisados éste ocurrió anterior a las 24 horas de la intervención (Al-Khabbaz, et al., 2007, Fortin, et al., 2007, Hashem, et al., 2006, González, et al., 2005, Guarinos, et al., 1998, Muller \& Ríos, 2001, Peñarrocha, et al., 2000, Urban \& Wenzel, 2010). En cuanto a la inflamación postoperatoria, los resultados obtenidos como sucede con el dolor, son considerablemente inferiores a los encontrados en el resto de estudios analizados. El grado máximo de inflamación fue de intensidad moderada y se produjo a las 24 horas de la intervención, aunque sólo la presentaron el 12\% de los pacientes (González, et al., 2005, Guarinos, et al., 1998, Muller \& Ríos, 2001, Peñarrocha, et al., 2000, Urban \& Wenzel, 2010). El hematoma postoperatorio se presentó en menos del 10\% de los pacientes intervenidos, alcanzando su grado máximo a las 48 horas de la intervención.

Consideramos que estos resultados se deben a dos motivos fundamentalmente. Por un lado, a que la mayoría de nuestros pacientes se sometieron a la colocación de un número reducido de implantes, lo que conllevó un postoperatorio más confortable, y por otro lado, a que, a diferencia de los artículos revisados, a los pacientes de este estudio se les administró analgésico y antiinflamatorio, inmediatamente después de la intervención, retrasando así la aparición del dolor y la inflamación postquirúrgicos y ejerciendo un mayor control sobre los mismos (Aznar, et al., 2012).

A la vista de los resultados obtenidos en nuestro estudio, en relación al postoperatorio implantológico, podemos afirmar que el protocolo de medicación administrado a nuestros pacientes para controlar el dolor, la inflamación y el hematoma postquirúrgicos fue suficiente para proporcionarles un postoperatorio confortable. Por lo 


\section{Capitulo 5: Discusión}

tanto, consideramos que, aunque la tendencia actual es la premedicación del paciente para reducir los sintomas postoperatorios, los bajos niveles de dolor obtenidos en este estudio ponen de manifiesto que no es necesario administrar análgesicos o antiinflamatorios antes de la intervención y que no se precisa la utilización de corticoides ni opioides para el control de dichos síntomas, ya que el riesgo de posibles efectos secundarios y el buen control del dolor postoperatorio que producen los AINES, no justifican su utilización. Por otro lado, creemos que en cirugías de colocación de pocos implantes o de pequeña envergadura, tampoco es necesario administrar análgesico de rescate (metamizol, $575 \mathrm{mg}$.), para potenciar el efecto del AINE elegido (ibuprofeno 600 mg.).

El sexo de los pacientes intervenidos no mostró diferencias estadísticamente significativas, pero sí encontramos tendencia de las mujeres a padecer más dolor que los hombres después de la intervención. Nuestros resultados concuerdan con la mayoría de los estudios revisados, aunque también existen autores que encontraron diferencias estadísticamente significativas al respecto (Al-Khabbaz, et al., 2007, Urban \& Wenzel, 2010). Creemos que estos resultados pueden deberse a que las mujeres son más sensibles al dolor y padecen más ansiedad que los hombres que, a su vez, influidos por expectativas sociales, manifiestan menos el dolor padecido. Por lo tanto, consideramos que en las mujeres hay que explicar más detenidamente en que consiste la intervención, cuanto tiempo va a durar ésta aproximadamente, qué síntomas van a padecer y cuanto tiempo van a durar los mismos, de manera, que éstas tengan en todo momento referencias de lo que esta ocurriendo y podamos así reducir al máximo su ansiedad.

La relación entre la edad de los pacientes intervenidos y el dolor y la inflamación postoperatorios fue altamente significativa. En este sentido, obtuvimos que el dolor y la inflamación eran mayores a medida que aumentaba la edad de los pacientes (Figura 64). Por otro lado, en relación al dolor E.V.A., encontramos que los pacientes mayores de 50 años padecieron más dolor que los menores de 50 (Figura 63). Nuestros resultados difieren ampliamente de la literatura revisada, en la que no se encontró una relación significativa entre la edad de los pacientes y el dolor y la inflamación postoperatoria. No obstante, creemos que nuestros resultados son coherentes, pues las personas de mayor edad no tienen la misma capacidad de recuperación que los jóvenes, los tejidos no tienen la misma elasticidad, presentan peor coagulación, mayor densidad ósea, etc. Por lo tanto, creemos que

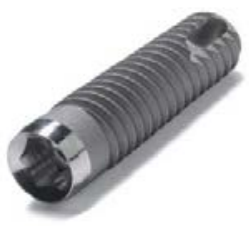


se debe explicar a las personas de mayor edad que en los resultados postoperatorios obtenidos, a pesar de que existe tendencia de éstos a padecer más dolor, esta diferencia no es importante, pues el dolor postoperatorio estuvo muy controlado en ambos casos. Sin embargo, a la vista de que estos pacientes muestran dicha tendencia, consideramos que necesitan mayor atención y, en ocasiones en las que se realicen cirugías complejas, aumentar el tratamiento médico mediante la utilización de un análgesico de rescate (metamizol 575 mg.).

En el estudio del postoperatorio en cirugía oral existen dos factores ampliamente estudiados: el tabaco y la higiene de los pacientes. Con respecto al tabaco, al igual que la mayoría de los estudios revisados, no encontramos diferencias significativas entre los pacientes fumadores y no fumadores, en lo que se refiere al dolor y la inflamación postoperatorios (Al-Khabbaz, et al., 2007, Guarinos, et al., 1998, Urban \& Wenzel, 2010), aunque sí una tendencia de los pacientes no fumadores a padecer más dolor. En la bibliografía revisada sólo Urban et al., encontraron diferencias estadísticamente significativas, pero al contrario que nosotros, éstos obtuvieron que fueron los fumadores los que padecieron mayor dolor postoperatorio. Existe una tendencia general a pensar que los pacientes fumadores presentan peor postoperatorio que los fumadores, sin embargo, nosotros consideramos que el efecto nociceptivo de la nicotina, la medicación administrada y el corto periódo postquirúrgico proporcionan un postoperatorio similar a fumadores y no fumadores. La higiene de los pacientes juega un papel importante en el dolor padecido por los mismos tras la colocación de implantes dentales, siendo ésta más importante las primeras horas después de la intervención. Así, los pacientes con mala higiene sufrieron más dolor que los que presentaban una higiene regular o buena, coincidiendo con lo que encontraron otros autores en sus estudios (García, et al., 2007, Guarinos \& Peñarrocha, 1994, Larrazábal, et al., 2010, Peñarrocha, et al., 2001, Peñarrocha, et al., 2006, Sáez, et al., 1999). Estos resultados parecen obvios pues, la higiene del área quirúrgica es fundamental durante las primeras horas, ya que es en estos momentos cuando existe más riesgo de colonización bacteriana de la zona intervenida. Por este motivo, pensamos que es fundamental motivar al paciente para que mantenga buena higiene durante los primeros días 


\section{Capitulo 5: Discusión}

del postoperatorio. Esta motivación es muy importante, pues la mayoría de los pacientes no se cepillan en la zona intervenida por miedo a hacierse daño.

Los pacientes que presentaban alguna clase de alergia, antes de la colocación de implantes dentales presentaron valores de dolor e inflamación postoperatorios mucho mayores que los que no la padecían. Ninguno de los artículos revisados estudió esta relación y tampoco sabemos exlicar por qué existió tanta diferencia entre ambos grupos de pacientes. Consideramos que es necesario investigar esta relación con profundidad pues los resultados son significativos y no existen artículos que analicen dicha relación. Clínicamente, creemos que antes de intervenir a pacientes alérgicos, hay que reforzar el resto de factores que tienen relación directa con el postoperatorio implantológico como reducir la ansedad del paciente, mejorar la higiene, etc. Por otro lado, los resultados obtenidos nos animan a aumentar el tratamiento médico en este tipo de pacientes, utilizando analgésicos de refuerzo al tratamiento de protocolo.

Existen varios factores relacionados con el acto quirúrgico que juegan un papel fundamental en el postoperatorio implantológico. Éntre ellos, el número de implantes colocados a los pacientes fue el que más relación presentó con respecto al dolor y la inflamación postoperatorios. De esta manera, y de acuerdo con todos los artículos revisados, la colocación de mayor número de implantes produjo un aumento del dolor, la inflamación y el hematoma postoperatorios (Al-Khabbaz, et al., 2007, González, et al., 2005, Guarinos, et al., 1998, Peñarrocha, et al., 2000). Otro factor que se relacionó fuertemente con el postoperatorio, fue la apertura de colgajo con despegamiento del periostio y descargas mesiales y distales. Así, encontramos que cuando se realizó la apertura de este tipo de colgajos, se produjo un aumento del dolor, la inflamación y el hematoma postoperatorios, debido a la interrrupción de la vascularización y el drenaje venoso, a diferencia de cuando el colgajo fue más conservador. Consideramos que ambos factores están relacionados pues, cuanto mayor es el número de implantes que se pretenden colocar, mayor es el área quirúrgica y el colgajo que es necesario realizar para obtener buena visibilidad de la zona. Además, es normal que el postoperatorio se complique en estos casos, ya que se precisan zonas quirúrgicas de mayor tamaño, incisiones y colgajos más amplios, mayores ostectomías, cirugías de mayor duración, etc. Cuando se presenten este tipo de intervenciones hay que tener en cuenta varios factores. En primer lugar, debemos explicar

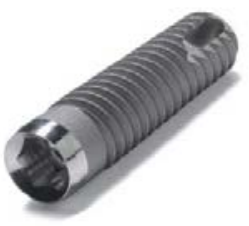


detenidamente el postoperatorio al paciente, para reducir su ansiedad y que encuentre normal, el dolor y la inflamación que va a padecer los primeros días. En segundo lugar, consideramos que en los casos en los que se coloquen 3 o más implantes o se realicen colgajos agresivos será fundamental añadir analgésicos de refuerzo al tratamiento base. Por último, debemos motivar al paciente para que extreme las medidas postoperatorias (Anexo 3. Instrucciones postquirúrgicas).

Otro factor quirúrgico que presentó una relación altamente significativa con el postoperatorio implantológico fue la colocación anterior o posterior de los implantes dentales. Los resultados obtenidos muestran que cuando éstos se colocan en la zona anterior los pacientes padecen más dolor, inflamación y hematoma que cuando son colocados en zonas posteriores, independientemente de si son implantados en el maxilar superior o inferior. Creemos que estos resultados tienen un fuerte componente psicosocial, ya que un hematoma en la zona anterior de la cara, que altera la estética facial de forma directa, no afecta al paciente de igual manera que uno en la zona posterior donde apenas tiene repercusión en la vida diaria del mismo. Desde nuestro punto de vista, consideramos fundamental informar al paciente de que la si la intervención es en la zona anterior, lo normal que es que padezca más dolor e inflamación, para que éstos tengan en todo momento, control sobre el postoperatorio y puedan ajustar su vida social al tratamiento, evitando compromisos los días próximos a la intervención. Otro aspecto fundamental es la motivación del paciente para que utilice todos los instrumentos a su alcance para combatir la inflamación postoperatoria como la aplicación de fríó en la zona, no tumbarse hasta pasadas unas horas, etc. Por otro lado, creemos que en estos pacientes se debe administrar siempre un análgesico de refuerzo para ejercer mayor control sobre el dolor postoperatorio. Si la cirugía es en una mujer de edad avanzada, en la zona anterior y se van a colocacar 3 o más implantes, podemos valorar la asociación de AINES y corticoides para ejercer mayor control sobre la inflamación postoperatoria.

Los pacientes que se sometieron a colocación de implantes dentales con la realización simultánea de regeneración ósea o elevación de seno, presentaron una clara tendencia a padecer peor postoperatorio general. Estos resultados no llegaron a ser estadísticamente significativos, pero ello podría deberse a que en la muestra de estudio se 


\section{Capitulo 5: Discusión}

realizaron pocos tratamientos de esta clase y pensamos que es probable que si la muestra hubiera sido mayor, el postoperatorio de estos pacientes habriá sido considerablemente peor que el de los pacientes a los que únicamente se les colocaron implantes dentales. La realización de estas técnicas avanzadas supone áreas quirúrgicas más amplias, colgajos más amplios y agresivos, ostectomías mayores, cirugías de mayor duración, colocación de biomateriales, etc.

Los resultados obtenidos en este trabajo muestran que el tratamiento postoperatorio fue suficiente para proporcionar un estado más confortable a los pacientes, sin embargo, estudiando las características descritas anteriormente, podremos ejercer mayor control en pacientes con tratamientos más complejos aumentando las instrucciones iniciales al paciente, el tratamiento médico, las medidas postoperatorias, etc.

Desde nuestro punto de vista los resultados postoperatorios fueron tan satisfactorios porque se controlaron muy bien los tres factores explicados anteriormente. En primer lugar, se dedicó mucho tiempo a explicar la cirugía a los pacientes y lo que iba a padecer posteriormente, reduciendo considerablemente su ansiedad y aumentando su grado de confianza en nosotros. Por otro lado, creemos que la medicación administrada se ajustó bien a las necesidades de los pacientes porque se produjo gran control sobre los síntomas postoperatorios como demuestran los resultados obtenidos. Por último, se motivó a los pacientes a llevar a cabo de manera estricta las medidas postoperatotias como la aplicación de frió en la zona, aumento de la higiene, etc.

Consideramos que las sucesivas líneas de investigación deben centrarse en la utilización de otros protocolos de mediación, para comprobar si se consiguen mejores resultados a los obtenidos en nuestro estudio, como por ejemplo, la comparación de pacientes que sean medicados antes de la cirugía, con respecto a otros que sólo reciban medicación postoperatoria. Según los resultados obtenidos en este trabajo, creemos que otra línea de estudio podría basarse en la comparación del postoperatorio en pacientes que sean sometidos a cirugía minimamente invasiva frente a los que sean tratados de manera convencional. Por otro lado, creemos que se debe investigar la relación entre los pacientes alérgicos y el postoperatorio implantológico.

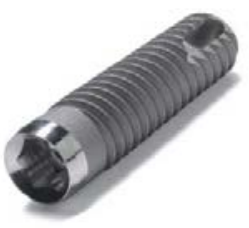


Los resultados de nuestro estudio ponen de manifiesto que la colocación de implantes dentales produce un postoperatorio muy predecible y controlado, siempre y cuando se tengan en cuenta todos los factores de cada paciente de manera individual y se informe y motive a los mismos para mejorar dicho postoperatorio. 
Capítulo 6

CONCLUSIONES 



\footnotetext{
ras la explicación del estudio realizado, el análisis estadístico de los datos recogidos, el estudio de los resultados y después de haber discutido los mismos, podemos llegar a las siguientes conclusiones:
}

1. La mayoría de los pacientes que se colocaron implantes dentales sufrieron dolor ligero o ausencia del mismo, alcanzando el pico máximo a las 24 horas de la intervención. Lo mismo sucedió con la inflamación que fue nula o ligera para la mayor parte de los estudiados, alcanzando su pico máximo a las 24 de la intervención, mientras que la gran mayoría de los pacientes del estudio no padeció hematoma postoperatorio. Los valores de dolor, inflamación y hematoma postoperatorio fueron menores que los encontrados en el resto de la literatura revisada.

2. Considerando la escasa incidencia de dolor moderado o severo, creemos que el protocolo de medicación postoperatorio utilizado se adapta perfectamente a las necesidades del paciente y conlleva unos resultados clínicos muy aceptables. Por este motivo, creemos también que no es necesaria la medicación del paciente antes de la intervención.

3. Los pacientes mayores de 50 años padecen más dolor que los jóvenes, existiendo un claro aumento del dolor postoperatorio a medida que aumenta la edad de los pacientes. Los pacientes que presentan mejor higiene padecen menos dolor, siendo ésta más importante los dos primeros días postoperatorios. Los pacientes alérgicos padecieron más dolor e inflamación que los que no lo eran durante el postoperatorio implantológico.

4. Cuanto mayor es el número de implantes colocados mayor dolor, inflamación y hematoma padecen los pacientes. La apertura de colgajo con descargas produce más dolor e inflamación postoperatoria respecto a una apertura mínimamente invasiva, 
mientras que los implantes colocados a nivel anterior provocan más dolor, inflamación y hematoma que los colocados a nivel posterior.

5. Las mujeres muestran mayor tendencia que los hombres a padecer más dolor postoperatorio. Los pacientes fumadores no padecen peor postoperatorio que los no fumadores.

6. Existe una fuerte relación entre los pacientes que se somenten a elevación de seno y regeneración ósea y un aumento del dolor y la inflamación postquirúrgicos. 
Capítulo 7

BIBLIOGRAFÍA 

1. Adeyemo W, Ladeinde A, Ogunlewe M. Clinical evaluation of post-extraction site wound healing. J Contemp Dent Pract. 2006;7(3):40-49.

2. Akural E, Järvimäki V, Länsineva A, Niinimaa A, Alahuhta S. Effects of combination treatment with ketoprofen $100 \mathrm{mg}+$ acetaminophen $1000 \mathrm{mg}$ on postoperative dental pain: a single-dose, 10-hour, randomized, double-blind, activeaand placebo-controlled clinical trial. Clin Ther. 2009;31(3):560-568.

3. Al-Khabbaz A, Griffin T, Al-Shammari K. Assessment of pain associated with the surgical placement of dental implants. J Periodontol. 2007;78(2):239-246.

4. Al-Khateeb T, Alnahar A. Pain Experience After Simple Tooth Extraction. J Oral Maxillofac Surg. 2008;66(5):911-917.

5. Alexander R. Dental extraction wound management. A case against medacating postextraction sockets. J Oral Maxillofac Surg. 2000;58(5):538-551.

6. Alexander R, Throndson R. A review of perioperative corticosteroid use in dentoalveolar surgery. Oral Surg Oral Med Oral Pathol Oral Radiol Endod. 2000;90(4):406-415.

7. Allen L, Grover A. A comparison of preoperative and postoperative naproxen sodium for suppression of postoperative pain. J Oral Maxillofac Surg. 1990;48(7):674-678.

8. Álvarez R. Estadística multivariante y no paramétrica. Aplicación a las ciencias de la salud. $1^{a}$ ed. Madrid: Díaz de Santos S.A.; 1995.

9. Amini P, Araujo M, Wu M, Charles C, Sharma N. Comparative antiplaque and antigingivitis efficacy of three antiseptic mouthrinses: a two week randomized clinical trial. Braz Oral Res. 2009;23(3):319-325.

10. Anderson P. Anesthetic and analgesic effects of locally administered fentanyl in inflamed dental models. Int J Oral Maxillofac Surg. 2000;58:74-75.

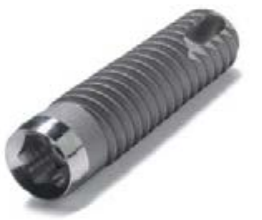


11. Antila H, Lehtinen R, Heinaro I, Lansineva A, Salonen M. Successful pain management by Finnish oral surgeons. A clinical follow-up study. Oral Surg Oral Med Oral Pathol. 1992;74(1):19-23.

12. Antunes A, Avelar R, Martins E, Frota R, Dias E. Effect of two routes of administration of dexamethasone on pain, edema, and trismus in impacted lower third molar surgery. Oral Maxillofac Surg. 2011;15(4):217-223.

13. Arteagoitia I, Díez A, Barbier L, Santamaría G, Santamaría J. Efficacy of amoxicillin/clavulanic acid in preventing infectious and inflammatory complications following impacted mandibular third molar extraction. Oral Surg Oral Med Oral Pathol Oral Radiol Endod. 2005;100(1):8-11.

14. Aznar L, Harutunian K, Figueiredo R, Valmaseda E, Gay C. Effect of preoperative ibuprofen on pain and swelling after lower third molar removal: a randomized controlled trial. Int J Oral Maxillofac Surg. 2012;41(8):1005-1009.

15. Baig M, Rajan M. Effects of smoking on the outcome of implant treatment: a literature review. Indian J Dent Res. 2007;18(4):190-195.

16. Bain C, Moy P. The association betwen the failure of dental implans and cigarette smoking. Int J Oral Maxillofac Implants. 1993;7(6):609-615.

17. Barden J, Derry S, McQuay H, Moore R. Single dose oral ketoprofen and dexketoprofen for acute postoperative pain in adults. Cochrane Database Syst Rev. 2009;7(4):CD007355.

18. Becker D, Reed K. Local anesthetics: review of pharmacological considerations. Anesth Prog. 2012;59(2):90-101.

19. Becker W, Goldstein M, Becker B, Sennerby L, Kois D, Hujoel P. Minimally invasive flapless implant placement: follow-up results from a multicenter study. J Periodontol. 2009;80(2):347-352. 


\section{Capitulo 7: Bibliografía}

20. Becker W, Goldstein M, Becker B, Sennerby L. Minimally invasive flapless implant surgery: a prospective multicenter study. Clin Implant Dent Relat Res. 2005;7(1):2127.

21. Beirne $\mathrm{O}$, Hollander B. The effect of methylprednisolone on pain, trismus, and swelling after removal of third molars. Oral Surg Oral Med Oral Pathol. 1986;61(2):134-138.

22. Bello S, Adeyemo W, Bamgbose B, Obi E, Adeyinka A. Efect of age, impaction types and operative time on inflammatory tissue reactions following lower third molar surgery. Head Face Med. 2011;7(8):8.

23. Benediktsdottir I, Wenzel A, Petersen J, Hintze H. Mandibular third molar removal: risk indicators for extended operation time, postoperative pain and complication. Oral Surg Oral Med Oral Pathol Oral Radiol Endod. 2004;97(4):438-446.

24. Berge T, Bøe O. Predictor evaluation of postoperative morbidity after surgical removal of mandibular third molars. Acta Odontol Scand. 1994;52(3):162-169.

25. Binahmed A, Stoykewych A, Peterson L. Single preoperative dose versus long-term prophylactic antibiotic regimens in dental implant surgery. Int J Oral Maxillofac Implants. 2005;20(1):115-117.

26. Brand H, Gortzak R, Palmer-Bouva C, Abraham R, Abraham-Inpijn L. Cardiovascular and neuroendocrine responses during acute stress induced by different types of dental treatment. Int Dent J. 1995;45(1):45-48.

27. Brånemark $\mathrm{P}$, Albrektsson T. Dental implant Consensus Conference. In National Institutes of Health and Harvard University; 1978; Harvard University. Cambridge.

28. Brånemark P, Breine U. Formation of bone marrow in isolated segmente of rib periosteum in rabbit and dog. Blut. 1964;10:236-252.

29. Brånemark P, Hansson B, Adel R, Breine U, Linstrom J, Hallen $\mathrm{O}$, et al. Osseointegrated implants in the treatment of the edentolous jaw. Experience from a 10-year period. Scand J Plast Reconstr Surg Suppl. 1977;16:1-132. 
30. Brånemark P. The Brånemark Novum Protocol for Same-Day Teeth. A global perspective. $1^{\mathrm{a}}$ ed. Berlin: Quintessence Publishing Co; 2000.

31. Breine $\mathrm{U}$, Brånemark $\mathrm{P}$, Johanson $\mathrm{B}$. Regeneration of bone marrow. A clinical and experimental study (preliminary report). Acta Chir Scand. 1961;122:125-130.

32. Brisman D. The effect of speed, pressure, and time on bone temperature during the drilling of implant sites. Int J Oral Maxillofac Implants. 1996;11(1):35-37.

33. Brown C, Moodie J, Dickie G, Wild V, Smith B, Clarke P, Evans S, Bynum L. Analgesic efficacy and safety of single-dose oral and intramuscular ketorolac tromethamine for postoperative pain. Pharmacotherapy. 1990;10(6):59-70.

34. Bruce R, Frederickson G, Small G. Age of patients and morbidity associated with mandibular third molar surgery. J Am Dent Assoc. 1980;101(2):240-244.

35. Burgess P, Perl E. Cutaneous mechanoreceptors and nociceptors. En: AlbenFessard D, Andres K. Somatosensory System. $1^{\text {a }}$ ed. Berlin: Springer Berlin Heidelberg; 1973. 29-78.

36. Buyukkurt M, Gungormus M, Kaya O. The effect of a single dose prednisolone with and without diclofenac on pain, trismus, and swelling after removal of mandibular third molars. J Oral Maxillofac Surg. 2006;64(12):1761-1766.

37. Bystedt H, Nordenram A. Effect of methylprednisolone on complications after removal of impacted mandibular third molars. Swed Dent J. 1985;9(2):65-69.

38. Calatayud I, Mártinez J, Blanco Y, Gómez R, Donado M. Estudio comparativo entre metamizol y paracetamol en el tratamiento del dolor postoperatorio del tercer molar inferior. Rev Acta Odontol. 1992;18:130-132.

39. Canakçi C, Canakçi V. Pain experienced by patients undergoing different periodontal therapies. J Am Dent Assoc. 2007;138(12):1563-1573. 


\section{Capitulo 7: Bibliografía}

40. Capuzzi P, Montebugnoli L, Vaccaro M. Extraction of impacted thirds molars. A longitudinal prospective study on factors that affect postoperative recovery. Oral Surg Oral Med Oral Pathol. 1994;77:p. 341.

41. Cheung L, Chow L, Tsang M, Tung L. An evaluation of complications following dental extractions using either sterile or clean gloves. Int J Oral Maxillofac Surg. 2001;30(6):550-554.

42. Chong B, Pitt Ford T. Postoperative pain after root-end resection and filling. Oral Surg Oral Med Oral Pathol Oral Radiol Endod. 2005;100(6):762-766.

43. Christensen G. Contribución de la prostodoncia sobre implantes a la odontología restauradora. Av Odontoestomatol. 1991;7:227-237.

44. Collins M, Young I, Sweeney P, Fenn G, Stratford M, Wilson A, et al. The effect of tramadol on dento-alveolar surgical pain. Br J Oral Maxillofac Surg. 1997;35(1):5458.

45. Cooper S, Precheur H, Rauch D, Rosenheck A, Ladov M, Engel J. Evaluation of oxycodone and acetaminophen in treatment of postoperative dental pain. Oral Surg Oral Med Oral Pathol. 1980;50(6):496-501.

46. Cooper S, Quinn P, MacAfee K, Hersh E, Sullivan D, Lamp C. Ibuprofen controlled-release formulation. A clinical trial in dental impaction pain. Oral Surg Oral Med Oral Pathol. 1993;75(6):677-683.

47. Corah N, O'Shea R, Bissell G, Thines T, Mendola P. The dentist-patient relationship: Perceived dentist behaviors that reduce patient anxiety and increase satisfaction. J Am Dent Assoc. 1988;116(1):73-76.

48. Creekmore F, Lugo R, Weiland K. Postoperative opiate analgesia requirements of smokers and nonsmokers. Ann Pharmacother. 2004;38(6):949-953.

49. Cícero J, Daudt W. Implantes osteointegrados: cirugía y prótesis. $1^{\mathrm{a}}$ ed. Sao Paulo: Artes Médicas; 2003. 
50. Dahl J, Kehlet $\mathrm{H}$. The value of preemptive analgesia in the treatment of postoperative pain. Br J Anaesth. 1993;70:434-439.

51. Daniels S, Goulder M, Aspley S, Reader S. A randomised, five-parallel-group, placebo-controlled trial comparing the efficacy and tolerability of analgesic combinations including a novel single-tablet combination of ibuprofen/paracetamol for postoperative dental pain. Pain. 2011;152(3):632-642.

52. De Boer M, Raghnoebar G, Stegenga B, Schoen P, Boering G. Complications after mandibular third molar extraction. Quintessence Int. 1995;26(11):779-784.

53. Degidi M, Piattelli A. Comparative analysis study of 702 dental implants subjected to immediate functional loading and immediate non-funtional loading to traditional healing periods: A follow-up of 24 months. Int J Oral Maxillofac Implants. 2005;20(1):99-107.

54. DeLuca S, Habsha E, Zarb G. The effect of smoking on osseointegrated dental implants. Part I: implant survival. Int J Prosthodont. 2006;19(5):491-498.

55. Dent C, Olson J, Farish SBJ, Casino A, Morris H, Ochi S. The influence of preoperative antibiotics on success of endosseous implants up to and including stage II surgery: A study of 2,641 implants. J Oral Maxillofac Surg. 1997;55(12):1924.

56. Derry C, Derry S, Moore R, McQuay H. Single dose oral ibuprofen for acute postoperative pain in adults. Cochrane Database Syst Rev. 2009;8(3):CD001548.

57. Diccionario de la Lengua Española. 22nd ed. Madrid: Espasa Libros, S.L.U.; 2001.

58. Dionne R. Additive analgesic effects of oxycodone and ibuprofen in the oral surgery model. J Oral Maxillofac Surg. 1999;57(6):673-678.

59. Dionne R, Bryant P, Sessle B. Temporomandibular disorders and related pain conditions. Seattle: IASP Press; 1995. 273-292. 


\section{Capitulo 7: Bibliografía}

60. Dionne R, Gordon S. Antiinflamatorios no esteroideos para el alivio del dolor agudo. Clin odontol norte am. 1994;4:627-648.

61. Dionne R. Pharmacologic advances in orofacial pain: From molecules to medicine. J Dent Educ. 2001;65(12):1393-1403.

62. Dionne R. Preemptive analgesia vs preventive analgesia: which approach improves clinical outcomes?. Compend Contin Educ Dent. 2000;21(1):48-56.

63. Dodson T. Paracetamol is an effective drug to use for pain following oral surgery. Evid Based Dent. 2007;8(3):79-80.

64. Dorlands W. Dorlands illustrated medical dictionary. 32nd ed. Philadelphia: Elsevier; 2011.

65. Dworkin S, Chen A. Pain in clinical and laboratory contexts. J Dent Res. 1982;61(6):772-774.

66. Edwards J, Meseguer F, Faura C, Moore R, McQuay H. Single-dose dipyrone for acute postoperative pain. Cochrane Database Syst Rev. 2001;(3). Cochrane Database Syst Rev. 2001;3:CD003227.

67. Edwards R, Fillingim R, Yamauchi S, Sigurdsson A, Bunting S, Mohorn S, et al. Effects of gender and acute dental pain on thermal pain responses. Clin J Pain. 1999;15(3):233-237.

68. Eglen R, Hunter J, Dray A. Ions in the fire: Recent ion-channel research and approaches to pain therapy. Trends Pharmacol Sci. 1999;20(8):337-342.

69. Eli I, Uziel N, Baht R, Kleinhauz M. Antecedents of dental anxiety: learned responses versus personality traits. Community Dent Oral Epidemiol. 1997;25(3):233-237.

70. Eli I, Schwartz-Arad D, Baht R, Ben-Tuvim H. Effect of anxiety on the experience of pain in implant insertion. Clin Oral Implants Res. 2003;14(1):115-118. 
71. Eli I, Baht R, Kozlovsky A, Simon H. Effect of gender on acute pain prediction and memory in periodontal surgery. Eur J Oral Sci. 2000;108(2):99-103.

72. Esen E, Taşar F, Akhan O. Determination of the anti-inflammatory effects of methylprednisolone on the sequelae of third molar surgery. J Oral Maxillofac Surg. 1999;57(10):1201-1206.

73. Espósito M, Coulthard P, Oliver R, Thomsen P, Worthington H. Antibiotics to prevent complications following dental implant treatment. Cochrane Database Syst Rev. 2003;3:CD004152.

74. Espósito M, Hirsch J, Lekholm U, Thomsen P. Biological factors contributing to failures of osseointegrated oral implants (II). Etiopathogenesis. Eur J Oral Sci. 1998;106(3):721-764.

75. Espósito M, Grusovin M, Polyzos I, Felice P, Worthington H. Timing of implant placement after tooth extraction: immediate, immediate-delayed or delayed implants? A Cochrane systematic review. Eur J Oral Implantol. 2010;3(3):189-205.

76. Farris D, Fiedler M. Preemptive analgesia applied to postoperative pain management. AANA J. 2001;69(3):223-228.

77. Felzani R. Sutura de los tejidos en el área de cirugía bucal: Revisión de la literatura. Acta Odontol Venez. 2007;45(4).

78. Fillingim R, Edwards R, Powell T. The relationship of sex and clinical pain to experimental pain responses. Pain. 1999;83(3):419-425.

79. Fisher S, Frame J, Rout P, McEntegart D. Factors affecting the onset and severity of pain following the surgical removal of unilateral impacted mandibular third molar teeth. Br Dent J. 1988;164(11):351-354.

80. Fortin T, Bosson J, Isidori M, Blanchet E. Effect of flapless surgery on pain experienced in implant placement using an image-guided system. Int J Oral Maxillofac Implants. 2007;21(2):298-304. 


\section{Capitulo 7: Bibliografía}

81. Francetti L, Del Fabbro M, Testori T, Weinstein R. Chlorhexidine spray versus chlorhexidine mouthwash in the control of dental plaque after periodontal surgery. $\mathrm{J}$ Clin Periodontol. 2000;27(6):425-430.

82. Francetti L, Del Fabbro M, Basso M, Testori T, Taschieri S, Weinstein R. Chlorhexidine spray versus mouthwash in the control of dental plaque after implant surgery. J Clin Periodontol. 2004;31(10):857-862.

83. Frazer M, Hampson S. Some personality factors related to dental anxiety and fear of pain. Br Dent J. 1988;165(12):436-439.

84. García A, Sampedro F, Rey J, Torreira M. Trismus and pain after removal of impacted lower third molars. J Oral Maxillofac Surg. 1997;55(11):1223-1226.

85. García B, Peñarrocha M, Martí E, Gay C. Pain and swelling after periapical surgery related to oral hygiene and smoking. Oral Surg Oral Med Oral Pathol Oral Radiol Endod. 2007;104(2):271-276.

86. García B, Larrazábal P, Peñarrocha M, Peñarrocha M. Pain and swelling in periapical surgery. A literature update. Med Oral Patol Oral Cir Bucal. 2008;13(11):726-729.

87. Gaskell H, Derry S, Moore R, McQuay H. Single dose oral oxycodone and oxycodone plus paracetamol (acetaminophen) for acute postoperative pain in adults. Cochrane Database Syst Rev. 2009;8(3):CD002763.

88. Gay C. Cirugía bucal. $1^{a}$ ed. Barcelona: Ergon S.A.; 1999.

89. Gay C, Berini L. Profilaxis de la infección odontogénica. En: Gay C, Berini L. Infección odontogénica. Madrid: Rhone-Poulenc S.A.; 1997.

90. Gelb H. New concepts in craneomandibular and chronic pain management. $1^{\mathrm{a}} \mathrm{ed}$. Barcelona: London Mosby-Wolf; 1994.

91. Gersema L, Baker K. Use of corticosteroids in oral surgery. J Oral Maxillofac Surg. 1992;50(3):270-277.

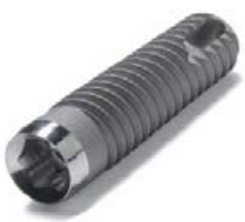


92. Gillies G, Kenny G, Bullingham R, Mc Ardle C. The morphine sparing effect of ketorolac tromethamine. Anaesthesia. 1987;42(7):727-731.

93. Gjermo P. Chlorhexidine and related compounds. J Dent Res. 1989;68:750-760.

94. González S, Boviara M, Peñarrocha M, Peñarrocha D. Relación entre la ansiedad preoperatoria y el grado de satisfacción postoperatorio en cirugía de implantes dentales, con sedación consciente intravenosa. Med Oral Patol Oral Cir Oral. 2012:15(2):125-128.

95. González G, de Francisco J, García R, Bowen A, Carmona J. Complicaciones en implantología. Gaceta dent. 2006;23(Supl):277-278.

96. González H, Peñarrocha M, Guarinos J, Balaguer J. Estudio del dolor e inflamación tras la colocación de 131 implantes dentales. Med Oral Patol Oral Cir Bucal. 2005;10(3):258-263.

97. Gorsuch R. Factor Analysis. 1ª ed. Londres: Saunders; 1974.

98. Graziani F, D'Aiuto F, Arduino P, Tonelli M, Gabriele M. Perioperative dexamethasone reduces post-surgical sequelae of wisdom tooth removal. A splitmouth randomized double-masked clinical trial. Int J Oral Maxillofac Surg. 2006;35(3):241-246.

99. Grossi G, Maiorana C, Garramone R, Borgonovo A, Creminelli L, Santoro F. Assessing postoperative discomfort after third molar surgery: a prospective study. $\mathrm{J}$ Oral Maxillofac Surg. 2007;65(5):901-917.

100. Guarinos J, Peñarrocha M, Sanchís J, Torrella F. Estudio del dolor y la inflamación en 70 pacientes, tras la colocación de 163 implantes (ITI ${ })$ dentales. RCOE. 1998;3:329-333.

101. Guarinos J, Peñarrocha M, Peñarrocha M. Tratamiento del dolor y la inflamación en cirugía oral. Rev Actual Odontoestomatol Esp. 1994;44(10):33-46. 


\section{Capitulo 7: Bibliografía}

102. Gutiérrez J. Third molar infections. Med Oral Patol Oral Cir Bucal. 2004;9(Supl):122-125.

103. Guzeldemir E, Toygar H, Cilasun U. Pain perception and axiety during scaling in periodontally halthy subjects. J Periodontol. 2008;79(12):2247-2255.

104. Gynther G, Köndell PML, Heimdahl A. Dental implant installation without antibiotic prophylaxis. Oral Surg Oral Med Oral Pathol Oral Radiol Endod. 1998;85(5):509-511.

105. Coulthard P, Espósito M, Slater M, Worthington H, Kay E. Prevention. Part 5: Preventive strategies for patients requiring osseointegrated oral implant treatment. Br Dent J. 2003;195(4):187-194.

106. Haas D. An update on local anesthetics in dentistry. J Can Dent Assoc. 2002;68(9):546-551.

107. Hansson P, EKblom A, Thomsson M, Fjellner B. Pain development and consumption of analgesics after oral surgery in relation to personality characteristics. Pain. 1989;37(3):271-277.

108. Happonen R, Bäckström A, Ylipaavalniemi P. Br J Oral Maxillofac Surg. British Journal of Oral and Maxillofacial Surgery. 1990;28(1):12-15.

109. Hargreaves K, Roszkowski M, Jackson D, Bowlles W, Richardson J, Swift J. Neuroendocrine and immune responses to injury, degeneration and repair. En: Dionne R, Bryant P, Sessle B. Temporomandibular disorders and related pain conditions. Seattle: IASP Press; 1995.

110. Hashem A, Claffey N, O'Connell B. Pain and anxiety following the placement of dental implants. Int J Oral Maxillofac Implants. 2006;21(6):943-950.

111. Hedenberg-Magnusson B, Ernberg M, Alstergren P, Kopp S. Pain mediation by prostaglandin E2 and leukotriene B4 in the human masseter muscle. Acta Odontol Scand. 2001;59(6):348-355. 
112. Heitz F, Heitz-Mayfield L, Lang N. Effects of post-surgical cleansing protocols on early plaque control in periodontal and/or periimplant wound healing. J Clin Periodontol. 2004;31(11):1012-1018.

113. Higuchi K, Folmer T, Kultje C. Implant survival rates in partially edentulous patients: a 3-year prospective multicenter study. J Oral Maxillofac Surg. 1995;53(3):264-268.

114. Hinode D, Tanabe S, Yokoyama M, Fujisawa K, Yamauchi E, Miyamoto Y. Influence of smoking on osseointegrated implant failure: a meta-analysis. Clin Oral Implants Res. 2006;17(4):473-478.

115. Hoffmann-Axthelm W. History of dentistry. $1^{\text {a }}$ ed. Michigan: Quintessence Pub. Co.; 1981.

116. Holland C. The influence of methylprednisolone on post-operative swelling following oral surgery. Br J Oral Maxillofac Surg. 1987;25(4):293-299.

117. Hooley J, Francis F. Betamethasone in traumatic oral surgery. J Oral Surg. 1969;27(6):398-403.

118. Huskisson E. Visual analogue scales. En: Melzack R. Pain Measurement and Assessment. New York: Raven Press; 1983. 33-37.

119. Infante P, Espín F, Mayorga F, Hernández J, Rendón J, Delgado M. Estudio de los factores relacionados con la recuperación postoperatoria tras la exodoncia de terceros molares inferiores retenidos. Av Odontoestomatol. 1995;11:569-573.

120. Iqbal M, Kratchman S, Guess G, Karabucak B, Kim S. Microscopic periradicular surgery: perioperative predictors for postoperative clinical outcomes and quality of life assessment. J Endod. 2007;33(3):239-244.

121. Isler S, Cansiz E, Tanyel C, Soluk MSF, Cebi Z. The effect of irrigation temperature on bone healing. Int J Med Sci. 2011;8(8):704-708. 


\section{Capitulo 7: Bibliografía}

122. Jamner L, Girdler S, Shapiro D, Jarvik M. Pain inhibition, nicotine, and gender. Exp Clin Psychopharmacol. 1998;6(1):96-106.

123. Jeske A, Zahrowski J. Good evidence supports ibuprofen as an effective and safe analgesic for postoperative pain. J Am Dent Assoc. 2010;141(5):567-568.

124. Jiménez E, Gasco C, Arrieta J, Gómez J, Bartolome B. Study of the analgesic efficacy of Dexketoprofen Trometamol 25mg. vs. Ibuprofen 600mg. after their administration in patients subjected to oral surgery. Med Oral. 2004;9(2):138-143.

125. Jolliffe I. Principal Component Analysis. 2ª ed. New York: Springer; 2002.

126. Jones A, Zachariae R, Arendt-Nielsen L. Dispositional anxiety and the experience of pain: gender-specific effects. Eur J Pain. 2003;7(5):387-395.

127. Jung Y, Kim M, Um Y, Park H, Lee E, Kang J. The effects on postoperative oral surgery pain by varying NSAID administration times: comparison on effect of preemptive analgesia. Oral Surg Oral Med Oral Pathol Oral Radiol Endod. 2005;100(5):559-563.

128. Kalkman C, Visser K, Moen J, Bonsel G, Grobbee D, Moons K. Preoperative prediction of severe postoperative pain. Pain. 2003;105(3):415-423.

129. Karapetian V, Duddeck D, Rothamel D, Neugebauer J, Zöller J. Técnicas de incisión y sutura en la cirugía oral y la cirugía implantológica. Quintessence. 2012;25(2):63-68.

130. Kelly D, Ahmad M, Brull S. Preemptive analgesia II: recent advances and current trends. Can J Anaesth. 2001;48(11):1091-1101.

131. Kent G. Dental phobia. En Davey G. Phobias. A handbook of theory and research. London: John Wiley and Sons; 1997.

132. Kim K, Brar P, Jakubowski J, Kaltman S, Lopez E. The use of corticosteroids and nonsteroidal antiinflammatory medication for the management of pain and 
inflammation after third molar surgery: a review of the literature. Oral Surg Oral Med Oral Pathol Oral Radiol Endod. 2009;107(5):630-640.

133. Kissin I. Preemptive analgesia. Anesthesiology. 2000;93(4):1138-1143.

134. Kvist T, Reit C. Postoperative discomfort associated with surgical and nonsurgical endodontic retreatment. Endod Dent Traumatol. 2000;16(2):71-74.

135. Laney W, Tolman D, Keller E. Dental implants: tissue-integrated prosthesis utilizing the osseointegration concept. Mayo Clin Proc. 1986;61(2):91-97.

136. Lang N, Wilson T, Corbet E. Biological complications with dental implants: their prevention, diagnosis and treatment. Clin Oral Implants Res. 2000;11(Supl):146155.

137. Lang N, Hotz P, Graf H, Geering A, Saxer U, Sturzenberger O, et al. Effects of supervised chlorhexidine mouthrinses in children. A longitudinal clinical trial. J Periodontal Res. 1982;17(1):101-111.

138. Lang N, Pun L, Lau K, Li K, Wong M. A systematic review on survival and success rates of implants placed immediately into fresh extraction sockets after at least 1 year. Clin Oral Implants Res. 2012;23(5):39-66.

139. Larrazábal C, García B, Peñarrocha M, Peñarrocha M. Influence of oral hygiene and smoking on pain and swelling after surgical extraction of impacted mandibular third molars. J Oral Maxillofac Surg. 2010;68(1):43-46.

140. Laskin D, Dent C, Morris H, Ochi S, Olson J. The influence of preoperative antibiotics on success of endosseous implants at 36 months. Ann Periodontol. 2000;5(1):166-174.

141. Laureano J, Maurette P, Allais M, Cotinho M, Fernandes C. Clinical comparative study of the effectiveness of two dosages of Dexamethasone to control postoperative swelling, trismus and pain after the surgical extraction of mandibular impacted thirid molars. Med Oral Patol Oral Cir Bucal. 2008;13(2):129-132. 


\section{Capitulo 7: Bibliografía}

142. Lawler B, Sambrook P, Goss A. Antibiotic prophylaxis for dentoalveolar surgery: is it indicated? Aust Dent J. 2005;50(4):54-59.

143. Lee D, Choi B, Jeong S, Xuan F, Kim H.. Effects of flapless implant surgery on soft tissue profiles: a prospective clinical study. Clin Implant Dent Relat Res. 2011;13(4):324-329.

144. Levrini L, Carraro M, Rizzo S, Salgarello S, Bertelli E, Pelliccioni G, et al. Prescriptions of NSAIDs to patients undergoing third molar surgery: an observational, prospective, multicentre survey. Clin Drug Investig. 2008;28(10):657668.

145. Lin S, Levin L, Emodi O, Abu I, Peled M. Etodolac versus dexamethasone efffect in reduction of postoperative symptoms following surgical endodontic treatment: a double-bling study. Oral Surg Oral Med Oral Pathol Oral Radiol Endod. 2006;101(6):814-817.

146. Lindsay S, Jackson C. Fear of routine dental treatment in adults: its nature and management. Psychol Health. 1993;8(2-3):135-153.

147. Litkowski L, Christensen S, Adamson D, Van Dyke T, Han S, Newman K. Analgesic efficacy and tolerability of oxycodone $5 \mathrm{mg} /$ ibuprofen $400 \mathrm{mg}$ compared with those of oxycodone $5 \mathrm{mg}$ /acetaminophen $325 \mathrm{mg}$ and hydrocodone 7.5 $\mathrm{mg} /$ acetaminophen $500 \mathrm{mg}$ in patientes with moderate to severe postoperative pain. Clin Ther. 2005;27(4):418-429.

148. LLorca G, Villoria J, García L, Díaz A. Psicología y psicopatología. En: Muriel C. Tratamiento del dolor rebelde. Salamanca; 1989. 35-41.

149. Löe H, Schiott $C$. The effect of mouthrinses and topical application of chlorhexidine on the development of dental plaque and gingivitis in man. J Periodontal Res. 1970;5(2):79-83. 
150. Lombardía E, González M, Junquera L, Gener M. Estudio del dolor postoperatorio habido tras la extracción de terceros molares inferiores (I). Rev Esp Cir Oral Maxilofac. 1989;11(2):98-103.

151. Lombardía E, Gracía M, González M, Gener M. Profilaxis antimicrobiana en la cirugía del tercer molar. Arch Odontoestomatol. 1987;(3):130-134.

152. López C, Gómez R, Martínez J, Donado M. Influence of smoking upon the postoperative course of lower third molar surgery. Med Oral Patol Oral Cir Bucal. 2006;11(1):56-60.

153. Machín J. Implantes inmediatos postextracción. $1^{\text {a }}$ ed. Oviedo; 2002.

154. Mahan P, Allining C. Facial Pain. $3^{\text {a }}$ ed. Philadelphia: Lea \& Febiger ; 1991.

155. Mankodi S, Mostler K, Charles C. Comparative antiplaque/antigingivitis efficacies of two antiseptic mouthrinses. J Periodontal Res. 1990;69.

156. Marco A, Greenwald M, Higgins M. A preliminary study of 24-hour post-cesarean patient controlled analgesia: postoperative pain reports and morphine requests/utilization are greater in abstaining smokers than non-smokers. Med Sci Monit. 2005;11(6):255-261.

157. Martín A, Luna del Castillo JD. Bioestadística para las ciencias de la salud. $4^{\mathrm{a}} \mathrm{ed}$. Madrid: Normal Capitel; 2004.

158. Mark D, Granquist E. Are prophylactic oral antibiotics indicated for the treatment of intraoral wounds?. Ann Emerg Med. 2008;52(4):368-372.

159. Markiewicz M, Brady M, Ding E, Dodson T. Corticosteroids reduce postoperative morbidity after third molar surgery: a systematic review and meta-analysis. J Oral Maxillofac Surg. 2008;66(9):1881-1894. 


\section{Capitulo 7: Bibliografia}

160. Martínez M, Bermuda L, González A, Montes J, Valiente A. Evaluación de ketorolaco, ketoprofeno y tramadol en el dolor postoperatorio en cirugía oral ambulatoria. Av Odontoestomatol. 1995;11:385-388.

161. Martorell L, García B, Pañerrocha M. Actualización en el tratamiento del dolor orofacial. Med Oral. 2004;9:293-299.

162. Mazzocchi A, Passi L, Moretti R. Retrospective analysis of 736 implants inserted without antibiotic therapy. J Oral Maxillofac Surg. 2007;65(11):2321-2323.

163. Meechan J, Blair G. The effect of two different local anaesthetic solutions on pain experience following apicectomy. Br Dent J. 1993;175(11-12):410-413.

164. Meechan R, Seymour A. The use of third molar surgery in clinical pharmacology. Br J Oral Maxillofac Surg. 1993;31(6):360-365.

165. Mehlisch D. The efficacy of combination analgesic therapy in relieving dental pain. J Am Dent Assoc. 2002;133(7):861-871.

166. Mehlisch D, Aspley S, Daniels S, Southerden K, Christensen K. A single-tablet fixed-dose combination of racemic ibuprofen/paracetamol in the management of moderate to severe postoperative dental pain in adult and adolescent patients: a multicenter, two-stage, randomized, double-blind, parallel-group, placebo control. Clin Ther. 2010;32(6):1033-1049.

167. Mehlisch D, Aspley S, Daniels S, Bandy D. Comparison of the analgesic efficacy of concurrent ibuprofen and paracetamol with ibuprofen or paracetamol alone in the management of moderate to severe acute postoperative dental pain in adolescents and adults. Clin Ther. 2010;32(5):882-895.

168. Melzack R. The McGill Pain Questionnaire: major properties and scoring methods. Pain. 1975;1(3):277-299.

169. Micó J, Satorres M, Gargallo J, Arnabat J, Berini L, Gay C. Efficacy of methylprednisolone in controlling complications after impacted lower third molar surgical extraction. Eur J Clin Pharmacol. 2006;62(9):693-698.

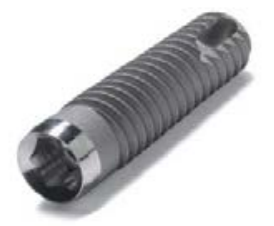


170. Misch C, Dietsh-Misch F, Hoar J, Beck G, Hazen R, Misch C. A bone quality-based implant system: first year of prosthetic loading. J Oral Implantol. 1999;25(3):185197.

171. Misch C. Prótesis dental sobre implantes. $1^{\mathrm{a}}$ ed. Madrid: Elsevier Mosby; 2006.

172. Misch C. Implantología Contemporánea. $3^{a}$ ed. Barcelona: Elsevier España; 2009.

173. Misir A, Sumer M, Yenisey M, Ergioglu E. Effect of surgical drill guide on heat generated from implant drilling. J Oral Maxillofac Surg. 2009;67(12):2663-2668.

174. Møiniche S, Kehlet H, Dahl J. A qualitative and quantitative systematic review of preemptive analgesia for postoperative pain relief: the role of timing of analgesia. Anesthesiology. 2002;96(3):725-741.

175. Moore A, Collins S, Carroll DMH. Paracetamol with and without codeine in acute pain: a quantitative systematic review. Pain. 1997;70(2-3):193-201.

176. Moore A, Collins S, Carroll D, McQuay H, Edwards J. Single dose paracetamol (acetaminophen), with and without codeine, for postoperative pain. Cochrane Database Syst Rev. 2000;2:CD001547.

177. Moore R, Straube S, Paine J, Derry S, McQuay H. Minimum efficacy criteria for comparisons between treatments using individual patient meta-analysis of acute pain trials: examples of etoricoxib, paracetamol, ibuprofen, and ibuprofen/paracetamol combination after third molar extraction. Pain. 2011;152(5):982-989.

178. Morin C, Lund J, Villarroel T, Clokie C, Feine J. Differences between the sexes in post-surgical pain. Pain. 2000;85(1-2):79-85.

179. Morris H, Ochi S, Plezia R, Gilbert H, Dent C, Pikulski J, et al. AICRG, Part III: The influence of antibiotic use on the survival of a new implant design. J Oral Implantol. 2004;30(3):144-151. 


\section{Capitulo 7: Bibliografía}

180. Muller E, Ríos M. Pain and dental implantology: Sensory quantification and affective aspects. Part I: At the private dental office. Implant Dent. 2001;10(1):14 22.

181. Muriel C, Vara F, Garzón N, Garcia-Ortega E. Dolor postoperatorio. En Muriel C. Tratamiento del dolor rebelde. Salamanca; 1989. 145-154.

182. Nathanson N, Seifert D. Betamethasone in dentistry. Oral Surg Oral Med Oral Pathol. 1964;18:715.

183. National Institutes of Health. The integated approach to the management of pain. Consensus Development Conference Statement. US Government Printing Office. 1986;6(3):491-292-41148.

184. Neumann S, Soubell T, Leslie T, Woolf C. Inflammatory pain hypersensitivity mediated by phenotype switch in myelinated primary sensory neurons. Nature. 1996;384(6607):360-364.

185. Okeson J. Dolor Orofacial según Bell. 6a ed. Quintessence S.L.; 2006.

186. Olmedo M, Vallecillo M, Gálvez R. Relación de las variables del paciente y de la intervención con el dolor y la inflamación postoperatorios en la exodoncia de los terceros molares. Med Oral. 2002;7(5):360-369.

187. Olmedo M, Gálvez R, Vallecillo M, Galindo P. Tratamiento del dolor postextracción. Av Odontoestomatol. 1995;11:453-458.

188. Ong C, Seymour R, Lirk P, Merry A. Combining paracetamol (acetaminophen) with nonsteroidal antiinflammatory drugs: a qualitative systematic review of analgesic efficacy for acute postoperative pain. Anesth Analg. 2010;110(4):1170-1179.

189. Otto M, Dougher M. Sex diferences and personality factors in responsivity to pain. Percept Mot Skills. 1985;61(2):383-390.

190. Pain terms: A list with definitions and notes on usage-Pain. Pain. 1979;14:205-208. 
191. Pain Assessment and Management: an Organizacional Approach. Joint Commission on Accreditation of Healthcare Organization. 2000.

192. Pederson A. Inter-relationship of complaints after removal of impacted third molars. Int J Oral Maxillofac Surg. 1985;14:241-247.

193. Peñarrocha M, Guarinos J, Sanchís J, Balaguer J. Estudio clínico retrospectivo (1994-99) de 441 implantes ITI ${ }^{\circ}$ en 114 pacientes, con un seguimiento medio de 2,3 años. Med Oral. 2002;7(2):144-155.

194. Peñarrocha M, Sanchís J, Guarinos J, Soriano I, Balaguer J. Estudio comparativo entre la técnica convencional y la de los osteodilatadores para la creación del lecho implantológico. A propósito de 226 implantes (ITI@) colocados en 80 pacientes. Periodoncia. 2000;10(3):189-198.

195. Peñarrocha M, Ayet C, Oltra M, Sanchís J. Dolor orofacial postquirúrgico. Arch Odontoestomatol. 2001;17:615-630.

196. Peñarrocha M, Sanchís J, Sáez U, Gay C, Bagán J. Oral hygiene and postoperative pain after mandibular third molar surgery. Oral Surg Oral Med Oral Pathol Oral Radiol Endod. 2001;92(3):260-264.

197. Peñarrocha M, García B, Martí E, Balaguer J. Pain and inflammation after periapical surgery in 60 patients. J Oral Maxillofac Surg. 2006;64(3):429-433.

198. Perl E. Causalgia, pathological pain and adrenergic receptors. Proc Natl Acad Sci U S A. 1999;96(14):7664-7667.

199. Peterson L. Long term antibiotic prophylaxis is not necessary for placement of dental implants. J Oral Maxillofac Surg. 1996;54(3):76.

200. Planas M, Gay C, Bagán J, Santamaría J, Peñarrocha M, Donado M, et al. Oral metamizol ( $1 \mathrm{~g}$ and $2 \mathrm{~g}$ ) versus ibuprofen and placebo in the treatment of lower third molar surgery pain: randomised double-blind multi-centre study. Eur J Clin Pharmacol. 1998;53(6):405-409. 


\section{Capitulo 7: Bibliografía}

201. Polizzi G, Grunder U, Goené R, Hatano N, Henry P, Jackson W, et al. Immediate and delayed implant placement into extraction sockets: a 5-year report. Clin Implant Dent Relat Res. 2000;2(2):93-99.

202. Pomerleau O. Nicotine as a psychoactive drug: anxiety and pain reduction. Psychopharmacol Bull. 1986;22(3):865-869.

203. Price D, McGrath P, Rafii A, Buckingham B. The validation of visual analog scale measures for chronic and experimental pain. Pain. 1983;17(1):45-56.

204. Quirynen M, De Soete M, Van Steenberghe D. Infectious risks for oral implants: A review of the literature. Clin Oral Implants Res. 2002;13(1):1-19.

205. Raspall G. Cirugía oral e implantológica. $2^{\mathrm{a}}$ ed. Madrid: Medica Panamericana; 2006.

206. Redding S, Montgomery M. Dentistry in Systemic Disease: Diagnostic and Therapeutic Approach to Patient Management. $1^{\mathrm{a}}$ ed. Portland: JBK Publishing; 1990.

207. Romero M, Infante P, Gutiérrez J. Actuaciones y tratamientos complementarios en la exodoncia de los cordales incluidos. (Medidas pre e intraoperatorias). En: Romero M, Gutiérrez J. El tercer molar incluido. Madrid: GSK; 2001. 209-221.

208. Romero M, Infante P, Gutiérrez J. Actuaciones y tratamientos complementarios en la exodoncia de los cordales incluidos. (Medidas postoperatorias). En: Romero M, Gutiérrez J. El tercer molar incluido. Madrid: GSK; 2001. 223-241.

209. Romero M, Herrero M, Torres D, Gutiérrez J. Protocolo de control del dolor y la inflamación postquirúrgica. Una aproximación racional. RCOE. 2006;11(2):205-215.

210. Romero M, Serrano A, Infante P, Gómez J TD, Gutiérrez J. Tendencias actuales en el control del dolor y la inflamación tras la extracción de terceros molares incluidos (Parte 1). Rev Eur Odontoestomatol. 2001;13:261-266.

211. Rousseau P. Flapless and traditional dental implant surgery: an open, retrospective comparative study. J Oral Maxillofac Surg. 2010;68(9):2299-2306.

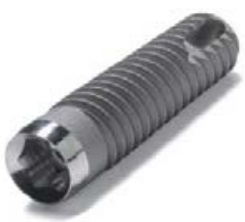


212. Rubin G, Slovin M, Krochak M. The psychodynamics od dental enxiety and dental phobia. Dent Clin North Am. 1988;32(4):647-656.

213. Rugh J. Componentes psicológicos del dolor. Dent Clin North Am. 1987;4:733-748.

214. Ruiz J, Alejos E, Berini L, Gay C. Analgesia preventiva en cirugía bucal. Revisión de la literatura. Arch Odontoestomatol. 2003;19:252-262.

215. Ruta D, Bissias E, Ogston S, Ogden G. Assessing health outcomes after extraction of third molars: the postoperative symptom severity (PoSSe) scale. Br J Oral Maxillofac Surg. 2000;38(5):480-487.

216. Sada J, Guisado B, Donado M. Implantes osteointegrados. En Donado M. Cirugía Bucal. Patología y técnica. 3 a ed. Madrid: Elsevier Masson; 1990. 659-690.

217. Sáez U, Peñarrocha M, Sanchís J, Gay C. Estudio del postoperatorio de 100 terceros molares mandibulares incluidos, en relación a la edad, el sexo, el tabaco y la higiene bucal. RCOE. 1999;4:471-475.

218. Sánchez M, Carrillo J, Díaz M, Calatayud J. Influencia de la edad de los pacientes en las complicaciones que aparecen después de la exodoncia del tercer molar inferior retenido. Rev Esp Cir Oral Maxilofac. 1995;17:173-178.

219. Sanchís J, Peñarrocha M. Dolor orofacial postquirúrgico. Etiología, diagnóstico y tratamiento. $1^{\text {a }}$ ed. Barcelona: Masson SA; 1997.

220. Santamaría J, Iglesia M, Arteagoitia M. Implantología oral y dolor. En: Bascones A, Manso F. Dolor orofacial: Diagnóstico y tratamiento. Madrid: Ediciones Avances; 1997. 237-289.

221. Sessle B. Anatomy, physiology and pathophysiology of orofacial pain. En Jacobson A, Donlon W. Headache and facial pain. New York: Raven Press; 1990. 1-24.

222. Scharf D, Tarnow D. Success rates of osseointegration for implants placed under sterile versus clean conditions. J Periodontol. 1993;64(10):954-956. 


\section{Capitulo 7: Bibliografía}

223. Schmelzeisen R, Frölich J. Prevention of postoperative swelling and pain by dexamethasone after operative removal of impacted third molar teeth. Eur J Clin Pharmacol. 1993;44(3):275-277.

224. Schultze-Mosgau S, Schmelzeisen R, Frölich J, Schmele H. Use of ibuprofen and methylprednisolone for the prevention of pain and swelling after removal of impacted third molars. J Oral Maxillofac Surg. 1995;53(1):2-7.

225. Seymour R, Simpson J, Charlton J, Phillips M. An evaluation of length and endphrase of visual analogue scales in dental pain. Pain. 1985;21(2):177-185.

226. Seymour R, Meechan J, Blair G. An investigation into post-operative pain after third molar surgery under local analgesia. Br J Oral Maxillofac Surg. 1985;23(6):410-418.

227. Seymour R, Meechan J, Blair G. Postoperative pain after apicoectomy. A clinical investigation. Int Endod J. 1986;19(5):242-247.

228. Siegrist B, Gusberti F, Brecx M, Weber H, Lang N. Efficacy of supervised rinsing with chlorhexidine digluconate in comparison to phenolic andnplant alkaloid compounds. J Periodontal Res. 1986;21:60-65.

229. Sisk A, Bonnington G. Evaluation of methylprednisolone and flurbiprofen for inhibition of the postoperative inflammatory response. Oral Surg Oral Med Oral Pathol. 1985;60(2):137-145.

230. Slade G, Foy S, Shugars D, Phillips C, White R. The impact of third molar symptoms, pain, and swelling on oral health-related quality of life. J Oral Maxillofac Surg. 2004;62(9):p. 1118.1124.

231. Smedberg J, Lothigius E, Bodin I, Frykholm A, Nilner K. A clinical and radiological two-year follow-up study of maxillary overdentures on osseointegrated implants. Clin Oral Implants Res. 1993;4(1):39-46.

232. Smyth J. Some problems of dental treatment. Part 1. Patient anxiety: some correlates and sex differences. Aust Dent J. 1993;38(5):354-359.

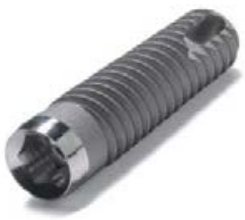


233. Soh G, Yu P. Phases of dental fear for four treatment procedures among military personnel. Mil Med. 1992;157(6):294-297.

234. Spiekermann H. Atlas de implantología. $1^{\text {a }}$ ed. Madrid: Masson; 1995.

235. Stabholz A, Peretz B. Dental anxiety among patients prior to different dental treatments. Int Dent J. 1999;49(2):90-94.

236. Stedman T. Stedman medical dictionary. 28th ed. Baltimore: Lippincott Williams \& Wilkins; 2005.

237. Stimmel B. Tratamiento farmacológico del dolor. $1^{a}$ ed. Mexico: Editorial Científica PLM; 1985.

238. Sundqvist G, Carlsson J, Herman B, Tärnvik A. Degradation of human inmonoglobulins $\mathrm{G}$ and $\mathrm{M}$ and complement factor $\mathrm{C} 3$ and $\mathrm{C} 5$ by black pigmented bacteroides. J Med Microbiol. 1985;19(1):85-94.

239. Taenzer P, Melzack R, Jeans M. Influence of psychological factors on postoperative pain, mood and analgesic requirements. Pain. 1986;24(3):331-342.

240. The integrated approach to the management of pain. National Institute Health consensus development conference consensus statement. 1986;6(3):1-8.

241. Tiigimae-Saar J, Leibur E, Tamme T. The effect of prednisolone on reduction of complaints after impacted third molar removal. Stomatologija. 2010;12(1):17-22.

242. Toms L, Derry S, Moore R, McQuay H. Single dose oral paracetamol (acetaminophen) with codeine for postoperative pain in adults. Cochrane Database Syst Rev. 2009;21(1):CD001547.

243. Torabinejad M. Mediators of acute and chronic periradicular lesions. Oral Surg Oral Med Oral Pathol. 1994;78(4):511-521. 


\section{Capitulo 7: Bibliografía}

244. Touyz L, Marchand S. The influence of postoperative telephone calls on pain perception: a study of 118 periodontal surgical procedures. J Orofac Pain. 1998;12(3):219-225.

245. Treede R, Jensen T, Campbell J, Cruccu G, Dostrovsky J, Griffin J, et al. Neuropathic pain: redefinition and a grading system for clinical and research purposes. Neurology. 2008;70(18):1630-1635.

246. Troullos E, Hargreaves K, Butler D, Dionne R. Comparison of nonsteroidal antiinflammatory drugs, ibuprofen and flurbiprofen, with methylprednisolone and placebo for acute pain, swelling, and trismus. J Oral Maxillofac Surg. 1990;48(9):945-952.

247. Trowbridge H. Inmunological aspect of chronic inflammation and repair. J Endod. 1990;16:54-61.

248. Tsesis I, Fuss Z, Lin S, Tilinger G, Peled M. Analysis of postoperative symptoms following surgical endodontic treatment. Quintessence Int. 2003;34(10):756-760.

249. Tssesis I, Shoshani Y, Givol N, Yahalom R, Fuss Z, Taicher S. Comparison of quality of life after surgical endodontic treatment using two techniques: a prospective study. Oral Surg Oral Med Oral Pathol Oral Radiol Endod. 2005;99(3):367-371.

250. Unruh A. Gender variations in clinical pain experience. Pain. 1996;65:123-167.

251. Urban T, Wenzel A. Discomfort experienced after immediate implant placement associated with three different regenerative techniques. Clin Oral Implants Res. 2010;21(11):1271-1277.

252. Urquarth E. Agentes analgésicos y estrategias en el modelo del dolor dental. J Dent. 1994;22:336-341.

253. Ustün Y, Erdogan O, Esen E, Karsli E. Comparison of the effects of 2 doses of methylprednisolone on pain, swelling, and trismus after third molar surgery. Oral Surg Oral Med Oral Pathol Oral Radiol Endod. 2003;96(5):535-539. 
254. Van Dyke T, Litkowski L, Kiersch T, Zarringhalam N, Zheng H, Newman K.

Combination oxycodone $5 \mathrm{mg} /$ ibuprofen $400 \mathrm{mg}$ for the treatment of postoperative pain: a double-blind, placebo- and active-controlled parallel-group study. Clin Ther. 2004;26(12):2003-2014.

255. Van Steenberghe D, Lekholm U, Bolender C, Folmer T, Henry P, Herrmann I, et al. The applicability of osseointegrated oral implants in the rehabilitation of partial edentulism: a prospective mult. Int J Oral Maxillofac Implants. 1990;5(3):272-281.

256. Vassend O. Anxiety, pain and discomfort associated with dental treatment. Behav Res Ther. 1993;31(7):659-666.

257. Villa L, Sánchez A, Pérez A, Albarrán F. Uso clínico de los antiinflamatorios no esteroideos. Medicine. 1999;7(5):7.

258. Visch L, Van Waas M, Schmitz P, Levendag P. A clinical evaluation of implants in irradiated oral cancer patients. J Dent Res. 2002;81(12):856-859.

259. Vogel R, Desjardins P, Major K. Comparison of presurgical and immediate postsurgical ibuprofen on postoperative periodontal pain. J Periodontol. 1992;63(11):914-918.

260. Walton G, Rood J, Snowdon A, Rickwood D. Ketorolac and diclofenac for postoperative pain relief following oral surgery. Br J Oral Maxillofac Surg. 1993;21(3):158-160.

261. Wardle J. Psychological management of anxiety and pain during dental treatment. J Psychosom Res. 1983;27(5):399-402.

262. Weil K, Hooper L, Afzal Z, Espósito M, Worthington H, Van Wijk A, et al. Paracetamol for pain relief after surgical removal of lower wisdom teeth. Cochrane Database Syst Rev. 2007;18(3):CD004487. 


\section{Capitulo 7: Bibliografía}

263. Weng D, Jacobson Z, Tarnow D, Hürzeler M, Faehn OSF, Barkvoll P, et al. A prospective multicenter clinical trial of $3 \mathrm{i}$ machined-surface implants: results after 6 years of follow-up. Int J Oral Maxillofac Implants. 2003;18(3):417-423.

264. Wiesenfeld-Hallin Z. Sex differences in pain perception. Gend Med. 2005;2(3):137.

265. Wong M, Lytle W. A comparison of anxiety levels associated with root canal therapy and oral surgery treatment. J Endod. 1991;17(9):461-465.

266. Woolf C, Chong M. Preemptive analgesia--treating postoperative pain by preventing the establishment of central sensitization. Anesth Analg. 1993;77(2):362-379.

267. Workin R, Mirolar B, Rowbot H. Advances in neuropathic pain. J Am Med Assoc. 2003;60:1536-1625.

268. Yuasa H, Sugiura M. Clinical postoperative findings after removal of impacted mandibular third molars: prediction of postoperative facial swelling and pain based on preoperative variables. Br J Oral Maxillofac Surg. 2004;42(3):209-214.

269. Zhang W, Li Wan Po A. Analgesic efficacy of paracetamol and its combination with codeine and caffeine in surgical pain--a meta-analysis. J Clin Pharm Ther. 1996;21(4):261-282. 

ANEXOS 

Capitulo 8: Anexos

\section{Anexo 1. Protocolo de prevención y tratamiento de las complicaciones irales debidas a la radioterapia de cabeza y cuello.}

\begin{tabular}{|c|c|}
\hline MEDIDAS & CONTENIDOS \\
\hline Secuelas & $\begin{array}{l}\text { Si la radiación ha sido mayor de 60-70 Gy en las } \\
\text { glándulas salivales la hiposialia será irreversible }\end{array}$ \\
\hline Instrucciones de higiene oral & $\begin{array}{l}\text { Mantener un alto nivel de higiene oral } \\
\text { Fluoruración tópica, a criterio del profesional } \\
\text { según la calidad de la higiene oral y la evolución. } \\
\text { Es posible realizar profilaxis (tartrectomías) y } \\
\text { raspadosalisados radiculares }\end{array}$ \\
\hline Odontología conservadora & $\begin{array}{l}\text { Obturación inmediata de cualquier nueva caries } \\
\text { Es posible realizar conductoterapia } \\
\text { Evitar apicectomía, por el riesgo de } \\
\text { osteorradionecrosis }\end{array}$ \\
\hline Exodoncias & $\begin{array}{l}\text { Se recomienda retrasarlas hasta unos } 6 \text { a } 12 \\
\text { meses despuésdela radioterapia } \\
\text { Prescribir protección antibiótica de amplio } \\
\text { espectro desde varios días antes de la extracción } \\
\text { hasta dos semanas después. } \\
\text { La oxigenoterapia hiperbárica previa y posterior } \\
\text { es útil para prevenir la osteorradionecrosis. }\end{array}$ \\
\hline Prostodoncia (prótesis) & $\begin{array}{l}\text { Esperar tres meses desde el fin de la radioterapia } \\
\text { para volver a usar sus prótesis } \\
\text { En caso de exodoncias previas a la radioterapia, } \\
\text { el tiempo de espera para el uso de prótesis } \\
\text { removibles debería ampliarse a seis meses }\end{array}$ \\
\hline Implantes & $\begin{array}{l}\text { Aunque el riesgo de fracaso en la } \\
\text { osteointegración es algo mayor que en pacientes }\end{array}$ \\
\hline
\end{tabular}




\begin{tabular}{|l}
\hline no irradiados, la radioterapia previa no es \\
necesariamente una contraindicación para la \\
colocación de implantes mandibulares: el riesgo \\
de osteorradionecrosis sigue siendo mínimo, \\
siempre que se evite o minimice el \\
despegamiento perióstico de la cortical interna, \\
que es la principal fuente de vascularización de la \\
mandíbula. \\
Se recomienda demorar dos años la colocación \\
de implantes mandibulares, por el riesgo de \\
enmascaramiento de recidivas del tumor, que \\
predominantemente acontece en ese periodo. \\
La oxigenación hiperbárica es de gran utilidad. \\
Extirpación del hueso necrótico y reconstrucciór \\
mandibular con un colgajo microvascularizado \\
\hline Oilocarpina (5 mg tres veces al día) u otros \\
sialogogos. \\
iAtención a las contraindicaciones: asma \\
enfermedad pulmonar obstructiva crónica \\
(EPOC)! \\
Efectos secundarios: Sudoración e \\
hipermotilidad gastrointestinal \\
Salivas artificiales a base de carboximetilcelulosa, \\
mucina o enzimas. \\
\hline iadianecrosis
\end{tabular}


Capitulo 8: Anexos

\section{Anexo 2. Datos generales y preoperatorios.}
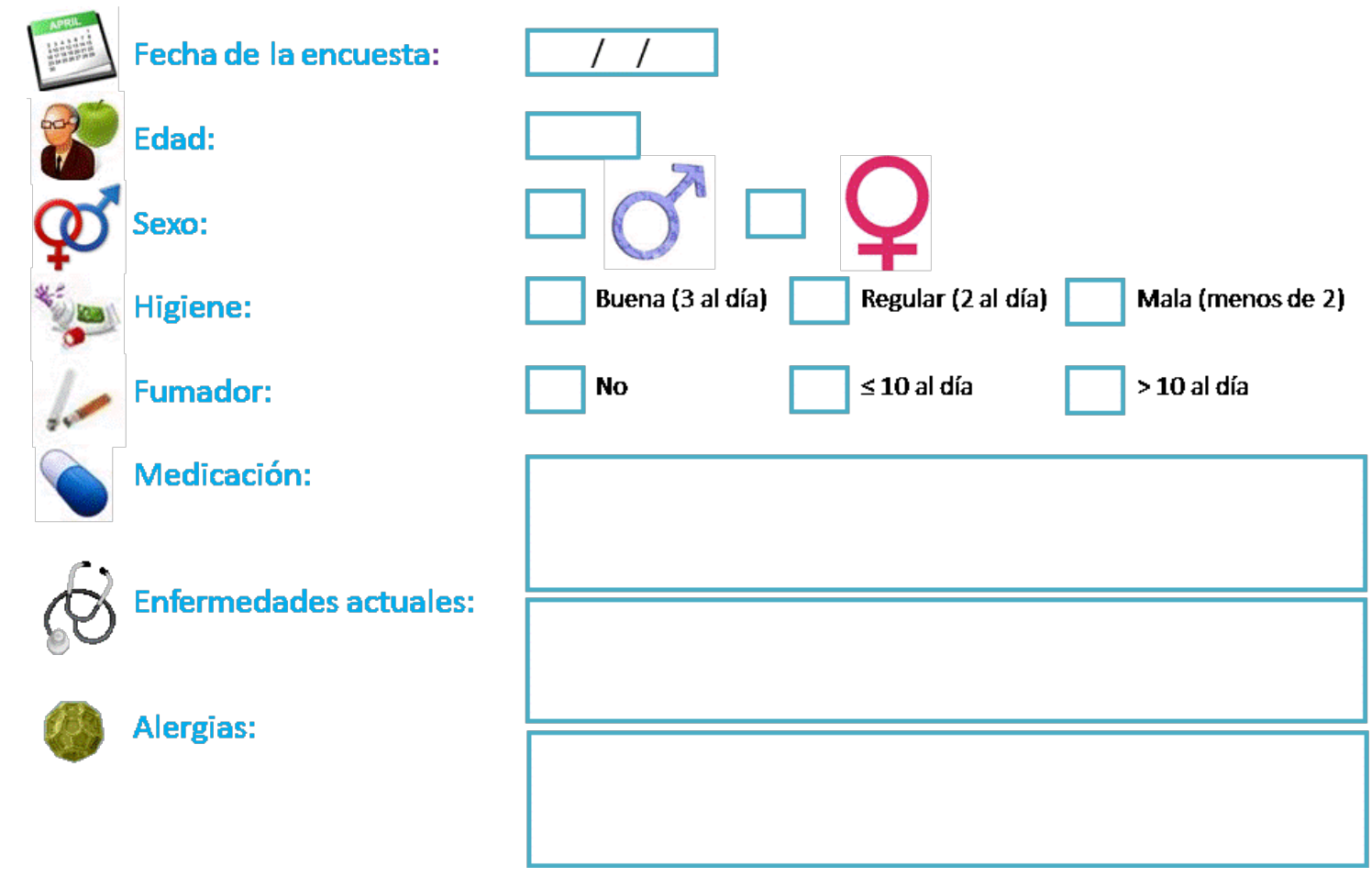

Alergias:

Tipo de edentulismo:

$\square$ Extremo libre

$\square$ Esp. interdental Completo

Número de implantes:
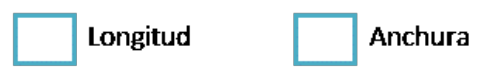

Marca

(2) Localización:

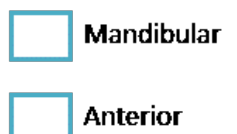

Maxilar

Regeneración ósea:

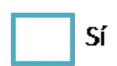

Posterior
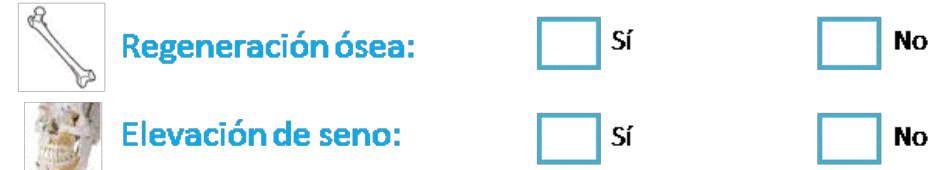

Sedación:
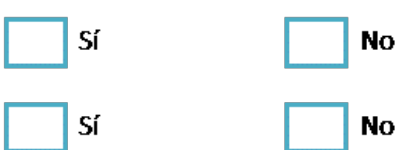

si

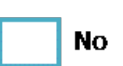

Medīcación sumininistrada: 



\section{Anexo 3. Instrucciones postquirúrgicas.}

\section{JOSE MARÍA YARTE AGUADO}

Aplicar hielo en la zona hasta 24 horas después (cada 10min).

No tumbarse después de la cirugía y mantener la cabeza alta.

No ingerir alimentos hasta 4-6 horas después.

Dieta blanda y fría el día de la intervención.

No fumar ni ingerir alcohol.

No cepillar la zona hasta 24 horas después.

A las 24 horas cepillado suave y con abundante pasta.

Enjuagues de agua y sal después del cepillado.

Enjuagues de clorhexidina después del cepillado.

Aplicar gel de clorhexidina en zona de la intervención.

Seguir pauta antibiótica y analgésica con rigor. 

Capitulo 8: Anexos

\section{Anexo 4. Datos postoperatorios.}

DOLOR $0($ sin dolor $)-1-2-3-4-5-6-7-8-9-10$ (dolor extremo)

1: No dolor 2: Ligero dolor (molestia leve. No requiere analgésicos) 3: Dolor moderado (requiere analgésicos) 4: Dolor fuerte (requiere combinación de analgésicos)

\begin{tabular}{|l|l|l|l|l|l|l|l|}
\hline & DOLOR & $12 \mathrm{H}$ & $24 \mathrm{H}$ & $48 \mathrm{H}$ & 3Días & 5 Días & 7Días \\
\hline 1 & NO & & & & & & \\
\hline 2 & LIGERO & & & & & & \\
\hline 3 & MODERADO & & & & & & \\
\hline 4 & GRAN DOLOR & & & & & & \\
\hline
\end{tabular}

\section{INFLAMACIÓN}

1: No inflamación 2: Inflamación ligera (inflam. en la zona intervenida) 3: Inflamación moderada (inflam. zona intervenida y zonas vecinas) 4: Fuerte inflamación (inflam. notable externamente)

\begin{tabular}{|l|l|l|l|l|l|l|l|}
\hline & INFLAMACIÓN & $12 \mathrm{H}$ & $24 \mathrm{H}$ & $48 \mathrm{H}$ & 3 Días & 5 Días & 7 Días \\
\hline 1 & NO & & & & & & \\
\hline 2 & LIGERA & & & & & & \\
\hline 3 & MODERADA & & & & & & \\
\hline 4 & GRAN INFLAM & & & & & & \\
\hline
\end{tabular}

\section{HEMATOMA}

1: No hematoma 2: Ligero hematoma (a nivel de la zona intervenida) 3: Hematoma moderado (afecta a zonas vecinas) 4: Gran hematoma (irradiado a otras zonas y con gran tamaño)

\begin{tabular}{|l|l|l|l|l|l|l|l|}
\hline & HEMATOMA & $12 \mathrm{H}$ & $24 \mathrm{H}$ & $48 \mathrm{H}$ & 3Días & 5 Días & 7Días \\
\hline 1 & NO & & & & & & \\
\hline 2 & LIGERO & & & & & & \\
\hline 3 & MODERADO & & & & & & \\
\hline 4 & GRAN HEMAT & & & & & & \\
\hline
\end{tabular}



Anexo 5. Historia médica y odontológica.

\section{ANAMNESIS}

APELLIDOS:

NOMBRE:

EDAD: $\quad$ SEXO: RAZA:

PROFESION:

E. CIVIL:

DOMICILIO:

POBLACION:

PROVINCIA:

C. POSTAL:

TELEFONO:

Motivo de la consulta:

ANTECEDENTES DE INTERÉS:

ANTECEDENTES PERSONALES:

Enfermedades:

Intervenciones quirúrgicas:

Alergias:

Hábtios nocivos:

Anestesias odontológicas previas:

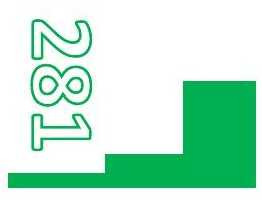


Medicación actual y ¿por qué?:

ENFERMEDADES ACTUALES:

EXPLORACIÓN EXTRABUCAL:

EXPLORACION INTRABUCAL:

EXPLORACION ATM:

ODONTOGRAMA:

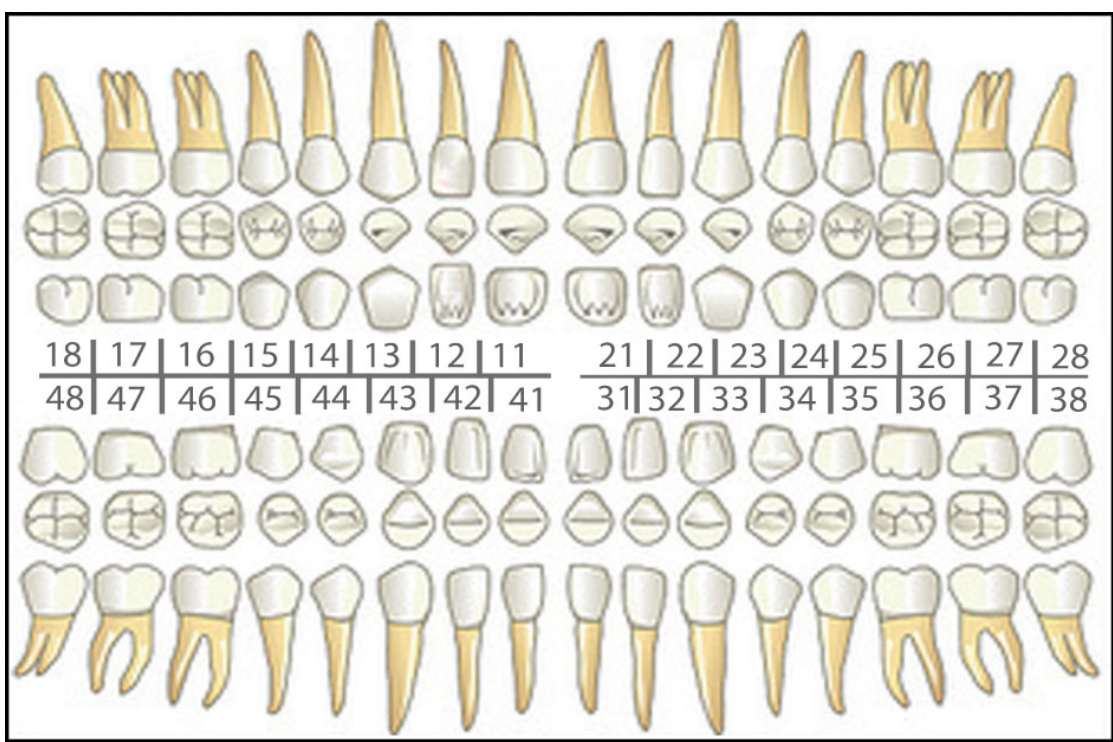


HISTORIA BUCAL:

Tecnica de higiene oral:

Motivo de perdidas dentarias:

Molestias orales referidas:

Hábitos con repercusión oral:

Valoracion personal de sus problemas orales:

ANALISIS OCLUSAL:

ANALISIS ENDOPULPAR:

VALORACION GLOBAL:

PRONOSTICO: 


\section{Anexo 6. Consentimiento informado.}

\section{CONSENTIMIENTO INFORMADO PARA COLOCACIÓN DE IMPLANTES OSTEOINTEGRADOS}

Dn/Dña

D.N.I.

y domicilio en

\section{DECLARO}

Que el Dr. D. José María Yarte Aguado me ha explicado que es conveniente proceder en mi situación, a la COLOCACIÓN DE IMPLANTES OSTEOINTEGRADOS.

1. - El propósito principal de la intervención es la reposición total o parcial de los dientes perdidos. Sé que alternativamente podría recurrir a prótesis convencionales, de menor coste, pero lo descarto por los beneficios que se pueden obtener con la técnica implantológica.

2. - El procedimiento se llevará a cabo bajo anestesia local y accesoriamente, si fuera necesario, bajo sedación intravenosa asistida por un anestesista, de cuyos posibles riesgos también se me ha informado.

3. - El procedimiento se llevará a cabo en dos fases, la primera consistirá en la fijación de los implantes al hueso mediante la realización, con fresas quirúrgicas, de un lecho o alveolo artificial y una segunda fase pasado un tiempo variable (varios meses), cuando el/los implantes estén integrados en el hueso, en la que se colocará un pilar sobre los mismos para recibir posteriormente los aditamentos protésicos. En estas fases podría ser necesario la realización de injertos óseos, utilización de biomateriales y en general cualquier técnica quirúrgica que sea necesaria para el éxito de mi tratamiento.

4. - Aunque se me han realizado los medios diagnósticos precisos (radiografías, tomografías, radiografías panorámicas, periapicales, etc.), comprendo que es posible que puedan producirse procesos edematosos, inflamación, hematomas, dolor o laceraciones en la mucosa de la mejilla o del labio, o en la lengua, que no dependen de la técnica empleada ni de su correcta realización, e incluso la posibilidad de lesionar el seno y provocar una sinusitis que deba ser tratada posteriormente por el especialista competente.

También se me ha explicado que, con menos frecuencia e independientemente de la técnica empleada y de su correcta realización, es posible que se produzcan lesiones de tipo nervioso, por afectar a terminaciones nerviosas o nervios próximos, lo que generará pérdida de sensibilidad de los labios, la lengua o la encía, según cual sea el 
nervio afectado. Generalmente la pérdida de sensibilidad es transitoria, aunque puede llegar a ser permanente.

Menos frecuentemente, pueden producirse comunicaciones con senos nasales o con las fosas nasales y lesionar raíces de dientes adyacentes incluso podría producirse fractura maxilar o intrusión de un implante en el seno maxilar que requieran tratamiento posterior.

He sido informado de que no hay ningún método para predecir la completa integración de los implantes en el hueso adyacente y que aunque la técnica se realice correctamente existe un porcentaje entre el $8 \%$ y $10 \%$ que pueden requerir la repetición de la intervención y que este porcentaje aumenta en caso de ser fumador, por lo que se recomienda dejar de fumar 15 días antes de la intervención. Me han explicado que en caso de no integrarse adecuadamente deben extraerse.

Entiendo que el tratamiento no concluye con la colocación del/los implantes, sino que será preciso visitar periódicamente al facultativo y seguir escrupulosamente las normas de higiene y cuidados que me han explicado.

Se me ha informado que es imprescindible un seguimiento cada cierto número de meses, a fin de detectar y tratar precozmente la aparición de cualquier complicación, como la periimplantitis (enfermedad periimplantaria).

Se me ha informado de los posibles riesgos y complicaciones involucradas en el procedimiento quirúrgico y prostodóntico, uso de medicamentos y anestesias, tipos de prótesis y alternativas a mi completa satisfacción.

5. - El Dentista me ha explicado que todo acto quirúrgico lleva implícitas una serie de complicaciones comunes y potencialmente serias que podrían requerir tratamientos complementarios tanto médicos como quirúrgicos.

He comprendido las explicaciones que se me han facilitado en un lenguaje claro y sencillo, y el facultativo que me ha atendido me ha permitido realizar todas las observaciones y me ha aclarado todas las dudas que le he planteado.

Por ello, manifiesto que estoy satisfecho/a con la información recibida y que comprendo el alcance y los riesgos del tratamiento.

Y en tales condiciones consiento que se me practique,

\section{LA COLOCACIÓN DE IMPLANTES OSTEOINTEGRADOS.}

En Salamanca, a..................de.......

Fdo. Dr. D. José María Yarte Aguado

Fdo. El paciente 


\section{ÍNDICE TEMÁTICO}


Indice Temático

A

Acetilcolina $\cdot 63$

Ácido clavulánico $\cdot 54,88$

Agresión tisular $\cdot 80,82$

AINE $\cdot 89,91,92$

Alodinia $\cdot$ 67, 68, 69, 70, 71

Amoxicilina $\cdot 54$

Análisis de la varianza $\cdot 132$

Anestésicos · 37, 38, 39, 95

Ansiedad · 28, 58, 59, 60, 71, 72, $78,79,80,81,83,84,85,106$, 206

Antibióticos $\cdot 87,91$

Articaína $\cdot 37,38,116$

Aspartato $\cdot 63$

$\bar{B}$

Betametasona $\cdot 96,97$

Bisturí · 37, 39, 115, 116, 117

Brånemark · 25, 26, 27, 30, 45,

243,244

$\bar{C}$

Carga inmediata $\cdot 26,27$

\section{Ch}

Chi-cuadrado $\cdot 134,180,181,187$

\section{C}

$\boldsymbol{F}$

Clorhexidina $\cdot 37,89,90,91,115$, 121,275

Codeína $\cdot 94$

Colgajo $\cdot 40,41,42,45,46,47$, $49,61,80,111,118,149,153$, 154

Corticoides · 95, 96

Cuestionario · 110, 111, 128, 195

$\bar{D}$

Daño tisular $\cdot 56,57,61$

Dexametasona $\cdot 96$

Dexketoprofeno $\cdot 89,92$

Dolor agudo $\cdot 57$

Dolor crónico $\cdot 57$

Dolor neuropático $\cdot 59$

Dolor nociceptivo $\cdot 59$

$\bar{E}$

Elevaciones de seno $\cdot 41,69,95$

Ensayo clínico · 87, 107, 194

Eritromicina $\cdot 54,88$

Escáner · 33, 34, 114

Esterilidad $\cdot 36$
Fármacos · xiii, 92, 93, 95, 107

Férula quirúrgica $\cdot 35,114$

Fibras A · 67, 69, 70

Fibras C · 65, 66, 67, 68

Fibras primarias $\cdot 65$

Fresado óseo $\cdot 42,62,118$

$\boldsymbol{G}$

Glutamato $\cdot 67,70$

$\bar{H}$

Hiperalgesia · 66, 67, 68, 69, 70, 71 Hipótesis · 108, 109, 129, 131, 132, 133, 135, 195

I

Ibprofeno 54

Infección · 88, 91

$\bar{K}$

Ketoprofeno $\cdot 92$

Kruskal-Wallis · 133, 174, 175, 176 
$L$

Lesión tisular · 57, 61, 62, 63, 69

Lidocaína $\cdot 38$

\section{$M$}

Mediadores plasmáticos $\cdot 63$

Medicación · 53, 110

Mepivacaína $\cdot 37,95$

Metamizol · 54, 92, 93

Metilprednisolona $\cdot 96$

Misch · 26, 27, 28, 30, 31, 32, 35,

$37,38,40,41,43,56,96,106$

258

N

Neurotransmisores $\cdot 63$

Nociceptores $\cdot 62,63,69,70,84$

Noradrenalina $\cdot 63$

Núcleo caudal $\cdot 66$

0

Opioide $\cdot 86,94$

Oseointegración · 25, 26, 27, 30

Oxicodona $\cdot 94,95$
$\boldsymbol{P}$

Paracetamol · 92, 93, 94

Placa bacteriana $\cdot 89,90$

Población · 78, 106, 112, 127, 130, 194, 196

Prednisolona $\cdot 96$

Prevención · xii, 82

Proceso cognitivo $\cdot 84$

Profilaxis antibiótica $\cdot 87,88$

Prostaglandinas $\cdot 62,63$

\section{$\boldsymbol{R}$}

Regeneración ósea · 33, 82, 111, 153

Resonancia $\cdot 109$

$S$

Sedación · 111, 149, 154

Subnúcleo caudal · 64, 65

Sustancia P · 63, 67, 69, 70

$T$

Tapón de cicatrización · 45, 46, 47,48

Técnicas descriptivas 129
Técnicas inferenciales $\cdot 129$

Tejido blando $\cdot 25,35,40,45,46$ 49,154

Tejido óseo $\cdot 25,27,32$

Titanio $\cdot 25,26,30$

Tracto anterolateral $\cdot 65$

Tracto espinal $\cdot 64$

Tronco cerebral $\cdot 64,65$

Tumor Necrosis Factor $\cdot 67$

U

U-Mann Whitney · 131, 174

V

Validez $\cdot$ 107, 194

Vasodilatación · 62, 63

Vía oral $\cdot 88,96$

W

Wide Dynamic Range · 67 
